\title{
Pension fund asset allocation and performance
}

\author{
Citation for published version (APA):
}

Andonov, A. (2014). Pension fund asset allocation and performance. [Doctoral Thesis, Maastricht University]. Datawyse / Universitaire Pers Maastricht. https://doi.org/10.26481/dis.20140521aa

Document status and date:

Published: 01/01/2014

DOI:

10.26481/dis.20140521aa

Document Version:

Publisher's PDF, also known as Version of record

\section{Please check the document version of this publication:}

- A submitted manuscript is the version of the article upon submission and before peer-review. There can be important differences between the submitted version and the official published version of record.

People interested in the research are advised to contact the author for the final version of the publication, or visit the DOI to the publisher's website.

- The final author version and the galley proof are versions of the publication after peer review.

- The final published version features the final layout of the paper including the volume, issue and page numbers.

Link to publication

\footnotetext{
General rights rights.

- You may freely distribute the URL identifying the publication in the public portal. please follow below link for the End User Agreement:

www.umlib.nl/taverne-license

Take down policy

If you believe that this document breaches copyright please contact us at:

repository@maastrichtuniversity.nl

providing details and we will investigate your claim.
}

Copyright and moral rights for the publications made accessible in the public portal are retained by the authors and/or other copyright owners and it is a condition of accessing publications that users recognise and abide by the legal requirements associated with these

- Users may download and print one copy of any publication from the public portal for the purpose of private study or research.

- You may not further distribute the material or use it for any profit-making activity or commercial gain

If the publication is distributed under the terms of Article $25 \mathrm{fa}$ of the Dutch Copyright Act, indicated by the "Taverne" license above, 


\section{Pension Fund}

Asset Allocation

and Performance

ALEKSANDAR ANDONOV

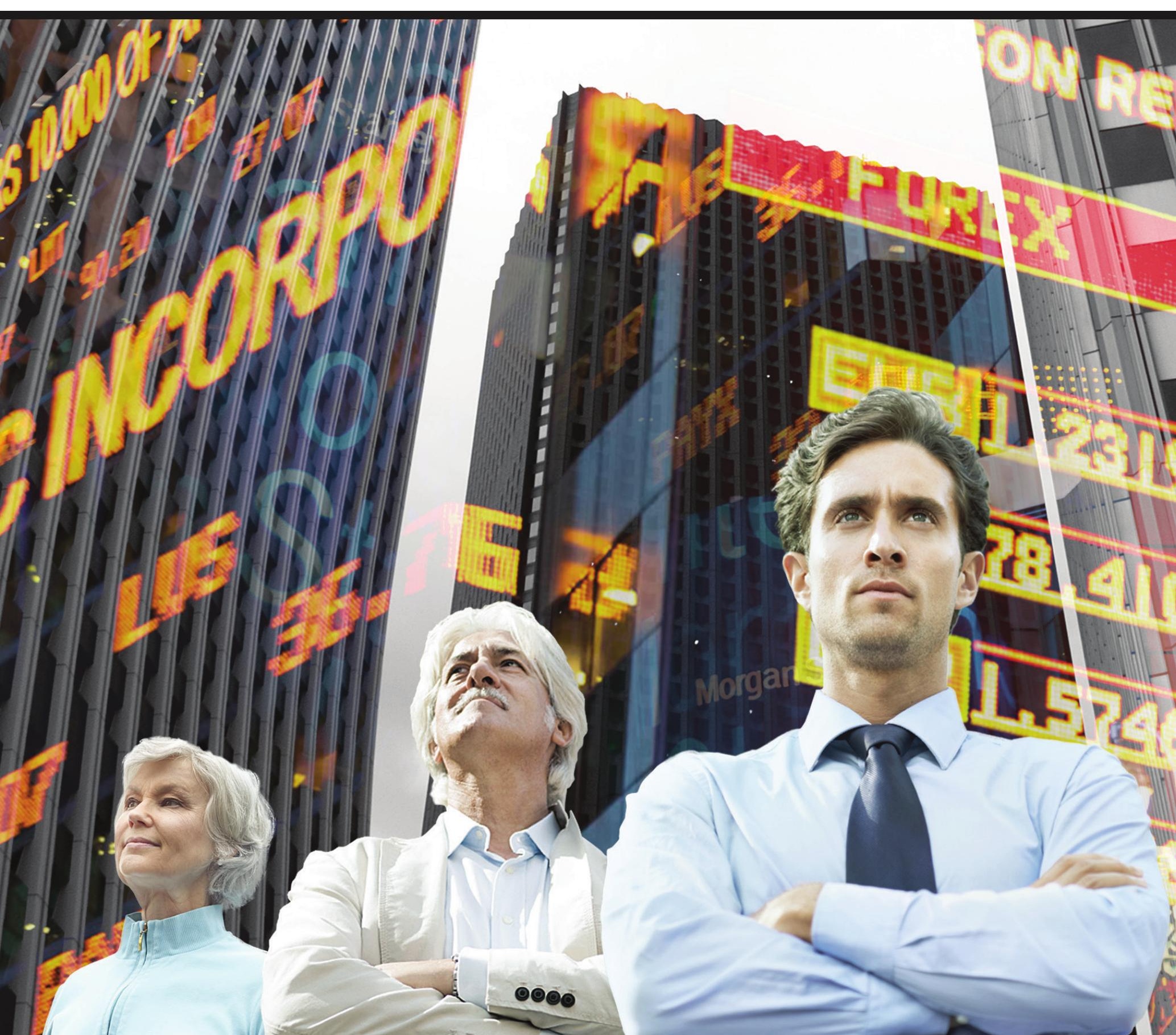




\title{
Pension Fund Asset Allocation and Performance
}

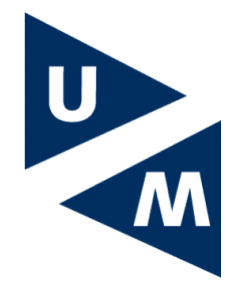

\author{
Aleksandar Andonov \\ Maastricht University School of Business and Economics \\ Maastricht
}

A thesis submitted for the degree of

Doctor of Philosophy at Maastricht University

21 May 2014 
All rights reserved. No part of this publication may be reproduced, stored in a retrieval system, or transmitted, in any form, or by any means, electronic, mechanical, photocopying, recording or otherwise, without the prior permission in writing from the author.

ISBN 9789461593320

Cover design by Filip Mishevski (www.filipthedesigner.com) with photographs by Yuukin and Jiahui Huang

Printed by Datawyse / Universitaire Pers Maastricht 


\title{
Pension Fund Asset Allocation and Performance
}

\author{
DISSERTATION \\ to obtain the degree of Doctor at Maastricht University, \\ on the authority of Prof. dr. L.L.G. Soete, Rector Magnificus, \\ in accordance with the decision of the Board of Deans, \\ to be defended in public \\ on Wednesday, $21^{\text {st }}$ May 2014, at 16:00 \\ by
}

Aleksandar Andonov 
Promotors:

Prof. dr. Rob Bauer

Prof. dr. Piet Eichholtz

Evaluation committee:

Prof. dr. Peter Schotman, Chairman

Prof. dr. Franz Palm

Prof. dr. Joshua Rauh, Stanford University, USA

Prof. dr. Onno Steenbeek, Erasmus University Rotterdam 
To my grandfather Aleksandar 



\section{Acknowledgements}

My PhD journey commenced when I met Rob Bauer in the corridors of Maastricht University School of Business and Economics. I accepted the challenge of developing an academic career immediately, even though I only had a vague idea about the final product that I was supposed to deliver. The PhD process gave me the opportunity to learn a lot and to further develop personally. It has enabled me to live in a great country and also to travel around the world. In addition to doing research in finance, I learnt how to write songs for Sinterklaas, I carefully followed speed skating on winter Olympics and I felt disappointed after the World Cup 2010 final. During my PhD journey, I was continuously surrounded and supported by wonderful people. I owe a deep gratitude to everyone who helped me become an academic.

I am first and foremost grateful to my supervisors, Rob Bauer and Piet Eichholtz, who introduced me to the academic world.

Rob, I was very fortunate to work under your supervision, which was a perfect mix of freedom to research and constructive suggestions. You trusted me to present in front of many pension executives at the ICPM forum when I was only in my second year, while still providing detailed feedback until the end of my studies. I also benefited a lot from working as your teaching assistant. Your teaching approach combines great lectures, insightful articles, Monty Python videos and strict exams. I was honored to have you as a role model teacher. You are a great person with whom I enjoyed doing research, grading exams, and discussing Roda JC Kerkrade prospects.

Piet, I am grateful for having the opportunity to work under your supervision too. I learnt from you how to present and promote my research. You are a visionary thinker, great orator and precise writer. Your career advices and continuous support helped me realize my potential. I enjoyed learning from you about the history of Maastricht and attending your annual $\mathrm{PhD}$ BBQ events.

I am deeply indebted to my co-author and mentor, Martijn Cremers. Thank you for hosting me at Yale and Notre Dame University. I enjoyed the opportunity to work together with you on two research papers and to receive your support during the entire PhD process. I highly value your advice on how to grow professionally. Thank you for pushing me to go to the academic job market and mentoring me during this process. I look forward to continuing our collaboration in the future.

I also had the opportunity to work together with Nils Kok. Nils, you are a great co-author and a colleague. I learnt from you that becoming a successful academic requires persistence and innovative ideas. 
I would like to thank Franz Palm, Joshua Rauh, Peter Schotman and Onno Steenbeek for their contribution as members on my evaluation committee. You provided me with valuable feedback and suggestions on my dissertation manuscript.

My research on pension funds benefited a lot from the support by CEM Benchmarking Inc. and Rotman ICPM, and I am especially grateful to Keith Ambachtsheer, Karen Clarke, Chris Flynn, Mike Heale and Ann Henhoeffer. Your comprehensive data and continuous support improved the quality and visibility of my research. The Rotman ICPM forums enabled me to enter the pension world. I am grateful also to Theo Nijman and Netspar for the multiple opportunities to present my research.

Regarding the preparation help and insightful thoughts on the academic job market, I would like to thank Jaap Bos, Matt Embrey, Benjamin Golez, Ronald Peeters, Kim Peijnenburg, Thomas Post, Rachell Pownall, Paulo Rodrigues and Peter Schotman.

The Maastricht Finance Department has been a great place to work. I am grateful to everyone for the pleasant and friendly atmosphere. The department has not only high quality academics, but also great people with whom I enjoyed delightful lunches, parties and trips. I owe a lot to my paranymphs, Michael and Leonard. Michael, thank you for supporting me to start my PhD in Maastricht. You helped me become a successful teacher and researcher. Together we successfully learnt some econometrics, taught two courses and analyzed football matches. I hope you will find the 'right' side on the way to the 'dark' side. Leonard, thanks for the countless advices on many small and big decisions I had to make. We shared beer in Lindau, sharska in Macedonia, and burgers in Philly. You are a great friend and I wish you even more success in the future.

I would like to especially thank Jaap, Jeroen, Paulo and Peter for listening to me every time I was in doubt when experiencing research obstacles. You provided me with an invaluable support and I am grateful that your door was always open. I would also like to express my appreciation to my colleagues Arvid, Dennis, Joost, Rachel, Roger, Stefan, Stefanie and Thomas. At Maastricht, my life was made so much easier by the lovely ladies of the finance department secretariat. Els, Francien, Carina and Cecile, thank you very much for always helping me!

Many enjoyable moments during my $\mathrm{PhD}$ came from frequent discussions and less serious talks with my officemates: Leonard, Sajid, Sally, Anna and Simone. Leonard and Sajid, your suggestions helped me a lot at the beginning of my studies, even though my coffee consumption increased substantially during our talks. Sally, the multiple SpongeBobs laying all around our office and your drawings somehow created a productive and pleasant atmosphere in B1.04. Anna, I learnt from you to enjoy the life beyond the statistical package. Thanks for the positive energy and funny afternoon chats while eating lots of chocolate. Simone, it was a pleasure to go through the final steps of our studies together with you and thanks a lot for the long talks about our future careers.

I also managed to make friends outside the office. Matteo and Gildas, I will miss your walking rounds around the department. Your cheerful stories enabled me to laugh even when doing manual data work or staring at Stata output. Gildas, I wish you success as a finance 
researcher and football fan. Matteo, thanks for the great tips on articles, TV shows and restaurants in Sicily. Andrea, we went together through the PhD process from the beginning to the end. Thank you for the great advices on academic English, dissertation latex code, shopping in U.S. and New Haven crime rates. I hope I will be invited also in the future to your famous international Thanksgiving dinners. Paul, you are not only a great colleague, but you were also an entertaining companion to Pinkpop and Ohrid. I wish you a successful academic, music and poker career. Many thanks are also directed to Oana, my neighbor on the first and third floor. Oana, you are a great listener and it was good to have you always around. Rogier Q., thanks for proofreading my bootstrap code and helping me become a proper taxpayer. My work at Maastricht was also pleasant thanks to: Bart, Carl, Clarissa, Daniela, David, Erkan, Gaby, George, Hang, Iman, Judy, Katie, Lei, Mukul, Omar, Patrick, Robin, Rogier H., Sjoke, Thies and Wiebke. I also thank my former housemates and colleagues: Norbert and János.

During my PhD studies, I received a fantastic support from my family and friends. I am deeply thankful to my parents, Lidija and Branko, for pushing me to pursue master studies in Maastricht and then continue further to a PhD. Mama, you inspired me to study economics and provided an invaluable help on every stage of my career. Tato, you are an incredible source of positive energy and laughs. You managed even to help me find an accommodation in Maastricht after visiting me only for a week. Mama and Tato, I will never be able to thank you enough for all that you have done for me throughout my life, and especially during my $\mathrm{PhD}$. Without your limitless support and unconditional love, this $\mathrm{PhD}$ would not have been possible.

My sister, Teodora, provided also fantastic support with her frequent visits and our special cheerful talks. Tea, during your visits we played handball in my studio, had epic laughs, and went only on one painful bike ride. Grandmother Ranka, thank you wishing me luck in a Macedonian way for every single exam and presentation I went through in the last five years.

I am also deeply grateful to the other family members who supported me during this journey: Dragan, Lile, Vlado, Suzana, Pale, Branko, Simona, Damian, Bojana, Vele, Dragana, Marko, Irina, Riste and Ema. Thank you for your support during my PhD studies.

I owe also gratitude to my Skopje crowd for keeping up our friendship over all these years: Skot, Tod, Srbin, Trn, Cuki, Neno, Hac, Ljube, Slem and Pero. You are a great source of joy and recharging whenever I come back to Macedonia. Skot, thanks for the efficient online skype support and for hosting my homepage.

I was also lucky to have Macedonian friends (and family) in the Netherlands: Ole and Filip, thank you for making me feel at home in Maastricht. I loved our tasty dinners, relaxing trips and games (house football), and I hope that we will continue with this routine in the future. Ole, thanks for the positive energy, encouragement and legendary statements. Filip, thank you for designing my webpage as well as the cover of this dissertation.

Most of all I am grateful to Simona. Your love and support helped me succeed. And when that was not enough, you also worked with me on my dataset, listened to my presentation trials and read my job market statements. I am lucky to have you next to me in all difficult and joyful moments. Moni, my PhD achievement would not have been the same without you. 



\section{Contents}

Acknowledgements $\quad$ iii

List of Figures $\quad$ xi

List of Tables $\quad$ xiii

1 Introduction 1

1.1 Institutional investors $\ldots \ldots \ldots \ldots \ldots \ldots \ldots$

1.2 Pension fund asset allocation and performance . . . . . . . . . . . 3

1.2.1 Strategic asset allocation policy . . . . . . . . . . . . . 4

1.2.2 Pension fund asset management decisions . . . . . . . . . . 5

1.2.3 Financial intermediation in alternative assets . . . . . . . . . . . . . . 7

1.3 Implications for pension fund governance $\ldots \ldots \ldots \ldots$

2 Pension Fund Asset Allocation and Liability Discount Rates 11

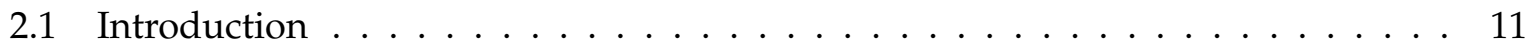

2.2 Optimal asset allocation and the regulation of pension funds . . . . . . . . . 15

2.2.1 The relation between risk taking, maturity, and inflation protection . . . . 16

2.2.2 How pension fund regulation affects asset allocation decisions and liability discount rates . . . . . . . . . . . . . . . . . . . 17

2.3 Data . . . . . . . . . . . . . . . . . . . . . 20

2.4 Pension fund investments in risky assets and asset valuation . . . . . . . . . . 27

2.4 .1 Pension fund maturity and risk taking . . . . . . . . . . . . . 27

2.4.2 Self-reported funding ratios and allocation to risky assets . . . . . . . . . 33

2.4 .3 Asset valuation smoothing . . . . . . . . . . . . . . . . . 34

2.5 Pension fund liabilities valuation $\ldots \ldots \ldots \ldots \ldots \ldots \ldots$

2.5 .1 Liability discount rates . . . . . . . . . . . . . . 36

2.5 .2 Inflation protection . . . . . . . . . . . . . . . 42

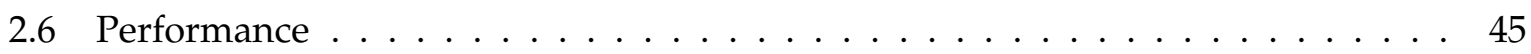

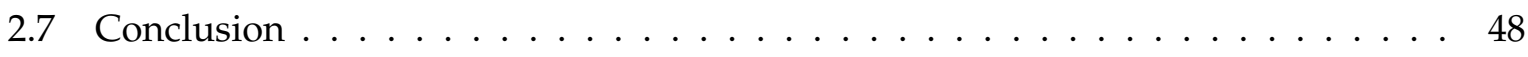


3 Can Large Pension Funds Beat the Market 51

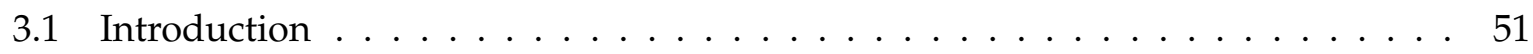

3.2 Characteristics of the CEM database $\ldots \ldots \ldots \ldots \ldots$

3.3 Methodology . . . . . . . . . . . . . . . . . . . . 63

3.4 Pension fund investment costs . . . . . . . . . . . . . . . . . . . 69

3.5 The performance of pension funds . . . . . . . . . . . . 70

3.5.1 Risk-adjusted performance at the pension fund level . . . . . . . . . 71

3.5.2 Market timing returns . . . . . . . . . . . . . . . . . . . 74

3.5.3 Security selection returns per asset class . . . . . . . . . . . . 76

3.6 Pension fund characteristics and performance $\ldots \ldots \ldots \ldots . \ldots . \ldots 79$

3.7 Persistence in pension fund performance . . . . . . . . . . . . . . 83

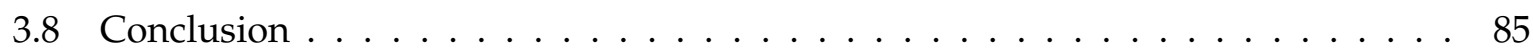

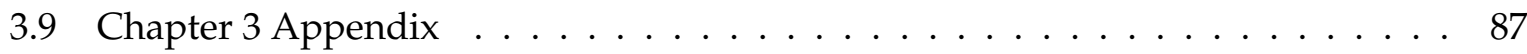

4 Delegated Investment Management in Alternative Assets $\quad 91$

4.1 Introduction . . . . . . . . . . . . . . . . . . . . . . . . . 91

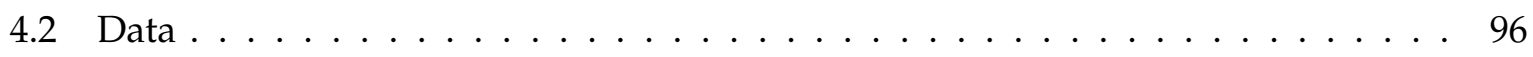

4.3 Institutional investments in alternative assets . . . . . . . . . . . . . . . 102

4.3.1 Percentage allocated to alternative assets . . . . . . . . . . . . . . 102

4.3.2 The number of simultaneous investments in alternative assets . . . . . . . 105

4.3.3 Financial intermediation levels . . . . . . . . . . . . . . . . . . . . 107

4.4 Investment costs . . . . . . . . . . . . . . . . . . . . . . . . . . . . . . . . . 109

4.5 Performance in alternative assets . . . . . . . . . . . . . . . . 112

4.5.1 Financial intermediation level and performance . . . . . . . . . . . 112

4.5.2 Specialization and performance . . . . . . . . . . . . . . . 118

4.6 The contribution of alternative assets to investor performance . . . . . . . . 122

4.7 Conclusion . . . . . . . . . . . . . . . . . . . . . . . . . . . 123

4.8 Chapter 4 Appendix . . . . . . . . . . . . . . . . . . . . 125

5 Value Added From Investment Managers in Private Markets 129

5.1 Introduction . . . . . . . . . . . . . . . . . . . . . . . . . . . . . . . . . . 129

5.2 How institutional investors invest in real estate . . . . . . . . . . . . . . 133

5.3 Data . . . . . . . . . . . . . . . . . . . . . . . . . . . . 135

5.4 Pension fund characteristics and real estate investments . . . . . . . . . . . . . . 141

5.5 The costs of pension fund real estate investments . . . . . . . . . . . . . 145

5.6 Pension fund performance in real estate investments . . . . . . . . . . . . . 151

5.6 .1 Benchmark-adjusted returns . . . . . . . . . . . . . . . . . . 151

5.6 .2 Performance and characteristics . . . . . . . . . . . . . . 155

5.6 .3 Persistence . . . . . . . . . . . . . . . . . . . . . . . . . 157

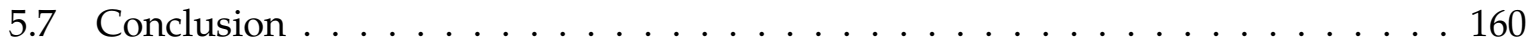

5.8 Chapter 5 Appendix . . . . . . . . . . . . . . . . . 163 
6.1 Agency conflicts among defined benefit pension funds . . . . . . . . . . 165

6.1.1 Implications for pension fund regulation . . . . . . . . . . . . . 166

6.1.2 Implications for pension fund investment management . . . . . . . . . . . 166

6.2 Future research . . . . . . . . . . . . . . . . . . . . . 167

6.2.1 The effect of regulation and governance on asset allocation policy . . . . 167

6.2.2 Institutional investor asset management decisions . . . . . . . . . . . . 168

6.2 .3 Investing in alternative assets . . . . . . . . . . . . . . . . . . . . 169

$\begin{array}{ll}\text { References } & 171\end{array}$

$\begin{array}{ll}\text { Curriculum Vitae } & 177\end{array}$ 



\section{List of Figures}

2.1 Percentage of retired members and percentage allocated to risky assets . . . . . 24

2.2 Liability discount rates (LDR) and Treasury yields . . . . . . . . . . . . . . 26

2.3 U.S. public funds: Self-reported funding ratios (SRFR) and asset valuation smooth-

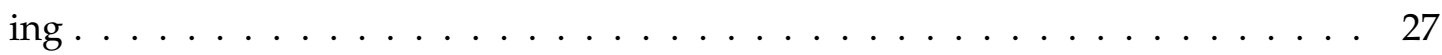

3.1 Asset allocation of U.S. pension funds . . . . . . . . . . . . . . 60

3.2 Asset allocation of U.S. funds within equity, fixed income and alternatives . . . 61

3.3 Investment costs in basis points . . . . . . . . . . . . . . 62

3.4 Gross returns in percentage points . . . . . . . . . . . . . . . . 64

3.5 Return components: total return, changes in asset allocation, market timing and security selection . . . . . . . . . . . . . . 72

3.6 Security selection returns (net benchmark-adjusted returns) by asset class _ . . 78

4.1 Institutional investments in alternative assets . . . . . . . . . . . . . . . . 98

4.2 Percentage allocated to internal managers, external managers and fund-of-funds 101

5.1 How pension funds invest in real estate: the institutional marketplace and the investment process . . . . . . . . . . . . . . . . . . . 134

5.2 Real estate as a percentage of total pension fund assets . . . . . . . . . . 138

5.3 Allocations to real estate subcategories and investment approaches . . . . . . . 140

5.4 Pension fund investment approach in real estate by size quintiles . . . . . . . . 144

5.5 Real estate investment costs by region and subcategory . . . . . . . . . . . . . . 146

5.6 Performance of U.S. pension funds in direct real estate . . . . . . . . . . . . 154 



\section{List of Tables}

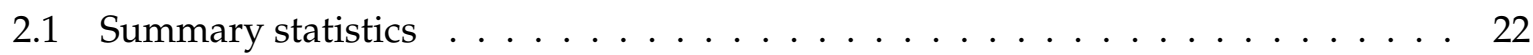

2.2 Panel regressions: Percentage allocated to risky assets . . . . . . . . . . . . . . . 29

2.3 Panel regressions: Percentage allocated to risky assets by region . . . . . . . . . . 31

2.4 Panel regressions: Percentage allocated to risky assets and Treasury yield . . . . 32

2.5 Panel regressions: Allocation to risky assets and self-reported funding ratios . . . 33

2.6 Logit regressions: Smoothing period in the asset valuation . . . . . . . . . . 35

2.7 Panel regressions: Liability discount rates . . . . . . . . . . . . . . . 38

2.8 Panel regressions: Liability discount rates and Treasury yields . . . . . . . . . . 39

2.9 Panel regressions: Liability discount rates by region . . . . . . . . . . . . . 40

2.10 Panel regressions: Liability discount rates and self-reported funding ratios . . . . 41

2.11 Logit regressions: Contractual inflation protection . . . . . . . . . . . . . 43

2.12 Panel regressions: Pension fund net benchmark-adjusted performance . . . . . . 46

2.13 Panel regressions: U.S. public pension fund net benchmark-adjusted performance 47

3.1 Number of funds and fund size $\ldots \ldots \ldots \ldots \ldots \ldots \ldots$

3.2 Cox proportional hazard model and self-reporting bias . . . . . . . . . . 58

3.3 Summary statistics: strategic (policy) and actual asset allocation . . . . . . . . . . 63

3.4 Summary statistics: returns and costs $\ldots \ldots \ldots \ldots \ldots \ldots$

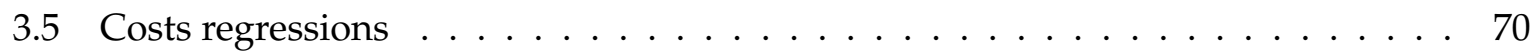

3.6 Risk-adjusted performance by return components on a total fund level . . . . . 73

3.7 Market timing returns . . . . . . . . . . . . . . . . . . . 75

3.8 Security selection returns . . . . . . . . . . . . . . . . . . . 77

3.9 Pension fund characteristics and return components on a total fund level . . . . 80

3.10 Pension fund active management tertiles: size and performance . . . . . . . . . 83

3.11 Ordered logit: persistence in pension fund performance . . . . . . . . . . . . . 84

A.1 Replication of Dyck and Pomorski (2011) . . . . . . . . . . . . . . . . 87

A.2 Risk-adjusted performance by return components on a total fund level . . . . . 88

A.3 Pension fund characteristics and security selection returns in equity . . . . . . . 89

A.4 Transition matrixes: persistence in pension fund performance . . . . . . . . . . 90

4.1 Summary statistics: Institutional investors . . . . . . . . . . . . . . . . . . 99

4.2 Summary statistics: Alternative asset classes . . . . . . . . . . . . . 100

4.3 Tobit regressions: Percentage allocated to alternative assets . . . . . . . . . . . 104 
4.4 Ordered logit regressions: Number of simultaneous investments (NSI) . . . . . 106

4.5 Tobit regressions: Percentage allocated to internal managers, external managers and fund-of-funds . . . . . . . . . . . . . . . . . . . . . 108

4.6 Panel regressions: Investment costs in alternative assets . . . . . . . . . . . . . 111

4.7 Net benchmark-adjusted return differences . . . . . . . . . . . . . . . . . . . 113

4.8 Panel regressions: Net benchmark-adjusted returns . . . . . . . . . . . . . 116

4.9 Fama-MacBeth regressions: Net benchmark-adjusted returns . . . . . . . . . . 117

4.10 Panel regressions: Net benchmark-adjusted returns with control variables . . . . 119

4.11 Panel regressions: Specialization and performance across size tertiles . . . . . . . 121

4.12 Scenario: Passive investments in public equity instead of alternative assets . . . . 123

B.1 Examples of self-reported benchmarks in the CEM data . . . . . . . . . . . . 125

B.2 Gross benchmark-adjusted return differences . . . . . . . . . . . . . . . . . . 126

B.3 Panel regressions: Private equity net benchmark-adjusted return . . . . . . . . . 127

5.1 The CEM database $\ldots \ldots \ldots$. . . . . . . . . . . . . . . . . . 137

5.2 Descriptive statistics: real estate holdings . . . . . . . . . . . . . . . . . . 139

5.3 Descriptive statistics: investment approach . . . . . . . . . . . . . . . . . . . . 141

5.4 Real estate investments and pension fund characteristics . . . . . . . . . . 143

5.5 Descriptive statistics: real estate investment costs . . . . . . . . . . . . . . . . . 147

5.6 Regression results: real estate investment costs . . . . . . . . . . . . . 150

5.7 Pension fund returns in real estate investments . . . . . . . . . . . . . . . 152

5.8 Regression results: performance and characteristics . . . . . . . . . . . . . 156

5.9 Persistence in the performance of pension fund real estate investments . . . . . 159

C.1 Regression results: performance and characteristics 1990-2007 . . . . . . . . . . 163

C.2 Regression results: performance persistence . . . . . . . . . . . . . . . . . . 164 


\section{Chapter 1}

\section{Introduction}

\subsection{Institutional investors}

Financial institutions enable people to shift resources across time and reach different financial goals. Traditionally, people do business mainly with banks, but over time people have started increasingly dealing directly with institutions like pension funds, insurance companies and mutual funds, and indirectly with sovereign wealth funds, endowment funds and other investment companies. Today, these institutional investors manage the vast majority of the savings of individuals. Individuals rely on financial institutions either because they lack the high level of expertise, confidence and time to manage their savings directly (Allen, 2001; Gennaioli, Shleifer, and Vishny, 2013), or because they are required to participate by law. The challenge is to ensure that the financial institutions to whom individuals entrust their money act in their interest.

In my dissertation, I focus mainly on one type of financial institution: defined benefit (DB) pension funds. In a DB pension fund, the sponsor promises a monthly retirement benefit that is predetermined by a formula based on the employee's earnings history, tenure of service and age, rather than depending directly on individual investment returns. On the other end of the retirement systems spectrum are defined contribution (DC) pension plans. In a DC pension plan, fixed contributions are paid by employers and employees, while future retirement benefits depend on the investment returns and interest rates. In DB plans, the pension fund board and executives are responsible for the benefit design, asset allocation policy and performance. The fiduciary duty of a pension fund's Board of Trustees as well as its executives is to act in the best interest of their beneficiaries. In the context of DC pension funds, plan sponsors select the menu of available investment options, while each plan member is individually responsible for the asset allocation decision as well as the retirement consumption decision.

The strength of DB pension funds is to provide insurance to the plan members against the risk of outliving their assets, in a way that allows for intergenerational as well as intragenerational risk-sharing (Merton, 1983; Shiller, 1999). Such risk-sharing makes the impact of shocks both smaller and more persistent (Ball and Mankiw, 2007), and is welfare-enhancing in standard economic models (Davidoff, Brown, and Diamond, 2005). For instance, generations of workers and retirees share the risk through changes in the contributions paid by workers and 
through changes in the inflation protection of pensions and pension rights. However, the involvement of multiple generations in a DB pension system creates potential agency conflicts.

Agency conflicts have been extensively studied in the corporate finance literature since Jensen and Meckling (1976) and Myers (1977), focusing on the firm as an institution. One side of corporate finance focuses on shareholders putting their money in the hands of managers who decide how it should be spent. Another side of this literature considers the conflict of interest between different stakeholders in a corporation, like bondholders and shareholders. Similar conflicts of interest exist in DB pension plans, where people rely on this pension system to manage savings and offer retirement packages.

First, different generations of plan beneficiaries have opposing interests depending on the funding status of the pension fund. During underfunding periods, the young generation would be tempted to leave the DB pension fund instead of guaranteeing the pension benefits of the retired generation through higher contributions. In periods when assets exceed the liabilities value, the old generation would consider closing the pension fund and distributing the surplus among the current members. However, the wealth transfers can affect not only the plan members, but also more broadly the taxpayers. If DB pension systems shift the funding burden in a hidden way, then there can be wealth transfers from the taxpayers towards the plan members because the pension promises are usually backed with implicit or explicit guarantees.

Second, all plan beneficiaries also need to ensure that pension fund executives act in their interest. There are multiple levels of intermediaries, such as board members, pension fund management team, asset managers, consultants and actuaries, between the plan members and their retirement assets. When delegating the management of retirement savings to these intermediaries, plan members are uncertain about their true incentives and skills. For example, pension funds decide whether to manage the investments directly or to delegate this responsibility to external managers and fund-of-funds. Pension fund boards and executives should make this decision based on their expertise and capacity to manage investments internally, but they could also consider their risk aversion, compensation structure, job preservation and other career concerns (Goyal and Wahal, 2008; Lakonishok, Shleifer, and Vishny, 1992). If these additional concerns alter the delegation decision, than the intermediaries can benefit to the detriment of plan members.

Over time, these two agency conflicts have become more evident as pension fund asset value declined substantially relative to their liabilities, which represent the future promised pension benefits (Brown, 2008; Novy-Marx and Rauh, 2011). The financial status of pension plans is one of the most important questions confronting state and local governments as well as private sector companies. ${ }^{1}$ In periods of underfunding, DB systems require increased contributions increase and threaten the ability of governments to adequately fund other public services and the ability of firms to invest in profitable investment projects. The rising costs and

\footnotetext{
${ }^{1}$ Novy-Marx and Rauh (2012) show that financial losses of U.S. state pension funds in 2008 accounted for 12 to 68 percent of the revenue generated by the state governments. When examining corporate decisions to freeze DB plans, Rauh, Stefanescu, and Zeldes (2013) document that firms save around 3 percent of payroll per year, and over a 10-year horizon they save more than 3 percent of total firm assets.
} 
soaring amount of unfunded liabilities also result in increasing demands for transparency and accountability.

The increased public scrutiny focuses especially on the asset allocation of pension funds and their relations with financial intermediaries as pension funds delegate more than 86 percent of the asset management in 2010 (source: CEM Benchmarking Inc. 2010 data) to external managers and fund-of-funds. Concerns have been raised about the way in which intermediaries are compensated (Stoughton, $\mathrm{Wu}$, and Zechner, 2011). Recently, agency conflicts in pension plan investing through placement agents and consultants were uncovered in the cases of CalPERS and the New York State pension plan. For example, in the CalPERS case, one of these placement agents received more than $\$ 50$ million in kickback payments from one asset management firm as a compensation for the assistance in obtaining the CalPERS business. ${ }^{2}$

The primary aim of this thesis is to provide greater understanding of these two agency conflicts that arise when individuals entrust their money to financial institutions. My dissertation focuses mainly on the agency problems in DB retirement plans, but the implications can be extended to collective DC pension funds, sovereign wealth funds and endowment funds. I analyze the asset allocation and performance of DB pension funds over the last two decades, and in this period pension funds faced maturing client population as well as declining interest rates. In the analysis of changes in strategic asset allocation of pension funds, I also incorporate the difference in regulation of pension funds across countries.

The finance literature generally presumes that the fundamental theoretical problem is to optimize the individual portfolio of investment assets. However, when designing retirement systems, the fundamental problem is the regulator's problem of monitoring the pension plans on behalf of individuals, some of whom are currently capable to manage their risks independently and some of whom are not. The regulator should promote the management of retirement risks not only among people who are currently actively managing their own risks, but also among people who are still minors or not born yet, and also among many adults who are not capable to fully manage their own risks, because of their limited financial knowledge, or limits of current retirement products (Shiller, 1999). In a DB pension context, the main responsibility of the regulator is to ensure that these funds can provide stable and adequate pension to their beneficiaries. The regulator should mitigate the potential agency conflicts in DB pension plans, by ensuring that the current generation does not benefit at the expense of future generation and by ensuring that pension fund boards and executives fulfil their fiduciary duty.

\subsection{Pension fund asset allocation and performance}

The first question this thesis explores is the design of a strategic asset allocation policy. I examine how pension funds modify the asset allocation policy and liability valuation in response to the maturing participant base and declining interest rates. Human capital life-cycle theory suggests that asset allocation and liability discount rate choices should be more conservative as

\footnotetext{
${ }^{2}$ see “Calpers Rocked by Pay to Play,” The Wall Street Journal, October 15, 2009.
} 
a fund matures. I analyze whether differences in regulation influence the response of pension funds to these two trends that are exogenous to individual pension fund boards' decisions.

Next, I investigate how pension funds implement the asset allocation policy. Pension funds engage in three asset management decisions: changing the strategic asset allocation policy, market timing and security selection. I explore the role of size and liquidity for pension fund performance in all three asset management components. DB pension funds are particulary interesting vehicles to study the relation between size and performance, because pension fund inflows do not depend on performance, but on actuarial and demographic factors. This longterm liability structure potentially enables DB pension funds to make substantial investments in illiquid assets.

Gradually over time, institutional investors have modified their strategic asset allocation towards increased exposure to alternative assets, such as real estate, private equity and hedge funds. In alternative assets, institutional investors usually do not act as the ultimate portfolio manager, but rather delegate the asset management decisions to financial intermediaries, like external managers and fund-of-funds. I also consider the specialization decision, which captures whether institutions invest only in one alternative asset class, or invest simultaneously in two or three alternative asset classes. My main contribution is to consider how levels of intermediation and specialization relate to costs and performance of institutional investors in alternative assets.

In the remainder of this introduction, I briefly discuss the content of the different chapters and provide a summary of the key findings.

\subsubsection{Strategic asset allocation policy}

The challenge for DB pension funds is how to periodically update critical aspects of the pension deal, such as the contribution levels, strategic asset allocations, and the kind of inflation protection offered. These modifications are based on the financial situation of the pension fund, which compares the asset value with the projected value of liabilities. When estimating the financial situation, boards need to decide on a few key input parameters such as the level of expected returns, interest and inflation rates, and the discount rate used to value the liability stream, as well as a number of actuarial indicators such as life expectancies.

Depending on the regulatory framework, these decisions either can be left at the full discretion of the pension funds, or they can be heavily restricted by regulation or public policy. The regulations pertaining to Canadian and European public and private funds, as well as to corporate pension funds in the United States, require use of liability discount rates that are based on high quality interest rates. In contrast, U.S. public funds may link the liability discount rates to the expected rate of return on their assets. Financial theory (Brown and Wilcox, 2009; Novy-Marx and Rauh, 2011) suggests that future streams of pension benefit payments should be discounted at a rate that reflects the riskiness of their promised pension benefits. Beneficiaries of pension promises, for both public and corporate entities, seem well protected by law, implying that these pension payments are relatively certain and bear relatively little systemic risk (Brown, 2008; Brown and Wilcox, 2009). 
In Chapter 2, I empirically study the consequences of the distinct regulatory environment for U.S. public pension funds by examining their asset allocations, liability discount rates, and performance. I argue that the regulatory framework for U.S. public funds gives them incentives to invest more in risky assets in order to maintain a higher liability discount rate and present an improved funding position. Economic theory suggests that the asset allocation and liability discount rate choices should be more conservative as a pension fund matures. This is indeed how U.S. corporate pension funds and Canadian and European public and private funds have responded. These funds lower their liability discount rates if interest rates decline, and invest less in risky assets and use lower liability discount rates as their participant base matures. However, U.S. public pension funds are unique in choosing more risky asset allocations and not lowering the discount rates as their plan member base matures. Further, for U.S. public funds, I find no relation between their liability discount rates and interest rates.

These results suggest that part of the asset allocation decisions of U.S. public funds may be driven by a desire to camouflage or make up for underfunding. I find that the increased risk-taking of U.S. public pension funds has resulted in a relative underperformance of more than 60 basis points annually on a net benchmark-adjusted basis, which is consistent with asset allocation decisions being made sub-optimally.

These results point to a basic conflict of interest between current and future stakeholders of U.S. public pension funds. Current generation (including executives, members, and their board representatives; politicians; and taxpayers) has a direct incentive to underestimate the current value of existing promised pension benefits and transfer this risk to future generations. The underestimation of the existing liabilities value may allow the current stakeholders to pay lower required contributions to the pension funds and postpone tough changes in the pension benefits. For instance, in 2011 and 2012, CalPERS Board members decided not to lower the liability discount rate from $7.75 \%$ to $7.25 \%$, because this could have resulted in an even lower self-reported funding ratio (the funding ratio in 2010 was 83 percent) and increase in state's employee pension costs of approximately 4.2 percent of payroll per year. The increase in the required contributions would have been even higher for the local governments and public safety agencies. ${ }^{3}$

My findings indicate that the current regulatory framework allows U.S. public pension funds to make strategic decisions that camouflage the real value of their promised pension benefits. These decisions could result in substantial redistributions between generations and could have negative implications for future stakeholders and taxpayers.

\subsubsection{Pension fund asset management decisions}

Chapter 3 extends the analysis of pension fund asset allocation by examining how pension funds implement strategic asset allocation decisions over time. This chapter examines the performance of the three asset management decisions made by a large institutional investor: asset allocation, market timing, and security selection.

\footnotetext{
${ }^{3}$ see “CalPERS Should Cut Assumed Return to 7.25\% From 7.75\%, Actuary Recommends," Bloomberg News, March 7, 2012.
} 
I also explore the role of size and liquidity for pension fund performance in all three asset management components. On the positive side, less liquid investments have potentially higher expected returns. Large scale may provide significant bargaining power vis-a-vis external money managers or allow funds to attract investment talent internally. On the negative side, larger size may make trading in less liquid securities much more difficult, may limit the investment strategies available and create organizational complexities. Pension funds seem particularly interesting vehicles to study questions related to size and liquidity in investment management performance, because they tend to be larger than other institutional investors, like mutual funds or endowment funds. Pension fund incentives also differ substantially, as DB pension fund inflows do not depend on performance, but on actuarial and demographic factors. This long-term liability structure further enables pension funds to make substantial investments in illiquid assets.

The first component of asset management, asset allocation, compares the impact of the change in strategic asset allocation policy weights over last year, relative to not changing the previous year policy weights. The second component is market timing, defined as the difference between strategic policy and actual (realized) allocation weights. Market timing thus captures the performance related to overweighting or underweighting particular asset classes, relative to the policy weights in that year. The third component is security selection, corresponding to net benchmark-adjusted returns or the difference between realized net returns and benchmark returns for a given asset class. This captures the returns due to picking securities and timing industries and styles within an asset class.

After risk-adjusting, I find that pension funds obtain positive returns from changes in strategic asset allocation and market timing, but not from security selection. The positive abnormal market timing returns can be fully attributed to passive exposure to 'time series' momentum, and not to any active rebalancing. Pension funds benefit from simultaneously investing in multiple asset classes, but would have performed even better if they had invested more in passive mandates without frequent rebalancing across asset classes. For comparison, the average annual investment cost of passive mandates is 6 basis points compared to 45 basis points for active mandates.

Larger pension funds do not manage to transfer their lower investment costs into higher net returns. Rather, I document diseconomies of scale in pension fund performance. The diseconomies of scale are primarily apparent for funds investing in less liquid assets, as proxied by fund total return loadings on the Pastor and Stambaugh (2003) traded systematic liquidity factor. Smaller pension funds obtain higher total returns and especially higher market timing returns. The better market timing returns of smaller funds can be explained by two effects. First, smaller funds can be managed in a more flexible way that enables them to deviate further from their strategic asset allocation weights. Second, even if smaller pension funds have to rebalance to restore their strategic weights, such rebalancing has lower market impact.

Overall, pension funds seem to have most expertise in designing strategic asset allocation and market timing policies, rather than in actively selecting securities or in finding external managers with superior security selection skills. When I compare the total performance of 
funds depending on the percentage actively managed assets, I document that especially larger pension funds would have done better if they had invested in passive mandates without frequent rebalancing across asset classes. The most actively managed group of pension funds has significantly greater liquidity-related diseconomies of scale, as pension funds that are in the largest quartile group underperform similarly sized funds with much less active management by about 62 basis points per year.

\subsubsection{Financial intermediation in alternative assets}

During the 1990-2011 period, institutional investors have increased the amount of investments in alternative asset classes, attracted by the promise of superior absolute returns and low correlation with traditional assets such as equities and bonds. In Chapters 4 and 5, I examine the allocations of institutional investors to real assets, private equity and hedge funds. My main contribution is to consider how levels of intermediation and specialization relate to costs and performance of institutional investors in alternative assets.

I distinguish three levels of intermediaries serving as an interface between investors and assets. Institutional investors can manage the alternative investments internally (in-house), delegate the asset management to external managers or delegate even the selection of external managers to fund-of-funds. Establishing a competitive internal asset management division requires investors to pay high fixed costs for employee compensation, information gathering and structuring of investments. When delegating the asset management to financial intermediaries, institutional investors trade off higher anticipated returns from these intermediaries against the increased difficulty in coordinating their risk-taking and the greater uncertainty about their true incentives and skills. The private markets for alternative assets offer an appropriate setting to compare the performance across the three levels of intermediation, since the identification of good managers or projects is impeded by limited disclosure, a rapidly growing number of funds and proliferation of investment strategies in all three alternative asset classes.

In terms of net benchmark-adjusted returns, institutions that invest through internal managers tend to perform better than their counterparts, that rely on financial intermediaries. More layers of financial intermediation result in lower performance in all three alternative asset classes: real assets, private equity and hedge funds. The outperformance of internal managers compared to financial intermediaries stems from two sources. First, for sufficiently large institutional investors, establishing internal management divisions costs significantly less than investing through external managers and fund-of-funds. Second, internal managers can successfully compete with financial intermediaries in the private markets and manage to obtain similar or higher gross returns in all three alternative asset classes.

I consider also the specialization decision, which captures whether institutions invest only in one alternative asset class, or invest simultaneously in two or three alternative asset classes. From a mean-variance perspective, adding asset classes to the overall portfolio brings diversification benefits. However, each alternative asset class is different and requires its own expertise. The effect of specialization on performance is non-uniform and depends on mandate size. In general, institutions realize significant economies of scale in their alternative investments. 
However, smaller institutional investors that specialize in one alternative asset class perform significantly better than smaller investors that invest simultaneously in multiple alternative asset classes. The opposite is true for larger institutions. Large specializing investors may face liquidity related diseconomies of scale and are better off when investing simultaneously in multiple alternative assets.

The results regarding the effect of investment approach and size on performance in alternative assets are consistent with the model of financial intermediation by Stoughton, $\mathrm{Wu}$, and Zechner (2011). Fund-of-funds' underperformance on a gross and net basis relative to internal and external managers confirms the Stoughton et al. (2011) prediction that, in private markets with kickback compensations, underperforming assets are more likely to be sold indirectly, through multiple layers of financial intermediaries.

Chapter 5 extends the analysis on pension fund investments in alternative assets, by examining in more detail institutional allocations to real estate. Based on the assets under management, real estate is the most significant alternative asset class for institutional investors. Moreover, real estate represents an intersection between public and private markets. Only in real estate, investors have the option to substitute an illiquid product (direct real estate) with a liquid product, like real estate investment trusts (REITs).

Although listed REITs provide liquid and scalable property exposure, which should make these vehicles attractive to smaller investors, I document that larger funds are in fact more likely to invest in REITs. Allocations to REITs are mostly implemented as complementary investments to the direct real estate holdings of larger pension funds, while smaller funds allocate more capital to financial intermediaries in direct real estate. Smaller pension funds do not seem to recognize that REITs represent an investment approach in real estate that is comparable to selecting financial intermediaries investing in direct real estate, but with substantially lower investment costs.

I also analyze the contribution of alternative assets to the overall investor performance. I find that especially smaller institutional investors would have been better off by not investing in alternative assets. I document that smaller investors would have obtained at least two percentage points higher annual returns, if they had invested passively in public equity rather than alternative assets. Smaller institutional investors consistently underperform their self-reported public equity benchmarks with their investments in real assets, private equity and hedge funds.

\subsection{Implications for pension fund governance}

Pension funds serve as agents that enable the principle, plan members, to save for retirement. People rely on pension funds to manage their wealth because they are required by law to save through this institutions or because they lack knowledge and monitoring capacity to manage investments directly. However, the fact that the principle does not possess sufficient expertise and requires an agent creates additional agency conflicts (Allen, 2001).

In this dissertation, I show that among pension funds two agency conflicts exist. Both of these agency conflicts could be reduced substantially by greater transparency in the pension 
fund valuation as well as in the relations between pension funds and asset management industry.

First, different generations of plan members and taxpayers have opposing interests when a DB pension fund is underfunded. Current stakeholders have an incentive to postpone restructuring the pension benefit promises and to transfer the underfunding risk to the future generation. Chapter 2 shows that pension fund asset allocation decisions implemented by the current generation can be influenced by the regulatory incentives to mask funding problems and shift the risk to future generations as well as to tax payers. In the past two decades, U.S. public pension funds uniquely increased allocations to riskier investments, which allows them to maintain high discount rates even as interest rates decline, thereby camouflaging their degree of underfunding. The purpose of public and private DB pension plans is the same - to provide secure and affordable retirement benefits to their members. There is no good economic reason why public and private pension funds in the United States should be regulated in different ways. The current regulation of U.S. public pension funds reduces the transparency of pension funds' financial situation and could lead to substantial redistribution between generations and could have negative implications for future stakeholders and taxpayers.

In my policy implications, I do not argue that there is an optimal funding level of pension plans. Based on the Ricardian equivalence it is irrelevant for the public welfare whether the current retirement benefits are financed with debt or taxes (Ricardo, 1820). There are no intergenerational consequences of the public pension debt, because current generation could leave extra assets to their children as a compensation for the additional taxes or lower pensions due to intergenerational pension transfers. However, the Ricardian equivalence only holds if the current and future generations are informed about the level of pension plan underfunding and state indebtedness. The current regulation of U.S. public pension funds camouflages their funding situation and indirectly the public debt level, making it difficult for people to correctly assert the intergenerational transfers (Novy-Marx and Rauh, 2009). Providing accurate estimates of the pension fund financial situation and their projected cash-flows will enable the plan members and taxpayers to make informed financial decisions. Moreover, increasing the transparency in U.S. public pension fund reporting is a necessary precondition before discussing the potential reforms in the pension deal, required to overcome the significant underfunding problems.

Second, when plan members delegate the management of their retirement saving to pension funds, they anticipate higher returns from the expertise and economies of scale of these institutions. Pension fund asset management decisions are made in two stages. In the first stage, pension fund executives allocate capital to different asset classes, each managed by a different asset manager, and in the second stage, each manager decides in which assets within his class to invest the funds allocated to him (Binsbergen, Brandt, and Koijen, 2008). This twostage process involves many intermediaries, such as pension fund boards and executives, asset managers, placement agents and consultants. The multiple layers of delegation can generate several misalignments of incentives and may lead to substantial losses for the pension plan members. 
Chapters 4 and 5 show that multiple layers of intermediation result in higher investment costs and lower performance, especially in alternative assets. Even though delegated asset managers on average underperform the internal investments net of fees, this is an equilibrium for some institutional investors that delegate portfolio management to intermediaries because delegation reduces their anxiety about taking risk. When investing internally, institutions do not share the responsibility for future performance with financial intermediaries, which results in significantly higher risk aversion (Gennaioli, Shleifer, and Vishny, 2013; Lakonishok, Shleifer, and Vishny, 1992). Investors will retain the external managers, since an institutional investor who delegates the asset management to intermediaries in order to shift responsibility perceives the returns on risky investments delivered by this manager as less uncertain than those delivered by an internal investment division. However, institutional investors who rely on financial intermediaries in order to shift responsibility and reduce anxiety, seem to violate their fiduciary duty and do not seem to act in the best interest of their beneficiaries.

My findings have some general normative implications for the asset management industry. The large amount of asset under management enables DB pension fund to establish efficient internal investment divisions and to negotiate lower fees with external asset managers. However, the large size also exposes DB funds to potential liquidity-related diseconomies of scale. Based on Chapter 3, in traditional assets, such as equities and bonds, especially larger pension funds would have done better if they had invested in passive mandates without frequent rebalancing across asset classes. When investing actively in equities and bonds, large pension funds experience significant diseconomies of scale. The results suggest that larger institutional investors, like DB pension funds, can benefit more from designing strategic asset allocation and market timing policies, rather than selection of multiple active managers within the asset classes.

In alternative assets, where passive investing is not possible, larger investors should evaluate the possibility of investing internally because fewer levels of intermediation enable institutional investors to access better investment opportunities in alternative asset classes. Smaller institutions should consider substituting fund-of-funds with other investment approaches, and specializing in one alternative asset class, instead of simultaneously investing in multiple alternative assets. If smaller investors do not have sufficient skills and resources, they should invest passively in public equity instead of going into alternative assets.

This thesis shows that financial institutions are prone to significant agency conflicts because different groups of stakeholders have opposing interests and because they cover multiple layers of intermediation. In the pension fund context, the agency conflicts could result in a redistribution of assets between the different generations as well as a redistribution form the retirement plan members to the multiple layers of financial intermediaries. 


\section{Chapter 2}

\section{Pension Fund Asset Allocation and Liability Discount Rates: Camouflage and Reckless Risk Taking by U.S. Public Plans?*}

\subsection{Introduction}

Pension funds around the world are in a state of flux. In the past two decades, funds have faced financial crises, a maturing participant base, decreasing Treasury yields, tightening regulation and, as a result, increasing demands for transparency and accountability. Most defined benefit (DB) pension funds are underfunded or have asset values that are lower than the value of their liabilities (the pension benefit promises made), despite the fact that the valuation of the size of these liabilities in many cases is severely underestimated (see Novy-Marx and Rauh, 2011).

The challenge for DB pension funds is how to decide and periodically update, in conjunction with other stakeholders, critical aspects of their policies, such as the contribution levels of plan members, strategic allocations across various asset classes, and the kind of inflation protection offered. They do so by using projections of their liabilities (i.e., pension promises) and their expected future income from investments. When considering asset-liability management, boards need to decide on a few key input parameters such as the level of expected returns, interest and inflation rates, and the discount rate used to value the liability stream, as well as a number of actuarial indicators such as life expectancies.

The amount of latitude pension fund boards have in this process depends on the regulatory framework in which they operate. In general, these decisions either can be left at the full discretion of the pension funds, or, at the other end of the spectrum, they can be heavily restricted by regulation or public policy. Previous literature (see, for example, Brown and Wilcox, 2009; Novy-Marx and Rauh, 2011, 2009) has shown that regulation of U.S. public pension DB plans is relatively opaque and leaves wide discretion to their boards, setting them apart from

\footnotetext{
${ }^{*}$ This chapter is co-authored with Rob Bauer (Maastricht University) and Martijn Cremers (University of Notre Dame).
} 
e.g. Canadian and European public pension funds as well as from private pension funds in all three of these regions. In this paper, we empirically study the consequences of the distinct regulatory environment for U.S. public pension funds by examining their asset allocations, liability discount rates, inflation protection, asset valuation smoothing, and performance. Using the international CEM pension fund database that provides detailed annual information for an extensive sample of large pension funds over 1990 - 2010, our empirical approach is to compare U.S. public funds to U.S. private funds and both private and public funds in Canada and Europe. $^{2}$

U.S. public funds are distinct in that they can decide their strategic asset allocations and liability discount rates largely without regulatory interference under current Government Accounting Standards Board (GASB) guidelines. In particular, these guidelines link the liability discount rates of U.S. public funds to the (assumed and relatively subjective) expected rate of return on their assets. In contrast, U.S. private pension funds and (both public and private) Canadian and European pension funds are arguably subject to significantly stricter regulatory guidelines. Their regulations generally require that liability discount rates be chosen as a function of current interest rates (see, for example, the Canadian Institute of Actuaries, 2011 and Crossley and Jametti, 2013), as advocated by the economic theory literature (Brown and Wilcox, 2009; Lucas and Zeldes, 2009; Novy-Marx and Rauh, 2011, 2009). We argue that the distinct regulatory framework for U.S. public funds gives them strong incentives to shift a larger allocation to risky investments, as this increases the assumed expected rate of return on their asset portfolio and thus (through their regulation) results in higher liability discount rates. This in turn helps these pension funds camouflage their degree of underfunding and potentially delay making difficult decisions on contribution levels and pension benefits. Over the last two decades, increased allocations to assets with higher (assumed) expected returns has allowed U.S. public pension funds to maintain high liability discount rates, even as interest rates significantly declined.

We empirically document that the asset allocation and liability valuation of U.S. public DB pension funds have changed very differently in response to two critical developments in the last 20 years, both of which are exogenous to individual pension fund boards and have profound economic implications. The first development is the maturing of member populations, i.e. that the percentage of retired members (current or past workers who are beneficiaries) as a fraction of all members has significantly increased and thus the percentage of members paying into the defined benefit plan has decreased. On average, the percentage of retired members among private plans increased from 31 percent in 1993 to 52 percent in 2010, and from 28 percent in 1993 to 39 percent in 2010 among public pension funds. The second development is the

\footnotetext{
${ }^{2}$ The relatively long time series and broad cross-sectional coverage provide strong statistical power, such that our main results are derived in pooled panel regressions with pension fund fixed effects as well as year fixed effects, using robust standard errors that are independently double-clustered in both the time and fund dimensions. The CEM database offers an exclusive and very detailed look at the asset-liability management of pension funds around the globe. CEM data has been used previously by researchers such as French (2008) to study the cost of active investing, and by Andonov, Bauer, and Cremers (2012) to examine the asset allocation, market timing, and security selection skills of pension funds.
} 
steady decline in interest rates over this period. For example, the 10-year U.S. Treasury yield fell from about 7 percent in 1994 to about 3 percent in 2010.

In regard to the first major issue, the increased proportion of retired members, economic theory suggests that asset allocation and liability discount rate choices should be more conservative as the fund matures (see Benzoni, Collin-Dufresne, and Goldstein, 2007; Lucas and Zeldes, 2006, 2009; Sundaresan and Zapatero, 1997). We find that this is indeed how pension funds have generally responded. However, U.S. public pension funds are unique in not choosing more conservative asset allocations and not choosing lower discount rates as their plan member base matures. Instead, for U.S. public funds, the proportion of retirees relative to non-retirees is positively related to the allocation to risky assets: a 10 percent increase in the percentage of retired members of U.S. public pension funds is associated with a 2.05 percent increase in the allocation to risky assets, while a 10 percent increase in the percentage of retired members is associated with a 1.16 percent lower allocation to risky assets among all other pension funds. ${ }^{3}$ Further, and again in contrast to the other pension funds in our sample, for U.S. public funds, we find a positive association between their liability discount rates and the proportion of retired members: a 10 percent increase in the percentage of retired members is associated with a 21-31 basis point increase in the discount rate for U.S. public funds.

The second major development is that the three regions we consider all saw significant declines in interest rates over our time period, which should theoretically affect the choice of the liability discount rate. Financial theory suggests that future streams of pension benefit payments should be discounted at a rate that reflects their inherent riskiness, particularly their covariance with priced risks. Beneficiaries of pension promises, for both public and corporate entities, seem well protected by law, such that these pension payments are relatively certain or bear relatively little systemic risk (see, for example, Brown, 2008; Brown and Wilcox, 2009). ${ }^{4}$ As a result, Brown and Wilcox (2009) and Novy-Marx and Rauh (2011) propose using liability discount rates based on yields on government and municipal bonds and swap rates.

In our empirical analysis, we find that pension funds generally lower liability discount rates as interest rates decline, which is consistent with both their regulations and economic theory. However, U.S. public pension funds are again different, as we find no association between liability discount rates and interest rates. This is consistent with their incentives and their distinct regulation that explicitly links liability discount rates to their expected rate of return on assets rather than to the level of interest rates. This result holds even while controlling for the proportion of assets invested in risky asset classes, which means that U.S. public pension funds have made the economically surprising choice of not lowering their nominal expected return estimates on risky assets as interest rates decline.

\footnotetext{
${ }^{3}$ We define the percentage allocated to risky assets as investments in public equity, alternative assets (e.g., private equity, hedge funds, and real estate) and risky fixed income (e.g., high yield bonds).

${ }^{4}$ For public funds, pension promises in the United States are usually backed by constitutional non-impairment clauses as well as through statutory and common law (Brown and Wilcox, 2009). The Pension Benefit Guarantee Corporation backs pension promises of corporate defined benefit plans in the United States. Even if a firm enters bankruptcy with insufficient pension assets to cover its liabilities to workers, plan participants will still receive their annual pensions up to a statutory maximum amount.
} 
Moreover, we find that an increasing majority of U.S. public pension funds manages the asset side of the balance sheet by smoothing the valuation of the assets over time, for which applicable valuation standards allow wide discretion (see, for example, Actuarial Standards Board, 2007, 2009). We document that U.S. public pension funds with higher allocations to risky assets are more likely to smooth asset valuations, possibly because smoothing masks the volatility of the performance of risky investments.

We also study the decision to provide contractual inflation protection. Public pension funds (especially in the U.S.) are more likely to promise inflation-indexed pension benefits to their participants. Brown and Wilcox (2009) argue that pension funds promising inflation protection should use risk-free real interest rates (e.g., yields on TIPS) to discount their pension promises. However, we find no association between liability discount rates and whether or not the DB fund offers inflation protection. This suggests that funds may be underestimating the cost of their inflation protection promises.

In summary, over the past 20 years, U.S. public pension funds have uniquely increased their allocation to riskier investment strategies, which has allowed them to maintain high discount rates and present lower liability valuations, in line with the predictions of Brown and Wilcox (2009). ${ }^{5}$ During our time period, U.S. public pension funds increased allocations to risky assets, especially if their proportion of retired members increased. At the beginning of our sample, U.S. public pension funds had liability discount rates and allocations to risky assets that were similar to or below the other funds in our sample (for example 57 percent compared to 67 percent for U.S. private funds in 1993). By the end of our sample period in 2010, U.S. public funds as a group had the highest discount rates (190 basis points above U.S. private funds and even more above typical discount rates of Canadian and European pension funds) as well as the largest allocations to risky assets (on average 73 percent compared to an average of 64 percent for U.S. private pension funds, while Canadian and European funds have even lower allocations to risky assets).

This risk-taking behavior can be explained by the GASB rules linking liability discount rates to the riskiness of the assets, which creates the incentive to invest more in risky assets in order to keep liability discount rates high and present lower liability valuations, and thus (at least on paper) a better funding position. Our results point to a basic conflict of interest between current and future stakeholders of U.S. public pension funds. Current stakeholders (including boards, members, and their representatives; politicians; and taxpayers) have a direct incentive to underestimate the current value of existing promised pension benefits and transfer this risk to future generations. In this era of general underfunding, when the average self-reported funding ratio of U.S. public funds in 2010 was 75 percent, such underestimation of the value of the existing liabilities may allow the current stakeholders to postpone tough choices. ${ }^{6}$

\footnotetext{
${ }^{5}$ Our findings on U.S. private pension funds are also in line with Rauh (2009), who documents a positive correlation between risk taking and the share of active employees in corporate pension plans.

${ }^{6} \mathrm{~A}$ recent example illustrates the economic magnitude. The actuary of CalPERS recommended lowering the liability discount rate from 7.75\% to 7.25\%, according to a news article (Bloomberg News, March 7, 2012, "CalPERS Should Cut Assumed Return to 7.25\% From 7.75\%, Actuary Recommends"). The article states: "Lowering the return would boost the state's employee pension costs, as a percent of payroll, as much as 4.2 percent in the year beginning July 1, according to a CalPERS staff report. Local governments could see an increase of as much as 4.5
} 
Our results further suggest that part of the asset allocation decisions of U.S. public funds may be driven by considerations other than asset-liability management and their views on where the best investment opportunities are. In effect, the increased risk-taking is arguably reckless to the extent that it is driven not by such economic considerations but rather by a desire to camouflage or make up for underfunding. We find evidence suggesting that the increased risk-taking of U.S. public pension fund has resulted in an underperformance of more than 60 basis points annually (on a net benchmark-adjusted basis, and compared to all other pension funds), which is consistent with asset allocation decisions being made sub-optimally. Moreover, U.S. public pension funds that are more mature had worse underperformance. A 10 percent increase in the maturity of U.S. public pension funds is associated with 25-48 basis point lower net benchmark-adjusted returns.

We discuss policy implications by comparing U.S. public pension funds to public funds in Europe (mainly funds from the U.K. and the Netherlands) and Canada, as well as to private pension funds in all three regions. The results for Canadian and European funds suggest that public and private pension funds behave similarly when they face a similar regulatory environment. As a result, we recommend bringing U.S. public fund regulation in line with the regulation applying to U.S. private pension funds and to (either public or private) Canadian/ European pension funds.

The remainder of the chapter is organized as follows. In section 2.2, we discuss the regulatory environment of pension funds for the three regions we investigate. Section 5.3 introduces the pension fund databases we use and provides summary statistics on our key variables of interest. In section 2.4, we investigate how the allocation to risky assets is related to characteristics in our pension fund database, including smoothing of the asset valuation. In section 2.5, we explore how reported liability discount rates are related to pension fund characteristics and which funds are more likely to provide inflation protection to their members. Section 5.6 examines whether the increased risk-taking of certain pension funds results in better performance. Section 5.7 concludes with a discussion of policy implications, including the recent GASB $(2011,2012)$ proposals pertaining only to U.S. public pension funds.

\subsection{Optimal asset allocation and the regulation of pension funds}

In this section, we explain the predictions about pension funds' risk-taking behavior and their choice of liability discount rates (and how these relate to fund maturity and interest rates) from two different perspectives. We first consider economic theory and then discuss possible shortterm incentives in the context of underfunded DB pension plans and regulation. "Risk-taking behavior" refers to the proportion of assets invested in risky assets, such as public equity, private equity, real estate, and alternative assets. The "liability discount rate" is the rate that is

percent the following year. The costs for some public-safety agencies could jump as much as 6.5 percent. ... The board rejected a similar proposal ... last year. Board members at the time expressed concern that lowering the rate to 7.5 percent would burden local governments when they were already facing financial strains." One week later, the CalPERS board decided to indeed lower the discount rate, but by only half as much as recommended by its actuary (see "CalPERS Lowers Investment Target to 7.5\%," Wall Street Journal, March 14, 2012). 
used by the pension fund to discount its projections of future pension payments. In our empirical section, we test these predictions about how the level of interest rates, plan maturity, and contractual inflation protection relate to the allocation to risky assets and the liability discount rate.

\subsubsection{The relation between risk taking, maturity, and inflation protection}

Theoretical models imply that optimal asset allocation should be a function of fund maturity, salary growth, and promised inflation protection. In principle, these variables should have similar effects across all funds, regardless of geographical region, regulatory requirements, or plan type (public or private).

Economic theory and empirical work argue that returns on risky assets and the growth in average aggregate labor earnings are positively correlated in the long-run, although shortrun correlation is typically low. Lucas and Zeldes (2006) show theoretically that when labor earnings growth and stock returns are positively correlated over longer horizons, obligations to older workers and retirees behave more like bonds and can be valued and hedged as such. However, because of future salary risk, obligations to younger workers are risky or behave more like stocks. As a result, Sundaresan and Zapatero (1997) and Lucas and Zeldes (2009) argue that the proportion of pension fund assets invested in risky assets should be positively related to the percentage of active participants, because pension benefits are tied to salaries, which are positively correlated with stock returns in the long run.

Rauh (2009) finds a positive correlation between risk taking and the share of active employees in U.S. private pension plans, whereas Lucas and Zeldes (2009) find an insignificant relation between the share of active participants and the percentage allocated to public equity among U.S. public pension funds. We expand this prior research by examining not only the cross-sectional dimension, but also how allocations to risky assets have changed over a relatively long and dynamic time period. Moreover, we incorporate international evidence on both public and private pension plans. Lucas and Zeldes (2009) sample consists of 109 state and 87 local plans in a single year (2006), and Rauh (2009) focuses only on U.S. corporate funds. In comparison, our sample includes 804 public and private defined benefit pension funds in three regions over a 20-year period.

Further, Campbell and Viceira (2005) argue that optimal pension fund asset allocation also depends on the contractual indexation policy, whether the liabilities are fixed in real or nominal terms, and show that holding bonds to maturity is akin to accumulating inflation risk. Boudoukh and Richardson (1993) and Schotman and Schweitzer (2000) document that stocks can serve as an inflation hedge in the long run.

Regarding the appropriate rates to discount the pension liabilities, financial theory suggests that the streams of future pension payments should be discounted at a rate that reflects the inherent risk of these cash flows, particularly their covariance with priced risks. In the case of pension funds, the "risk" associated with the liabilities relates primarily to whether the promised benefits will be paid in full in the future. For public funds in the United States, pension promises are usually backed by constitutional non-impairment clauses as well as through 
statutory and common law (Brown and Wilcox, 2009). Pension promises of corporate DB plans in the United States are backed by the Pension Benefit Guarantee Corporation (PBGC). If a firm enters bankruptcy with insufficient pension assets to cover its liabilities to workers, the PBGC (and potentially the U.S. government) provides plan recipients with their annual pensions up to a statutory maximum amount. In addition, underfunded private plans have to contribute a deficit reduction ("catch-up") contribution (Brown, 2008). Hence, pension promises of both public and private funds are well protected, with little uncertainty about whether the promised benefits will have to be paid. As a result, Brown and Wilcox (2009) and Novy-Marx and Rauh (2011) propose using Treasury rates, municipal rates, and swap rates to discount pension liabilities, because these rates reflect the low uncertainty surrounding the promised pension payments.

The implication that follows is that liability discount rates should decrease in line with decreasing government bond yields. Further, as the yield curve is generally upward sloping, we would expect that more mature pension funds, those plans whose liabilities have shorter durations, should typically use lower discount rates than younger funds. Furthermore, public pension funds should use lower discount rates than private pension funds, because public plan benefits are virtually free of risk as they are usually backed by constitutional guarantees; in contrast, members of private plans still risk losing part of their pensions if the firm enters bankruptcy.

\subsubsection{How pension fund regulation affects asset allocation decisions and liability discount rates}

We examine the effect of differences in pension fund regulation by contrasting the regulatory framework for U.S. public pension funds with those of U.S. private funds and both public and private pension funds in Canada and Europe. Specifically, we argue that these regulatory differences give rise to different incentives regarding the choice of the proportion of assets invested in risky asset classes and the liability discount rate used. The main difference across pension funds is the regulations concerning the liability discount rates. U.S., Canadian, and European pension funds generally face few limits on the proportion of investments they can make in risky assets. ${ }^{7}$

In the United States, significant differences in regulation exist between private and public pension plans. U.S. public pension funds are subject to the Government Accounting Standards Board (GASB) guidelines for discounting liabilities. These guidelines allow U.S. public pension funds to base their liability discount rates on the expected rates of return on their assets. U.S. public fund boards are largely unconstrained in the proportion of their assets that can be invested in risky assets and in their assumptions on the expected rate of return in the various asset classes, giving these boards substantial latitude in choosing their liability discount rate. We argue that U.S. public pension funds have considerably more leeway in their choices than U.S. private funds or (public and private) pension funds in Canada and Europe.

\footnotetext{
${ }^{7}$ See the OECD Secretariat (2011) Survey of Investment Regulation of Pension Funds.
} 
Novy-Marx and Rauh $(2011,2009)$ and Brown and Wilcox (2009) argue that this latitude gives rise to strong incentives to invest more in risky assets, with higher expected rates of return. The resulting higher liability discount rates allow the U.S. public pension funds to present lower liability estimates and better funding status, even though the nature of their liabilities remains the same. In times when public funds are typically severely underfunded (even using their relatively high liability discount rates), this relieves pressure on the public entities involved as well as on politicians and taxpayers, at least in the short term.

Despite the critiques from academic economists, GASB still maintains the view that "as long as plan assets related to current employees, retirees, and their beneficiaries are projected to be sufficient to make the projected benefit payments for those individuals, governments would discount projected benefit payments using the long-term expected rate of return" (GASB, 2011, 2012). Ambachtsheer (2010) argues that under this GASB rule, pension obligations will continue to be underfunded and underreported by U.S. public sector pension plans. Novy-Marx (2011) shows that under this rule it is possible for a plan to improve its official measure of funding status by literally burning money. ${ }^{8}$

Using time series data on the trends in strategic asset allocations over the last 20 years, we are able to test directly whether U.S. public pension funds use their freedom strategically. When facing decreasing bond yields, their typical discount rates of around 7 to 8 percent can only be maintained by allocating even more assets to equity and alternatives. This riskier allocation thereby camouflages the level of underfunding. This camouflaged underfunding amplifies the risk that DB plans will run out of assets before they run out of liabilities, which would involve a significant wealth transfer from future to current generations of workers and taxpayers.

Pennacchi and Rastad (2011) document that U.S. state pension plans gamble by choosing riskier portfolios following periods of relatively poor investment performance. We extend this analysis by associating changes in asset allocation to changes in fund maturity and government yields over a long time horizon (1990-2010), contrasting U.S. public funds to U.S. private funds and international public and corporate pension funds. We also examine pension fund performance following increased risk-taking.

Using yields on taxable municipality and Treasury bonds, discount rates that reflect the very limited uncertainty of future public pension fund payments, Novy-Marx and Rauh (2011) show that all state pension plans in the United States were severely underfunded in 2009 . The collective underfunding is in the range of \$1.26-2.49 trillion. Hence, all public funds in the United States are tempted to continue to use high discount rates, even when interest rates decline, to present a more favorable situation to beneficiaries, taxpayers, and creditors. Within public U.S. funds, we expect that funds with a greater percentage of retired members have especially strong incentives to use higher discount rates, as the shorter maturity increases the

\footnotetext{
${ }^{8}$ Novy-Marx (2011) shows that the GASB penalizes a plan for holding cash and bonds by forcing it to recognize a larger liability if it does so: "By destroying a dollar's worth of T-bills, or other cash-equivalents, a manager decreases a plan's assets, but increases the remaining assets' expected returns. These higher expected returns are used as a discounting rate and decrease the present value of plan's liability, as recognized by GASB, and this decrease can more than offset the loss of assets."
} 
present value of their liabilities and limits their ability to camouflage their underfunding. Thus, we expect that more mature public funds in the United States are using higher discount rates.

U.S. private pension funds face different regulatory standards and do not have clear incentives to invest more in riskier assets over time. Most importantly for our empirical identification, individual firms in the United States have less discretion over their reported pension liabilities and discounting rates than public pension funds. Until 2004, U.S. firms were required to discount their liabilities using the 30-year Treasury rate, both for funding purposes and when estimating their deficit reduction ("catch-up") contributions. Since 2006, firms have been allowed to discount their liabilities using a discount rate that is a blend of long-term corporate bonds, including both upper-medium and high-grade securities (Rauh, 2006).

At the same time, let us emphasize that we are making a comparison and that we are not arguing that U.S. corporate plans had no regulatory latitude at all. First, Love, Smith, and Wilcox (2011) argue that various forms of government intervention, such as benefit guarantees through the PBGC, can provide the firm with an incentive to shift risk to other parties. To the extent that the PBGC insurance is underpriced and not risk-adjusted, firms could increase the value of their "pension put option" by taking on more risk in their pension portfolio. Second, FASB rules allow firms to take credit for the expected rate of return on their income statement, as a reduction in the net period pension expense. Bergstresser, Desai, and Rauh (2006) show that firms use higher assumed rates of return on pension assets when they prepare to acquire other firms, when they are near critical earnings thresholds, and when their managers exercise stock options.

However, Rauh (2009) shows that the risk management incentives to avoid costly financial distress dominate risk-shifting incentives in private DB pension funds, especially amid tightening regulation. Brown (2008) presents examples of ways in which accounting standards that existed prior to the Pension Protection Act of 2006 allowed firms to hide the true economic costs of pension promises. ${ }^{9}$ Since 2006 , their asset-liability management has been subject to more regulatory scrutiny. Moreover, firms also have incentives to use appropriate discount rates and to shore up underfunded pension plans, because firms that are sufficiently overfunded are exempt from the PBGC insurance premiums and pension overfunding reduces the probability of a ratings downgrade in such a way that the value of the firm is increased (Bergstresser, Desai, and Rauh, 2006; Rauh, 2006).

In Canada, pension fund accounting standards generally require that the discount rate be selected based on market yields of high-quality corporate debt instruments with cash flows that match the timing and amount of the expected benefit payments. These standards seem to leave only limited room for discretion (primarily by allowing latitude in defining "high quality"),

\footnotetext{
${ }^{9}$ For instance, prior to the adoption of the Pension Protection Act of 2006, firms were only required to fund 90 percent of their liabilities. They were permitted to "smooth" interest rates over four years (which allowed firms to report smaller liabilities in periods of declining interest rates), were allowed to use the smoothed "actuarial" value rather than the market value of plan assets (with up to a 20 percent deviation from actual market values permitted), and were allowed to avoid making cash contributions to their pension plans by making use of various accounting credits even if the plan was underfunded. The Pension Protection Act of 2006 addressed these issues by, for example, mandating minimum contribution rules that, after a phase-in period, are based on 100 percent of a plan's liabilities, rather than 90 percent funding. In addition, the time period for smoothing assets and liabilities was reduced to two years (Brown, 2008).
} 
which specific debt instruments are to be included, and how to address the lack of suitable debt instruments at very long-term maturities (Canadian Institute of Actuaries, 2011).

Furthermore, and in sharp contrast to the United States, Canadian public and private pension plans are regulated in the same way, generally under the domain of the financial market supervisors of the province where they are registered. In Canada, only the province of Ontario (where around 50 percent of the plans are registered) has established pension benefit insurance. Crossley and Jametti (2013) find that insured plans in Canada invest about 5 percent more in equities than do similar plans without benefit guarantees. Our dataset does not include the province in which Canadian pension funds are registered, but we control for fund fixed effects, which should absorb the differences in asset allocation due to such cross-jurisdiction variation.

Our small sample of European pension funds consists almost entirely of Dutch funds (plus a few from the U.K.). In the Netherlands, pension funds have almost no discretion in choosing their liability discount rate. Until 2004, Dutch pension funds were obliged to use 4 percent as their discount rate. Thereafter, the Financial Assessment Framework (FTK), which is part of the Pensions Act, set the requirements for discounting the liabilities by using the term structure (swap-curve) of nominal risk-free interest rates (or real in case of inflation indexation guarantees). In this tight regulatory regime, poorly funded pension funds are less inclined to invest in riskier assets. If there is a funding shortfall, which is defined as a coverage ratio of less than 105 percent, the fund must submit a recovery plan. The coverage ratio must regain the 105 percent level within three years. In the U.K., private plans discount their liabilities using AA yields, whereas public pension funds use a 3.0 percent discount rate, set based on the expected GDP growth in the long run.

\subsection{Data}

We study the link between pension fund asset allocation and liabilities, looking at both crosssectional relations and relations within plans over time. We use the unique international CEM dataset, which comprises more than 800 defined benefit pension funds for the 1990-2010 period. The CEM database provides a detailed perspective on the pension fund strategic (target) asset allocations on a lower aggregation level. This detailed information enables us to precisely estimate the riskiness of the strategic asset allocation policy. Because our data cover three regions (the United States, Canada, and Europe), we are able to provide international evidence and examine the effect of different regulatory standards on pension fund asset allocation.

On the liabilities side, CEM provides information on the maturity of the fund, the indexation policy, and the liability discount rates. The dataset contains information on the number of active and retired plan members, which enables us to infer the percentage of retired members. We use the percentage of retired members as a proxy for fund maturity. The database also provides information on the characteristics of the indexation policy, such as whether a fund provides full, ad hoc, or no inflation protection. CEM also collects the discount rates that pension funds use to calculate the present value of their liabilities. 
On the assets side, we focus on the percentage allocated to risky assets based on the reported strategic asset allocation policy. Every year, pension funds submit their strategic (target) asset allocation policy and their actual (realized) asset allocation policy to CEM. In practice, the actual asset allocation policy can be affected by market movements due to expected transaction costs of rebalancing or inertia. For example, large positive returns on the equity market will increase the share of this asset class in a pension fund's actual asset allocation. Hence, to avoid the effects of market movements and to capture more precisely pension fund boards' asset allocation decisions, we focus on the strategic asset allocation policy. ${ }^{10}$

We define the percentage allocated to risky assets as allocations to equity, alternative asset classes, and risky fixed income investments. Alternative asset classes incorporate allocations to real estate, private equity, hedge funds, commodities, natural resources, infrastructure, and tactical asset allocation mandates. We classify mortgages and high yield mandates as risky fixed income investments. ${ }^{11}$ The non-risky assets include investments in cash and investmentgrade fixed income assets.

In our empirical analysis, we also split the sample into public and private pension funds. Our sample of U.S. public pension funds includes both state and local plans. The private subsample captures the funds classified as "corporate" and "other" in the CEM database. In the United States and Canada, the "other" category is mainly composed of multi-employer or TaftHartley funds, often referred to as "union" funds. In Europe, the "other" category covers mainly industry-wide funds, which are common in the Netherlands. We combine the category "other" with "corporate" and label this group "private" funds, because these pension funds are established by private-sector employers and they are subject to the same regulation. For example, in the United States, all private DB pension plans are regulated by the Employee Retirement Income Security Act (ERISA) and have an insurance program within the PBGC.

Table 2.1 presents summary statistics for the pension funds in our sample. Panel A shows that the CEM database includes more than 800 funds and about 4,800 observations. The majority of the observations are U.S. pension funds, followed by Canadian pension funds and a smaller number of (mostly large) European pension funds. Pension funds included in the CEM database had more than \$3.66 trillion in assets under management in 2010 and covered around 25 percent of global DB pension fund assets (which is also more than 14 percent of total global pension fund assets). ${ }^{12}$ Over the 1990-2010 period, U.S. pension funds included in the dataset controlled more than 40 percent of total assets under management by the U.S. DB pension fund sector. Canadian pension funds included in the CEM database held approximately 80-90 percent of the total assets under management by Canadian pension funds. To our knowledge, this is the broadest global database on pension fund asset allocation and performance available for 
Table 2.1: Summary statistics

This table provides descriptive statistics for pension fund asset allocation, maturity, liability discount rates, fund size, and inflation protection. In Panel A, rows \#Funds and \#Obs. present the number of funds and observations. In Panels B and C, we show the means and standard deviations (in parentheses) of variables separately in 1993 and 2010. \%Risky shows the average percentage allocation to risky assets based on the strategic asset allocation policy. The risky assets include allocations to equity, alternative asset classes (i.e., hedge funds, private equity, and real estate), high yield bonds, and mortgages. $\%$ Retired presents the average percentage of retired members from total plan members. LDR presents the average liability discount rates used by the pension funds. The Fund size row reports the average total assets under management (in billions US\$) of the pension funds. Inflation protection refers to the percentage of funds providing contractual inflation protection. We show the statistics for all funds and separately by region. We also report the statistics separately for public and private (corporate) funds.

\begin{tabular}{|c|c|c|c|c|c|c|c|c|}
\hline & \multicolumn{2}{|c|}{ All funds } & \multicolumn{2}{|c|}{ U.S. } & \multicolumn{2}{|c|}{ Canada } & \multicolumn{2}{|c|}{ Europe } \\
\hline & Public & Private & Public & Private & Public & Private & Public & Private \\
\hline \multicolumn{9}{|c|}{ Panel A: Total number of pension funds and observations } \\
\hline \#Funds & 226 & 593 & 160 & 348 & 57 & 177 & 9 & 68 \\
\hline \#Obs. & 1653 & 3168 & 1171 & 1761 & 448 & 1173 & 34 & 234 \\
\hline \multicolumn{9}{|c|}{ Panel B: Summary statistics in 1993} \\
\hline \#Obs. & 37 & 148 & 32 & 84 & 5 & 64 & & \\
\hline \multirow{2}{*}{ \%Risky } & 0.562 & 0.630 & 0.567 & 0.665 & 0.531 & 0.585 & & \\
\hline & (0.177) & $(0.126)$ & (0.187) & $(0.135)$ & $(0.101)$ & $(0.097)$ & & \\
\hline \multirow[t]{2}{*}{$\%$ Retired } & 0.276 & 0.311 & 0.287 & 0.322 & 0.205 & 0.296 & & \\
\hline & $(0.107)$ & $(0.160)$ & $(0.104)$ & $(0.167)$ & $(0.112)$ & $(0.151)$ & & \\
\hline \multirow[t]{2}{*}{ LDR } & 7.742 & 7.986 & 7.621 & 8.211 & 8.400 & 7.695 & & \\
\hline & (1.238) & $(0.881)$ & (1.298) & $(0.782)$ & $(0.548)$ & $(0.921)$ & & \\
\hline \multirow[t]{2}{*}{ Fund size } & 8.772 & 2.278 & 8.998 & 3.401 & 7.323 & 0.804 & & \\
\hline & $(14.686)$ & $(5.826)$ & $(15.422)$ & $(7.488)$ & (9.727) & (1.203) & & \\
\hline Inflation protection & 0.676 & 0.152 & 0.656 & 0.012 & 0.800 & 0.328 & & \\
\hline \multicolumn{9}{|c|}{ Panel C: Summary statistics in 2010} \\
\hline \#Obs. & 93 & 214 & 64 & 130 & 24 & 51 & 5 & 33 \\
\hline \multirow[t]{2}{*}{ \%Risky } & 0.701 & 0.621 & 0.728 & 0.643 & 0.636 & 0.611 & 0.659 & 0.551 \\
\hline & $(0.097)$ & $(0.133)$ & $(0.081)$ & $(0.138)$ & $(0.079)$ & $(0.082)$ & (0.193) & (0.151) \\
\hline \multirow[t]{2}{*}{ \%Retired } & 0.389 & 0.522 & 0.385 & 0.554 & 0.406 & 0.485 & 0.360 & 0.450 \\
\hline & $(0.138)$ & $(0.240)$ & $(0.090)$ & $(0.242)$ & $(0.230)$ & $(0.224)$ & $(0.086)$ & $(0.239)$ \\
\hline \multirow[t]{2}{*}{ LDR } & 7.035 & 5.480 & 7.617 & 5.723 & 6.115 & 5.914 & 3.990 & 3.602 \\
\hline & (1.326) & (1.030) & $(0.967)$ & $(0.629)$ & $(0.569)$ & $(0.684)$ & (1.326) & (1.030) \\
\hline \multirow[t]{2}{*}{ Fund size } & 23.125 & 7.065 & 22.715 & 7.162 & 11.020 & 2.156 & 86.479 & 14.269 \\
\hline & $(44.347)$ & (13.537) & $(36.021)$ & (11.793) & $(21.532)$ & $(2.892)$ & (127.407) & (23.537) \\
\hline Inflation protection & 0.602 & 0.224 & 0.563 & 0.100 & 0.708 & 0.471 & 0.600 & 0.333 \\
\hline
\end{tabular}


academic research.

In Panels B and C of Table 2.1, we show pension fund size, allocation to risky assets, maturity, liability discount rates, and the percentage of pension funds providing contractual inflation protection over time. When analyzing the allocation to risky assets, we document different trends between public and private pension plans. The strategic allocation to risky assets of public pension funds has increased from 56.2 percent in 1993 to 70.1 percent in 2010, mainly due to increased risk-taking among U.S. public pension funds. Private pension plans have decreased their allocation to risky assets marginally, from 63.0 percent in 1993 to 62.1 percent in 2010. Panel A of Figure 2.1 shows that the allocation to risky assets among U.S. public pension funds has increased steadily over time, while among private funds it was rather stable until 2004 and decreasing thereafter. Additionally, we observe significant regional effects: compared to Canadian and European pension funds, U.S. pension funds on average allocate a greater percentage of their assets to riskier investments.

Pension fund maturity summary statistics in Table 2.1 are estimated based on retired members as a percentage of total plan members. We document that the vast majority of the pension funds are maturing over time and that private pension funds are generally more mature than public pension funds. The percentage of retired members among private plans has increased from 31.1 percent in 1993 to 52.2 percent in 2010, while among public pension funds the percentage of retired members has increased from 27.6 percent in 1993 to 38.9 percent in 2010. This difference in maturity between public and private funds is the result of a growing number of U.S. corporations having chosen to freeze DB pension plans and replace them with defined contribution (DC) plans for new employees (see Rauh, Stefanescu, and Zeldes, 2013). Hence, private DB pension plans in the United States mature faster than public funds, as confirmed by Panel A of Figure 2.1 (\%Retired). Panel B indicates that in Canada there is no difference in the percentage of retired members between public and private pension funds. In Europe, the sample is much smaller, but again we find no clear difference between public and private funds.

In Table 2.1, we also observe the percentage of pension funds providing contractual inflation protection to their members. We create a dummy variable that takes a value of 1 if a pension fund provides contractual inflation protection, and 0 if the fund provides ad hoc inflation protection or no protection at all. In all three regions, public pension funds are significantly more likely to provide contractual inflation protection as compared to private pension funds during the entire sample period. Interestingly, the percentage of U.S. public pension funds providing such protection has decreased slightly from 65.6 percent in 1993 to 56.3 percent in 2010.

\footnotetext{
${ }^{10}$ All our results are robust to using the risky assets estimated based on the actual asset allocation policy instead of the strategic asset allocation.

${ }^{11}$ Our findings are robust to removing the high yield and mortgage assets from the definition of percentage allocated to risky assets.

${ }^{12}$ The comparison is based on the Global Pension Assets Study 2011 conducted by Towers Watson. For more information, see: http://www.towerswatson.com/en-AE/Insights/IC-Types/Survey-Research-Results/2011/ 02/Global-Pensions-Asset-Study-2011
} 
Figure 2.1: Percentage of retired members and percentage allocated to risky assets

Panel A: U.S. funds - Percentage allocated to risky assets and percentage of retired members

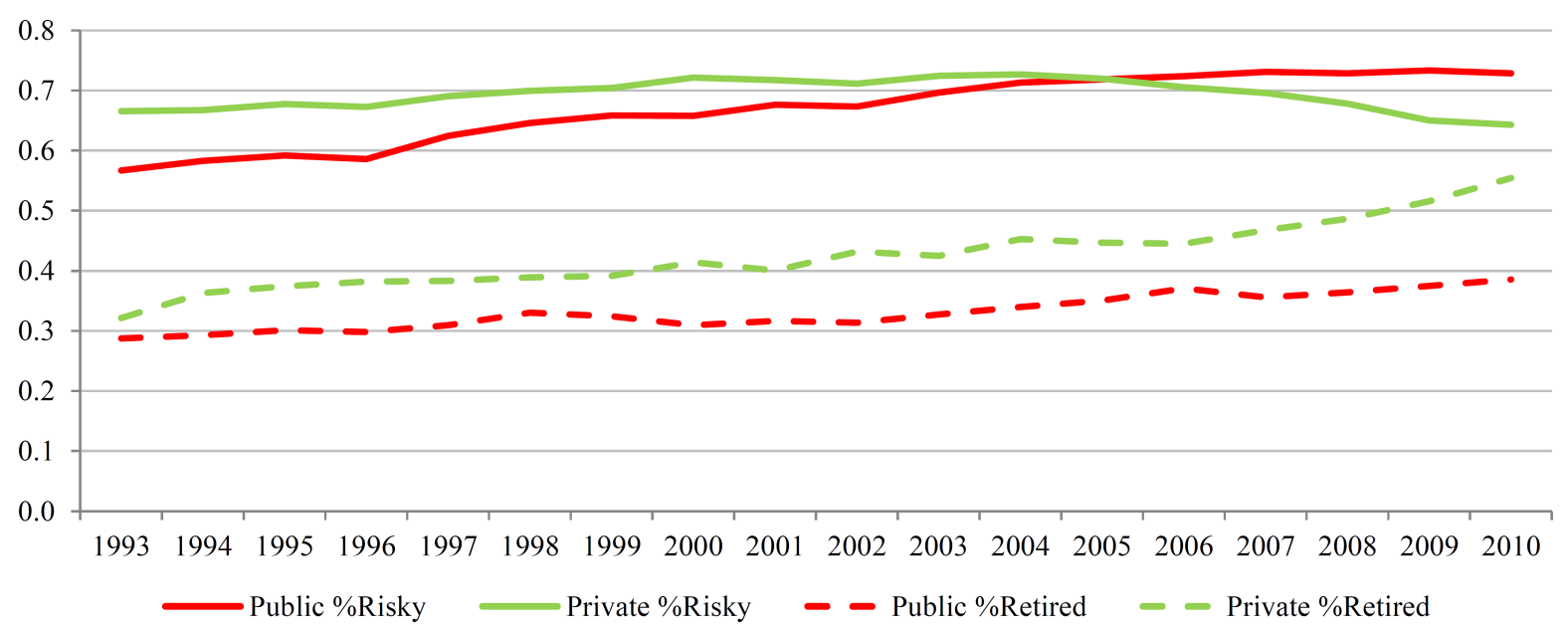

Panel B: Canadian funds - Percentage allocated to risky assets and percentage of retired members

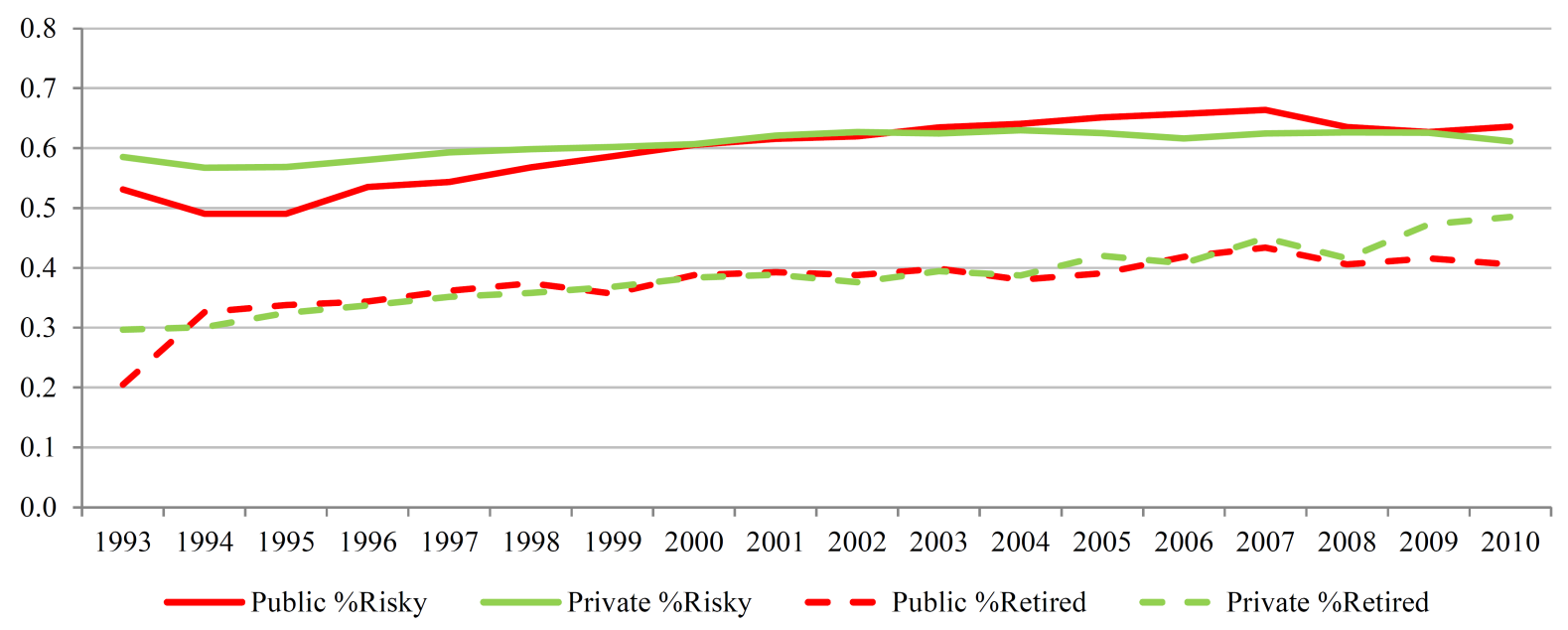

Panel C: European funds - Percentage allocated to risky assets and percentage of retired members

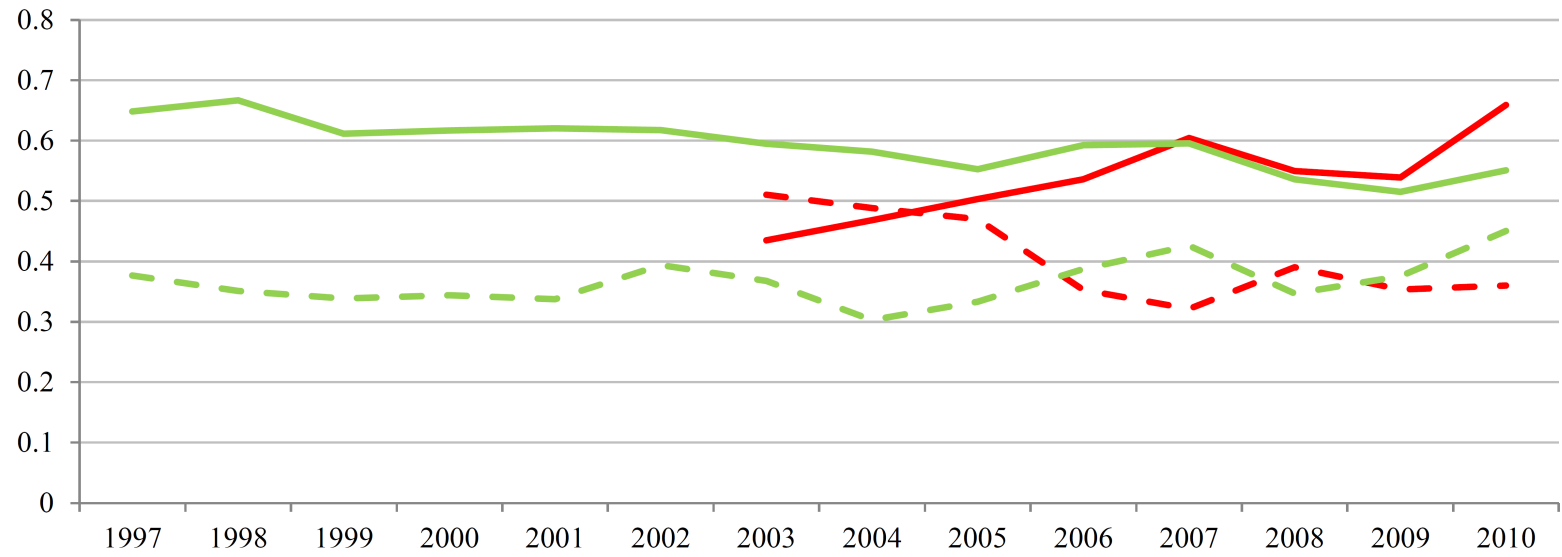

- Public \%Risky $\quad$ Private \%Risky - Public \%Retired - Private \%Retired 
In Table 2.1 and Figure 2.2, we also present summary statistics of liability discount rates. U.S. pension funds, on average, always use higher discount rates than Canadian pension funds and, especially, European pension funds. Figure 2.2 displays the trend in government bond yields and liability discount rates of public and private pension funds, for each region. ${ }^{13}$ Among U.S. funds, public pension funds maintain steady discount rates around 7.5-8.0 percent during the entire 1993-2010 period. $^{14}$ In sharp contrast, the liability discount rates used by U.S. private pension funds decrease over time from 8.2 percent in 1993 to 5.7 percent in 2010, closely following the pattern in ten-year Treasury yields. The discount rates used by Canadian pension funds are also decreasing over time, but not to the same extent as Canadian government bond yields. Most European funds use fixed discount rates of 4 percent before 2000, following strict regulatory guidelines. Afterwards, their liability discount rates move together with the government bond yields, consistent with the revised guidelines (see the previous section for details). In both Europe and Canada, there is no significant difference between the discount rates used by public and private pension funds.

To extend the analysis on U.S. public pension funds, we merge the CEM database with the Comprehensive Annual Financial Reports (CAFRs) submitted by public (state and local) pension funds in the United States as a source of information about the self-reported funding ratios and asset valuation methods of these pension funds. The majority of the additional data is obtained from the Center for Retirement Research at Boston College, but some data points are manually collected from the CAFRs. The data from the Center for Retirement Research at Boston College covers the 2001-2010 period. We are able to extend it back by a few years by hand-collecting data in the CAFRs. This results in a sufficient number of cross-sectional observations for the self-reported funding ratios of U.S. public pension funds for the 1998-2010 period. Figure 2.3 presents the trend in self-reported funding ratios of U.S. public pension funds during the 1998-2010 period. Even though U.S. public pension funds, on average, employ higher liability discount rates than all other pension funds in our sample, most of the U.S. public funds are underfunded during the entire period. The average self-reported funding ratio decreases from 92 percent in 1998 to 75 percent in 2010. Overall, Figure 2.3 shows that the funding problems of U.S. public pension funds are increasing over time and the vast majority of them are significantly underfunded in 2010, despite the use of a (too high) discount rate that is not in line with the riskiness of liabilities.

In addition to their large discretion in setting liability discount rates, U.S. public pension funds are also allowed to smooth asset valuations when reporting their funding ratios. Unlike the choice of higher liability discount rates, which by construction always leads to higher funding ratios, smoothing asset valuations may not always result in better reported funding levels. However, smoothing asset valuations lowers the volatility of reported asset values across time,

\footnotetext{
${ }^{13}$ For Europe, we use the Eurozone countries' 10-year government bond yields (changing composition over time and weighted average) provided by Eurostat.

${ }^{14}$ The summary statistics in Table 2.1 and Figure 2.2 start in 1993, because in the 1990-1992 period we have an insufficient number of cross-sectional observations for the liability discount rates of U.S. and Canadian public and private pension funds.
} 
Figure 2.2: Liability discount rates (LDR) and Treasury yields

Panel A: U.S. funds - Liability discount rates (LDR) and 10-year Treasury yield

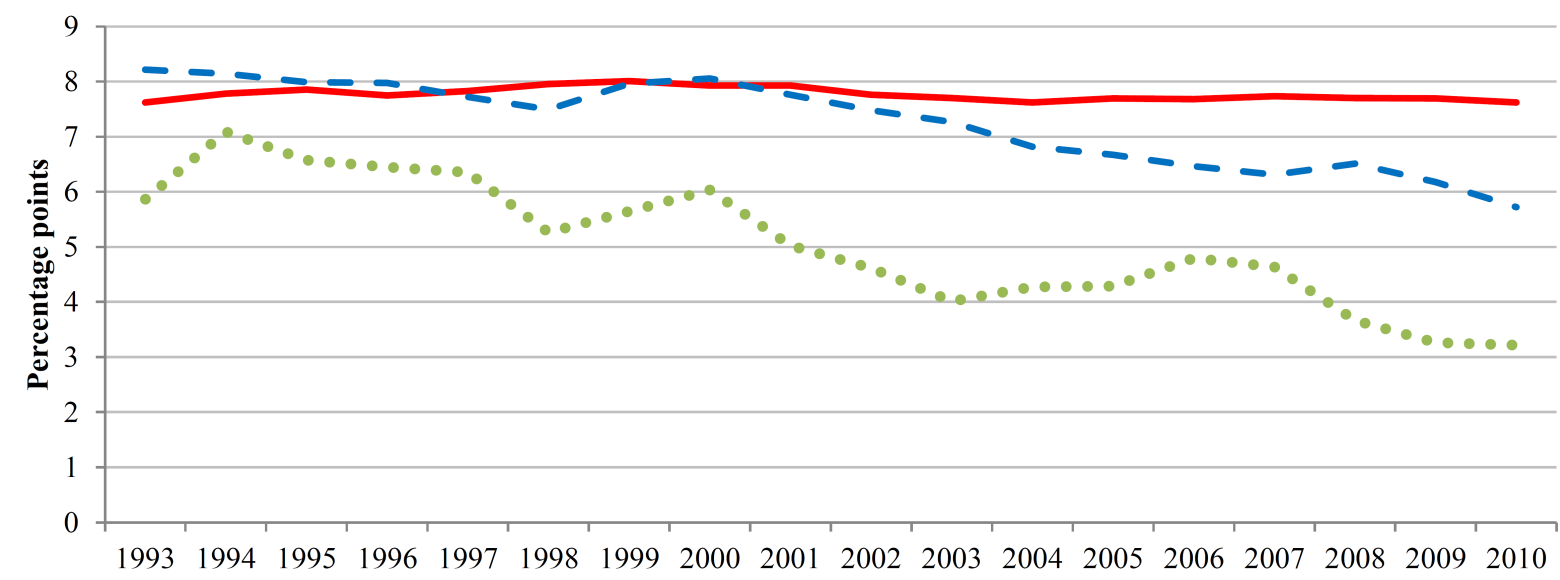

LDR Public funds $\quad-\quad$ LDR Private funds $\ldots$ Treasury yield

Panel B : Canadian funds - Liability discount rates (LDR) and 10-year Treasury yield

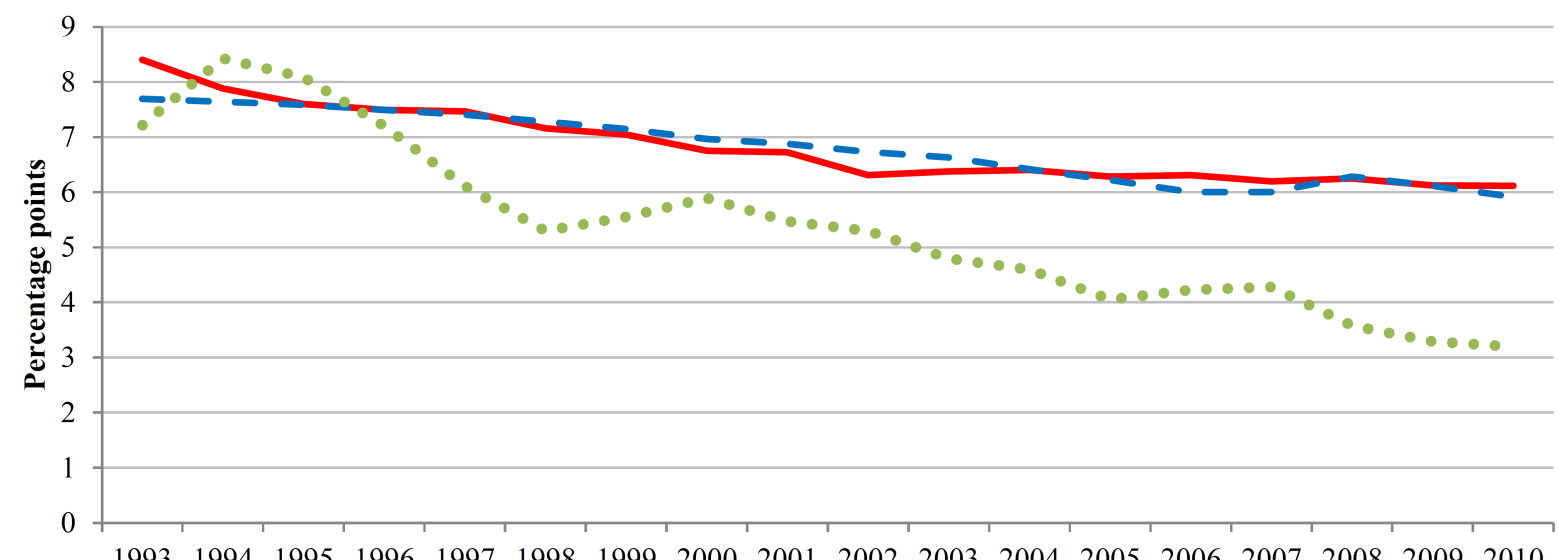

$19931994199519961997199819992000200120022003 \quad 2004200520062007200820092010$

$\longrightarrow$ LDR Public funds $\quad-\quad$ LDR Private funds $\cdots$ Treasury yield

Panel C: European funds - Liability discount rates (LDR) and 10-year Treasury yield

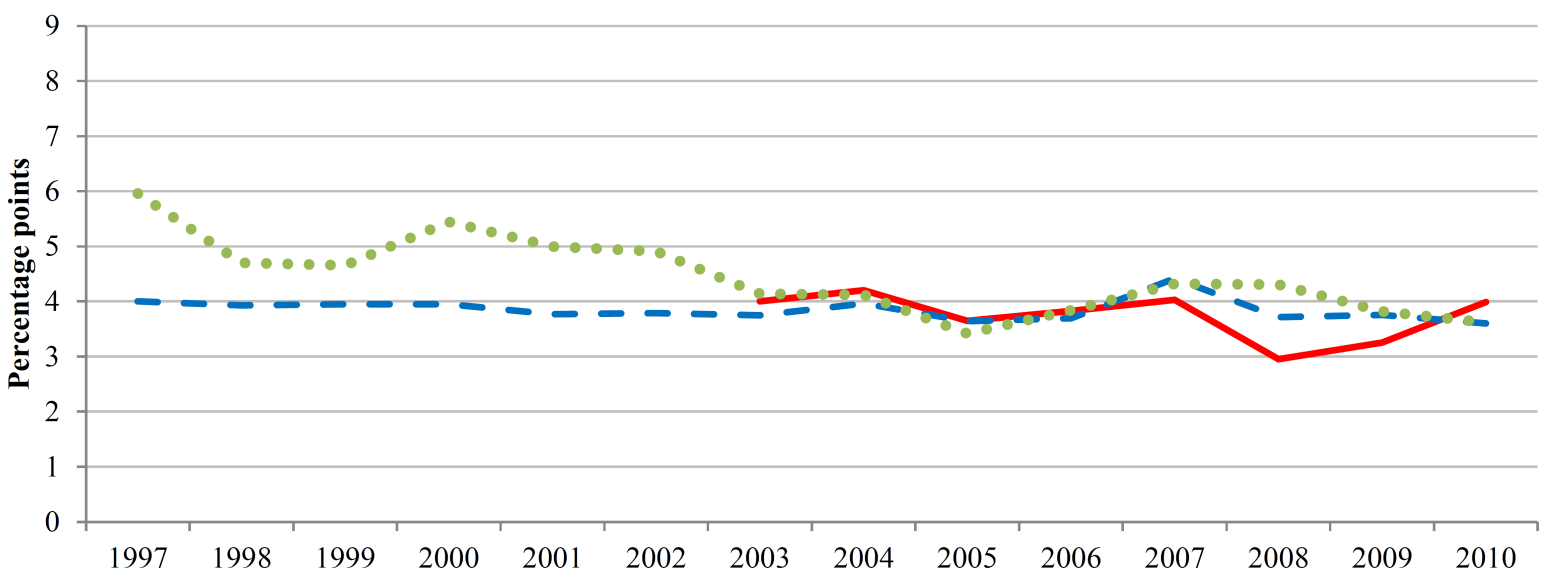

- LDR Public funds $\quad-\quad$ LDR Private funds $\ldots \ldots$ Treasury yield 
Figure 2.3: U.S. public funds: Self-reported funding ratios (SRFR) and asset valuation smoothing

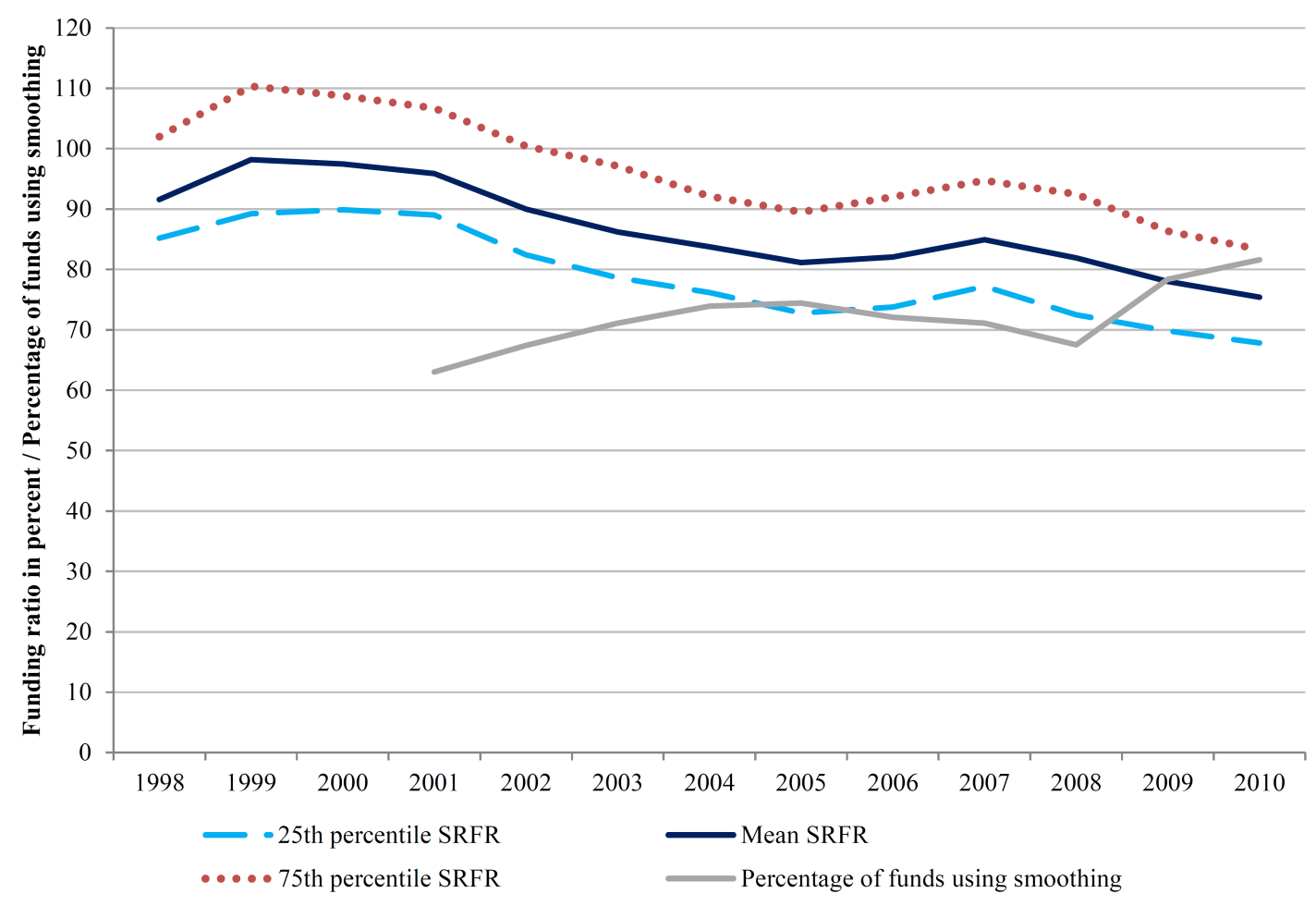

thereby enabling public pension funds to tolerate investments in volatile and risky assets more easily. Figure 2.3 shows that the majority of U.S. public pension funds smooth asset valuation across the last five years. Some pension funds use an even longer period, smoothing assets over ten years. The figure further shows that the percentage of U.S. public pension funds that smooth is increasing over time, especially after 2008, perhaps because pension funds camouflaged their increased underfunding after the downturn in financial markets. Specifically, the percentage of U.S. public pension funds smoothing asset valuation increases from 63 percent in 2001 to 68 percent in 2008, and to 82 percent in 2010.

\subsection{Pension fund investments in risky assets and asset valuation}

We first explore how the strategic allocation to risky assets is related to pension fund maturity and other characteristics. Subsection 2.4.2 focuses on U.S. public pension funds and analyze the association between changes in the percentage allocated to risky assets and changes in selfreported funding ratios. Subsection 2.4.3 analyzes how the allocation to risky assets influences the probability that U.S. public pension funds smooth asset valuation

\subsubsection{Pension fund maturity and risk taking}

The standard deviations of our key variables of interest in Table 2.1 show that there is considerable variation in the allocation to risky assets and fund maturity among the pension funds. We relate the percentage allocated to risky assets based on the strategic asset allocation policy 
$\left(\% R i s k y_{i, t}\right)$ to the percentage of retired members and other relevant pension fund characteristics using pooled panel regressions with year and regional, or fund fixed effects:

$$
\% \text { Risky }_{i, t}=\beta_{0}+\beta_{1} \% \text { Retired }_{i, t}+\beta_{2} X_{i, t}+\beta_{3} Y D_{t}+\beta_{4} F E_{i}+u_{i, t}
$$

where \%Retired refers to the percentage of retired members, and $X_{i, t}$ captures other control variables, such as fund size, inflation protection dummy variable, and plan type dummy variable (public or private pension fund). $Y D$ are the year dummies, FE captures regional or fund fixed effects, and $u_{i, t}$ is the idiosyncratic error. We independently double cluster the robust standard errors in all regressions by pension fund and by year. In the regressions, we include interaction terms to capture the effect of U.S. public funds.

Table 2.2 presents the results of the panel regressions for the allocation to risky assets jointly for U.S., Canadian, and European pension funds. Column (1) indicates that funds with a higher proportion of retired members, in line with theoretical predictions, invest less in risky assets, controlling for fund size, the level of inflation protection, and regional and year fixed effects. In column (6), we include fund fixed effects and find that a 10 percent increase in the percentage of retired members is associated with a 1.31 percent reduction in the allocation to risky assets.

Pension funds with more assets under management (i.e., with a larger Fund size) allocate proportionally more assets to risky investments. In particular, a one-unit increase in the log of assets under management (i.e., doubling the pension fund size) increases the allocation to risky assets by 0.5 to 0.9 percent. The effect of fund size on the allocation to risky assets is not significant when controlling for fund fixed effects in columns (6)-(8). ${ }^{15}$ The decision to provide contractual inflation protection does not seem related to the asset allocation policy.

In column (2), we add a Public dummy that indicates whether the pension fund is public or not, which allows us to estimate the effect of plan type (public or private) on the strategic asset allocation policy. Public pension funds allocate 3.2 percent less to risky assets, on average. Column (5) and (8) show that U.S. public funds behave differently. In contrast to other funds, more mature U.S. public funds (i.e., with a higher \%Retired) allocate more to risky assets. The positive relation between \% Retired and risk taking for U.S. public funds is not consistent with the negative relation that is predicted by economic theory, and in sharp contrast to the negative unconditional coefficient on \%Retired in columns (1)-(8). Based on column (5), for all funds except U.S. public pension funds, a 10 percent increase in the percentage of retired members is associated with a 1.16 percent lower allocation to risky assets. However, for U.S. public pension funds, a 10 percent increase in the percentage of retired members is associated with a 2.05 percent increase in the allocation to risky assets $\left(0.1^{*}(-0.116)+0.1^{*} 0.321=0.0205\right)$. The magnitude is slightly smaller, but still positive and significant, when we control for fund fixed effects in column (8).

The large negative coefficients on the dummies for Canadian and European pension funds indicate significant regional differences in the allocation to risky assets. Controlling for matu-

\footnotetext{
${ }^{15}$ This may be no surprise, as fund fixed effects remove considerable variation and assets under management do not vary strongly over time, especially relative to the large cross-sectional variation in size and to removing year fixed effects.
} 
rity, fund size, and plan type, U.S. pension funds allocate around 8 percent more to risky assets than Canadian funds, and 14 percent more than European funds.

\section{Table 2.2: Panel regressions: Percentage allocated to risky assets}

In this table, we estimate a panel model. The dependent variable is the percentage allocated to risky assets based on the strategic asset allocation of pension funds. The risky assets include allocations to equity, alternative asset classes (i.e., hedge funds, private equity, and real estate), high yield bonds, and mortgages. As independent variables, we include \%Retired, the percentage of retired members from total pension fund members; Fund size, the logarithm of total pension fund assets; Inflation protection, a dummy variable taking a value of one if a fund provides a contractual inflation protection; Public, a dummy variable taking a value of one if a pension fund is public; Public *U.S., an interaction term capturing U.S. public funds; \%Retired $*$ Public, an interaction term capturing the percentage of retired members among public funds; \%Retired $*$ Public $*$ U.S., an interaction term capturing the percentage of retired members among U.S. public funds; and Canada and Europe, regional dummy variables (the base result refers to U.S. funds). Where indicated, we include year dummies and fund fixed effects. We independently double cluster the robust standard errors by pension fund and by year. We report standard errors in brackets. ${ }^{*}{ }^{* *}$, and ${ }^{* * *}$ indicate significance levels of $0.10,0.05$, and 0.01 , respectively.

\begin{tabular}{|c|c|c|c|c|c|c|c|c|}
\hline & (1) & (2) & (3) & (4) & (5) & (6) & (7) & $(8)$ \\
\hline & \multicolumn{8}{|c|}{ Dependent variable: Percentage allocated to risky assets based on strategic asset allocation } \\
\hline \multirow[t]{2}{*}{ \%Retired } & $-0.079^{* * *}$ & $-0.089^{* * *}$ & $-0.092^{* * *}$ & $-0.117^{* * *}$ & $-0.116^{* * *}$ & $-0.131^{* * *}$ & $-0.137^{* * *}$ & $-0.144^{* * *}$ \\
\hline & [0.023] & [0.021] & [0.021] & [0.022] & [0.022] & [0.036] & [0.035] & {$[0.036]$} \\
\hline \multirow[t]{2}{*}{ Fund size } & $0.005^{* *}$ & $0.007^{* * *}$ & $0.007^{* * *}$ & $0.008^{* * *}$ & $0.009^{* * *}$ & 0.021 & 0.020 & 0.019 \\
\hline & [0.002] & [0.002] & {$[0.002]$} & {$[0.002]$} & {$[0.002]$} & {$[0.014]$} & {$[0.014]$} & {$[0.014]$} \\
\hline \multirow[t]{2}{*}{ Inflation protection } & -0.002 & 0.010 & 0.011 & 0.011 & 0.011 & & & \\
\hline & [0.007] & {$[0.007]$} & [0.007] & [0.007] & [0.007] & & & \\
\hline \multirow[t]{2}{*}{ Public } & & $-0.032^{* *}$ & -0.020 & $-0.066^{* *}$ & -0.030 & & & \\
\hline & & {$[0.014]$} & {$[0.014]$} & {$[0.029]$} & [0.029] & & & \\
\hline \multirow[t]{2}{*}{ Public*U.S. } & & & -0.019 & -0.016 & $-0.127^{* * *}$ & & & \\
\hline & & & [0.017] & [0.016] & [0.045] & & & \\
\hline \multirow[t]{2}{*}{$\%$ Retired*Public } & & & & $0.117^{*}$ & 0.024 & & 0.089 & 0.015 \\
\hline & & & & [0.065] & {$[0.056]$} & & [0.065] & {$[0.068]$} \\
\hline \multirow[t]{2}{*}{ \%Retired*Public*U.S. } & & & & & $0.321^{* * *}$ & & & $0.253^{* *}$ \\
\hline & & & & & {$[0.111]$} & & & {$[0.125]$} \\
\hline \multirow[t]{2}{*}{ Canada } & $-0.071^{* * *}$ & $-0.075^{* * *}$ & $-0.082^{* * *}$ & $-0.082^{* * *}$ & $-0.082^{* * *}$ & & & \\
\hline & [0.007] & {$[0.008]$} & [0.010] & [0.010] & [0.010] & & & \\
\hline \multirow[t]{2}{*}{ Europe } & $-0.128^{* * *}$ & $-0.138^{* * *}$ & $-0.142^{* * *}$ & $-0.145^{* * *}$ & $-0.144^{* * *}$ & & & \\
\hline & [0.020] & {$[0.018]$} & [0.019] & [0.019] & {$[0.019]$} & & & \\
\hline Year dummies & Yes & Yes & Yes & Yes & Yes & Yes & Yes & Yes \\
\hline Fund fixed effects & No & No & No & No & No & Yes & Yes & Yes \\
\hline Double clustering & Yes & Yes & Yes & Yes & Yes & Yes & Yes & Yes \\
\hline Observations & 4,806 & 4,806 & 4,806 & 4,806 & 4,806 & 4,821 & 4,821 & 4,821 \\
\hline$R^{2}$ & 0.195 & 0.208 & 0.209 & 0.215 & 0.226 & 0.750 & 0.751 & 0.753 \\
\hline
\end{tabular}

The main conclusion from Table 2.2 is that more mature pension funds generally allocate fewer assets to risky investments, the only exception being U.S. public pension funds. Contrary to the predications from economic theory that maturing pension funds should reduce their exposure to risky assets, we find that mature U.S. public pension funds allocate a larger percentage of their assets to risky investments.

In Table 2.3, we analyze the relation between fund maturity and risk-taking for every region separately as a robustness check. ${ }^{16}$ We find a significant negative relation, on average,

\footnotetext{
${ }^{16}$ In particular, the separate U.S. and Canadian samples provide a robustness check of the main result in Table 2.2 that came from the positive coefficient on the triple interaction of \%Retired $*$ Public $*$ U.S. We do not show results for European pension funds separately due to our limited sample size.
} 
between fund maturity and risk taking in the U.S. and the Canadian samples. For U.S. pension funds (see Panel A, columns (3) and (5)), we find that a 10 percent increase in fund maturity is associated with a reduction in the allocation to risky assets of 1.43-1.76 percent among private pension funds. However, for U.S. public funds this relation is positive. Based on column (3), a 10 percent increase in the percentage of retired members is associated with a 2.31 percent increase in the allocation to risky assets of a U.S. public pension fund $\left(0.1^{*}(-0.143)+0.1^{*} 0.374\right)$. When controlling for fund fixed effects in column (5), a 10 percent increase in the percentage of retired members is associated with a 1.10 percent increase in the allocation to risky assets of a U.S. public fund.

Results for Canada show that an increase in fund maturity reduces the allocation to risky assets (Panel B of Table 2.3). Whether a plan is private or public seems unrelated to the strategic asset allocation policy of Canadian pension funds. Public and private pension funds in Canada reduce their exposure to risky assets in a similar way as they mature.

Throughout 1990-2010, yields on government bonds continuously declined in all regions. For example, the yield on ten-year U.S. Treasury notes decreased from 7.08 percent in 1994 to 3.22 percent in 2010 (see Figure 2.2). To investigate whether these decreasing Treasury yields have an effect on the allocation to risky assets, we also add the ten-year Treasury yield in the previous year to the model presented in equation (1). Table 2.4 examines whether declining yields, as a proxy for the expected return on non-risky assets like cash and government bonds, influence the allocation to risky assets by pension funds. Our results indicate that only public pension funds, and especially U.S. public funds, increase their allocation to risky assets in response to declining government bond yields.

Controlling for fund fixed effects in columns (5)-(8), we find that the association between the government bond yield and the allocation to risky assets remains statistically significant only for U.S. public pension funds. According to column (7), for U.S. public funds, the approximately 4 percentage point decline in the yield on ten-year Treasury securities over this period is associated with a 11 percentage point increase in the allocation to risky assets $\left(4^{*}\left[-1^{*}(-0.010)\right.\right.$ $\left.\left.+(-1)^{*}(-0.018)\right]\right)$. This finding is robust to controlling for the percentage of retired members in columns (4) and (8).

Summarizing, we show that more mature pension funds invest less in risky assets, the only exception being U.S. public pension funds. Moreover, U.S. public pension funds take substantially more risk in response to declining government bond yields. The increased risk-taking by U.S. public funds when faced with low interest rates is particularly noteworthy as these pension funds have even less ability (relative to, for example, U.S. private pension funds) to scale back spending if risky assets underperform expectations, because their promised benefits often have special protections in state constitutions as well as through statutory and common law (see Brown and Wilcox, 2009). 
Table 2.3: Panel regressions: Percentage allocated to risky assets by region

In this table, we estimate a panel model. The dependent variable is the percentage allocation to risky assets based on the strategic asset allocation of pension funds. We present the results for U.S. funds in Panel A and Canadian funds in Panel B. As independent variables, we include \%Retired, the percentage of retired members from total pension fund members; Fund size, the logarithm of total pension fund assets; Inflation protection, a dummy variable taking a value of one if a fund provides a contractual inflation protection; Public, a dummy variable taking a value of one if a pension fund is public; and $\%$ Retired $*$ Public, an interaction term capturing the percentage of retired members among public funds. Where indicated, we include year dummies and fund fixed effects. We independently double cluster the robust standard errors by pension fund and by year. We report standard errors in brackets. ${ }^{*}, * *$, and ${ }^{* * *}$ indicate significance levels of $0.10,0.05$, and 0.01 , respectively.

\begin{tabular}{|c|c|c|c|c|c|}
\hline & (1) & (2) & (3) & (4) & (5) \\
\hline \multicolumn{6}{|c|}{ Panel A: U.S. pension funds } \\
\hline$\%$ Retired & $\begin{array}{c}-0.076^{* *} \\
{[0.032]}\end{array}$ & $\begin{array}{c}-0.100^{* * *} \\
{[0.028]}\end{array}$ & $\begin{array}{c}-0.143^{* * *} \\
{[0.027]}\end{array}$ & $\begin{array}{c}-0.157^{* * *} \\
{[0.046]}\end{array}$ & $\begin{array}{c}-0.176^{* * *} \\
{[0.047]}\end{array}$ \\
\hline Fund size & $\begin{array}{c}0.002 \\
{[0.003]}\end{array}$ & $\begin{array}{c}0.005^{*} \\
{[0.003]}\end{array}$ & $\begin{array}{c}0.008^{* * *} \\
{[0.003]}\end{array}$ & $\begin{array}{c}0.027 \\
{[0.020]}\end{array}$ & $\begin{array}{c}0.019 \\
{[0.019]}\end{array}$ \\
\hline Inflation protection & $\begin{array}{c}-0.000 \\
{[0.010]}\end{array}$ & $\begin{array}{l}0.023^{* *} \\
{[0.012]}\end{array}$ & $\begin{array}{l}0.024^{* *} \\
{[0.012]}\end{array}$ & & \\
\hline Public & & $\begin{array}{c}-0.044^{* *} \\
{[0.019]}\end{array}$ & $\begin{array}{c}-0.176^{* * *} \\
{[0.049]}\end{array}$ & & \\
\hline \%Retired*Public & & & $\begin{array}{c}0.374^{* * *} \\
{[0.110]}\end{array}$ & & $\begin{array}{l}0.286^{* *} \\
{[0.114]}\end{array}$ \\
\hline Year dummies & Yes & Yes & Yes & Yes & Yes \\
\hline Fund fixed effects & No & No & No & Yes & Yes \\
\hline Double clustering & Yes & Yes & Yes & Yes & Yes \\
\hline Observations & 2,919 & 2,919 & 2,919 & 2,932 & 2,932 \\
\hline$R^{2}$ & 0.065 & 0.088 & 0.120 & 0.704 & 0.710 \\
\hline \multicolumn{6}{|c|}{ Panel B: Canadian pension funds } \\
\hline$\%$ Retired & $\begin{array}{c}-0.091^{* * *} \\
{[0.029]}\end{array}$ & $\begin{array}{c}-0.090^{* * *} \\
{[0.028]}\end{array}$ & $\begin{array}{c}-0.083^{* * *} \\
{[0.027]}\end{array}$ & $\begin{array}{l}-0.078^{*} \\
{[0.042]}\end{array}$ & $\begin{array}{l}-0.078^{*} \\
{[0.041]}\end{array}$ \\
\hline Fund size & $\begin{array}{c}0.006 \\
{[0.005]}\end{array}$ & $\begin{array}{c}0.008 \\
{[0.005]}\end{array}$ & $\begin{array}{c}0.007 \\
{[0.005]}\end{array}$ & $\begin{array}{c}0.015 \\
{[0.026]}\end{array}$ & $\begin{array}{c}0.015 \\
{[0.025]}\end{array}$ \\
\hline Inflation protection & $\begin{array}{c}-0.003 \\
{[0.009]}\end{array}$ & $\begin{array}{c}-0.001 \\
{[0.010]}\end{array}$ & $\begin{array}{c}-0.002 \\
{[0.010]}\end{array}$ & & \\
\hline Public & & $\begin{array}{c}-0.015 \\
{[0.015]}\end{array}$ & $\begin{array}{c}-0.007 \\
{[0.033]}\end{array}$ & & \\
\hline \%Retired*Public & & & $\begin{array}{c}-0.019 \\
{[0.064]}\end{array}$ & & $\begin{array}{c}0.004 \\
{[0.062]}\end{array}$ \\
\hline Year dummies & Yes & Yes & Yes & Yes & Yes \\
\hline Fund fixed effects & No & No & No & Yes & Yes \\
\hline Double clustering & Yes & Yes & Yes & Yes & Yes \\
\hline Observations & 1,619 & 1,619 & 1,619 & 1,621 & 1,621 \\
\hline$R^{2}$ & 0.149 & 0.154 & 0.154 & 0.701 & 0.701 \\
\hline
\end{tabular}




\section{Table 2.4: Panel regressions: Percentage allocated to risky assets and Treasury yield}

In this table, we estimate a panel model. The dependent variable is the percentage allocated to risky assets based on the strategic asset allocation of pension funds. The risky assets include allocations to equity, alternative asset classes (i.e., hedge funds, private equity, and real estate), high yield bonds, and mortgages. Compared to previous results, we control for Yield $t_{t-1}$, the Treasury yield in the previous year; Public $*$ Yield $_{t-1}$, an interaction term capturing the effect of the previous year's Treasury yield on public funds; and Public $*$ Yield $t_{-1} *$ U.S., an interaction term capturing the effect of the previous year's Treasury yield on U.S. public funds. As independent variables, we include Fund size, the logarithm of total pension fund assets; In flation protection, a dummy variable taking a value of one if a fund provides contractual inflation protection; \%Retired, the percentage of retired members from total pension fund members; Public, a dummy variable taking a value of one if a pension fund is public; Public *U.S., an interaction term capturing U.S. public funds; and Canada and Europe, regional dummy variables (the base result refers to U.S. funds). Where indicated, we include year dummies and fund fixed effects. We double cluster the standard errors by pension fund and by year. We report standard errors in brackets. ${ }^{*}{ }^{* *}$, and ${ }^{* * *}$ indicate significance levels of $0.10,0.05$, and 0.01 , respectively.

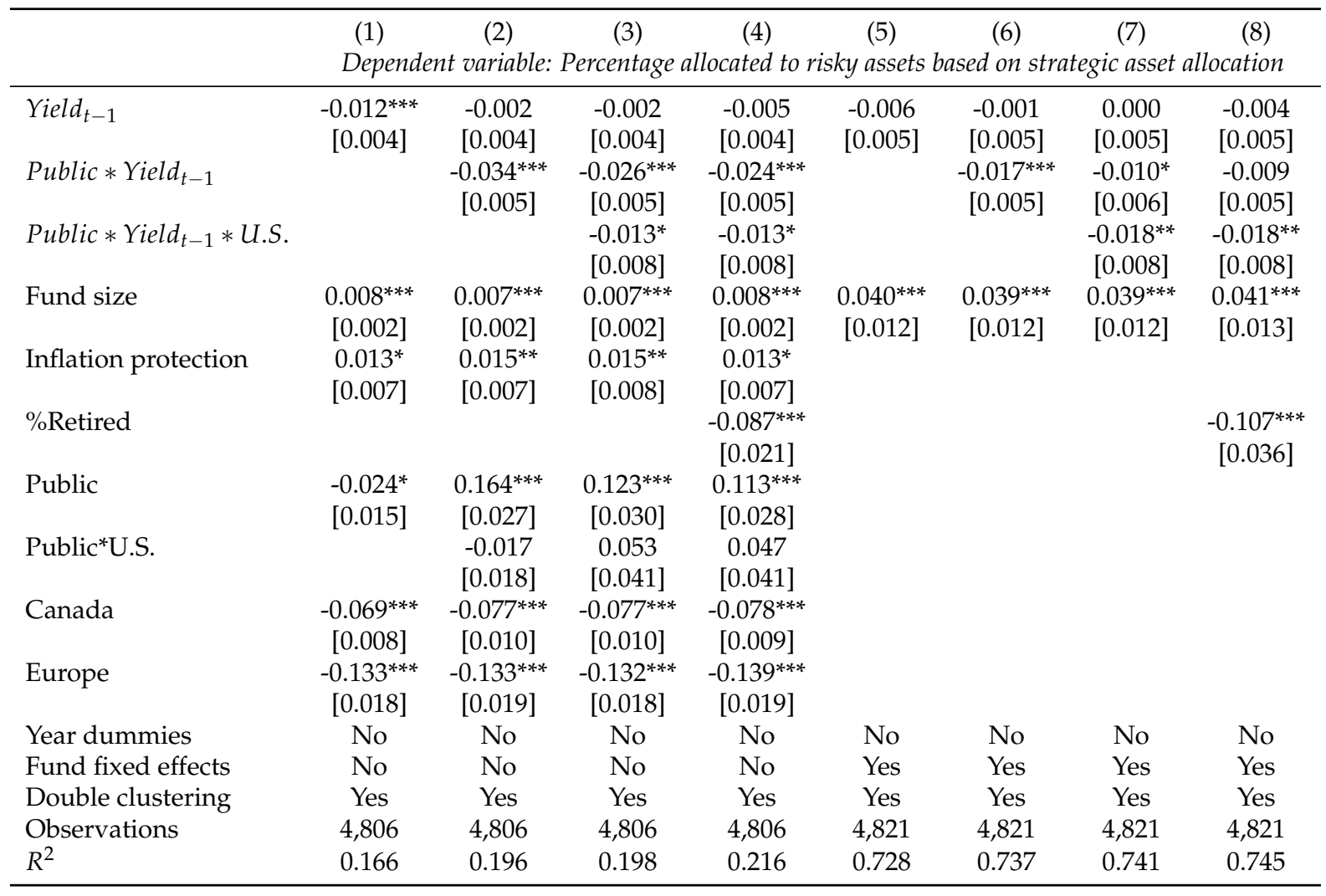




\subsubsection{Self-reported funding ratios and allocation to risky assets}

So far, we have seen that U.S. public pension funds are different from all other public and private pension funds in our sample, and that more mature U.S. public funds allocate a larger share of their assets to risky investments. We turn now to the effect of underfunding on the allocation to risky assets of U.S. public pension funds. Incorporating the levels of self-reported funding ratios directly into the analysis is problematic because these ratios can be influenced significantly by pension funds through two valuation decisions: choosing higher liability discount rates or using smoothed asset valuations. These two valuation decisions are stable over time, which implies that the self-reported funding ratios may not show accurately the pension fund underfunding problems; in contrast, changes in funding ratios more realistically present the dynamics and heterogeneity in funding problems across U.S. public funds. Hence, we focus on the effect of lagged changes in self-reported funding ratios on changes in allocation to risky assets.

Table 2.5: Panel regressions: Allocation to risky assets and self-reported funding ratios

In this table, we estimate a panel model. The dependent variable is the change in the percentage allocated to risky assets based on the strategic asset allocation of pension funds. We focus on the effect of Cumulative $\triangle S R F R$, the cumulative change in the self-reported funding ratio of U.S. public pension funds over the last years. The cumulative change includes the change in self-reported funding ratio from year $t-1$ to year $t\left(\triangle S R F R_{t}\right)$ and the change from year $t-2$ to year $t-1\left(\triangle S R F R_{t-1}\right)$. We also control for the change in the percentage of retired members $(\Delta \%$ Retired) and the change in fund size $(\Delta F u n d$ size) between year $t$ and year $t-1$. In models (1)-(3) we use all observations, whereas in models (4)-(6) we focus on the subperiod 2006-2010. In all models, we include year dummies and fund fixed effects. We independently double cluster the robust standard errors by pension fund and by year. We report standard errors in brackets. ${ }^{*} * *$, and ${ }^{* * *}$ indicate significance levels of $0.10,0.05$, and 0.01 , respectively.

\begin{tabular}{lcccccc}
\hline & $\begin{array}{c}(1) \\
\text { Dependent variables: changes in } \\
\text { All observations }\end{array}$ & $\begin{array}{c}(4) \\
\text { percentage allocated to risky assets } \\
\text { 2006-2010 subperiod }\end{array}$ \\
\hline Cumulative $\Delta S R F R$ & $-0.040^{* * *}$ & $-0.042^{* *}$ & & $-0.059^{* *}$ & $-0.084^{* * *}$ \\
& {$[0.015]$} & {$[0.020]$} & & {$[0.026]$} & {$[0.025]$} & \\
$\Delta S R F R_{t}$ & & & $-0.060^{* *}$ & & & $-0.082^{* *}$ \\
& & & {$[0.030]$} & & & {$[0.034]$} \\
$\Delta S R F R_{t-1}$ & & & -0.024 & & & $-0.086^{* * *}$ \\
& & & {$[0.031]$} & & & {$[0.028]$} \\
$\Delta \%$ Retired & & -0.013 & -0.009 & & 0.143 & 0.143 \\
& & {$[0.125]$} & {$[0.124]$} & & {$[0.132]$} & {$[0.131]$} \\
$\Delta$ Fund size & & 0.029 & 0.029 & & $0.113^{* * *}$ & $0.113^{* * *}$ \\
& & {$[0.046]$} & {$[0.045]$} & & {$[0.040]$} & {$[0.041]$} \\
Year dummies & Yes & Yes & Yes & Yes & Yes & Yes \\
Fund fixed effects & Yes & Yes & Yes & Yes & Yes & Yes \\
Double clustering & Yes & Yes & Yes & Yes & Yes & Yes \\
Observations & 527 & 508 & 508 & 260 & 252 & 252 \\
$R^{2}$ & 0.206 & 0.207 & 0.208 & 0.150 & 0.199 & 0.199 \\
\hline
\end{tabular}

Table 2.5 shows that lagged changes in self-reported funding ratios have a negative effect on changes in the allocation to risky assets. The cumulative change in self-reported funding ratios (Cumulative $\triangle S R F R$ in the table) captures changes over the previous two years: from year 
$t-2$ to year $t$. The mean cumulative change in self-reported funding ratios is a decline of 3.45 percent (see Figure 2.3), which leads to a 15 basis point $(-0.042 * 0.0345$, using the coefficient on Cumulative $\triangle S R F R$ in column 2) increase in the strategic allocation to risky assets. The average annual change in allocation to risky assets among U.S. public funds is 109 basis points, so changes in self-reported funding ratios predict a significant part of the changes in the allocation to risky assets. The results in models (4)-(6) show that the economic magnitude of this relation doubled in the last five years of our sample period, when underfunding among U.S. public pension funds increased substantially. During this subperiod, an average cumulative decrease in self-reported funding ratios results in an increase of about 30 basis points in the allocation to risky assets. Our results indicate that U.S. public pension funds responded to the deteriorating funding situation by investing more in risky assets.

\subsubsection{Asset valuation smoothing}

Figure 2.3 shows that the majority of U.S. public pension funds use a smoothing period when valuing assets. Actuarial guidelines allow wide discretion in valuation methods (see Actuarial Standards Board, 2007, 2009) and also vary by state. For example, the State of New Jersey's Public Employees' Retirement System values assets by their average market value over the last five years. ${ }^{17}$ While New Jersey public pension fund is typical in its use of a five-year smoothing period, some pension funds use up to ten years to smooth asset valuation. Such smoothing reduces the reported volatility in investment performance, which in turn may enable the pension fund to better tolerate the volatility of risky investments, present more stable self-reported funding ratios, and keep the contribution level constant even in periods of large market volatility. In Table 2.6, we estimate the probability that U.S. public pension funds use a smoothing period in their asset valuation using the following logit model:

$$
\operatorname{Pr}\left(\text { Smoothing }_{i, t}=1 \mid X\right)=F\left(\delta_{1} \% \text { Risky }_{i, t}+\delta_{2} \text { Return }_{i, t-1}+\delta_{3} Z_{i, t}+\epsilon_{i, t}\right)
$$

where $F$ is a logit function that takes on values strictly between zero and one, and Smoothing $g_{i, t}$ is a binary dependent variable. The dependent binary variable is 0 if a U.S. public pension fund $i$ does not smooth asset valuations in year $t$, and equals 1 otherwise. We model the probabilities as a function of pension fund characteristics, focusing on the strategic allocation to risky asset classes (\%Risky $\left.y_{i, t}\right)$ of fund $i$ in year $t$. We control for the lagged pension funds returns $\left(\operatorname{Return}_{i, t-1}\right)$. When examining the role of performance, we investigate the effect of the fund's prior year net returns, lagged U.S. equity market returns, and the fund's prior year net benchmark-adjusted returns. $Z_{i, t}$ captures other control variables, such as lagged changes in the allocation to risky assets, the percentage of retired members, fund size, and inflation protection. In all regressions, we include year dummies and independently double cluster the robust standard errors by pension fund and by year.

\footnotetext{
${ }^{17}$ See http://www.nj.gov/treasury/pensions/annrpt2011/pers11.pdf, page 24.
} 
Table 2.6: Logit regressions: Smoothing period in the asset valuation

We present the results of logit regressions determining whether U.S. public pension funds smooth the valuation of their assets. As independent variables on risk-taking we include \%Risky, the percentage strategically allocated to risky assets, or we decompose it to \%Equity, the percentage allocated to equity; \%Alternatives, alternative assets; and \%RiskyFI, risky fixed income assets. We also control for $\Delta \%$ Risk $y_{t-1}$, the lagged change in the percentage allocated to risky assets; \%Retired, the percentage of retired members from total pension fund members; Fund size, the logarithm of total pension fund assets; and Inflation protection, a dummy variable taking a value of one if a fund provides a contractual inflation protection. As independent variables that capture the previous year returns, we include $N T R_{t-1}$, the net return of pension funds in the previous year; $M K T_{t-1}$, the equity market return in $t-1$; and $N T R-B M_{t-1}$, the net benchmark-adjusted return of pension funds in the previous year. We present the marginal effects (elasticities) at the means of the independent variables. The marginal effects for the dummy variables are estimated for discrete changes from 0 to 1 . We also include year dummies and independently double cluster the standard errors by pension fund and by year. We report standard errors in brackets. ${ }^{* * *}$, and $* *$ indicate significance levels of $0.10,0.05$, and 0.01 , respectively.

\begin{tabular}{|c|c|c|c|c|c|c|}
\hline \multirow{2}{*}{\multicolumn{7}{|c|}{$\begin{array}{ccccc}(1) & (2) & (3) & (4) & (5)\end{array}$}} \\
\hline & & & & & & \\
\hline \%Risky & $\begin{array}{l}1.349^{*} \\
{[0.714]}\end{array}$ & $\begin{array}{l}1.351^{*} \\
{[0.799]}\end{array}$ & $\begin{array}{l}1.392^{*} \\
{[0.812]}\end{array}$ & $\begin{array}{l}1.323^{*} \\
{[0.802]}\end{array}$ & $\begin{array}{l}1.371^{*} \\
{[0.820]}\end{array}$ & \\
\hline \%Equity & & & & & & $\begin{array}{l}1.609^{*} \\
{[0.893]}\end{array}$ \\
\hline$\%$ Alternatives & & & & & & $\begin{array}{c}1.009 \\
{[0.936]}\end{array}$ \\
\hline \%RiskyFI & & & & & & $\begin{array}{c}2.374 \\
{[2.119]}\end{array}$ \\
\hline$\Delta \%$ Risky $_{t-1}$ & $\begin{array}{c}-0.488 \\
{[0.565]}\end{array}$ & $\begin{array}{l}-0.472 \\
{[0.571]}\end{array}$ & $\begin{array}{l}-0.217 \\
{[0.578]}\end{array}$ & $\begin{array}{l}-0.484 \\
{[0.577]}\end{array}$ & $\begin{array}{l}-0.175 \\
{[0.611]}\end{array}$ & $\begin{array}{l}-0.240 \\
{[0.633]}\end{array}$ \\
\hline$\%$ Retired & & $\begin{array}{l}-0.245 \\
{[1.096]}\end{array}$ & $\begin{array}{l}-0.081 \\
{[1.055]}\end{array}$ & $\begin{array}{l}-0.263 \\
{[1.091]}\end{array}$ & $\begin{array}{l}-0.207 \\
{[1.064]}\end{array}$ & $\begin{array}{l}-0.149 \\
{[1.157]}\end{array}$ \\
\hline Fund size & $\begin{array}{l}-0.084 \\
{[0.065]}\end{array}$ & $\begin{array}{c}-0.086 \\
{[0.067]}\end{array}$ & $\begin{array}{c}-0.099 \\
{[0.062]}\end{array}$ & $\begin{array}{c}-0.086 \\
{[0.067]}\end{array}$ & $\begin{array}{c}-0.098 \\
{[0.061]}\end{array}$ & $\begin{array}{c}-0.094 \\
{[0.062]}\end{array}$ \\
\hline Inflation protection & & $\begin{array}{c}0.099 \\
{[0.114]}\end{array}$ & $\begin{array}{c}0.091 \\
{[0.115]}\end{array}$ & $\begin{array}{c}0.099 \\
{[0.114]}\end{array}$ & $\begin{array}{c}0.09 \\
{[0.115]}\end{array}$ & $\begin{array}{c}0.111 \\
{[0.117]}\end{array}$ \\
\hline$N T R_{t-1}$ & & & $\begin{array}{c}0.612 \\
{[0.980]}\end{array}$ & & & \\
\hline$M K T_{t-1}$ & & & & $\begin{array}{c}0.767 \\
{[0.671]}\end{array}$ & & \\
\hline$N T R-B M_{t-1}$ & & & & & $\begin{array}{l}-1.972^{*} \\
{[1.156]}\end{array}$ & $\begin{array}{l}-2.121^{*} \\
{[1.167]}\end{array}$ \\
\hline Year dummies & Yes & Yes & No & No & No & No \\
\hline Double clustering & Yes & Yes & Yes & Yes & Yes & Yes \\
\hline Observations & 374 & 372 & 370 & 372 & 370 & 370 \\
\hline Pseudo $R^{2}$ & 0.066 & 0.077 & 0.090 & 0.078 & 0.096 & 0.104 \\
\hline
\end{tabular}


For pension funds with an average allocation to risky investments (72 percent), the probability that a fund is smoothing asset valuations equals 73.71 percent. The logit regression results indicate that U.S. public pension funds with a higher allocation to risky assets are more likely to smooth asset valuations. ${ }^{18}$ For example, the probability of smoothing asset valuations for pension funds with a 64 percent (one standard deviation decrease relative to the mean) allocation to risky assets is 62.09 percent. The probability of smoothing increases to 82.75 percent for U.S. public pension funds that allocate 79 percent (one standard deviation increase) to risky assets.

Lagged net returns and lagged equity market returns are not significantly related to the smoothing probability. However, the previous year's net benchmark-adjusted returns are significantly negatively related to the probability that the fund uses asset valuation smoothing. This negative relation suggests that some U.S. public pension funds recently started smoothing their asset valuations in response to relative underperformance, compared to their benchmarks and peers, rather than as a response to declining asset market values per se. According to column (5), the probability of using smoothing for a pension fund that outperforms its benchmark on a net basis by 219 basis points (one standard deviation change) is 70 percent. This probability increases to 74 percent if pension funds have zero net benchmark-adjusted returns, and increases further to 78 percent if U.S. public pension funds underperform their benchmarks net of costs by 219 basis points (a one standard deviation change).

\subsection{Pension fund liabilities valuation}

In this section, we analyze the valuation and composition of pension fund liabilities. First, we discuss the relation between liability discount rates and pension fund maturity and risk-taking. Subsection 2.5.2 analyzes the probability that U.S. public pension funds provide contractual inflation protection to their members.

\subsubsection{Liability discount rates}

This subsection explores whether the liability discount rates reported to CEM are related to certain pension fund characteristics. We focus on the relation of fund maturity and risky asset allocation with the discount rate used by pension funds to value their liabilities. We estimate the following pooled panel regression model with year and regional, or fund fixed effects:

$$
L D R_{i, t}=\gamma_{0}+\gamma_{1} \% \text { Risky }_{i, t}+\gamma_{2} \% \text { Retired }_{i, t}+\gamma_{3} X_{i, t}+\gamma_{4} Y D_{t}+\gamma_{5} F E_{i}+\varepsilon_{i, t}
$$

where $L D R_{i, t}$ represents the liability discount rate of fund $i$ in year $t$, and $\varepsilon_{i, t}$ is the idiosyncratic error. $X_{i, t}$ captures other control variables, such as fund size, inflation protection dummy variable, and plan type dummy variable (public or private pension fund).

\footnotetext{
${ }^{18}$ Smoothing will matter most for U.S. public pension funds that invest a greater share of their assets in public equity. Returns in alternative assets are naturally smoothed because these assets are traded on private markets and pension funds do not really need the additional smoothing period.
} 
Results in Table 2.7 show that the allocation to risky assets is positively related to liability discount rates. In columns (1) and (8), we document that an increase in the allocation to equity, alternative assets, and riskier fixed income assets is associated with a higher liability discount rate. Further, more mature pension funds use lower discount rates, which is in line with economic theory.

We observe substantial regional differences in liability discount rates. Canadian pension funds use rates to discount their liabilities that are 30.9-58.6 basis points lower as compared to U.S. funds. European funds use liability discount rates more than 300 basis points lower relative to their U.S. counterparts, which is consistent with the regulatory differences.

Whether a pension fund is public or private has a strong effect on the liability discount rate in the United States. Column (3) indicates that U.S. public pension funds typically use discount rates that are 64 basis points higher than U.S. private funds. In Canada and Europe, plan type does not affect the liability discount rates - in those regions, public and private funds behave in a similar way (see the insignificant coefficient on the Public dummy in columns 3, 5, and 7).

According to column (5), U.S. public pension funds that allocate a larger percentage of their assets to risky investments tend to use higher liability discount rates. Surprisingly, an even more important determinant of the liability discount rate among U.S. public pension funds is fund maturity. Contrary to what economic theory would predict, more mature public pension funds in the United States use even higher discount rates. In particular, the interaction term $\%$ Retired $*$ Public $*$ U.S. is positive and statistically significant. Hence, based on column (7), for U.S. public pension funds, a 10 percent increase in the percentage of retired members is associated with an increase in the discount rate of 21 basis points $(0.1 *(2.393-0.299))$. Controlling for fund-fixed effects in column (12), this economic magnitude increases to 31 basis points $(0.1$ * (3.989-0.931)). ${ }^{19}$

In summary, our results show that pension funds that invest in riskier assets typically use higher rates to discount their liabilities. More mature pension funds in Europe and Canada, and more mature private pension funds in the United States use lower liability discount rates. However, in sharp contrast, more mature U.S. public pension funds use the highest discount rates during 1990-2010 period.

In Table 2.8, we estimate the association between interest rates and liability discount rates by adding 10-year government bond yields instead of year dummies to the pooled panel regressions. Brown and Wilcox (2009) and Novy-Marx and Rauh (2011) argue that liability discount rates should be based on the nominal (or real, if inflation protection is offered) Treasury yields, municipal interest rates, or swap rates. ${ }^{20}$ Consistent with their typical regulation, we find that

\footnotetext{
${ }^{19}$ As a comparison, based on column (7), a 10 percent increase in the percentage of retired members is associated with a reduction in the discount rate of 3 basis points among private funds in the United States and all fund types in other regions.

${ }^{20}$ Novy-Marx and Rauh (2011) find that the effective average duration of U.S. public state funds over the range of various discount rates is roughly 13 years. We examine whether the liability discount rates follow the trend in ten-year Treasury yields in the United States, Canada, and Europe (consistent with the duration of liabilities). We use the ten-year Treasury rate, because the 15-year rate is not available in all regions covered by our study and because in our estimations we are focused on the trend in Treasury yield, which is highly correlated across Treasury yields of different maturities.
} 


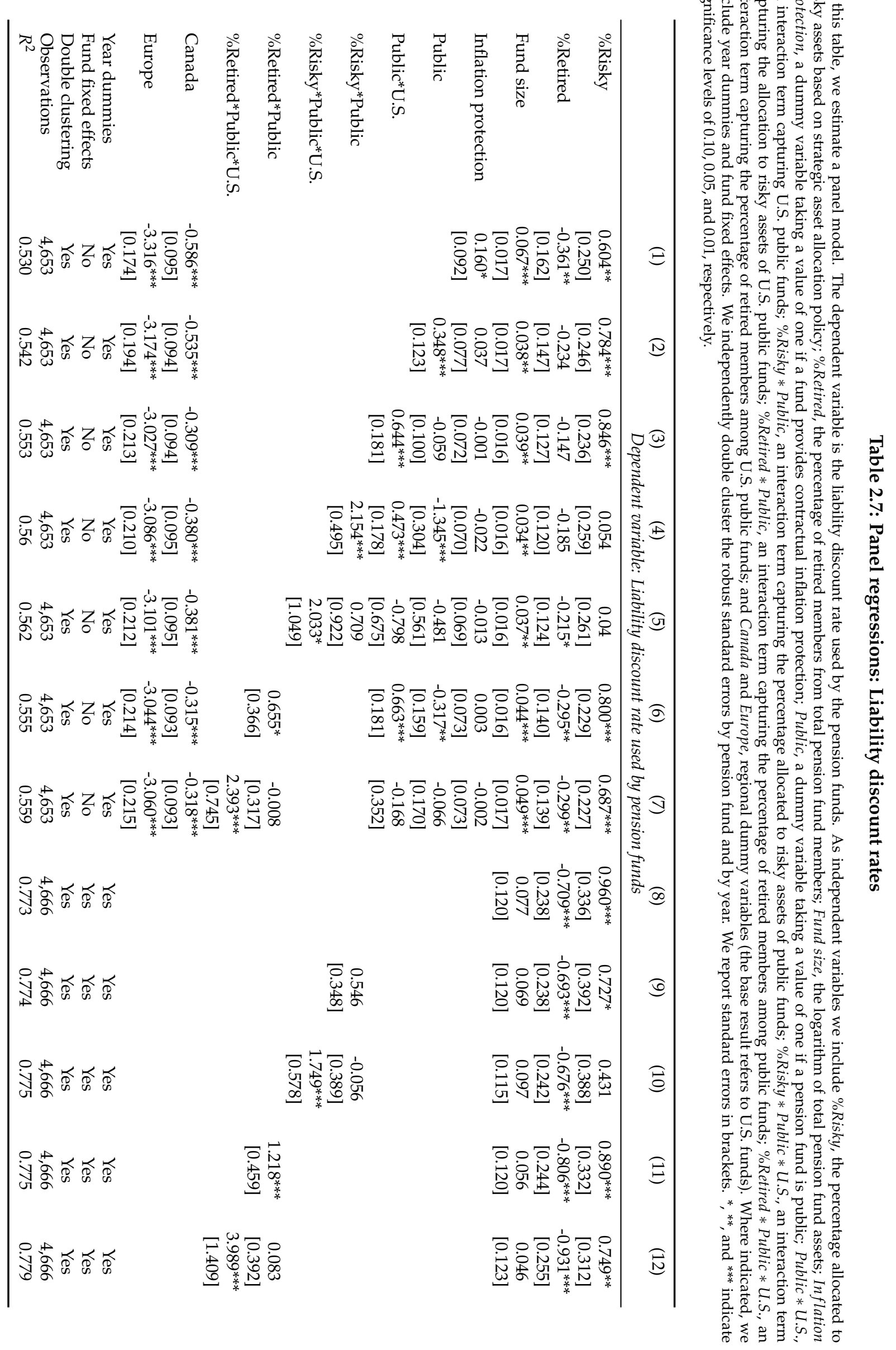


discount rates are strongly positively associated with yields. The average response is less than proportional, as a 100 basis point decrease in the ten-year government bond yield is associated with a decrease in the liability discount rate of around 30-40 basis points. Even when controlling for Treasury yields, the percentage of retired members remains negative and significant, especially in the regressions with fund fixed effects. More mature pension funds use lower discount rates regardless of the trend in Treasury yields. The percentage allocated to risky assets also remains positive and significant.

\section{Table 2.8: Panel regressions: Liability discount rates and Treasury yields}

In this table, we estimate a panel model. The dependent variable is the liability discount rate used by the pension funds. We control for Yield, the 10-year Treasury yield; Public * Yield, an interaction term capturing the effect of the Treasury yield on public funds; and Public *Yield $*$ U.S., an interaction terms capturing the effect of the Treasury yield on U.S. public funds. As independent variables we include $\%$ Risky, the percentage allocated to risky assets based on strategic asset allocation policy; \%Retired, the percentage of retired members from total pension fund members; Fund size, the logarithm of total pension fund assets; Inflation protection, a dummy variable taking a value of one if a fund provides contractual inflation protection; Public, a dummy variable taking a value of one if a pension fund is public; Public *U.S., an interaction term capturing U.S. public funds; and Canada and Europe, regional dummy variables (the base result refers to U.S. funds). Where indicated, we include year dummies and fund fixed effects. We independently double cluster the robust standard errors by pension fund and by year. We report standard errors in brackets. ${ }^{*}, * *$, and ${ }^{* * *}$ indicate significance levels of $0.10,0.05$, and 0.01 , respectively.

\begin{tabular}{|c|c|c|c|c|c|c|c|c|}
\hline & (1) & $(2)$ & (3) & (4) & (5) & (6) & (7) & (8) \\
\hline & \multicolumn{8}{|c|}{ Dependent variable: Liability discount rate used by pension funds } \\
\hline \multirow[t]{2}{*}{ Yield } & $0.389^{* * *}$ & $0.392^{* * *}$ & $0.390^{* * *}$ & $0.462^{* * *}$ & $0.462^{* * *}$ & $0.249^{* * *}$ & $0.278^{* * *}$ & $0.297^{* * *}$ \\
\hline & {$[0.032]$} & {$[0.031]$} & [0.030] & {$[0.042]$} & {$[0.042]$} & {$[0.035]$} & {$[0.044]$} & {$[0.048]$} \\
\hline \multirow[t]{2}{*}{ Public*Yield } & & & & $-0.257^{* * *}$ & -0.077 & & $-0.089^{*}$ & 0.015 \\
\hline & & & & [0.051] & [0.055] & & [0.047] & {$[0.041]$} \\
\hline \multirow[t]{2}{*}{ Public*Yield*U.S. } & & & & & $-0.298^{* * *}$ & & & $-0.251^{* * *}$ \\
\hline & & & & & [0.057] & & & {$[0.070]$} \\
\hline \multirow[t]{2}{*}{ \%Risky } & $0.559^{* *}$ & $0.727^{* * *}$ & $0.773^{* * *}$ & $0.497^{* *}$ & $0.457^{*}$ & $0.855^{* *}$ & $0.686^{*}$ & 0.522 \\
\hline & {$[0.273]$} & [0.265] & {$[0.255]$} & {$[0.230]$} & {$[0.234]$} & {$[0.380]$} & [0.353] & [0.355] \\
\hline \multirow[t]{2}{*}{$\%$ Retired } & $-0.472^{* * *}$ & $-0.339 * *$ & $-0.257^{* *}$ & $-0.231^{*}$ & $-0.243^{*}$ & $-1.180^{* * *}$ & $-1.119^{* * *}$ & $-1.082^{* * *}$ \\
\hline & [0.166] & {$[0.148]$} & [0.129] & [0.125] & {$[0.126]$} & {$[0.242]$} & {$[0.245]$} & [0.237] \\
\hline \multirow[t]{2}{*}{ Fund size } & $0.058^{* * *}$ & 0.028 & $0.028^{*}$ & 0.026 & 0.025 & $-0.314^{* *}$ & $-0.316^{* * *}$ & $-0.294^{* *}$ \\
\hline & [0.016] & [0.017] & [0.016] & {$[0.016]$} & [0.016] & [0.122] & {$[0.121]$} & [0.118] \\
\hline \multirow[t]{2}{*}{ Inflation protection } & $0.151^{*}$ & 0.025 & -0.010 & 0.007 & 0.007 & & & \\
\hline & [0.092] & [0.077] & [0.072] & {$[0.070]$} & [0.069] & & & \\
\hline \multirow[t]{2}{*}{ Public } & & $0.358^{* * *}$ & -0.032 & $1.290^{* * *}$ & 0.379 & & & \\
\hline & & [0.123] & [0.103] & {$[0.254]$} & [0.277] & & & \\
\hline \multirow[t]{2}{*}{ Public*U.S. } & & & $0.613^{* * *}$ & $0.555^{* * *}$ & $2.052^{* * *}$ & & & \\
\hline & & & [0.188] & [0.195] & {$[0.286]$} & & & \\
\hline \multirow[t]{2}{*}{ Canada } & $-0.696^{* * *}$ & $-0.648^{* * *}$ & $-0.436^{* * *}$ & $-0.496^{* * *}$ & $-0.504^{* * *}$ & & & \\
\hline & [0.089] & [0.090] & [0.107] & [0.106] & [0.107] & & & \\
\hline \multirow[t]{2}{*}{ Europe } & $-3.363^{* * *}$ & $-3.218^{* * *}$ & $-3.080^{* * *}$ & $-3.094^{* * *}$ & $-3.077^{* * *}$ & & & \\
\hline & [0.153] & [0.175] & [0.195] & [0.191] & [0.189] & & & \\
\hline Year dummies & No & No & No & No & No & No & No & No \\
\hline Fund fixed effects & No & No & No & No & No & Yes & Yes & Yes \\
\hline Double clustering & Yes & Yes & Yes & Yes & Yes & Yes & Yes & Yes \\
\hline Observations & 4,653 & 4,653 & 4,653 & 4,653 & 4,653 & 4,666 & 4,666 & 4,666 \\
\hline$R^{2}$ & 0.508 & 0.521 & 0.531 & 0.544 & 0.549 & 0.761 & 0.762 & 0.767 \\
\hline
\end{tabular}

In sharp contrast to all other pension funds, but consistent with the trend in Panel A of 
Figure 2.2, the liability discount rates used by U.S. public pension funds are not responding to changes in Treasury yields. The triple interaction term Public $*$ Yield $*$ U.S. is negative and significant, completely outweighing the unconditional effect of the Treasury yield on discount rates. Based on column (8), which includes fund fixed effects, a 100 basis point decrease in the government bond yield reduces the discount rate by 29.7 basis points on average for private pension funds in United States and all pension fund types in other regions. However, Treasury yield changes have no discernible effect on the liability discount rates of U.S. public pension funds, as a 100 basis point decrease in the Treasury yield reduces the discount rate for U.S. public funds by around only 4 basis points $\left(1^{*} 0.297+1^{*}(-0.251)\right)$, which is not significantly different from zero.

\section{Table 2.9: Panel regressions: Liability discount rates by region}

In this table, we estimate a panel model. The dependent variable is the liability discount rate used by pension funds. We present the results separately for U.S. funds in columns (1) to (4) and Canadian funds in columns (5) to (8). As independent variables, we include Yield, the 10-year Treasury yield; Public * Yield, an interaction term capturing the effect of the Treasury yield on public funds; \%Risky, the percentage strategically allocated to risky assets; \%Retired, the percentage of retired members from total pension fund members; Fund size, the logarithm of total pension fund assets; Inflation protection, a dummy variable taking a value of one if a fund provides contractual inflation protection; Public, a dummy variable taking a value of one if a pension fund is public; \%Risky $*$ Public, an interaction term capturing the percentage allocated to risky assets of public funds; and \%Retired $*$ Public, an interaction term capturing the percentage of retired members among public funds. Where indicated, we include year dummies and fund fixed effects. We independently double cluster the robust standard errors by pension fund and by year. We report standard errors in brackets. ${ }^{*}, * *$ and ${ }^{* * *}$ indicate significance levels of $0.10,0.05$, and 0.01 , respectively.

\begin{tabular}{|c|c|c|c|c|c|c|c|c|}
\hline & (1) & (2) & (3) & (4) & (5) & (6) & (7) & (8) \\
\hline & \multicolumn{8}{|c|}{ Dependent variable: Liability discount rate used by pension funds } \\
\hline & U.S. & U.S. & U.S. & U.S. & Canada & Canada & Canada & Canada \\
\hline \multirow[t]{2}{*}{ Yield } & $0.580^{* * *}$ & $0.575^{* * *}$ & $0.410^{* * *}$ & $0.394^{* * *}$ & $0.358^{* * *}$ & $0.369^{* * *}$ & $0.215^{* * *}$ & $0.214^{* * *}$ \\
\hline & [0.055] & [0.054] & [0.072] & [0.071] & {$[0.040]$} & [0.041] & {$[0.051]$} & {$[0.052]$} \\
\hline \multirow[t]{2}{*}{ Public*Yield } & $-0.467^{* * *}$ & $-0.455^{* * *}$ & $-0.329^{* * *}$ & $-0.308^{* * *}$ & 0.042 & 0.001 & 0.034 & 0.037 \\
\hline & [0.061] & [0.060] & [0.084] & [0.077] & [0.048] & [0.047] & [0.046] & [0.048] \\
\hline \multirow[t]{2}{*}{ \%Risky } & 0.215 & $0.402^{*}$ & -0.073 & 0.362 & -0.196 & 0.220 & -0.097 & -0.088 \\
\hline & {$[0.276]$} & {$[0.222]$} & [0.525] & {$[0.394]$} & {$[0.457]$} & {$[0.558]$} & [0.579] & {$[0.435]$} \\
\hline \multirow[t]{2}{*}{$\%$ Retired } & $-0.487^{* * * *}$ & $-0.636^{* * *}$ & $-1.150^{* * * *}$ & $-1.450^{* * *}$ & -0.105 & 0.077 & $-0.617^{*}$ & $-0.615^{*}$ \\
\hline & [0.154] & [0.144] & {$[0.324]$} & {$[0.340]$} & {$[0.218]$} & {$[0.260]$} & [0.317] & [0.319] \\
\hline \multirow[t]{2}{*}{ Fund size } & $0.053^{* * * *}$ & $0.065^{* * * *}$ & $-0.301^{* *}$ & $-0.342^{* *}$ & 0.007 & 0.012 & $-0.451^{* *}$ & $-0.450^{* * *}$ \\
\hline & {$[0.017]$} & {$[0.018]$} & {$[0.152]$} & [0.149] & {$[0.036]$} & {$[0.036]$} & {$[0.206]$} & {$[0.204]$} \\
\hline \multirow{2}{*}{ Inflation protection } & 0.077 & 0.087 & & & -0.104 & -0.095 & & \\
\hline & [0.095] & [0.095] & & & [0.099] & {$[0.103]$} & & \\
\hline \multirow[t]{2}{*}{ Public } & $2.251^{* * *}$ & $2.229^{* * * *}$ & & & -0.934 & 0.192 & & \\
\hline & {$[0.488]$} & [0.439] & & & {$[0.770]$} & {$[0.322]$} & & \\
\hline \multirow[t]{2}{*}{ \%Risky*Public } & $0.818^{*}$ & & 1.444 & & 1.193 & & 0.005 & \\
\hline & {$[0.486]$} & $1.474^{* *}$ & & $3.724^{* * *}$ & [1. & -0.511 & & -0.049 \\
\hline \%Retired*Public & & [0.579] & & [1.122] & & [0.457] & & {$[0.470]$} \\
\hline Year dummies & No & No & No & No & No & No & No & No \\
\hline Fund fixed effects & No & No & Yes & Yes & No & No & Yes & Yes \\
\hline Double clustering & Yes & Yes & Yes & Yes & Yes & Yes & Yes & Yes \\
\hline Observations & 2,854 & 2,854 & 2,865 & 2,865 & 1,575 & 1,575 & 1,577 & 1,577 \\
\hline$R^{2}$ & 0.339 & 0.343 & 0.642 & 0.650 & 0.305 & 0.305 & 0.667 & 0.667 \\
\hline
\end{tabular}


Next, we perform a robustness check to examine the relation between liability discount rates and pension fund characteristics by region. Results in columns (1) to (4) in Table 2.9 confirm that U.S. private pension funds use lower liabilities discount rates when Treasury yields decline and that more mature private pension funds in the U.S. are using significantly lower discount rates. Consistent with Tables 2.7 and 2.8, U.S. public pension funds are behaving in the opposite way. We find no such differences between public and private pension funds for Canada in columns (5)-(8).

Table 2.10: Panel regressions: Liability discount rates and self-reported funding ratios

In this table, we estimate a panel model. The dependent variable is the liability discount rate used by U.S. public pension funds. As independent variables we include \%Risky, the percentage allocated to risky assets based on strategic asset allocation policy; \%Retired, the percentage of retired members from total pension fund members; Fund size, the logarithm of total pension fund assets; Inflation protection, a dummy variable taking a value of one if a fund provides contractual inflation protection; SRFR, the self-reported funding ratio of U.S. public funds; and Smoothing, a dummy variable taking a value of one if pension funds smooth their asset valuation over time. In columns (1)-(5) we use all observations, whereas in columns (6)-(7) we focus on the subperiod 2006-2010. In all models we include year dummies. We independently double cluster the robust standard errors by pension fund and by year. We report standard errors in brackets. ${ }^{*}, * *$, and ${ }^{* * *}$ indicate significance levels of $0.10,0.05$, and 0.01 , respectively.

\begin{tabular}{|c|c|c|c|c|c|c|c|}
\hline & (1) & (2) & (3) & (4) & (5) & (6) & (7) \\
\hline & \multicolumn{7}{|c|}{ Dependent variable: Liability discount rate used by U.S. public funds } \\
\hline \multirow[t]{2}{*}{ \%Risky } & $0.993^{* *}$ & & $0.893^{*}$ & $1.830^{* * *}$ & $1.503^{*}$ & $1.608^{* * *}$ & $1.476^{* *}$ \\
\hline & {$[0.440]$} & & [0.471] & [0.668] & {$[0.903]$} & {$[0.544]$} & [0.707] \\
\hline \multirow[t]{2}{*}{$\%$ Retired } & & $0.981^{* *}$ & $0.849^{*}$ & 1.34 & 2.023 & 1.174 & 2.687 \\
\hline & & [0.494] & [0.498] & [0.953] & {$[1.620]$} & [1.059] & [1.749] \\
\hline \multirow[t]{2}{*}{ Fund size } & $0.052^{* *}$ & $0.068^{* *}$ & $0.062^{* *}$ & $0.081^{*}$ & 0.065 & 0.108 & 0.080 \\
\hline & [0.026] & [0.027] & [0.027] & [0.043] & {$[0.057]$} & [0.067] & {$[0.052]$} \\
\hline \multirow[t]{2}{*}{ Inflation protection } & 0.133 & 0.162 & 0.140 & 0.233 & 0.141 & $0.309^{*}$ & 0.043 \\
\hline & {$[0.126]$} & {$[0.127]$} & {$[0.128]$} & [0.144] & {$[0.123]$} & {$[0.162]$} & [0.169] \\
\hline \multirow{2}{*}{ SRFR } & & & & $-1.139 * *$ & $-1.392^{*}$ & $-1.951^{* *}$ & $-2.162^{* *}$ \\
\hline & & & & [0.554] & {$[0.797]$} & [0.753] & [0.910] \\
\hline Smoothing & & & & & $\begin{array}{l}-0.282^{*} \\
{[0.168]}\end{array}$ & & $\begin{array}{l}-0.154 \\
{[0.236]}\end{array}$ \\
\hline Year dummies & Yes & Yes & Yes & Yes & Yes & Yes & Yes \\
\hline Fund fixed effects & No & No & No & No & No & No & No \\
\hline Double clustering & Yes & Yes & Yes & Yes & Yes & Yes & Yes \\
\hline Observations & 1,146 & 1,127 & 1,127 & 742 & 413 & 316 & 198 \\
\hline$R^{2}$ & 0.041 & 0.036 & 0.044 & 0.081 & 0.104 & 0.132 & 0.142 \\
\hline
\end{tabular}

Overall, the results indicate that U.S. public funds not only use higher discount rates if they are more mature, but also they do not take into account changes in Treasury yields when determining their discount rates, contrary to economic theory. Instead, regulations require U.S. public funds to set their liability discount rate equal to the expected asset portfolio return, giving them great latitude in determining what those expected returns are. As a result, another interpretation of the lack of any association between the level of interest rates and the liability discount rates of U.S. public pension funds, while controlling for the percentage allocated to risky assets, is that U.S. public pension funds have made the economically surprising choice of 
not lowering their expected return estimates on risky assets (in nominal terms) as interest rates decline.

Table 2.10 further explores the heterogeneity in liability discount rate decisions among U.S. public pension funds by considering their relation with self-reported funding ratios (SRFR). Although increasing the liability discount rate should mechanically increase the funding ratio (because using a higher discount rate reduces the present value of liabilities while not affecting asset values), we document that U.S. public pension funds with lower self-reported funding ratios use higher liability discount rates. The negative association between liability discount rates and self-reported funding ratios suggests that better funded U.S. public pension funds engage in less camouflaging behavior, while those with greater underfunding problems are more likely to do so. Economically, a 13.5 percent decrease in the self-reported funding ratio, which corresponds to a one standard deviation change, is associated with an increase in the liability discount rate of around 15-19 basis points. Columns (6) and (7), which only use data for 2006-2010, show that when underfunding problems become more severe, the economic association becomes stronger: a 10 percent decrease in the self-reported funding ratio results in an increase in the liability discount rate of around $20-22$ basis points. ${ }^{21}$ We thus conclude that self-reported funding ratios most likely offer a more realistic reflection of the funding situation of relatively better funded U.S. public pension funds and are more likely to mask the underfunding problems among poorly funded U.S. public pension funds.

\subsubsection{Inflation protection}

Next, we estimate the probability that a pension fund provides contractual inflation protection to its participants. We model these probabilities as a function of pension fund characteristics, focusing on fund maturity, fund size, and plan type (public or private). To answer this question, we use a binary response logit model:

$$
\operatorname{Pr}\left(\operatorname{InfProt}_{i, t}=1 \mid X\right)=F\left(\theta_{1} \% \text { Retired }_{i, t}+\theta_{2} Z_{i, t}+\theta_{3} Y D_{t}+\theta_{4} \text { Region }_{i}+v_{i, t}\right)
$$

where $F$ is a logit function that takes on values strictly between zero and one. Inf $\operatorname{Prot}_{i, t}$ is a binary dependent variable equal to 0 if a pension fund $i$ provides ad hoc inflation protection or no benefits indexation at all in year $t$, and 1 if the fund provides contractual inflation protection.

Our results in Table 2.11 indicate that public funds are significantly more likely to provide contractual inflation protection than private funds. Results in column (2) show that the probability that a private fund provides contractual inflation protection is 17.0 percent, whereas the probability for public pension funds is 58.7 percent. ${ }^{22}$ Column (3) shows that U.S. public funds have the highest probability of providing inflation protection among the pension funds in our sample.

\footnotetext{
${ }^{21}$ In unreported results, we document that the relation between self-reported funding ratios and liability discount rates is robust to the inclusion of fund fixed effects.

${ }^{22}$ The probabilities to provide contractual inflation protection are estimated for a discrete change in the Public dummy variable, setting all other variables at their mean values. The difference in the probability to provide contractual inflation protection between public and corporate funds is equal to 41.7 percent, which is the marginal
} 


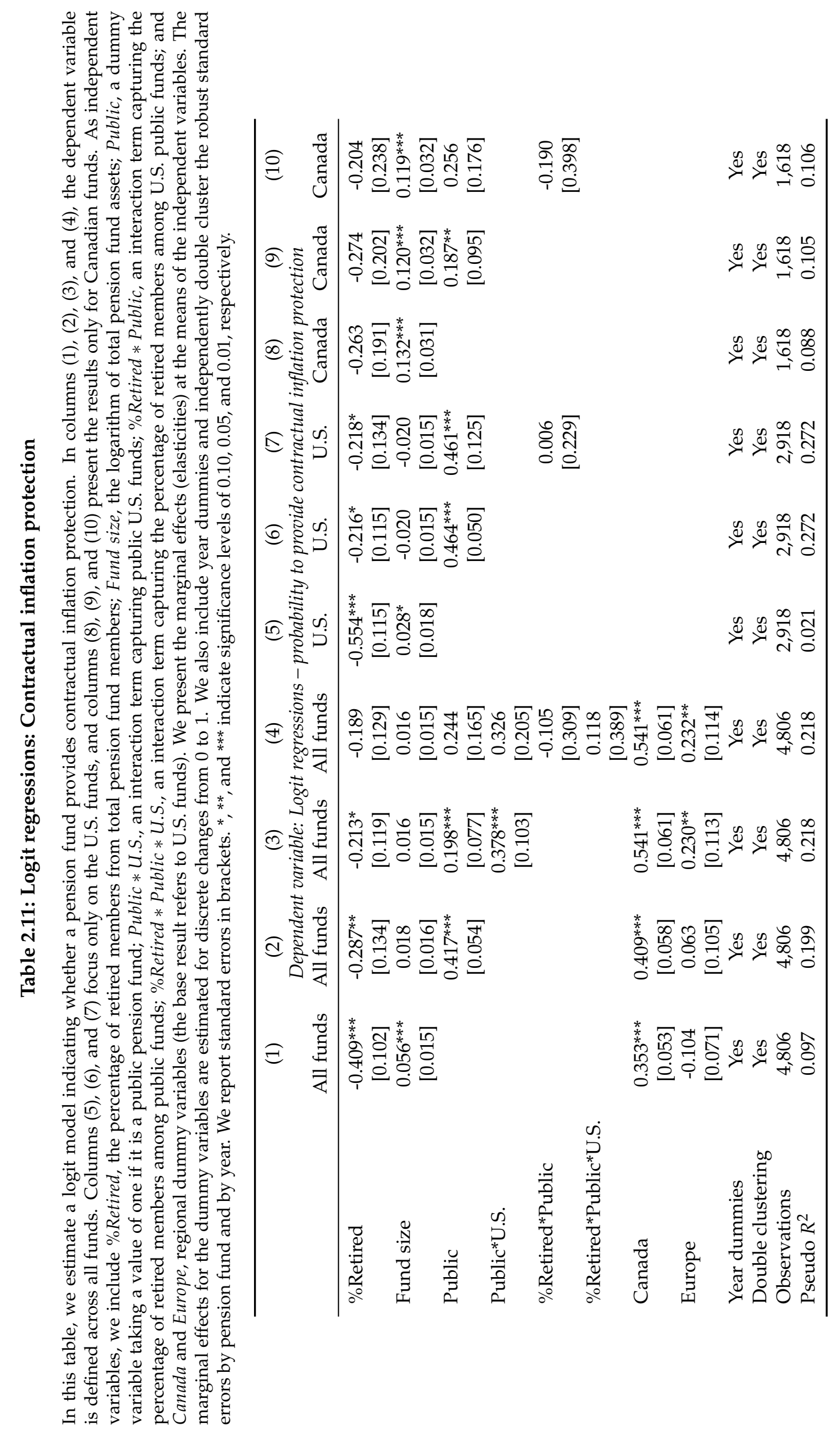


In columns (1) and (2) of Table 2.11, we also document that pension funds with a greater percentage of retired members are less likely to provide contractual inflation protection. For instance, based on column (2), the probability of providing contractual inflation protection for pension funds in which 27 percent of members are retired (25th percentile) is 32.0 percent. This probability decreases to 25.9 percent for funds that have 48 percent retired members (75th percentile). Fund maturity has a negative effect on the probability of providing contractual inflation protection by U.S. pension funds (the relation is negative, but insignificant among Canadian pension funds).

The negative relation between the percentage of retired members and the decision to provide contractual inflation protection indicates that "younger" pension funds may overpromise to their plan members. The risk younger cohorts face is that once pension funds mature and face funding difficulties in delivering the promised benefits, contractual inflation protection may be removed from the pension deal. Eliminating contractual inflation protection is one of the measures of last resort available to underfunded pension funds, but its implementation is difficult, especially in the U.S. context because pension benefit promises have strong protections. Nevertheless, Rhode Island and New Jersey's state pension plans recently received court approval to suspend future cost of living adjustments (COLA) starting January 1, 2011. ${ }^{23}$ It is worth noting that many U.S. public pension funds have COLAs that are not actually linked to the Consumer Price Index. For example, in Illinois, the COLA is set at 3 percent annually, regardless of the actual inflation rate. ${ }^{24}$

Furthermore, even after controlling for fund maturity, size, and plan type, the likelihood that Canadian pension funds provide inflation protection is significantly higher. Our results also indicate that in Canada, larger funds are more likely to provide inflation protection. Based on columns (8), (9), and (10), a one-unit increase in the logarithm of assets under management (i.e., doubling the fund size) increases the probability that a Canadian pension fund provides contractual inflation protection by 11.9-13.2 percent.

In the previous section, we showed that public pension funds use substantially higher liability discount rates. The results in Table 2.11 indicate that public pension funds are more generous because they are more likely to promise contractual inflation protection to their beneficiaries. Brown and Wilcox (2009) argue that if a pension fund promises inflation protection, then their liabilities should be discounted using real interest rates, namely inflation-indexed rates based on Treasury Inflation-Protected Securities (TIPS). Hence, public pension funds ignore both the trends in Treasury yields and the inflation protection promised to their beneficiaries when determining liability discount rates.

\footnotetext{
value of the Public dummy in Table 2.11 column (2).

${ }^{23}$ The Rhode Island Retirement Security Act of 2011 suspends cost of living adjustments for all public employees in the plan at the moment, and in the future, COLAs will be tied to the funding level of the pension system (see http://www.treasury.ri.gov/secure-path-ri/rirsa/legislation.php). The new regulation of the New Jersey State Treasury Department, Division of Pensions and suspended future COLAs for all retirees of all retirement systems (see http://www.nj.gov/treasury/pensions/ret-benefits.shtml\#cola).

${ }^{24}$ See the pension reform proposals for the Teachers' Retirement System of the State of Illinois regarding inflation protection: http://trs.illinois.gov/subsections/press/PensionReformProposals.htm.
} 


\subsection{Performance}

We have documented that U.S. public pension funds behave differently from all other pension funds by increasing allocations to risky assets despite their maturing member population and decreasing Treasury yields. While we argue that this is driven by their distinct regulations, an alternative hypothesis is that U.S. public pension funds collectively have become more positive about their skills or the investment opportunities in risky assets (irrespective of the incentives arising from their regulation that links liability discount rates to the expected returns on their assets). In this section, we examine whether pension fund returns justify their preference for a riskier asset allocation policy.

We calculate net benchmark-adjusted returns separately for each asset class by subtracting the total investment costs and the return from the self-reported benchmark (in that asset class) from the gross returns, and then aggregate up across all asset classes held by the fund. We relate the net benchmark-adjusted returns $\left(N T R-B M_{i, t}\right)$ of fund $i$ in year $t$ to fund characteristics, such as the percentage of retired members $\left(\%\right.$ Retired $\left._{i, t}\right)$, the percentage allocated to risky assets $\left(\% R i s k y_{i, t}\right)$, and other pension fund characteristics $\left(X_{i, t}\right)$, using pooled panel regressions with year $\left(Y D_{t}\right)$ and regional, or fund fixed effects $\left(F E_{i}\right)$ :

$$
\text { NTR }-B M_{i, t}=\rho_{0}+\rho_{1} \% \text { Risky }_{i, t}+\rho_{2} \% \text { Retired }_{i, t}+\rho_{3} X_{i, t}+\rho_{4} Y D_{t}+\rho_{5} F E_{i}+v_{i, t}
$$

We also include in the regressions interaction terms to capture the effect of U.S. public pension funds, the group with significantly different regulations. We independently double cluster the robust standard errors in all regressions by pension fund and by year.

Results in Table 2.12 show that the percentage of retired members and the allocation to risky assets are generally not related to the pension fund net benchmark-adjusted returns. In column (2) we add a public dummy variable and document that public pension funds underperform as compared to private funds by 24 basis points. Column (3) shows that this underperformance among public pension funds is due solely to U.S. public pension funds, which underperform by 59 basis points annually on a net benchmark-adjusted basis. There is no significant difference in the performance of Canadian and European public versus private pension funds. ${ }^{25}$

In columns (5) and (7), we document substantial heterogeneity in the net benchmark-adjusted returns of U.S. public pension funds, determined by two main factors: the allocation to risky assets and fund maturity. U.S. public pension funds with a greater allocation to risky assets underperform more. A 12 percent increase in the strategic allocation to risky assets of U.S. public pension funds, which corresponds to a one standard deviation change, is associated with an increase in underperformance of 14 basis points annually. In column (6), we find that more mature public pension funds underperform, but this underperformance is mainly due to the returns of U.S. public pension funds. Based on column (7), a 10 percent increase in the percentage of retired members of U.S. public funds results in an underperformance of 8 basis points

\footnotetext{
${ }^{25}$ We control for European and Canadian pension funds using regional dummy variables, but we do not find significant regional performance effects.
} 


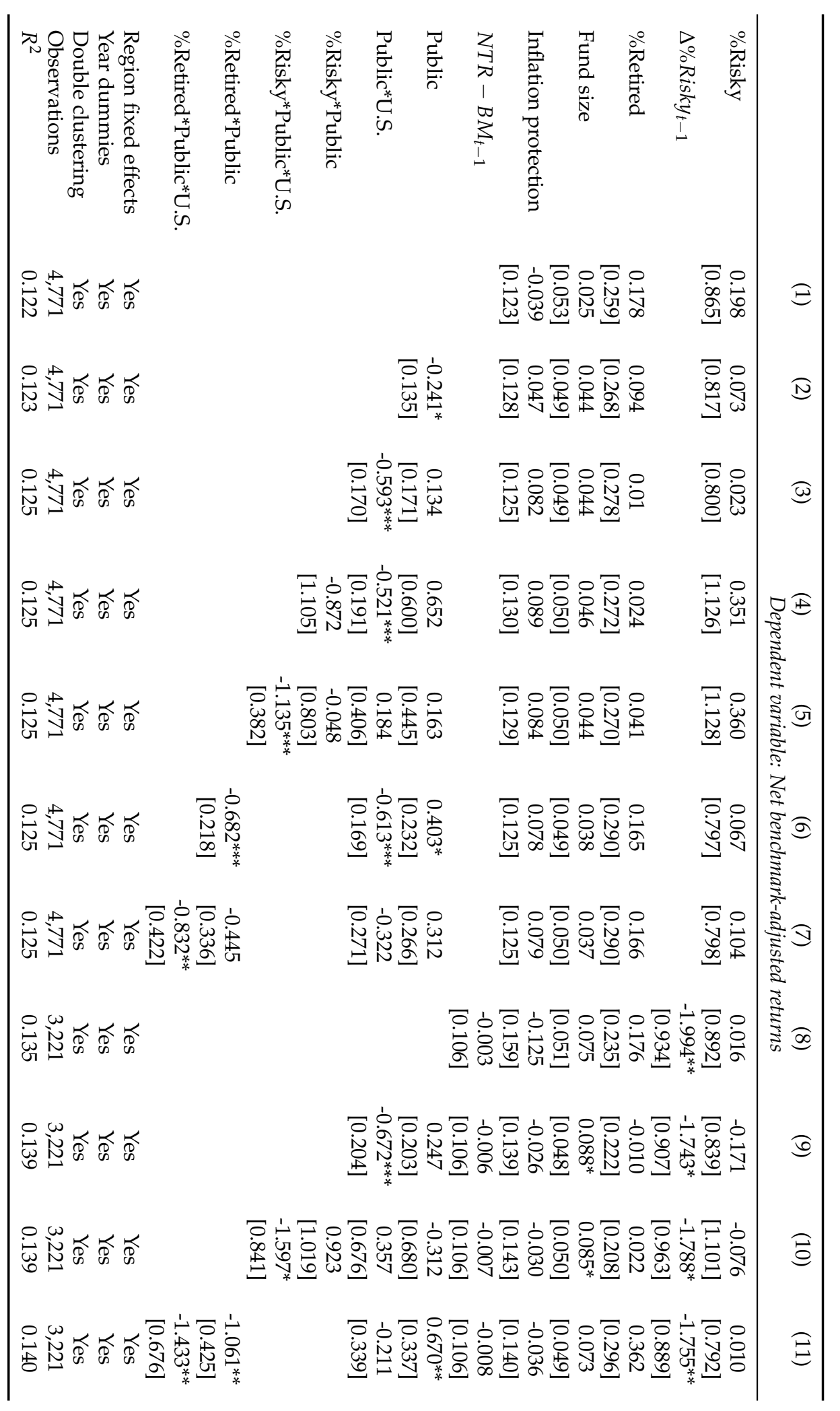

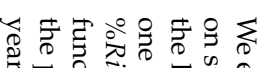

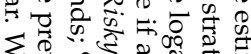

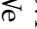

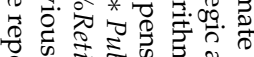

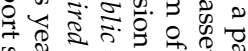

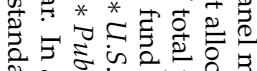

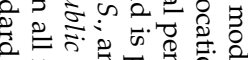

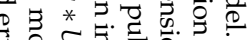

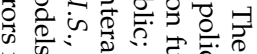

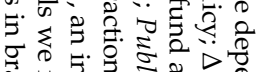

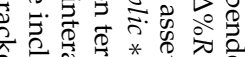

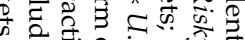
* o

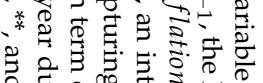

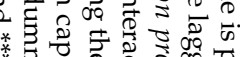

4 . E E

으.

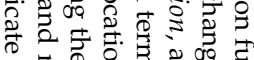
然. 둘유.

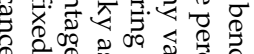

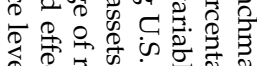

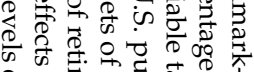

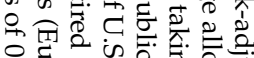

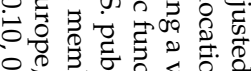
जै 0

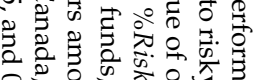

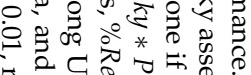

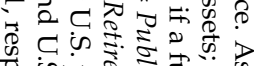
की

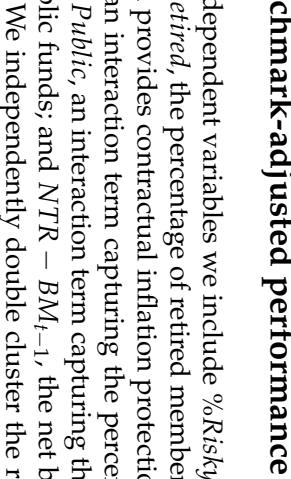

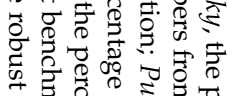

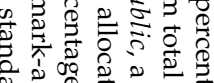

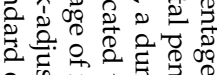

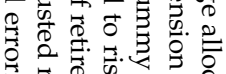

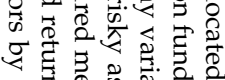

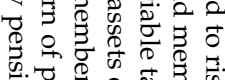
.

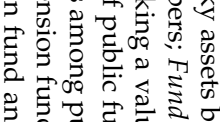

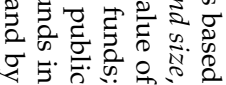


compared to all other pension funds. In columns (8)-(11) we add controls for the previous year's net benchmark-adjusted performance and for the lagged changes in allocation to risky assets. ${ }^{26}$ Even with these controls, U.S. public pension funds underperform by 67 basis points compared to other pension funds.

Table 2.13: Panel regressions: U.S. public pension fund net benchmark-adjusted performance

In this table, we estimate a panel model. The dependent variable is the net benchmark-adjusted performance of U.S. public pension funds. In columns (1) and (2), we use the net benchmark-adjusted returns as they are reported in the database. In columns (3) and (4), in the first stage we risk-adjust the net benchmark-adjusted returns using a five-factor model that includes the equity market return, SMB, HML, the momentum factor, and the Pastor and Stambaugh (2003) traded liquidity factor. In the second step, we augment the alphas retrieved from the first step with the error terms of the first step and estimate panel regressions. In the panel regressions we include the following independent variables: $\% R i s k y$, the percentage allocated to risky assets based on strategic asset allocation policy; $\Delta \% R i s k y_{t-1}$, the lagged change in the percentage allocated to risky assets; \%Retired, the percentage of retired members from total pension fund members; Fund size, the logarithm of total pension fund assets; Inflation protection, a dummy variable taking a value of one if a fund provides contractual inflation protection; Public, a dummy variable taking a value of one if a pension fund is public; and NTR $-B M_{t-1}$, the net benchmark-adjusted return of pension funds in the previous year. Where indicated, we include year dummies and fund fixed effects. We independently double cluster the robust standard errors by pension fund and by year. We report standard errors in brackets. ${ }^{*}, * *$, and ${ }^{* * *}$ indicate significance levels of $0.10,0.05$, and 0.01 , respectively.

\begin{tabular}{|c|c|c|c|c|}
\hline & (1) & (2) & (3) & (4) \\
\hline Dependent variable: & \multicolumn{2}{|c|}{ Net benchmark-adjusted returns } & \multicolumn{2}{|c|}{$\begin{array}{c}\text { Risk-adjusted net benchmark- } \\
\text { adjusted returns }\end{array}$} \\
\hline \multirow{2}{*}{ \%Risky } & -0.360 & 1.266 & 1.144 & 1.256 \\
\hline & [0.997] & [2.135] & [1.142] & [0.890] \\
\hline \multirow{2}{*}{$\Delta \%$ Risky $_{t-1}$} & -1.194 & -1.565 & $-4.981^{* *}$ & $-1.792^{*}$ \\
\hline & {$[1.356]$} & [1.664] & {$[2.132]$} & [0.924] \\
\hline \multirow[t]{2}{*}{$\%$ Retired } & $-2.747^{* *}$ & $-4.148^{*}$ & $-4.830^{*}$ & $-3.821^{* *}$ \\
\hline & [1.192] & {$[2.350]$} & [2.523] & {$[1.905]$} \\
\hline \multirow{2}{*}{ Fund size } & 0.060 & 1.689 & -0.256 & 1.266 \\
\hline & {$[0.105]$} & [2.013] & {$[0.230]$} & [0.792] \\
\hline \multirow[t]{2}{*}{ Inflation protection } & -0.116 & & -0.242 & \\
\hline & {$[0.305]$} & & {$[0.503]$} & \\
\hline \multirow{2}{*}{$N T R-B M_{t-1}$} & -0.130 & -0.203 & $0.129^{*}$ & 0.005 \\
\hline & {$[0.150]$} & [0.143] & [0.076] & [0.033] \\
\hline Year dummies & Yes & Yes & Yes & Yes \\
\hline Fund fixed effects & No & Yes & No & Yes \\
\hline Double clustering & Yes & Yes & Yes & Yes \\
\hline Observations & 843 & 843 & 805 & 805 \\
\hline$R^{2}$ & 0.127 & 0.225 & 0.099 & 0.732 \\
\hline
\end{tabular}

In Table 2.13, we further explore the underperformance of U.S. public pension funds by controlling for fund fixed effects and by risk-adjusting the returns. We risk-adjust the net

\footnotetext{
${ }^{26}$ Pension funds with greater increases in strategic allocation to risky assets in year $t-1$ underperform compared to their peers in year $t$. If a pension fund increased the allocation to risky assets by 10 percent in the previous year, then it has 17 to 20 basis points lower net benchmark-adjusted performance this year. We hence observe that a rapid increase in the exposure to risky assets results in underperformance, which implies that pension funds should build their riskier allocations gradually. This effect is not specific to U.S. public pension funds, but observable across all pension funds in our sample.
} 
benchmark-adjusted returns using a five-factor model that includes the excess equity market return, SMB, HML, the momentum factor, and the Pastor and Stambaugh (2003) traded liquidity factor. Results in columns (3) and (4) show that on a risk-adjusted basis, the percentage of retired members has an even stronger effect on performance. Among U.S. public pension funds, a 10 percent increase in the percentage of retired members is associated with a decrease in the annualized abnormal returns of 38-48 basis points. In addition, the lagged changes in the allocation to risky assets also maintain the significant negative effect on performance.

In summary, our results show that U.S. public pension funds underperform and that this underperformance is greater among more mature U.S. public plans and those with a higher strategic allocation to risky assets.

\subsection{Conclusion}

In this paper, we employ a comprehensive dataset of U.S., Canadian, and European public and corporate defined benefit pension funds and investigate their asset allocation, liability discount rates and contractual inflation protection over the last two decades. We find that U.S. public (state and local) pension funds behave differently from all other pension funds. We ascribe their different reaction to the maturing of their participant base and declining government bond yields to their incentives arising from a distinct regulatory framework. In particular, U.S. public pension can set their liability discount rate equal to the assumed expected rate of return on their investments, which means that by investing in more risky assets, they can adopt a higher liability discount rate and present an improved funding position. In contrast, the regulations pertaining to Canadian and European public and private funds, as well as to corporate pension funds in the United States, requires the use of liability discount rates that are based on high quality interest rates.

Economic theory predicts that mature pension funds should invest less in risky assets and use lower discount rates for the valuation of their liabilities. U.S. corporate pension funds and Canadian and European public and private funds indeed lower their liability discount rates if interest rates decline and use lower liability discount rates as their participant base matures. However, U.S. public pension funds are allowed to base their discount rates on the expected rate of return of their asset portfolio, which provides them with incentives to take more risk over time in response to declining government bond yields. Taking more risk thus enables public pension funds in the United States to maintain high discount rates and present more favorable funding ratios to the public, despite the fact that this does not in any way alter the nature of their liabilities. For U.S. public pension funds, we document that those with a larger percentage of retired members use even higher discount rates, possibly because the shorter maturity increases the present value of their liabilities and limits their ability to camouflage their underfunding.

Gradually, U.S. public funds have become the biggest risk-takers among pension funds around the globe, especially if they are more mature or the proportion of their members who are retired increases. At the same time, U.S. public funds have almost no ability to scale back 
spending if risky assets underperform expectations, as their benefits are often given special protections in state constitutions as well as through statutory and common law (Brown and Wilcox, 2009).

Moreover, we find that the increased risk-taking of U.S. public pension funds is associated with poorer investment performance. On average, U.S. public pension funds underperform their benchmarks annually by about 60 basis points more than other pension funds. Underperformance is more severe for more mature funds as well as for those with larger allocations to risky assets. These results are consistent with asset allocation decisions that are not based on investment opportunities or asset-liability management, but rather on regulatory incentives to report lower liabilities.

Hence, a major worry is that their increased risk-taking is reckless and could lead to substantial future costs to taxpayers or public entities if their more volatile risky investments fail to meet the expected rates of return. Moreover, the lack of any association between liability discount rates and contractual inflation protection (which applies particularly to U.S. public funds) raises the concern that these funds underestimate the costs of these promises, i.e. that U.S. public funds are camouflaging the real costs of pension promises made to their beneficiaries and taxpayers. The economic consequences of these practices could involve material wealth transfers from future taxpayers and workers to current pensioners and workers (see also Kocken, 2012).

The policy implications of our study are clear but challenging. The extent of this challenge is reflected in the severe levels of underfunding of U.S. public pension funds. In 2010, the average self-declared funding ratio of U.S. public pension funds was equal to 75 percent. However, as these funding levels are often based on high liability discount rates and smoothed asset valuation, the reported level of underfunding would be significantly worse if they had used market-based asset valuations and liability discount rates, which are based on the actual riskiness of the promised pension benefits (i.e., linked to, for example, yields on public bonds or other interest rates).

The purpose of public and private DB pension plans is the same-to provide a secure and affordable retirement provision to their members. We see no good economic reason why public and private pension funds in the United States should be regulated in different ways. Our findings indicate that a highly politicized setting, a lax regulatory framework, and a tough economic environment for pension funds in general combined to allow U.S. public pension funds to make strategic decisions that camouflage the real value of their promised pension benefits. These decisions could have alarmingly negative implications for future stakeholders and taxpayers through lower returns and masked funding problems. In sum, we argue that U.S. policy pertaining to public pension funds needs drastic reform and must be brought in line with regulations around U.S. private pension funds, as current laws and regulations effectively exempt states and cities from behaving prudently in how they manage and disclose the financing of pension systems of their employees.

Recently, the GASB issued new proposals that take a major step in this direction. Specifically, the GASB (2012) proposed severing the link between liability discount rates and expected 
rates of returns but only for funds that can be classified as underfunded, i.e., where the plan assets are not "projected to be sufficient to pay benefits and the net position projected to remain after each benefit payment can be invested long-term." The GASB notes that for such underfunded funds in which "the plan assets are projected not to be available to be invested long-term and, therefore, would be insufficient for paying benefits to current employees, retirees, and their beneficiaries, the projected benefit payments take on attributes that are similar to other forms of debt. In this circumstance, governments would incorporate into the discount rate a tax-exempt, high-quality 20-year municipal bond index rate to reflect that future benefit payments are not expected to be made from long-term investments. High quality would be defined as being rated AA or higher (or an equivalent rating)." However, for funds for which plan assets are projected to be sufficient, the wrong incentives would remain in place because the assumed rates of return of the assets could still be used to discount the liabilities. ${ }^{27}$ Moreover, these projections (of whether or not assets are sufficient to pay the benefits) can seemingly still be based on liability discount rates that are linked to expected asset returns. As a result, the new GASB proposals seem to create even stronger incentives to camouflage liabilities and engage in reckless risk-taking for funds that are close to being underfunded (and that may indeed be underfunded if liabilities were to be discounted at lower high-quality municipal yields) and that rationally want to avoid being classified as underfunded. We thus conclude that the new GASB guidelines are overly complicated and do not solve the incentives problem, but that subjecting U.S. public DB pension funds to the same regulations currently pertaining to U.S. corporate plans would.

\footnotetext{
${ }^{27}$ Another problem that remains in the guidelines is that GASB still recommends using a fixed liability discount rate number of around 8 percent to discount all liabilities, regardless of their maturity of the promised pension benefits, instead of using a term structure of liability discount rates that matches the term structure of promised benefits.
} 


\section{Chapter 3}

\section{Can Large Pension Funds Beat the Market? Asset Allocation, Market Timing, Security Selection, and the Limits of Liquidity ${ }^{*}$}

\subsection{Introduction}

Can large, sophisticated investors beat the market? And if so, what investment skills are most prevalent? Can investors outperform by periodically changing strategic asset allocation weights, by deviating from those in short-term market timing, or by selecting particular securities within asset classes? Are there (dis)economies of scale and liquidity limitations in asset allocation, market timing or security selection? In this paper, we try to address these questions by investigating a unique database of the largest U.S. defined benefit (DB) pension funds.

Questions of investment skill and the importance of size and liquidity have been most intensively investigated in the mutual fund literature. However, this literature has focused almost exclusively on the third component of active management, security selection, largely sidestepping the performance in asset allocation and market timing. We are the first, to the best of our knowledge, to examine the returns from changes in asset allocation of institutional investors, as until now a large data sample on strategic asset allocation policy has not been available. On market timing performance, Blake, Lehmann, and Timmermann (1999) and Blake, Rossi, Timmermann, Tonks, and Wermers (2013) find that external managers employed by U.K. pension funds did not have superior market timing (also called tactical asset allocation) skills across asset classes. Among mutual funds, Bollen and Busse (2001) and Jiang, Yao, and Yu (2007) find that actively managed equity funds have some positive timing ability, whereas Chen, Ferson, and Peters (2010) find that bond mutual funds have neutral to weakly positive market timing skills. All of these studies conflate changes in strategic asset allocation with more short-term market timing. Using our unique data on the strategic asset allocation policy weights, we can

\footnotetext{
${ }^{*}$ This chapter is co-authored with Rob Bauer (Maastricht University) and Martijn Cremers (University of Notre Dame).
} 
directly assess asset allocation skills and distinguish them more accurately from market timing decisions (which are captured by the deviations between the policy weights and the actual asset allocation weights).

There is a very large literature on security selection performance, especially among mutual funds. For example, Malkiel (1995), Gruber (1996) and Chan, Chen, and Lakonishok (2002) find that, on average, mutual funds underperform the market by about the amount of expenses charged to investors. However, Kacperczyk, Sialm, and Zheng (2008) and Cremers and Petajisto (2009) document evidence that at least some subset of mutual fund managers may have skill. Kosowski, Timmermann, Wermers, and White (2006) find not only that a sizable subgroup of mutual fund managers exhibits stock-picking skills, but also that the superior alphas of these managers persist.

We focus on pension funds and our main contribution to the security selection literature is to document the average security selection skills at the total fund level, rather than at the level of portfolios managers hired by the pension funds, as considered by Lakonishok, Shleifer, and Vishny (1992), Goyal and Wahal (2008) and Blake et al. (2013). The existing pension fund literature focuses primarily on equity investments through external managers. As external managers are often hired by more than one pension fund and funds typically employ more than one external manager, such research does not allow for direct analysis of the total performance of pension funds. We study the overall fund performance, which incorporates the performance in equity, fixed income and alternative assets. ${ }^{2}$ Pension funds in our sample have both internal and external managers, and combine both active and passive strategies.

Moreover, we are the first paper to explore the role of size and liquidity for all three components of asset management: asset allocation, market timing and security selection. In an important paper, Chen, Hong, Huang, and Kubik (2004) find diseconomies of scale related to mutual fund size, but economies of scale related to mutual fund family size. They relate the former primarily to within-fund organizational and liquidity problems and the latter to the advantage of centralizing research and marketing efforts. More recently, Lopez de Silanes, Phalippou, and Gottschalg (2010) document diseconomies of scale for private equity and Fung, Hsieh, Naik, and Ramadorai (2008) for hedge funds. Pension funds seem particularly interesting vehicles to study questions related to size and liquidity in investment management performance. With their larger average size (about $\$ 10$ billion in our sample), they are vastly larger than typical mutual funds, and may be more akin to mutual fund families rather than individual mutual funds. Further, incentives differ substantially. Mutual funds with the best performance receive large cash inflows (see, for example, Sirri and Tufano, 1998). As mutual fund manager pay depends on the size of the assets under management and the relative performance compared to the benchmark, this can create substantial incentives for mutual fund managers to engage in

\footnotetext{
${ }^{2}$ A closely related paper is Blake et al. (1999), who investigate the asset allocation and performance of U.K. pension funds throughout the period 1986-1994. Their data includes only U.K. funds that maintained the same external management group during the entire sample period. Another related paper is Brown, Garlappi, and Tiu (2010), who consider endowment funds. Similar to pension funds, endowment funds also invest in multiple asset classes. However, the amount of assets under management of pension funds is substantially larger. According to Brown et al. (2010), endowment funds had on average $\$ 287$ million assets, while the mean holdings of pension funds in our sample is $\$ 10$ billion.
} 
active management or chase short-term performance. Defined benefit pension fund inflows do not depend on performance, but on actuarial and demographic factors. This long-term liability structure further enables pension funds to make substantial investments in illiquid assets.

As a result, the role of size and liquidity for pension fund performance is ex ante unclear. On the positive side, less liquid investments have potentially higher expected returns. Large scale may provide significant bargaining power vis-a-vis external money managers or allow funds to attract investment talent internally. On the negative side, larger size may make trading in less liquid securities much more difficult, may limit the investment strategies available and create organizational complexities. Moreover, the size of the assets of DB plans is driven by the number of plan members and pension promises made to the workers, and not by scale efficiency considerations (unlike mutual funds that can be closed to new investments due to diseconomies of scale).

To answer these questions, we use the unique CEM dataset, comprised of 557 U.S. defined benefit pension funds for the period 1990-2010. Our main findings are six-fold, collectively suggesting some evidence for the ability of the pension funds in our sample to modestly outperform at the total fund level, though this outperformance is subject to significant liquidity and size limitations.

First, pension fund investment costs are on average 37 basis points per year. Investment costs are stable during the first half of our sample, but increase to 55 basis points in 2010 due to the higher allocation to alternative assets. We document significant scale advantages in costs: one standard deviation increase in the log of assets reduces the total investment costs by 7 basis points. The scale advantage is much more pronounced for alternative investments, where a one-unit increase in the log of alternative assets results in 111 basis points lower costs. As expected, funds managing a greater percent of their assets through active and external mandates have higher investment costs.

The second contribution is methodological. We decompose pension fund returns in three components (asset allocation, market timing and security selection) and evaluate the performance of each. The first component, asset allocation, consists of the changes over time in each fund's ex-ante declared strategic (target) asset allocation policy weights times the self-declared benchmark returns of the different asset classes. For each asset class within each fund, we observe the self-declared benchmark as well as the return on these benchmarks. Asset allocation performance evaluation thus compares the performance of the change in policy weights over last year, relative to not changing last year's policy weights.

The second component is market timing (tactical asset allocation), defined as the difference between strategic policy and actual (realized) allocation weights. Market timing thus captures the performance related to overweighting or underweighting particular asset classes, relative to the target weights in that year. ${ }^{3}$ We further decompose this market timing component into

\footnotetext{
${ }^{3}$ For instance, if a fund's strategic weight for equity is $60 \%$, but the realized weight is $65 \%$ (and say for fixed income the strategic weight is $40 \%$ and the realized weight is $35 \%$ ), the market timing components for equity (fixed income) equals $+5 \%(-5 \%)$, multiplied by the relevant benchmark return. The main difference between asset allocation and market timing is horizon. Strategic asset allocations change less frequently: $32.67 \%$ of the fund-years observations show no change in these strategic weights in year $t$ as compared to year $t-1$. Market timing is shorterterm, as only $0.51 \%$ of the fund-years observations have no difference between the target and the actual weights in
} 
a passive and an active part, where the passive part consists of changes in actual weights due to benchmark market movements and the active part is due to reallocations of investments, taking market movements into account.

The third component is security selection, corresponding to net benchmark-adjusted returns or the difference between realized net returns and benchmark returns for a given asset class. This captures the returns due to picking securities and timing industries and styles within an asset class.

Third, we find that pension funds have, on average at the total fund level, positive abnormal returns of 89 basis points per year after risk-adjusting for equity market, size, value, liquidity and fixed income market factors, to which each of three components of active management contributes about equally. Pension funds obtain 25 basis point annual alpha from setting the asset allocation policy weights and 26 basis points annual alpha due to timing of asset allocation decisions. Security selection produces returns that are on average 25 basis points per year above the benchmark returns, but this becomes insignificant after controlling for risk factors (and can completely be attributed to momentum in equity markets).

Pension funds obtain positive returns from changes in the strategic asset allocation mainly by increasing their exposure over time to alternative assets in years in which these asset classes had high positive returns. The 26 basis points abnormal market timing returns can be fully attributed to passive exposure to 'time series' momentum, and not to any active rebalancing. Times series momentum is the phenomenon that past returns in a particular asset class tend to be predictive for the return in the asset class, as documented by Moskowitz, Ooi, and Pedersen (2012). They find that '12-month time series momentum profits are positive, not just on average across these assets, but for every asset contract we examine (58 in total).' Combined with the insignificant security selection performance, this suggests that pension funds benefit from simultaneously investing in multiple asset classes, but would do better (after costs and on average) if they would have invested exclusively in passive mandates without frequent rebalancing across asset classes. For comparison, the average investment cost of passive mandates is 5.67 basis points compared to 45.22 basis points for active mandates.

Fourth, we relate the risk-adjusted returns for asset allocation, market timing and security selection components to the total size and liquidity of the funds' holdings. Our proxy for liquidity is the fund's loading on the traded liquidity factor of Pastor and Stambaugh (2003). We find that the direct association between the size of the assets under management and performance is only significantly associated for market timing, which smaller funds do more effectively. In general, the scale advantage in costs is thus not translated into better overall performance for larger funds.

All three components of active management exhibit significant liquidity limitations related to size. The economic effects are meaningful and comparable across the three components of active management. For example, increasing liquidity by lowering the liquidity beta by 10 percentage points is associated with an improvement of the alpha of a fund at the $75^{\text {th }}$ size 
percentile by 13 basis points per year more than the improvement of the alpha of a fund at the median size percentile.

Fifth, as previously mentioned, our results suggest that especially the largest pension funds would have performed better if they had invested more in passively managed mandates. We group all funds into three groups depending on the percentage of their assets that is actively managed. The most actively managed group has significantly greater size-induced liquidity constraints, and the largest funds in this group underperform similarly sized funds with much less active management by about 62 basis points a year. We thus document three reasons for the attractiveness of passive management, especially for the largest funds. First, pension funds on average had insignificant risk-adjusted security selection performance. Second, passive management is much cheaper than active management. Third, performance in passive mandates is less subject to liquidity-related diseconomies of scale.

Sixth and finally, we document strong performance persistence for both market timing and security selection using annual quintile rankings. Funds are more likely to end up in a better performing quintile next year, if they also do so this year, and they are more likely to perform worse in the ranking next year if they performed relatively poorly this year. Such persistence is a useful confirmation that we are able to pick up skill, even though our performance data is limited to the annual frequency.

Blake et al. (1999) find negative returns from market timing, attributed to negative timing returns within foreign equity (see also Timmermann and Blake, 2005). One important difference in the construction of the market timing return component is that we have access to the strategic asset allocation weights and self-determined benchmarks, whereas Blake et al. (1999) use one benchmark index per asset class as a return proxy for all pension funds and estimate the strategic weights based on the trend in realized weights. Another difference is that we also include internal mandates across all asset classes in our analysis. Moreover, we do not require that a single external manager is employed during the entire sample period.

Similar to our findings, the security selection returns of U.K. funds are positive, but not always significant (Blake et al., 1999). Busse, Goyal, and Wahal (2010) document that institutional asset management firms hired by U.S. pension funds deliver alphas statistically indistinguishable from zero. In line with our findings, they also find that the security selection alphas of these institutional managers are mainly driven by momentum in equity markets.

Our findings of liquidity-related diseconomies of scale and the inability to take concentrated positions in equity among pension funds are consistent with Chen et al. (2004), who exclusively focus on security selection by mutual funds. That paper does not directly assess any fund's exposure to liquidity, but indirectly infers this by comparing the performance of smallcap funds to large caps funds (which presumably are more liquid). In contrast, we directly estimate each fund's loading to the systematic traded liquidity factor of Pastor and Stambaugh (2003).

Our results partially contradict the existence of economies of scale in pension fund management as discussed in Dyck and Pomorski (2011), as we find that larger U.S. funds do not perform better than smaller U.S. funds both before and after risk-adjusting performance. The 
difference in results can largely be explained by a difference in methodology: we analyze not only the non-risk-adjusted returns, but we also risk-adjust fund performance for factor returns, investigate the importance of momentum and control for fund fixed effects. Dyck and Pomorski (2011) do not risk-adjust returns and focus on specifications without fund fixed effects and without controlling for momentum. ${ }^{4}$ In our view, especially risk-adjustment is critical for performance evaluation and merely benchmark-adjusting is insufficient, as is borne out by our results.

Persistence in security selection performance has been documented by Tonks (2005) and Blake et al. (2013) among U.K. pension funds' domestic equity investments, even after riskadjusting. When analyzing the security selection skills of U.S. domestic equity institutional managers, Busse et al. (2010) find only modest evidence of persistence using three-factor models and little to none using four-factor models. Our contribution is to document persistence in both market timing and security selection returns on a total fund level, which incorporates the performance of all managers in all assets. However, we only have access to annual data and thus cannot test persistence in risk-adjusted alphas.

The chapter proceeds as follows. Section 5.3 describes the CEM dataset and considers possible self-reporting biases. Section 3.3 explains the methodology to decompose fund returns into asset allocation, market timing and security selection components. Section 3.4 focuses on the effects of investment style and size on costs. Section 5.6 presents the returns from asset allocation, market timing and security selection before and after risk-adjusting. Section 5.6.2 describes the relation between fund risk-adjusted performance and its characteristics. Section 5.6 .3 briefly discusses the persistence in pension fund performance. Concluding comments are provided in section 5.7 .

\subsection{Characteristics of the CEM database}

CEM Benchmarking Incorporated (CEM) collects U.S. pension fund data through yearly questionnaires. ${ }^{5}$ We focus on defined benefit (DB) funds only, where the pension fund's Board makes the asset allocation decisions and is responsible for performance. In defined contribution (DC) funds, plan sponsors select the menu of available investment options, while each plan member individually is responsible for the asset allocation decision. Thus, asset allocation outcomes within DC funds belong more to the literature on individual investors' decision making. The CEM database includes details on each fund's strategic and actual asset allocation decisions, the self-declared benchmarks for each asset class, and the precise cost structure and performance for all separate asset classes and their benchmarks. Table 3.1 provides the number of funds reporting to CEM. In the period 1990-2010, a total of 557 U.S. pension funds have reported to CEM. The pension funds in our sample on average had around $\$ 10$ billion assets under management. Fund size is positively skewed, indicating that the CEM universe consists

\footnotetext{
${ }^{4}$ In Appendix Table A.1 we replicate part of Dyck and Pomorski (2011) findings of economies of scale among pension funds before risk-adjusting.

${ }^{5}$ Other papers using the CEM database are French (2008), Andonov, Bauer, and Cremers (2013), Bauer, Cremers, and Frehen (2010) and Dyck and Pomorski (2011).
} 


\section{Table 3.1: Number of funds and fund size}

This table presents the number of U.S. pension funds in the CEM database in the sample period 19902010. We also show the number of funds entering and exiting the database in a given year. The Fund Size column presents the average assets under management in billion USD. The Total row shows the total number of funds reporting at least one year to the CEM and the time series average of cross-sectional mean fund size.

\begin{tabular}{ccccc}
\hline Year & \# Funds & \# Enter & \# Exit & Fund Size \\
\hline 1990 & 35 & 35 & 0 & 9.46 \\
1991 & 63 & 39 & 11 & 7.28 \\
1992 & 83 & 38 & 18 & 7.45 \\
1993 & 134 & 70 & 19 & 5.92 \\
1994 & 168 & 68 & 34 & 4.85 \\
1995 & 192 & 62 & 38 & 5.64 \\
1996 & 185 & 36 & 43 & 6.22 \\
1997 & 168 & 29 & 46 & 7.73 \\
1998 & 174 & 37 & 31 & 9.11 \\
1999 & 182 & 40 & 32 & 10.41 \\
2000 & 164 & 22 & 40 & 12.02 \\
2001 & 176 & 36 & 24 & 10.56 \\
2002 & 156 & 15 & 35 & 10.80 \\
2003 & 158 & 27 & 25 & 11.02 \\
2004 & 167 & 26 & 17 & 12.18 \\
2005 & 156 & 15 & 26 & 13.12 \\
2006 & 147 & 18 & 27 & 15.79 \\
2007 & 218 & 88 & 17 & 12.76 \\
2008 & 212 & 37 & 43 & 12.25 \\
2009 & 203 & 34 & 43 & 12.22 \\
2010 & 201 & 42 & 44 & 13.32 \\
\hline Total & 557 & & & 10.00 \\
\hline
\end{tabular}

of several very large and many smaller funds. For instance, the 25 percentile, median and 75 percentile of fund size are $\$ 1.3, \$ 3.0$ and $\$ 8.6$ billion, respectively.

The main motive for funds to enter the database is to benchmark their investment costs against peers. Funds sometimes decide to stop submitting the questionnaires to CEM for various reasons, such as termination of the service due to costs savings, mergers, acquisitions and bankruptcies of the underlying corporations, etc. As reporting to CEM is voluntary, the dataset is potentially vulnerable to self-reporting bias. Bauer, Cremers, and Frehen (2010) address the self-reporting bias by matching the CEM data with the Compustat SFAS data and testing whether the decision to either start or stop reporting is related to the overall fund performance. Their results indicate that there is no evidence of a self-reporting bias related to performance in the exiting and entering years.

Here, we address the self-reporting problem by constructing a Cox proportional hazard model. We test whether the decision of a particular pension fund to exit the database is related to its returns, costs or size. The event of interest is the decision of the pension funds not to report to CEM in a given year. In the Cox hazard model, we treat each fund re-entry as a new fund, which explains why the number of units in Table 3.2 is higher than the total number 
of funds presented in Table 3.1. The results in Table 3.2 indicate that fund size (LogSize, i.e. $\log$ of the total assets under management) has the strongest effect on the fund's exit rate, with smaller funds much more likely to exit the CEM database. This is consistent with the idea that specialized benchmarking services provided by CEM are more relevant and cost-effective for larger funds.

Table 3.2: Cox proportional hazard model and self-reporting bias

This table presents the results of a survival analysis using the Cox proportional hazard model. The event of interest is the decision of the pension funds not to report to CEM in a given year. We treat each fund re-entry as a new fund which explains why the number of Units is higher than the number of Funds presented in Table 3.1. Exit Events presents the number of observations when pension funds decided not to report to CEM again. Observations presents the total number of observations in the database. Independent variables included in the model are LogSize - logarithm of the asset under management, Total costs in basis points, Gross returns in percentage points, Net returns in percentage points, Net benchmarkadjusted returns in percentage points and Benchmark returns in percentage points. In this table the hazard ratios for each independent variable are reported together with their standard errors in brackets and significance levels with ${ }^{*}, * *$ and ${ }^{* * *}$, which correspond to $0.10,0.05$ and 0.01 , respectively. All regressions use robust standard errors clustered by year.

Interpretation of the hazard ratios: LogSize: when the logsize increases by 1 unit, the dropping rate decreases by $26.1 \%(-0.261)$. Total costs: when the total costs increase by 1 basis point, the dropping rate decreases by $0.9 \%(-0.009)$.

\begin{tabular}{|c|c|c|c|c|}
\hline Dependent variable: Exit event - & $\begin{array}{l}\text { cision of a } \\
\text { (1) }\end{array}$ & $\begin{array}{l}\text { ension fund } \\
\text { (2) }\end{array}$ & $\begin{array}{l}\text { not to repor } \\
\text { (3) }\end{array}$ & $\begin{array}{l}\text { to CEM } \\
\qquad(4)\end{array}$ \\
\hline LogSize & $\begin{array}{l}-0.261^{* * *} \\
{[0.043]}\end{array}$ & $\begin{array}{c}-0.261^{* * *} \\
{[0.043]}\end{array}$ & $\begin{array}{l}-0.260^{* * *} \\
{[0.044]}\end{array}$ & $\begin{array}{l}-0.262^{* * *} \\
{[0.042]}\end{array}$ \\
\hline Total costs & $\begin{array}{l}-0.009^{* * *} \\
{[0.003]}\end{array}$ & $\begin{array}{c}-0.009^{* * *} \\
{[0.003]}\end{array}$ & $\begin{array}{l}-0.009^{* * *} \\
{[0.003]}\end{array}$ & $\begin{array}{l}-0.009^{* * *} \\
{[0.003]}\end{array}$ \\
\hline Gross return & $\begin{array}{c}0.006 \\
{[0.011]}\end{array}$ & & & \\
\hline Net returns & & $\begin{array}{c}0.006 \\
{[0.011]}\end{array}$ & & \\
\hline Net benchmark-adjusted return & & & $\begin{array}{l}-0.004 \\
{[0.016]}\end{array}$ & $\begin{array}{c}-0.008 \\
{[0.013]}\end{array}$ \\
\hline Benchmark return & & & & $\begin{array}{c}0.008 \\
{[0.012]}\end{array}$ \\
\hline Units & 798 & 798 & 798 & 798 \\
\hline Exit events & 596 & 596 & 596 & 596 \\
\hline Observations & 3,298 & 3,298 & 3,298 & 3,298 \\
\hline
\end{tabular}

Further, we relate the fund exit rate to pension fund gross returns, net returns, benchmark returns and benchmark-adjusted returns. Benchmark returns are calculated using the benchmarks reported by pension funds for every asset class in which they invest. CEM asks funds to report, separately for every asset class in which a fund has holdings, the exact definition of the benchmark they employ as well as the return on that benchmark. We specify net benchmarkadjusted returns as gross returns minus costs, and minus benchmark returns. The hazard ratios on net returns, benchmark returns and net benchmark-adjusted returns are always insignificant, so exit events are not related to funds underperforming or outperforming their bench- 
mark. ${ }^{6}$ Hence, we find no evidence that the CEM database suffers from self-reporting bias related to performance. ${ }^{7}$

Funds included in the CEM database cover a substantial share of the pension fund assets under management and stock market capitalization. Over 1990-2010, U.S. funds included in the CEM database account for approximately $30-40 \%$ of the asset under management by U.S. pension funds. In 2010, the holdings in U.S. equity of U.S. pension funds included in the CEM universe represent $4.2 \%$ of the market capitalization of the NYSE, NASDAQ and AMEX and their fixed income holdings are equal to about $2 \%$ of the total outstanding U.S. bond market debt in $2010 .^{8}$

We can distinguish the following asset classes, with their average portfolio weights over the full sample: equity (57.52\%), fixed income (31.31\%), cash (1.98\%) and alternatives $(9.19 \%)$. Figure 3.1 presents the time trend in the allocation to equity, fixed income, cash and alternative assets. In the period 1990-2000, allocations to equity increase, while declining significantly after 2005. During the second decade of our sample period, alternative assets have been growing in importance at the expense of declining allocations to equity and fixed income. Around 85\% of the pension funds invested in alternative assets, which include investments in real estate, private equity, hedge funds, commodities, natural resources, infrastructure and global tactical asset allocation. The most important alternative asset class is real estate, while funds allocate also a significant percentage of their assets to private equity and, especially recently, to hedge funds.

Figure 3.2 plots the time variation in asset allocation within equity, fixed income and alternative asset classes. Panel A shows that pension funds invest the majority of their equity holdings in the domestic U.S. stock market, with international diversification increasing over time. For instance, funds invested $89.47 \%$ of their total equity holdings in U.S. markets in 1990, while this percentage decreased to $58.76 \%$ in 2010. The decrease in domestic equity is reallocated to either an EAFE mandates (equity investments in Europe, Australasia and Far East), capturing about $18 \%$ of the equity holdings, or a global equity (ACWxUS) mandates, which account for $17.21 \%$ of the equity assets in 2010 .

Panel B in Figure 3.2 plots the time variation of allocation to various fixed income asset classes. Here, the focus on domestic investments is even more striking. In 1990, funds held $96.64 \%$ of their fixed income investments in the U.S. market, with only very limited international diversification since then. For instance, the allocations to EAFE, Emerging Markets and Global fixed income mandates remain low and stable over the 1990-2010 period (less than 8\% combined).

\footnotetext{
${ }^{6}$ In Appendix Table A.4 we sort the funds into five quintiles based on their market timing and security selection returns. For both return components, the percentage of funds exiting the database is similar across all quintiles, i.e. top performers have very similar exit rates as the worst performers.

${ }^{7}$ Total costs are somewhat negatively related to the exit rate of U.S. funds. The hazard ratio of -0.009 indicates that an increase in costs by one basis point results in $0.9 \%$ decrease in the exit rate. Funds with higher costs may benefit more from the cooperation with CEM, because the company is specialized in advising on costs.

${ }^{8}$ For the comparison, we used market capitalization data from the World Federation of Exchanges (WFE).
} 
Figure 3.1: Asset allocation of U.S. pension funds

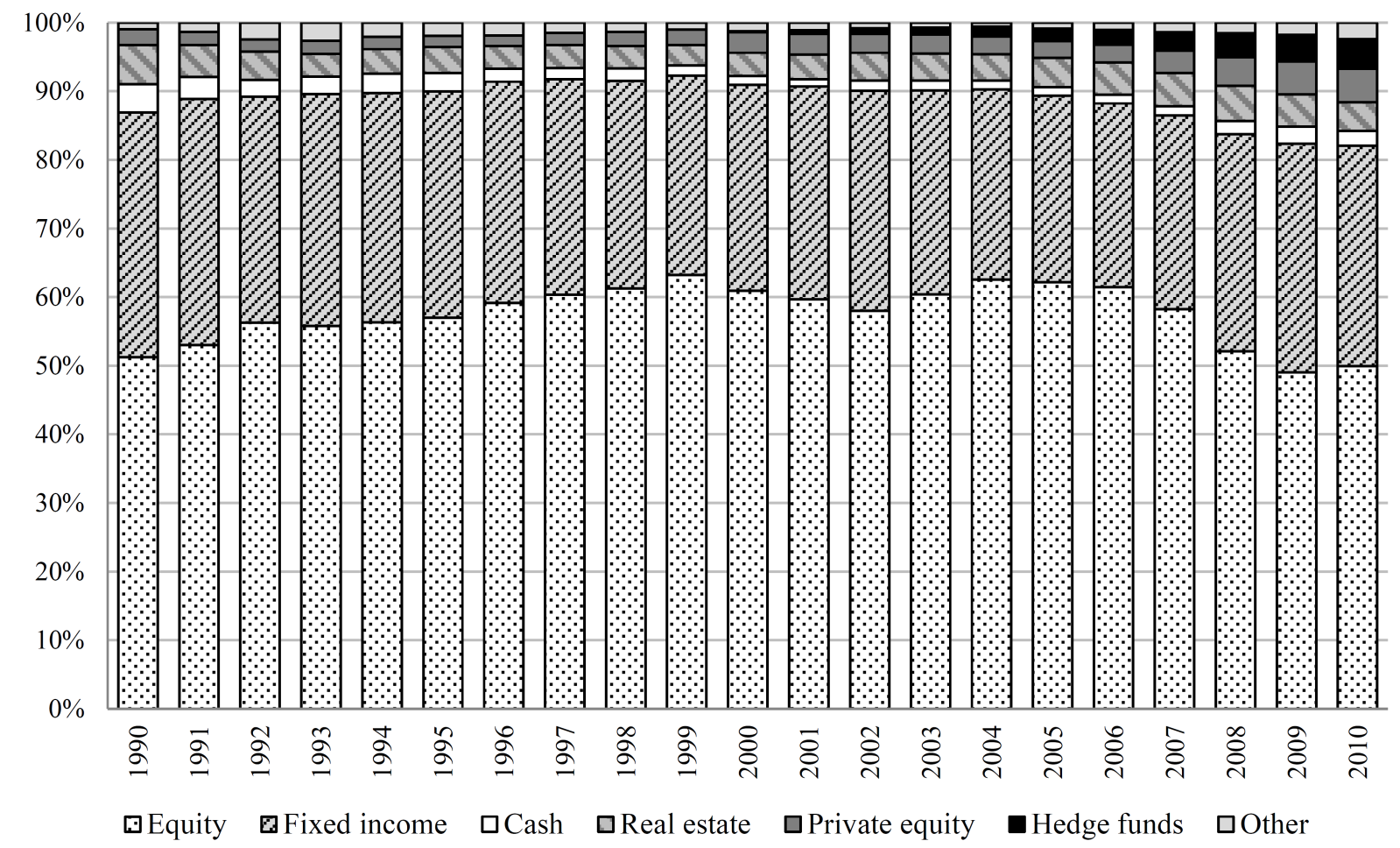

In addition to realized (actual) asset allocation weights, CEM also provides information on the pension fund strategic (target) policy weights, which are determined by the pension funds' Boards. The changes in policy weights from year $t-1$ to year $t$ show how pension fund strategic allocations evolve over time. Table 3.3 shows that funds modified their strategic allocation by adding more alternative assets at the expense of equity, fixed income and cash. Table 3.3 further presents that the differences between the reported strategic weights and actual weights are close to zero on average, but exhibit substantial (averaged across time) cross-sectional standard deviations of $2.36 \%$ to $5.50 \%$.

On the total fund level (All assets), Table 3.4 shows that pension funds paid on average 37 basis points for investing in all asset classes during 1990-2010. Figure 3.3 presents the trend in pension fund investment costs. Over the entire period, alternatives are the most expensive asset classes (average fees of 133 basis points), ${ }^{9}$ while the least expensive assets are fixed income (20 basis points). The total investment costs are steady during the 1990-2000, but significantly increase after 2000 from 31 basis points in 2000 to 55 basis points in 2010 . This trend is primarily due to the increasing costs for alternative investments as well as the greater allocations to these alternative assets.

Table 3.4 reports also the return summary statistics. The average gross return during the 1990-2010 is 9.89 percent. Figure 3.4 presents the annual gross returns on a fund level and separately for equity, fixed income and alternative assets. On average, funds obtain positive net

\footnotetext{
${ }^{9}$ This estimation understates the actual costs of investing in some alternative assets, like private equity (see Phalippou, 2009), as it captures only management fees, while performance fees are subtracted directly from the returns. In the calculation of private equity net returns both management and performance fees are deducted.
} 
Figure 3.2: Asset allocation of U.S. funds within equity, fixed income and alternatives

Panel A: Average allocation within equity

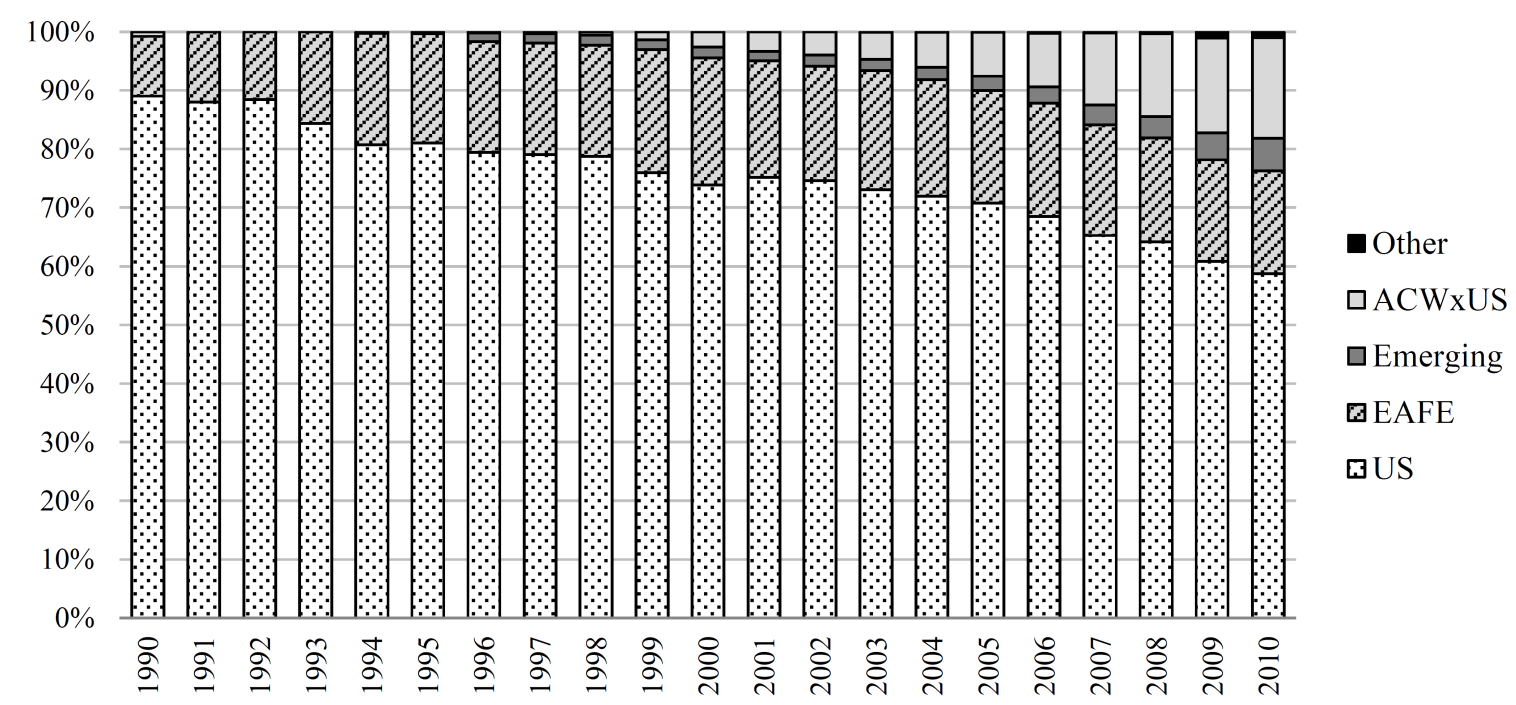

Panel B: Average allocation within fixed income

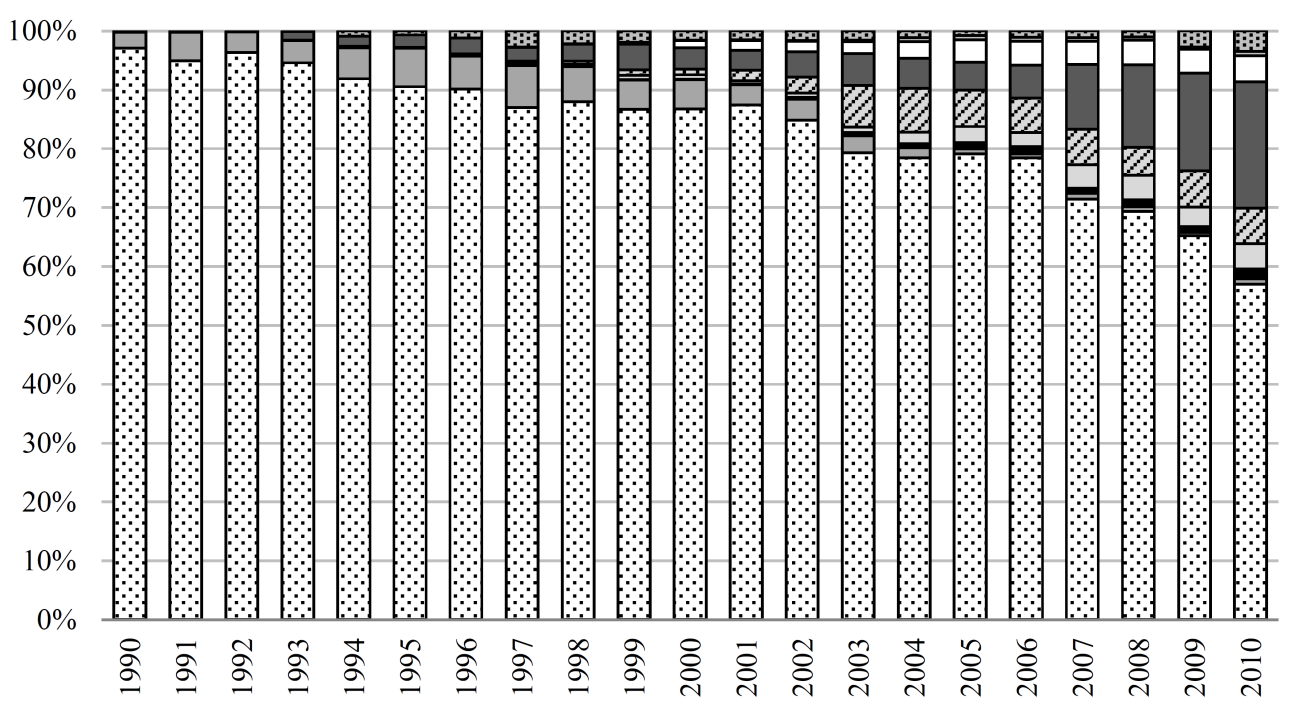

W Other

口Mortgages

口Inflat. Indexed

口Long Term

๑High Yield

口Global

- Emerging

口EAFE

DUS

Panel C: Average allocation within alternative assets

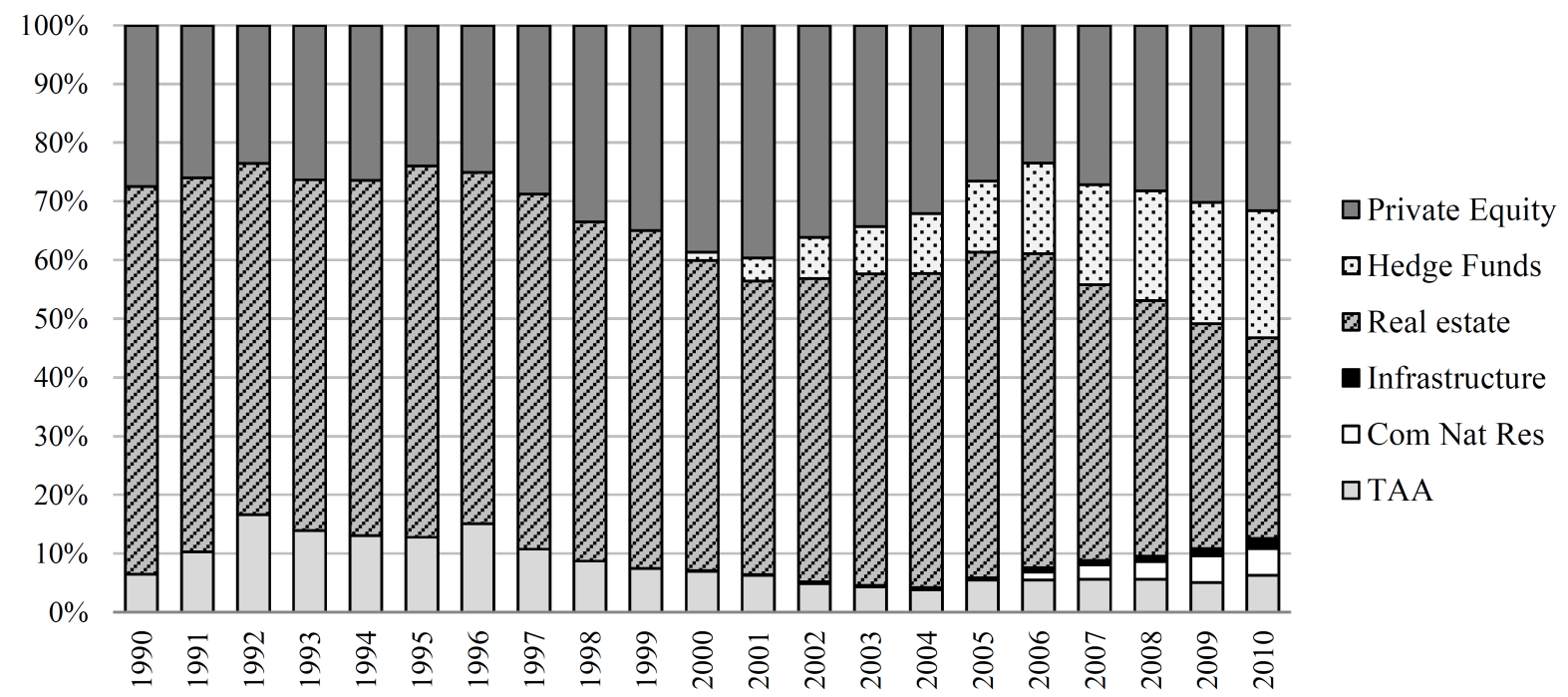




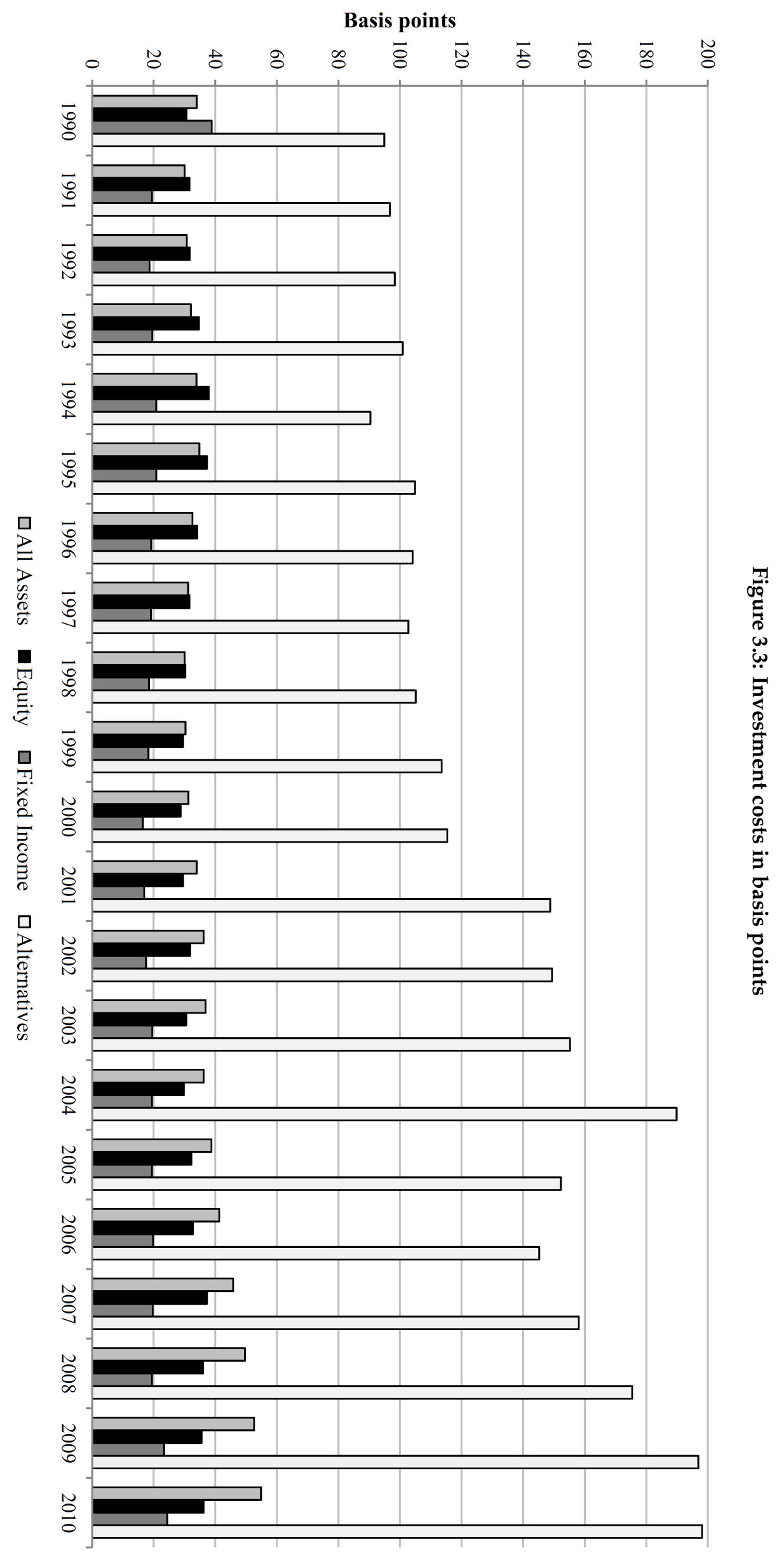


Table 3.3: Summary statistics: strategic (policy) and actual asset allocation

This table presents the strategic policy weights of the pension funds and the realized policy weights. Column Policy weight presents the time series averages of cross-sectional mean strategic policy weights (target weights) for different asset classes for the period 1990-2010. We present the results for equity, fixed income, cash and alternative assets. Alternative assets include investments in tactical asset allocation, commodities, natural resources, real estate, infrastructure, private equity and hedge funds. Column Actual weight presents the time series averages of cross-sectional mean realized weights for different asset classes for the period 1990-2010. The means in column Policy $t$ - Policy $y_{t-1}$ displays the time series averages of cross-sectional mean differences between the strategic policy weights in year $t$ and the strategic policy weights in the previous year $t-1$, whereas the StDev column presents the time series average of cross-sectional standard deviations of the differences between the strategic policy weights from year $t$ and year $t-1$. The means in column Actual - Policy $_{t}$ display the time series averages of cross-sectional mean differences between the actual weights and strategic policy weights, whereas the StDev column presents the time series average of cross-sectional standard deviations of the mean differences between the actual (realized) weights and strategic (target) weights.

\begin{tabular}{lcccccccc}
\hline & \multicolumn{2}{c}{ Policy weight } & \multicolumn{2}{c}{ Actual weight } & \multicolumn{2}{c}{ Policy $_{t}-$ Policy $_{t-1}$} & Actual $_{t}-$ Policy $_{t}$ \\
\hline & Mean & StDev & Mean & StDev & Mean & StDev & Mean & StDev \\
\hline Equity & $57.46 \%$ & $11.54 \%$ & $57.52 \%$ & $12.15 \%$ & $-0.18 \%$ & $4.65 \%$ & $0.06 \%$ & $5.50 \%$ \\
Fixed income & $31.71 \%$ & $11.07 \%$ & $31.31 \%$ & $11.57 \%$ & $-0.22 \%$ & $4.45 \%$ & $-0.40 \%$ & $4.95 \%$ \\
Cash & $1.16 \%$ & $2.60 \%$ & $1.98 \%$ & $3.14 \%$ & $-0.10 \%$ & $1.43 \%$ & $0.82 \%$ & $2.36 \%$ \\
Alternatives & $9.68 \%$ & $8.53 \%$ & $9.19 \%$ & $8.47 \%$ & $0.51 \%$ & $3.57 \%$ & $-0.49 \%$ & $5.21 \%$ \\
\hline
\end{tabular}

benchmark-adjusted returns on a total fund level, which are primarily due to positive performance in equity and fixed income. ${ }^{10}$ From the alternative asset classes, pension funds obtained lower gross returns than the stock market and net benchmark-adjusted returns equal to zero. However, returns on alternative investments have significantly higher cross-sectional variation compared to equity and fixed income investments, which can be seen in the high standard deviation. These high standard deviations imply that pension funds experience high volatility and large differences in performance in alternative asset classes.

\subsection{Methodology}

First, we analyze the overall level of investment costs, the differences in costs for equity, fixed income and alternative assets, and the role of investment style and size as determinants of cost differences. To disentangle effects of pension fund size, allocation decisions and investment style, we use pooled panel regressions with year and fund fixed effects:

$$
C_{i, t}=\beta_{0}+\beta_{1} \text { Size }_{i, t}+\beta_{2} \% \text { Act }_{i, t}+\beta_{3} \% \text { Ext }_{i, t}+\beta_{4} \% \text { Allocation }_{i, t}+\beta_{5} Y D_{t}+\beta_{6} F_{i}+u_{i, t}
$$

where $C_{i, t}$ refers to the investment costs of fund $i$ in year $t, F E_{i}$ captures fund-fixed effects and $u_{i, t}$ are idiosyncratic errors. Size $e_{i, t}$ is the log of the US\$ value of the pension fund assets,

\footnotetext{
${ }^{10}$ These are the most frequently reported benchmarks by the pension funds: U.S. equity - S\&P500, Russell 1000, Russell 2000 and Russell 3000; U.S. fixed income - Citi Group US Big Index and Barclays US Aggregate; real estate NCREIF and NAREIT; private equity - Wilshire $5000+200$ b.p., Cambridge Private Equity, Venture Economics and custom benchmarks; hedge funds - CSFB Tremont, HFRI Indices and custom benchmarks.
} 


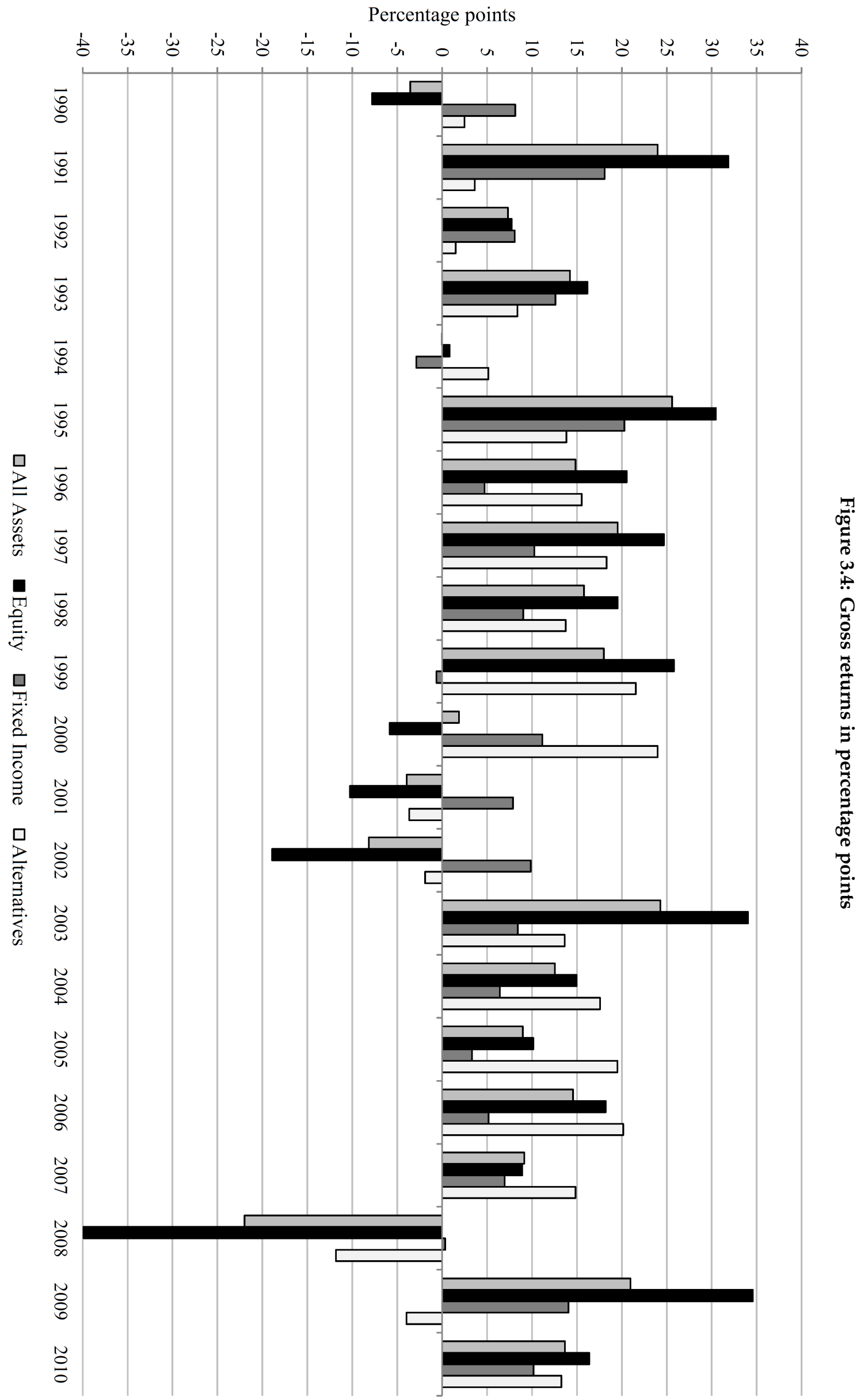


Table 3.4: Summary statistics: returns and costs

This table presents the pension fund costs, benchmark returns and realized return in percentages. Descriptive Statistics include the time-series averages of cross-sectional, annualized mean gross returns, costs, net returns, benchmark returns and net benchmark-adjusted returns (Net - Bench. return, i.e. the security selection return (SS) component) for the 1990-2010 period. Standard deviations are given between the brackets. All assets uses the overall returns in all asset classes on a fund level. We also report the results separately for equity, domestic equity, fixed income, domestic fixed income and alternative assets.

\begin{tabular}{lccccc}
\hline & $\begin{array}{c}\text { Gross } \\
\text { return }\end{array}$ & Costs & $\begin{array}{c}\text { Net } \\
\text { return }\end{array}$ & $\begin{array}{c}\text { Bench. } \\
\text { return }\end{array}$ & $\begin{array}{c}\text { Net-Bench. } \\
\text { return (SS) }\end{array}$ \\
\hline All assets & 9.89 & 0.37 & 9.52 & 9.21 & 0.31 \\
& {$[3.85]$} & {$[0.19]$} & {$[3.83]$} & {$[2.58]$} & {$[2.91]$} \\
Equity & 11.05 & 0.33 & 10.72 & 10.44 & 0.28 \\
& {$[3.81]$} & {$[0.17]$} & {$[3.80]$} & {$[2.27]$} & {$[3.24]$} \\
Domestic equity & 11.21 & 0.29 & 10.92 & 10.74 & 0.18 \\
& {$[3.34]$} & {$[0.17]$} & {$[3.33]$} & {$[1.54]$} & {$[3.26]$} \\
Fixed income & 8.17 & 0.20 & 7.96 & 7.54 & 0.42 \\
& {$[3.14]$} & {$[0.15]$} & {$[3.11]$} & {$[2.33]$} & {$[2.29]$} \\
Domestic fixed income & 7.89 & 0.19 & 7.70 & 7.24 & 0.46 \\
& {$[2.73]$} & {$[0.15]$} & {$[2.70]$} & {$[1.60]$} & {$[2.29]$} \\
Alternatives & 9.80 & 1.33 & 8.47 & 8.47 & 0.00 \\
& {$[12.67]$} & {$[0.99]$} & {$[12.80]$} & {$[7.73]$} & {$[11.80]$} \\
\hline
\end{tabular}

$\% A c t_{i, t}$ and $\% E x t_{i, t}$ refer to the percentage allocation to active mandates and external managers, respectively. $\%$ Allocation $_{i, t}$ represents the percentage of pension fund $i$ holdings invested in fixed income and alternative asset classes in year $t$.

Pension funds make three distinct active asset management decisions. First, they define their strategic asset allocation policy, which changes infrequently. For instance, $32.67 \%$ of the fund-years observations show no change in these strategic allocation weights in year $t$ as compared to year $t-1$. Second, pension funds engage in market timing by overweighting or underweighting particular asset classes relative to the strategic weights. Third, pension funds engage in security selection and try to beat their self-declared benchmarks within particular asset classes.

Our total return $\left(R_{i, t}\right)$ measure represents a sum of these three active asset management components:

$$
R_{i, t}=\sum_{j=1}^{M}\left(w_{i, j, t} r_{i, j, t}-w_{i, j, t-1}^{A A} r_{i, j, t}^{B M}\right)
$$

where $w_{i, j, t}$ is the actual (realized) weight of fund $i$ for asset class $j$ in year $t$, and $r_{i, j, t}$ is the realized net return of fund $i$ in asset class $j$ in year $t$. In the second term, $w_{i, j, t-1}^{A A}$ represents the strategic asset allocation policy weight of fund $i$ for asset class $j$ in year $t-1$, and $r_{i, j, t}^{B M}$ is the benchmark return on asset class $j$ for fund $i$ from the end of year $t-1$ to the end of year $t$ (i.e., in year $t$ ).

Next, we examine separately the contribution of each asset management return component. To estimate and evaluate the asset allocation skills of pension funds, we look at the yearly 
changes in pension fund strategic asset allocations. We look at the outcome of active decisions made by the pension fund to modify the strategic asset allocation policy in year $t$ compared to year $t-1$. The returns due to such changes $\left(R_{i, t}^{A A}\right)$ are estimated as the difference between pension fund's $i$ strategic policy (i.e., target) weights for asset class $j$ at the end of year $t$ compared to the policy weights at the end of year $t-1$, multiplied with the benchmark return of that asset class from the end of year $t-1$ to the end of year $t$ :

$$
R_{i, t}^{A A}=\sum_{j=1}^{M}\left(w_{i, j, t}^{A A}-w_{i, j, t-1}^{A A}\right) r_{i, j, t}^{B M}
$$

where $w_{i, j, t}^{A A}$ is the policy weight of fund $i$ for asset class $j$ in year $t$, and $r_{i, j, t}^{B M}$ is the benchmark return on asset class $j$ for fund $i$ from the end of year $t-1$ to the end of year $t$ (i.e., in year $t$ ).

We define market timing as the pension fund return due to a deviation from the strategic asset allocation policy weights. Therefore, $R_{i, t}^{M T}$ captures market timing as the difference between actual realized weights and target asset allocation weights in different asset classes, times the benchmark return on each asset class:

$$
R_{i, t}^{M T}=\sum_{j=1}^{M}\left(w_{i, j, t}-w_{i, j, t}^{A A}\right) r_{i, j, t}^{B M}
$$

The market timing term will account for returns due to changes only in the weights between asset classes, not within a particular mandate. For instance, it will capture returns due to a higher allocation to equity at the expense of bonds, or returns due to a higher allocation to domestic equity instead of an EAFE mandate. However, the market timing component will not capture returns due to overweighting particular industry sectors within the U.S. equity mandate.

In general, the differences between actual and policy weights can result from either market movements or active rebalancing decisions of investment managers. If the fund does not actively change asset allocations, then naturally asset classes with higher (lower) returns will have increased (decreased) actual weights. We decompose the market timing return component into these two parts, which allow us to distinguish changes in actual weights due to market movements versus active rebalancing.

In order to do so, we construct hypothetical actual asset allocation weights that the pension fund would have achieved if it would not have rebalanced across asset classes within a particular calendar year. The hypothetical weights are constructed in two steps. In the first step for each fund we multiply the actual asset weights at the end of year $t-1$ with the benchmark returns in year $t$, resulting in a hypothetical portfolio at the end of year $t$. In the second step, we rescale this portfolio such that the year $t$ weights sum to 1 . Using these hypothetical weights $\left(w_{i, j, t}^{H Y P}\right)$ we estimate the passive market timing return of fund $i$ in year $t$ (attributed to market movements) as:

$$
R_{i, t}^{P a s M T}=\sum_{j=1}^{M}\left(w_{i, j, t}^{H Y P}-w_{i, j, t}^{A A}\right) r_{i, j, t}^{B M}
$$


Next, the active market timing returns due to rebalancing $\left(R_{i, t}^{A c t M T}\right)$ is the difference between the actual asset allocation weights and the hypothetical allocation weights, times the benchmark returns in each asset class:

$$
R_{i, t}^{A c t M T}=\sum_{j=1}^{M}\left(w_{i, j, t}-w_{i, j, t}^{H Y P}\right) r_{i, j, t}^{B M}
$$

The third and last component of active management is security selection $\left(R_{i, t}^{S S}\right)$ estimated as the difference between the realized net returns and the benchmark returns. Hence, the security selection component is equivalent to net benchmark-adjusted returns and accounts for all returns that are not attributable to asset allocation policy decisions or market timing across asset classes (though it would include any market timing done within asset classes). Our security selection return component $\left(R_{i, t}^{S S}\right)$ of fund $i$ in year $t$ represents net benchmark-adjusted returns, i.e. returns that are due to deviations from self-declared benchmarks within particular asset classes:

$$
R_{i, t}^{S S}=\sum_{j=1}^{M} w_{i, j, t}\left(r_{i, j, t}-r_{i, j, t}^{B M}\right)
$$

When risk-adjusting the changes in asset allocation, market timing and security selection return components on a fund level, we run the following random coefficient model:

$$
R_{i, t}^{k}=\alpha_{i}+\beta_{1, i} M K T_{t}+\beta_{2, i} S M B_{t}+\beta_{3, i} H M L_{t}+\beta_{4, i} M O M_{t}+\beta_{5, i} L I Q_{t}+\beta_{6, i} F I M K T_{t}+\varepsilon_{i, t}
$$

where $k=A A, M T$, SS. The model assumes that $\alpha_{i}$ and $\beta_{i}$, the coefficients for fund $i$, are drawn independently from a distribution with constant mean and variance. We use the following factors: $M K T$ (excess market return), SMB (small-minus-big), HML (high-minus-low), FIMKT (fixed income excess market return) and LIQ (traded liquidity factor). We also add MOM (momentum factor) to the risk-adjusting model, to control for returns on momentum trading strategies. $M K T, S M B, H M L, M O M$ are taken from Kenneth French's website. The fixed income excess returns (FIMKT) are the returns on U.S. Broad Investment-Grade Bond Index (US BIG) from City Group.

The traded liquidity factor has been defined by Pastor and Stambaugh (2003) as the valueweighted return on the 10-1 portfolio from a sort of stocks into decile groups depending on their historical liquidity betas, or stock sensitivities to innovations in the aggregate liquidity. The aggregate liquidity captures the temporary price fluctuations induced by order flow and measures the liquidity dimension associated with the strength of volume-related return reversals, which seem most relevant for large investors (like pension funds) susceptible to market movements.

We examine separately the performance of pension funds in equity, fixed income and alternative assets (which includes real estate, private equity, hedge funds and other assets). For equity return components we run the following risk-adjusting random-coefficient model:

$$
R_{i, t}^{k}=\alpha_{i}+\beta_{1, i} M K T_{t}+\beta_{2, i} S M B_{t}+\beta_{3, i} H M L_{t}+\beta_{4, i} M O M_{t}+\beta_{5, i} L I Q_{t}+\varepsilon_{i, t}
$$


where $k=A A, M T, S S$. The return components capture changes in asset allocation, market timing and security selection within equity assets.

Following Blake, Elton, and Gruber (1993), Elton, Gruber, and Blake (1995) and Cici and Gibson (2010), we risk-adjust the performance of fixed income assets using the following factors: MKT (equity market), FIMKT (fixed income market), HY (high yield) and OPTION (option-like characteristics of mortgage securities):

$$
R_{i, t}^{k}=\alpha_{i}+\beta_{1, i} M K T_{t}+\beta_{2, i} F_{I M K T_{t}}+\beta_{3, i} H Y_{t}+\beta_{4, i} \mathrm{OPTION}_{t}+\varepsilon_{i, t}
$$

where $k=A A, M T, S S . H Y$ is the return difference of the Merrill Lynch High Yield and Government index for U.S. funds. OPTION is estimated as the return difference of the US BIG Mortgage Index and US BIG Government Index.

We use the random coefficient model because it allows for heteroskedasticity and fundspecific betas, while being more robust to outliers than the standard Fama and MacBeth (1973) approach. As Swamy (1970) explains, the random coefficient model is similar to a generalized least squares approach that puts less weight on the return series of funds that are more volatile.

In addition, we are interested in the relation between certain pension fund characteristics and pension fund performance. Particularly, we would like to see whether fund characteristics like asset size and investment style have a systematic association with any of the three return components. These relations are tested using Fama and MacBeth (1973) regressions of changes in asset allocation, security selection and market timing return components on the characteristics:

$$
\begin{gathered}
R_{i, t}=\alpha_{t}+\delta_{1, t} \operatorname{LogSize}_{i, t}+\delta_{2, t} \% \text { Act }_{i, t}+\delta_{3, t} \% \operatorname{Ext}_{i, t}+v_{i, t} \quad i=1,2, \ldots, N \text { for each } t \\
\hat{\alpha}=\frac{1}{T} \sum_{t=1}^{T} \hat{\alpha}_{t} \quad \hat{\delta}_{1}=\frac{1}{T} \sum_{t=1}^{T} \hat{\delta}_{1, t} \quad \hat{\delta}_{2}=\frac{1}{T} \sum_{t=1}^{T} \hat{\delta}_{2, t} \quad \hat{\delta}_{3}=\frac{1}{T} \sum_{t=1}^{T} \hat{\delta}_{3, t}
\end{gathered}
$$

where $R_{i, t}^{k}$ refers to the return components of fund $i$ in year $t$ and $v_{i, t}$ is a normally distributed zero-mean error term. We correct the standard errors for autocorrelation and heteroskedasticity using the Newey-West procedure with three lags. \%Act and \%Ext refer to the percentage allocation to active mandates or externally managed mandates and LogSize is the log of pension fund assets under management (fund size).

We run the Fama-MacBeth regressions on both non-risk-adjusted and risk-adjusted return components. When using the risk-adjusted return components, the estimation proceeds in two steps. In the first step, we perform a time-series regression of each fund's returns on the factor models as described above. We run these regressions for every fund that has at least one more observation than coefficients to be estimated (our findings do not change when we include only funds with at least 13 observations, see Appendix Table A.2). In the second step, we run FamaMacBeth regressions of the alphas plus residuals retrieved in the first step, correcting standard errors for autocorrelation and heteroskedasticity using the Newey-West procedure. 


\subsection{Pension fund investment costs}

Table 3.5 presents the results of pooled panel costs regressions. The investment costs include the costs of all internal and external money managers hired by the pension fund to invest in all asset classes. Internal investment costs include direct investment costs (compensation and benefits of employees managing internal portfolios and support staff, related travel and research expenses, etc.) and allocated overhead costs. External investment costs include all fees paid to third-party managers including investment management fees, fund-of-fund fees, performance-based fees, commitment fees and 'hidden' fees netted from the returns as well as fees paid to investment consultants. ${ }^{11}$ External investment costs also include the costs for internal staff whose sole responsibility is overseeing the external managers.

Regressions for total costs in Table 3.5 (columns 1-3) indicate that larger pension funds realize scale advantages in their investment costs, but only after controlling for the percentage allocation to the most expensive asset class of alternative assets in columns (2) and (3). Focusing on column (3), a one standard deviation increase in the log of the pension fund holdings reduces the costs by some 4.4 basis points $(1.464 * 4.816)$, when controlling also for investment style, percentage allocations to fixed income and alternative assets, year and fund-fixed effects.

Unsurprisingly, allocations to active and externally managed mandates increase the investment costs. For example, a 10 percentage points increase in the allocation to actively managed assets results in $1.8(0.1 * 18.130)$ basis points higher total costs.

In columns (4)-(6) we document economies of scale in investment costs on an asset class level. Pension funds that invest more assets in equity, fixed income and alternatives obtain lower costs in every asset class. The economies of scale are especially strong in alternative assets, where a one unit increase in the log of assets results in 111 basis points lower investment costs. In line with the results for total costs, a greater allocation to actively managed mandates and external managers results in higher investment costs for equity and fixed income assets. For alternative assets, an allocation to fund-of-funds results in substantially higher costs. For example, in column (6), a 10 percent points increase in the allocation to fund-of-funds results in 48 basis points $(0.1 * 478.236)$ increase in the investment costs in alternative assets.

Bauer et al. (2010) also document a negative relationship between fund size and costs for investing in U.S. equities. Andonov, Eichholtz, and Kok (2013) find cost economies of scale in real estate investments of U.S., Canadian, European and Australian funds. This negative relationship is robust to the investment style, i.e. it is not driven by the higher proportion of passive and internal investments among larger funds. Larger funds are able to negotiate lower fees for external mandates and organize more cost-efficient internal mandates. We find that the negative relationship between fund size and costs exists on a total fund level as well as within all asset classes. Summarizing, we document that larger pension funds realize strong scale

\footnotetext{
${ }^{11}$ The exception is that for private equity and real estate the performance fees, carried interest and rebates are subtracted directly from the returns and are not incorporated in the costs figures. Hence, the costs estimations for these alternative assets usually include only the management fees and understate the total investment costs. However, the returns even for these alternative assets are net of both management and performance fees.
} 
advantages in their investment costs. On the other hand, greater active management, external management and allocation to fund-of-funds considerably increase the overall investment costs. In section 5.6.2, we will consider whether the scale advantage in costs is translated into higher net performance.

Table 3.5: Costs regressions

This table reports the results of pooled panel regressions of the pension fund investment costs. Regressions (1), (2) and (3) report the results of pooled panel regressions of the total investment costs. In models (4)-(6) we use equity, fixed income and alternatives investment costs as dependent variables. Alternative assets include investments in real estate, private equity, hedge funds, tactical asset allocation, infrastructure, commodities and natural resources. As independent variables, we include the log of pension fund assets in millions of dollars (LogSize), and the percentage allocations to externally (\%Ext) and actively (\%Act) managed mandates. When analyzing the alternatives costs, we also include the percentage of assets allocated to fund-of-funds (\%FoF) as independent variable. In models (4)-(6), LogSize refers to the logarithm of holdings in the particular asset class. In models (2) and (3) we control for the percentage allocation to alternative assets (\%Alternatives), whereas in model (3) we also add the percentage allocation to fixed income assets (\%Fixed income) as independent variable. In the pooled panel regressions we include with year dummies and fund fixed effects. All regressions use robust standard errors clustered by fund. We report standard errors in brackets and significance levels with *,** and ***, which correspond to $0.10,0.05$ and 0.01 , respectively.

\begin{tabular}{|c|c|c|c|c|c|c|}
\hline & \multicolumn{6}{|c|}{ Dependent variable: Investment costs in basis points } \\
\hline & $\begin{array}{l}\text { Total costs } \\
\text { (1) }\end{array}$ & $\begin{array}{l}\text { Total costs } \\
\text { (2) }\end{array}$ & $\begin{array}{l}\text { Total costs } \\
\text { (3) }\end{array}$ & $\begin{array}{l}\text { Equity } \\
\text { (4) }\end{array}$ & $\begin{array}{l}\text { Fixed income } \\
\text { (5) }\end{array}$ & $\begin{array}{c}\text { Alternatives } \\
\text { (6) }\end{array}$ \\
\hline LogSize & $\begin{array}{c}-2.430 \\
{[3.343]}\end{array}$ & $\begin{array}{l}-4.411^{* *} \\
{[2.113]}\end{array}$ & $\begin{array}{l}-4.816^{* *} \\
{[2.196]}\end{array}$ & $\begin{array}{c}-4.053^{* *} \\
{[1.609]}\end{array}$ & $\begin{array}{l}-5.119^{* *} \\
{[2.189]}\end{array}$ & $\begin{array}{c}-111.023^{* *} \\
{[45.989]}\end{array}$ \\
\hline$\%$ Act & $\begin{array}{c}29.086^{* * *} \\
{[5.965]}\end{array}$ & $\begin{array}{c}17.348^{* * *} \\
{[3.528]}\end{array}$ & $\begin{array}{c}18.130^{* * *} \\
{[3.594]}\end{array}$ & $\begin{array}{c}26.717^{* * * *} \\
{[2.052]}\end{array}$ & $\begin{array}{c}8.223^{* * *} \\
{[2.433]}\end{array}$ & \\
\hline$\%$ Ext & $\begin{array}{l}13.967^{*} \\
{[8.410]}\end{array}$ & $\begin{array}{l}11.291^{* *} \\
{[4.845]}\end{array}$ & $\begin{array}{l}9.823^{* *} \\
{[4.402]}\end{array}$ & $\begin{array}{c}15.219^{* * *} \\
{[5.206]}\end{array}$ & $\begin{array}{c}14.669^{* * *} \\
{[3.380]}\end{array}$ & $\begin{array}{c}120.638^{* *} \\
{[51.442]}\end{array}$ \\
\hline$\% \mathrm{FoF}$ & & & & & & $\begin{array}{l}478.236^{* * *} \\
{[148.984]}\end{array}$ \\
\hline$\%$ Alternatives & & $\begin{array}{c}123.615^{* * *} \\
{[9.579]}\end{array}$ & $\begin{array}{c}118.675^{* * *} \\
{[10.341]}\end{array}$ & & & \\
\hline$\%$ Fixed income & & & $\begin{array}{c}-14.845^{* *} \\
{[5.762]}\end{array}$ & & & \\
\hline Year dummies & Yes & Yes & Yes & Yes & Yes & Yes \\
\hline Fund fixed effects & Yes & Yes & Yes & Yes & Yes & Yes \\
\hline Observations & 3,342 & 3,342 & 3,342 & 3,325 & 3,329 & 2,845 \\
\hline R-squared & 0.809 & 0.878 & 0.880 & 0.868 & 0.607 & 0.812 \\
\hline
\end{tabular}

\subsection{The performance of pension funds}

In this section, we discuss whether asset allocation, market timing and security selection decisions result in outperformance or underperformance of pension funds. We first analyze the performance on a fund level and then look separately at the performance in equity, fixed income and alternative assets. Our focus is on the changes in asset allocation, market timing and security selection return components as defined previously. 


\subsubsection{Risk-adjusted performance at the pension fund level}

In Figure 3.5, we show the average total returns and the three components at the (aggregated across asset classes) pension fund level. Security selection returns (the fourth bar in any given year) exhibit substantially higher volatility as compared to changes in asset allocation and market timing returns.

Table 3.6 indicates that U.S. pension funds on average obtain positive returns from their active asset management decisions. For the total return and for each component of active management, we first run a random coefficient regression with just a constant (columns 1, 4, 7 and 10). Next, we estimate random coefficient models that include multiple factors to assess whether the outperformance remains after risk-adjusting the returns. This adjustment is important because benchmarks are chosen (and reported) by the funds themselves, such that funds could potentially choose benchmarks that are relatively easy to beat. The standard model we employ includes five factors, namely the standard three Fama-French factors (market, size and value) augmented with the Pastor and Stambaugh (2003) traded liquidity factor and the excess return on a fixed income market index. We compare results using this baseline 5-factor model with using a 6-factor model that also includes the Carhart (1997) momentum factor. Results in Table 3.6 show the annual alpha and beta coefficients on these factors, plus the root mean squared error (RMSE) of the residuals. The robustness of our risk-adjusted results can be checked by comparing Appendix Table A.2 with Table 3.6, where we include only pension funds with a higher number of observations per fund in the regressions.

The results in column (1) show that pension funds obtain a positive return of 57 basis points at the total fund level from their active asset management decisions before risk-adjusting. After risk-adjusting, their total return increases to 89 basis points. The total return becomes insignificantly positive after controlling for momentum in column (3). However, if we include only funds with a higher number of observations, for which we can estimate risk loadings more accurately, the total return is significantly positive and equal to 55 basis points (see Appendix Table A.2). The total return incorporates all three asset management decisions: changes in asset allocation, market timing and security selection. Next, we look at each return component separately.

Before risk-adjusting, changes in the asset allocation policy produce an insignificant return of 5.2 basis points. After risk-adjusting (column 5), the changes in asset allocation policy deliver a significant positive alpha of 25 basis points per year. Inclusion of the momentum factor (column 6) increases the estimated asset allocation alpha of U.S. funds to 30 basis points per year. This suggests that changes in target weights are not made in order to capture asset class momentum. Positive returns from the changes in asset allocation policy over time are due to changes in policy weights across broader asset classes over time. For example, funds on average increased their policy allocation to private equity, hedge funds and other alternative assets at the expense of fixed income and equity. 


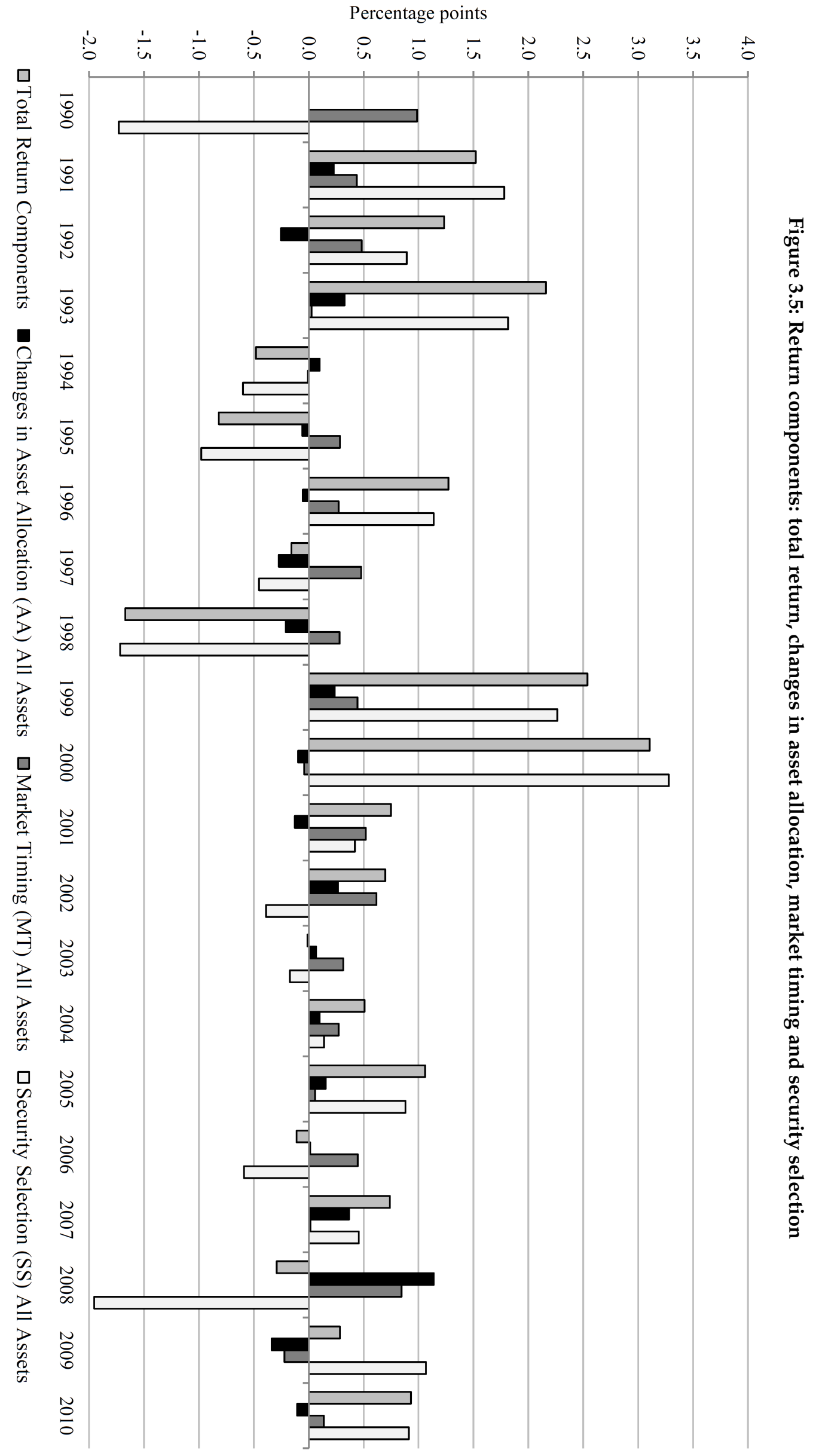




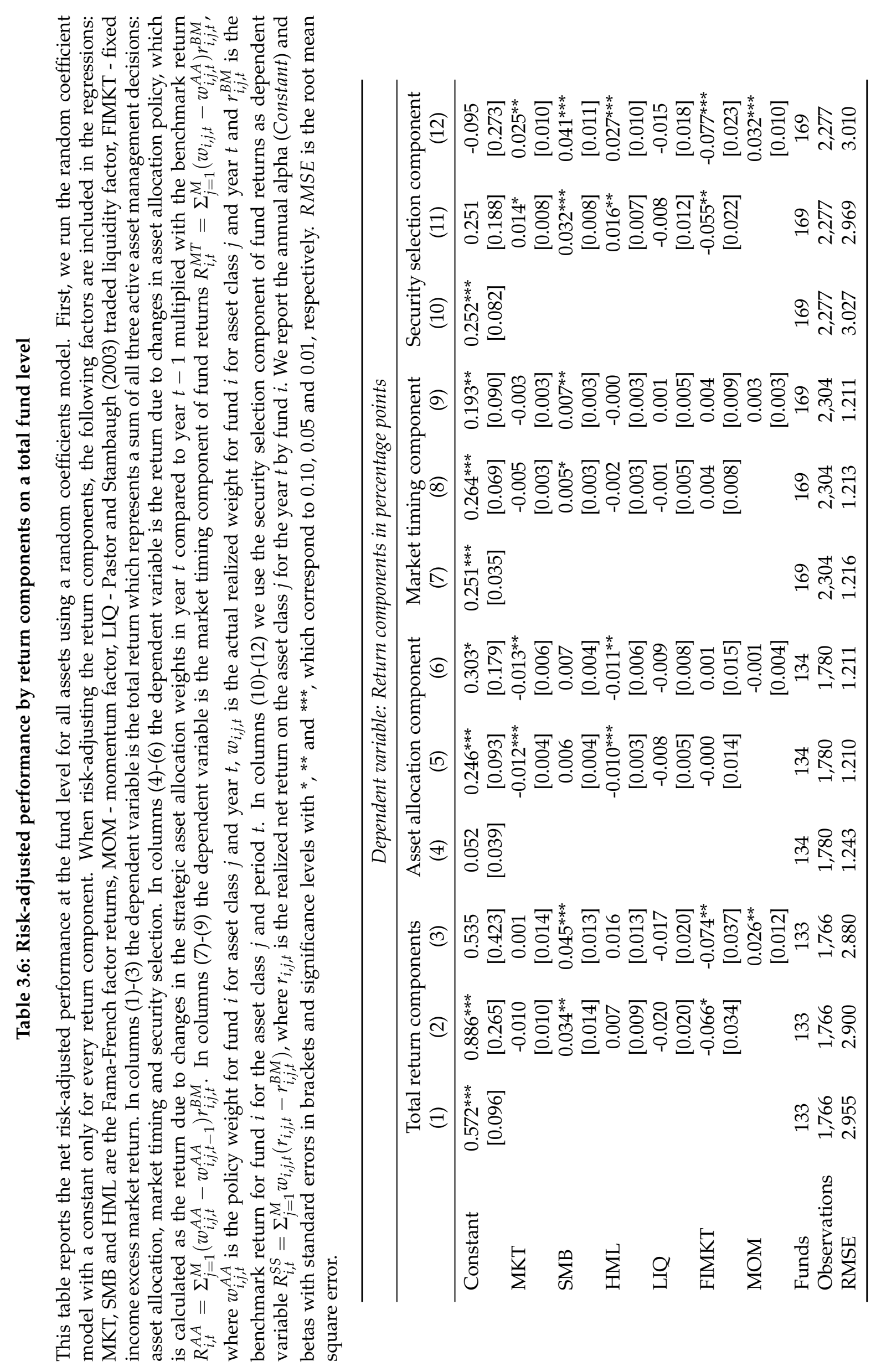


In columns (7)-(9) of Table 3.6, we find that market timing delivers about 25 basis points return per year before risk-adjusting. This is not materially affected by risk-adjusting with the 5and 6-factor models. The beta coefficients indicate that pension funds, on average, do not systematically overweight a particular style. There is an economically small positive marginally significant coefficient on the $S M B$ factor, but all other coefficients are statistically indistinguishable from zero. These results confirm the findings in Table 3.3, as the time averages of the mean differences for all asset classes are close to zero. However, Table 3.3 shows that pension funds' actual weights fluctuate substantially around policy weights. The results in Table 3.6 show that these fluctuations co-vary positively with benchmark returns, evidenced by the positive coefficient of the constant, indicating market timing skill.

The random coefficient model results for security selection (i.e., net benchmark-adjusted returns) show positive abnormal returns of 25 basis points per year from security selection (column 10). However, after risk-adjusting (column 11), security selection does not deliver a significant alpha. Once we add the momentum factor, the performance becomes even (though insignificantly so) negative: -9 basis points per year. These results indicate that momentum trading strategies on average deliver around 35 basis points annually. ${ }^{12}$

Overall, our paper provides clear evidence that pension funds obtain positive alphas from intentional changes in strategic asset allocation and market timing (or tactical asset allocation) decisions. The insignificantly negative security selection alpha (after controlling for momentum) offsets part of the positive returns from strategic asset allocation and market timing. These results suggest that pension funds have most expertise in dynamically maneuvering between various asset classes, rather than in security selection or identifying superior active managers for given asset classes.

\subsubsection{Market timing returns}

In Table 3.6, we document that pension funds obtain positive returns from market timing, i.e. from overweighting or underweighting particular asset classes, relative to the target weights in that year. In this section, we examine the sources of positive market timing returns in greater detail. First, we distinguish between market timing returns due to market movements (not rebalancing) versus performing resulting from active rebalancing decisions. Second, we examine the market timing returns within the two main asset classes of equity and fixed income, where funds can rebalance across multiple domestic, international and global sub-asset classes.

In Table 3.7, we distinguish between passive market timing and active market timing. Passive market timing can be interpreted as the performance when not rebalancing the portfolio, i.e. letting the portfolio drift towards or away from the strategic allocation weights depending on the benchmark returns. Active market timing can be interpreted as intentional deviations

\footnotetext{
${ }^{12}$ Controlling for momentum has even stronger effect on the security selection returns if we focus only on the 1990-2008 period. When examining only this shorter time period the security selection alpha is significantly negative and equal to -105 basis points after controlling for momentum factor. The momentum factor has weaker effect when adding the last two years of our sample period, because in 2009 this factor has an extreme negative return of -83.29 percent.
} 


\section{Table 3.7: Market timing returns}

In Panel A we split the market timing return into two parts. The passive market timing return component captures the returns due to market movement. The active market timing component captures the returns dues to active rebalancing. In Panel B we estimate the market timing alphas within equity and fixed income assets. Within equity and fixed income assets, we can estimate the returns due to market timing, because both of them incorporate multiple asset classes. We risk-adjust the market timing returns within equity for MKT, SMB, HML, LIQ and MOM. We risk-adjust the market timing returns within fixed income for MKT, FIMKT, HY and OPTION. We report the annual alpha with standard errors in brackets and significance levels with *,** and ${ }^{* * *}$, which correspond to $0.10,0.05$ and 0.01 , respectively. RMSE is the root mean square error.

\begin{tabular}{|c|c|c|c|c|c|c|c|c|}
\hline & \multicolumn{4}{|c|}{ Panel A: Two market timing components } & \multicolumn{4}{|c|}{ Panel B: Market timing return per asset class } \\
\hline & \multicolumn{2}{|c|}{ Passive market timing } & \multicolumn{2}{|c|}{ Active market timing } & \multicolumn{2}{|c|}{ MT within equity } & $\begin{array}{l}\text { MT wit } \\
\text { (7) }\end{array}$ & $\begin{array}{l}\text { ixed income } \\
\text { (8) }\end{array}$ \\
\hline Constant & $1.080^{* * *}$ & $1.300^{* * * *}$ & $-0.842^{* * *}$ & $-1.055^{* * *}$ & $0.224^{* * * *}$ & $0.208^{* * *}$ & 0.026 & 0.011 \\
\hline & {$[0.063]$} & {$[0.208]$} & [0.045] & {$[0.138]$} & {$[0.038]$} & {$[0.067]$} & {$[0.024]$} & [0.034] \\
\hline MKT & & $-0.033^{* * * *}$ & & $0.026^{* * *}$ & & 0.004 & & -0.003 \\
\hline & & {$[0.007]$} & & {$[0.005]$} & & {$[0.004]$} & & {$[0.003]$} \\
\hline FIMKT & & $0.069^{* * * *}$ & & $-0.068^{* * *}$ & & & & 0.008 \\
\hline & & {$[0.019]$} & & {$[0.013]$} & & & & [0.009] \\
\hline SMB & & $0.011^{* *}$ & & -0.000 & & 0.003 & & \\
\hline & & [0.006] & & [0.005] & & {$[0.004]$} & & \\
\hline HML & & $-0.022^{* * * *}$ & & $0.020^{* * *}$ & & 0.003 & & \\
\hline & & {$[0.007]$} & & {$[0.004]$} & & [0.002] & & \\
\hline LIQ & & -0.014 & & $0.013^{* *}$ & & 0.002 & & \\
\hline & & [0.010] & & [0.005] & & [0.005] & & \\
\hline MOM & & $-0.020^{* * * *}$ & & $0.022^{* * *}$ & & -0.002 & & \\
\hline & & [0.006] & & {$[0.004]$} & & [0.004] & & \\
\hline HY & & & & & & & & $\begin{array}{l}0.011^{* *} \\
{[0.005]}\end{array}$ \\
\hline OPTION & & & & & & & & -0.000 \\
\hline & & & & & & & & [0.024] \\
\hline Funds & 134 & 134 & 134 & 134 & 191 & 191 & 210 & 210 \\
\hline Observations & 1,780 & 1,780 & 1,780 & 1,780 & 2,447 & 2,447 & 2,571 & 2,571 \\
\hline RMSE & 1.899 & 1.758 & 1.376 & 1.187 & 1.184 & 1.180 & 1.210 & 1.187 \\
\hline
\end{tabular}

from strategic asset allocation weights, i.e. active rebalancing of the portfolio with actual trading. Such active rebalancing can be also be due to guidelines where funds define ex ante in which range individual asset class weights are allowed to drift (bandwidths).

Panel A of Table 3.7 shows that U.S. pension funds could have obtained substantially high alphas from market timing if they would have not rebalanced their portfolios. They would have obtained passive market timing returns of 108 basis points before and 130 basis points after risk-adjusting. The large positive alphas on the passive market timing component indicate that the market timing returns of pension funds in Table 6 are mainly due to market-wide movements, or the phenomenon that past asset class returns tend to positively predict future returns in the same asset class, termed 'time series' momentum by Moskowitz et al. (2012). However, pension funds cannot fully exploit time series momentum, as they are typically bound by the bandwidths stated in their investment guidelines. Columns (3) and (4) document that pension funds underperform when trying to actively rebalance money across asset classes, 84 basis points before and 106 basis points after risk-adjusting. The net (or aggregated) effect of passive and active market timing can be found in Table 6 ( 25 basis points before and 19 after 
risk adjusting).

In Panel B of Table 3.7, we present the market timing results within equity and fixed income, which can be measured only when funds invest in at least two categories within equity or fixed income assets. ${ }^{13}$ Results in columns (5) and (6) indicate that pension funds can create abnormal returns from timing their allocation decisions within equity investments. Before risk-adjusting, U.S. pension funds can beat their ex ante stated equity benchmarks by about 22 basis points per year using market timing. After risk-adjusting and controlling for momentum, the alpha remains 21 basis points. As the market timing results at the total fund level produced about 26 basis points alpha per year, this implies that a large part of the abnormal market timing return is due to timing the performance across various equity classes (such as moving from domestic equity to international equity), rather than timing the performance across broader asset classes (such as moving from equity to fixed income or real estate).

In columns (7) and (8), we examine the fixed income market timing returns. Our results indicate that market timing within fixed income assets does not deliver any abnormal returns. Before and after risk-adjusting, U.S. pension funds are not able to generate abnormal returns from timing their allocations between various fixed income categories.

\subsubsection{Security selection returns per asset class}

Table 3.8 presents the results for security selection returns separately for equity, fixed income and alternative assets. In columns (1)-(3), we focus on the security selection, i.e. net benchmarkadjusted returns within equity before and after risk-adjusting. We risk-adjust the security selection returns for exposure to MKT, SMB, HML and LIQ factors. In column (3) we also add momentum. In line with our findings at the total fund level, pension funds on average demonstrate security selection skills within equity, but only when not adjusting for momentum. Before risk-adjusting, the average fund beats its equity benchmarks by about 23 basis points using security selection. After controlling for risk factors, the alpha from random coefficient regressions on equity net benchmark-adjusted returns equals 37 basis points and is still significant at the $10 \%$ level. However, when we also control for momentum, the alpha from security selection becomes insignificant at 7 basis points. Again, these results show that the momentum factor plays an important role in explaining pension fund security selection returns.

In columns (4) and (5), we examine security selection skills within fixed income assets. Using a random-coefficient model, we risk-adjust the fixed income net benchmark-adjusted returns for MKT, FIMKT, HY and OPTION. Pension funds are able to outperform their benchmarks within fixed income assets before risk-adjusting (column 4). However, the results in column (5) show that alphas disappear after controlling for the high yield spread and option elements in fixed income returns. In Figure 3.6, we also observe that security selection returns within fixed income became much more volatile in the last three years of our sample period

\footnotetext{
${ }^{13}$ For example, based on the strategic policy a pension fund should invest in 50\% in U.S. equity, 30\% in EAFE equity and $20 \%$ in Emerging markets equity. If the actual allocation percentages are different from the abovementioned policy weights, that fund will generate returns from market timing within equity, measured as the difference between actual and policy weights times the benchmark returns. However, it does not capture returns from overweighting certain industries within U.S. equity mandate.
} 
(2008-2010). This trend closely matches the returns on high yield assets. Overall, pension funds are not able to obtain positive abnormal returns in fixed income assets after risk-adjusting.

\section{Table 3.8: Security selection returns}

In this table we analyze the security selection (net benchmark-adjusted) returns on an individual asset class level. For equity and fixed income assets, we run a random coefficient model with a constant only and we also risk-adjust the returns. We risk-adjust the security selection returns within equity using the following factors: MKT, SMB and HML - the Fama-French factor returns, MOM - momentum factor and LIQ - Pastor and Stambaugh (2003) traded liquidity factor. Within fixed income, security selection returns are risk-adjusted using the following factors: FIMKT - fixed income excess return, HY - high yield spread, OPTION - option-like characteristics of mortgage securities returns and MKT - equity excess return. For alternative assets, security selection returns (net benchmark-adjusted returns) we just run a random coefficient model with a constant. Alternative assets include investments in tactical asset allocation, commodities, natural resources, real estate, infrastructure, private equity and hedge funds. We report the annual alpha with standard errors in brackets and significance levels with *** and ***, which correspond to $0.10,0.05$ and 0.01 , respectively. RMSE is the root mean square error.

\begin{tabular}{|c|c|c|c|c|c|c|}
\hline \multicolumn{7}{|c|}{ Dependent variable: security selection (net benchmark-adjusted returns) per asset class } \\
\hline & $\begin{array}{l}\text { Equity } \\
\text { (1) }\end{array}$ & $\begin{array}{l}\text { Equity } \\
\text { (2) }\end{array}$ & $\begin{array}{l}\text { Equity } \\
\text { (3) }\end{array}$ & $\begin{array}{c}\text { Fixed income } \\
(4)\end{array}$ & $\begin{array}{l}\text { Fixed income } \\
\text { (5) }\end{array}$ & $\begin{array}{c}\text { Alternatives } \\
\text { (6) }\end{array}$ \\
\hline Constant & $\begin{array}{l}0.233^{* *} \\
{[0.095]}\end{array}$ & $\begin{array}{l}0.366^{*} \\
{[0.212]}\end{array}$ & $\begin{array}{c}0.071 \\
{[0.296]}\end{array}$ & $\begin{array}{c}0.330^{* * *} \\
{[0.080]}\end{array}$ & $\begin{array}{c}-0.061 \\
{[0.103]}\end{array}$ & $\begin{array}{c}-0.672 \\
{[0.724]}\end{array}$ \\
\hline MKT & & $\begin{array}{l}-0.016^{*} \\
{[0.009]}\end{array}$ & $\begin{array}{l}-0.010 \\
{[0.010]}\end{array}$ & & $\begin{array}{c}0.012 \\
{[0.008]}\end{array}$ & \\
\hline FIMKT & & & & & $\begin{array}{c}0.041^{*} \\
{[0.025]}\end{array}$ & \\
\hline SMB & & $\begin{array}{c}0.063^{* * *} \\
{[0.012]}\end{array}$ & $\begin{array}{c}0.073^{* * * *} \\
{[0.013]}\end{array}$ & & & \\
\hline HML & & $\begin{array}{c}0.002 \\
{[0.009]}\end{array}$ & $\begin{array}{c}0.012 \\
{[0.010]}\end{array}$ & & & \\
\hline LIQ & & $\begin{array}{l}-0.022 \\
{[0.016]}\end{array}$ & $\begin{array}{l}-0.022 \\
{[0.019]}\end{array}$ & & & \\
\hline MOM & & & $\begin{array}{l}0.022^{* *} \\
{[0.010]}\end{array}$ & & & \\
\hline HY & & & & & $\begin{array}{c}0.066^{* * *} \\
{[0.016]}\end{array}$ & \\
\hline OPTION & & & & & $\begin{array}{c}0.036 \\
{[0.066]}\end{array}$ & \\
\hline Funds & 191 & 191 & 191 & 211 & 207 & 343 \\
\hline Observations & 2,412 & 2,412 & 2,412 & 2,530 & 2,513 & 2,576 \\
\hline RMSE & 3.598 & 3.497 & 3.519 & 3.220 & 2.758 & 15.499 \\
\hline
\end{tabular}

Finally, we investigate the security selection skill of pension funds in alternative assets. Alternative assets include investments in external global tactical asset allocation (GTAA) mandates, commodities, natural resources, real estate, infrastructure, private equity and hedge funds. Results in column (6) of Table 3.8 indicate that pension fund benchmark-adjusted performance in all alternative assets together is negative, but insignificant. ${ }^{14}$

\footnotetext{
${ }^{14}$ This paper focuses on overall pension fund performance, such that we combine all alternative assets together as this group of assets represents only small part of total fund holdings, on average around 10 percent. We leave detailed analysis of pension fund performance in individual alternative asset classes, like private equity and hedge funds, for future research.
} 


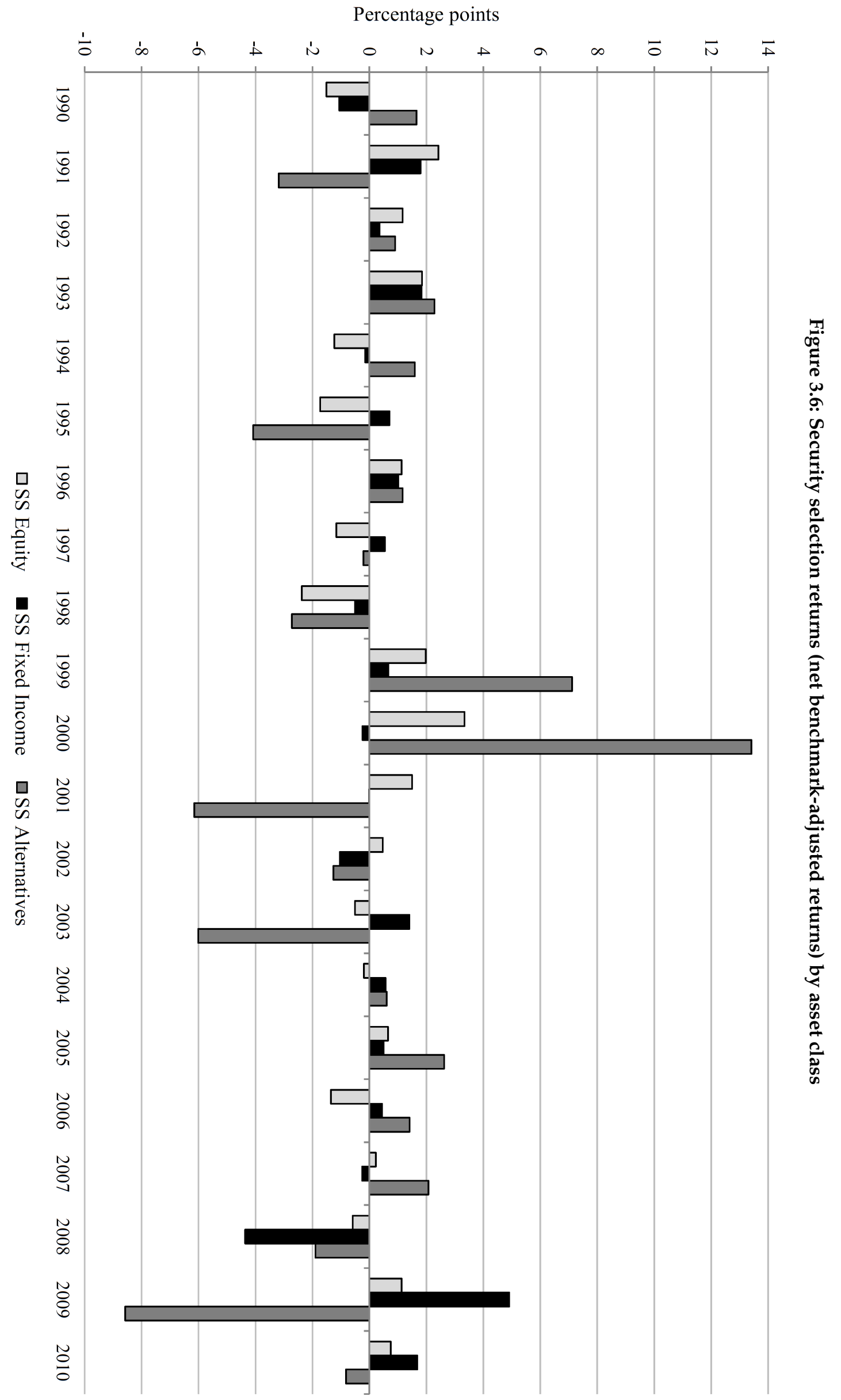




\subsection{Pension fund characteristics and performance}

In this section, we relate the risk-adjusted total return, asset allocation, market timing and security selection alphas to certain characteristics of pension funds using Fama-MacBeth regressions. Specifically, we examine whether differences in performance are associated with fund (asset class) size, liquidity, investment costs and investment style (referring to whether assets are managed internally or externally, and passively or actively). Fund size reflects the total size of the pension fund holdings, which is a sum of holdings in all asset classes, while 'asset class size' reflects the size of the holdings in a particular asset class, like equity or fixed income. The analysis again is first conducted on a fund level and later by individual asset class.

Table 3.9 presents the results for the total return and its three components (asset allocation, market timing and security selection returns). Estimation consists of two steps. In the first step, we risk-adjust returns using a six factor model that includes $M K T, S M B, H M L, L I Q$, FIMKT and MOM. In the second step, we augment the alphas with the error terms retrieved from the first step and run Fama-MacBeth regressions, while correcting for autocorrelation and heteroskedasticity using Newey-West standard errors with three lags.

When analyzing the total return, which represents the sum of all three return components, pension fund size (LogSize) is negatively related to performance, especially for funds whose investments have exposure to systematic liquidity risk. Columns (2) and (3) indicate that a one unit increase in the LogSize (i.e. doubling the fund size) results in 11-15 basis points lower performance. The interaction between fund size and the fund's liquidity beta (i.e. the exposure to the Pastor-Stambaugh traded liquidity factor) is negative and significant. Based on column (3), increasing liquidity by lowering the liquidity beta by 10 percentage points, would be associated with an improvement of the alpha of funds at the 75th size percentile by 16 basis points per year $(=-0.1 *-1.539 *(\ln [8582]-\ln [3025])$ more than the improvement of the alpha of a fund at the median size percentile. This result shows that larger pension funds face diseconomies of scale when redesigning their strategic asset allocation policy, timing the market in multiple asset classes and deviating from the benchmarks by active security selection.

Pension funds using more external managers realize lower total returns from asset management decisions. Column (3) shows that a 10 percentage points increase in the proportion of externally managed assets is associated with 5.4 basis points lower annual total returns. This may be partly due to lower investment costs for internal management (see Table 3.5). In addition, Lakonishok et al. (1992) suggest that external management may create potential agency conflicts or that incentives of internal managers may be better aligned with those of the overall pension fund.

When examining the return component separately, we find that fund size is not related directly to the abnormal returns from changes in asset allocation policy. However, the interaction between fund size and the fund's liquidity beta (i.e. the exposure to the Pastor-Stambaugh traded liquidity factor) is negative and significant. The interaction coefficient equals -1.991 in column (6) of Table 3.9. Economically, this coefficient means that increasing liquidity by lowering the liquidity beta by 10 percentage points, would be associated with an improvement of the 


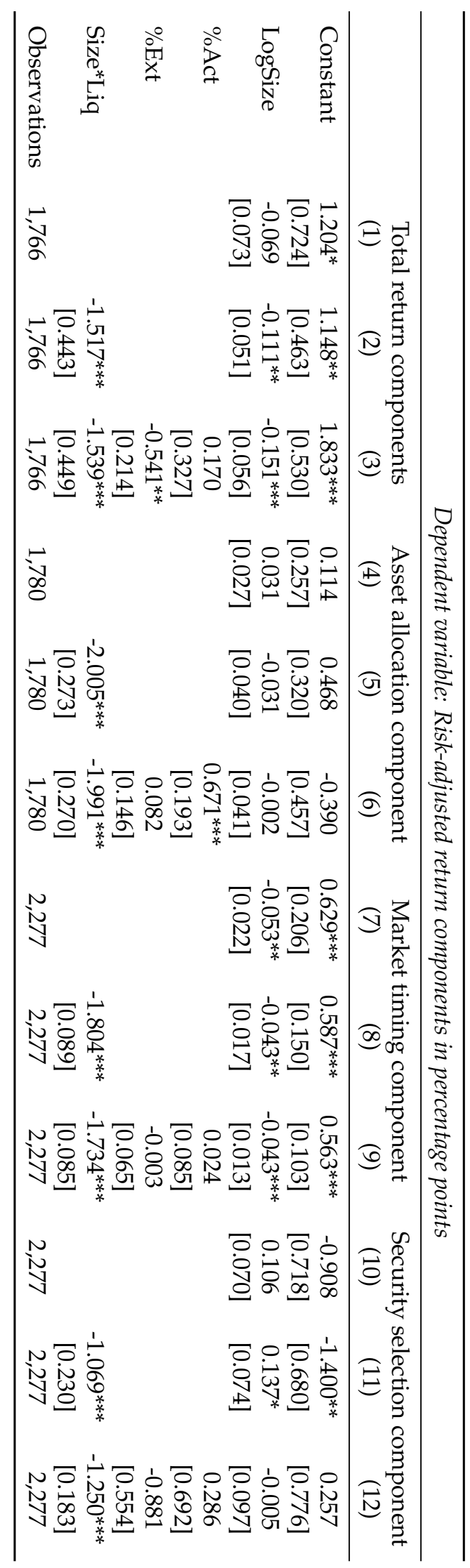

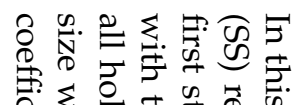

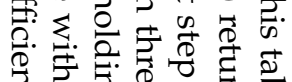
के

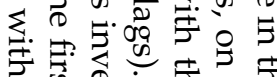

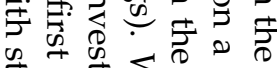
这

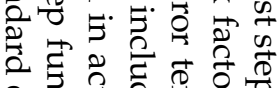
응 o to

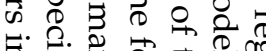

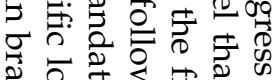

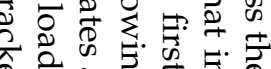

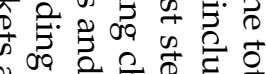
응

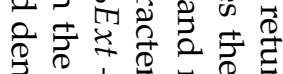

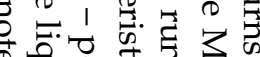
क. 产. 造

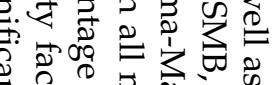

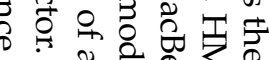

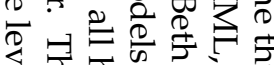
कृ

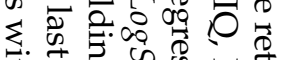

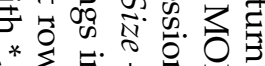

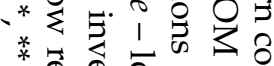

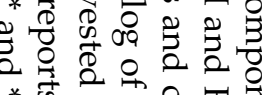
\% * 5 正 $\sum 0 \times$ 융제

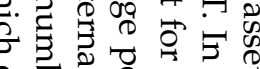
3 诃 (3)

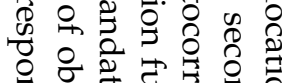

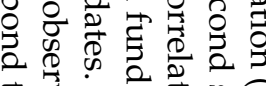

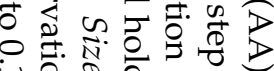
o영 ㄷ. ‥

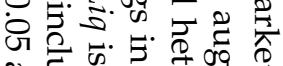

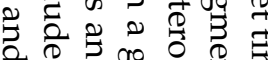

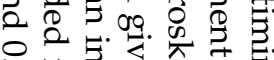

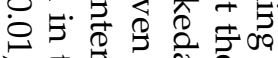

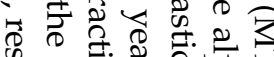

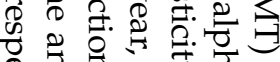
晒 . ० 1 \%

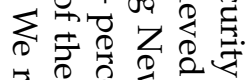
कृ

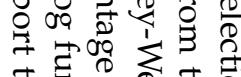

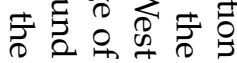


alpha of funds at the $75^{\text {th }}$ size percentile by 21 basis points per year $(=-0.1 \times-1.991 \times(\ln [8582]-$ $\ln [3025])$ more than the improvement of the alpha of a fund at the median size percentile. This finding implies that larger funds face significant liquidity limitations when redesigning their strategic asset allocation: shifts in the strategic asset allocation towards more illiquid assets hurt the performance of larger funds relative to smaller funds.

In columns (7)-(9) of Table 3.9, we consider the relation between market timing returns and pension fund characteristics. Fund size is negatively related to market timing abilities. Additionally, the interaction between fund size and the fund's liquidity beta is negative and highly significant. In columns (8) and (9), a one-unit increase in LogSize, i.e. doubling the fund size, reduces the market timing returns by 4.3 basis points. The interaction effect of size and liquidity has an even stronger economic effect on the market timing returns.

In the last part of Table 3.9, we analyze the relation between fund characteristics and the security selection component (net benchmark-adjusted returns). At the fund level, U.S. fund security selection performance is unrelated to fund size (column 12). Again, the security selection performance of larger funds seems particularly constrained by liquidity, as evidenced by the large, negative coefficients on the interaction between fund size and the liquidity beta. The interaction coefficient equals -1.250 in column 12 of Table 3.9. Economically, this coefficient means that increasing liquidity by lowering the liquidity beta by 10 percentage points, would be associated with an improvement of the alpha of funds at the $75^{\text {th }}$ size percentile by 13 basis points per year $(=-0.1 *-1.250 *(\ln [8582]-\ln [3025])$ more than the improvement of the alpha of a fund at the median size percentile.

We also look at the influence of pension fund characteristics on performance on a lower level of aggregation, or how concentration, size, liquidity, costs and investment style relate to the performance in individual asset classes. Appendix Table A.3 shows the results for pension fund security selection performance within equity. Funds with higher allocations to equity (as a percentage from total assets) have better performance in equity. Based on column (3), an increase in the allocation to equity of 10 percent points results in 21 basis point better net benchmark-adjusted returns in equity. The effect of the concentration in equity assets on the performance of equity is even stronger after risk-adjusting. However, our results in columns (5) and (7) indicate that the relation between concentration in equity and performance becomes insignificant, once we control for the liquidity-size interaction. This suggests that larger funds face liquidity constraints when investing in equity and cannot allocate a substantial share of their assets to equity investments. It likewise suggests that funds with high equity allocations tend to deviate from their benchmark by selecting relatively illiquid stocks, which only results in better performance if the funds are relatively small.

We also study the relation between pension fund characteristics and their performance in fixed income assets. In unreported results, we do not find a significant effect of the allocation to fixed income assets, size of the holdings or investment style on the cross-sectional differences in fixed income performance. Compared to equity, the influence of pension fund characteristics has a much lower effect on the fixed income performance. 
Next, we examine whether larger pension funds consider the liquidity-related diseconomies of scale when designing their investment approach. We split the pension funds into tertiles based on their percentage of assets allocated to actively managed mandates. In the first tertile, the median percentage of actively managed assets is 59 percent, whereas in the second and third tertile this precentage is 80 and 98 percent of the total assets, respectively. Pension fund size plays an important role when designing the investment approach. In line with our evidence on liquidity-diseconomies of scale, larger pension funds manage greater percentages of their assets passively. The median size of a pension fund belonging to the tertile with lowest active management is $\$ 10.37$ billion, while the median size of the funds in the second and third tertile is $\$ 4.82$ and $\$ 4.05$ billion, respectively.

Table 3.10 compares the relation between size and performance for the tertiles with lowest and highest degree of active management. In columns (1) and (5) we show that pension funds in both tertiles obtain positive total returns after risk-adjusting. However, the size-liquidity interaction has a significantly different association with the performance across the two tertiles. In both tertiles, the interaction term has a negative coefficient, but the economic magnitude is significantly larger in the tertile with highest percentage of actively managed assets (coefficient of $-2.269^{* * *}$ ) compared to the passively managed tertile (coefficient of $-0.887^{* *}$ ). Here, it is important to note that the liquidity betas themselves are not significantly different across the tertiles (average coefficient of $-0.041,-0.022$ and -0.029 in the three respective tercile groups).

In columns (4) and (8), we include dummy variables capturing the smallest and largest pension funds. These dummy variables are obtained by independently sorting the fund into quartiles based on their size, such that the Small (Large) dummy equals one for funds in the smallest (largest) quartile size group, and zero otherwise. The median size of the small quartile is $\$ 1.3$ billion assets, while the median size of the funds in the large quartile is $\$ 34$ billion. In the more passively managed tertile, the Small and Large dummy variables are similar and insignificant. However, in the more actively managed tertile, the dummy variable capturing the largest funds is significantly negative and reduces substantially their risk-adjusted total return. The most actively managed group of funds thus has significantly greater size-induced liquidity constraints, and its funds that are in the largest quartile group underperform similarly sized funds with much less active management by about $62(=45.8+40.1-91.7+68.0)$ basis points a year, which difference is statistically significant at $5 \%$.

To sum up, we find that the economies of scale in pension fund costs do not materialize in better returns. Larger pension funds perform worse in all three components of active management if they invest in less liquid assets (i.e., that have exposure to systematic liquidity risk). Large funds seem to experience liquidity-related diseconomies of scale, including in their largest asset class, equity. Larger pension funds that are predominantly actively managed may have done better if they would have implemented a more passive approach. 
Table 3.10: Pension fund active management tertiles: size and performance

In this table we sort the pension funds into tertiles base on their percentage allocation to actively managed assets. Afterwards, we regress the total returns on a six factor model that includes the MKT, SMB, HML, LIQ, MOM and FIMKT. In the next step we augment the alphas retrieved from the risk-adjusting regressions with the error terms of the first step and run Fama-MacBeth regressions and correct for autocorrelation and heteroskedasticity (using Newey-West with three lags). We include the following characteristics in all models: LogSize - log of average pension fund holdings in a given year and Size $*$ Liq is an interaction term of the log fund size with the first step fund-specific loading on the liquidity factor. We also include two dummy variables Small and Large. These dummy variables are constructed by independently sorting the pension funds into four quartiles based on their assets under management. Small dummy refers to the pension funds belonging to the smallest size quartile, while Large captures the pension funds from the largest quartile. Columns (1)-(4) present the results for the tertile with the lowest percentage of actively managed assets. Columns (5)-(8) show the results for the tertile with the highest percentage of actively managed assets. The last row reports the number of observations included in the analysis. We report the coefficients with standard errors in brackets and denote significance levels with ${ }^{* * *}$ and ${ }^{* * *}$, which correspond to $0.10,0.05$ and 0.01 , respectively.

\begin{tabular}{|c|c|c|c|c|c|c|c|c|}
\hline & \multicolumn{4}{|c|}{ Tertile with the lowest percentage active } & \multicolumn{4}{|c|}{ Tertile with the highest percentage active } \\
\hline & (1) & $(2)$ & (3) & $(4)$ & (5) & $(6)$ & $(7)$ & (8) \\
\hline \multirow{2}{*}{ Constant } & $0.669^{* * * *}$ & 0.984 & $1.172^{* *}$ & $0.458^{*}$ & $0.811^{* * *}$ & 1.619 & -0.993 & $0.917^{* * *}$ \\
\hline & [0.178] & [0.854] & [0.519] & {$[0.278]$} & {$[0.238]$} & [1.463] & [0.974] & [0.226] \\
\hline \multirow[t]{2}{*}{ LogSize } & & -0.034 & -0.093 & & & -0.105 & 0.168 & \\
\hline & & [0.091] & {$[0.063]$} & & & [0.144] & [0.125] & \\
\hline \multirow[t]{2}{*}{ Size ${ }^{*}$ Liq } & & & $-0.887^{* *}$ & & & & $-2.269^{* * *}$ & \\
\hline & & & [0.396] & & & & [0.767] & \\
\hline \multirow[t]{2}{*}{ Small } & & & & 0.351 & & & & 0.023 \\
\hline & & & & [0.387] & & & & {$[0.761]$} \\
\hline \multirow[t]{2}{*}{ Large } & & & & 0.401 & & & & $-0.680^{* *}$ \\
\hline & & & & [0.379] & & & & [0.341] \\
\hline Observations & 596 & 596 & 596 & 596 & 582 & 582 & 582 & 582 \\
\hline
\end{tabular}

\subsection{Persistence in pension fund performance}

Previous sections showed that pension funds obtain positive returns from market timing and security selection, some of which remain significant even after risk-adjusting. If this is due to skill, an important robustness check is whether there is any persistence in pension fund performance. To answer this question we split pension funds into five quintiles based on either their market timing or their net security selection performance (after costs). We run an ordered logit model, where the dependent variable is the quintile ranking based on the performance in year $t+1$ and the main independent variable is the quintile ranking in year $t$. Marginal effects from the ordered logit model for every outcome (quintile ranking) are presented in Table 3.11. Panel A presents the results for market timing returns, whereas Panel B covers the persistence in security selection returns of U.S. funds.

Results indicate that funds are more likely to end up in a better performing quintile next year, if they belong to a better performing quintile already this year. Pension funds are also more likely to be ranked among the worst performers next year, if they performed relatively poorly this year. The persistence is observed in both market timing and security selection returns. For example, looking at U.S. funds market timing returns (Panel A), an increase in the quintile ranking from 3 to 4 reduces the probability of ranking among the worst performers 
in year $t+1$ by 3.3\%. Results in models (2), (3) and (4) show that the marginal effects of last year's ranking remain even after controlling for fund size, costs, and the percentage of assets managed actively and externally.

Table 3.11: Ordered logit: persistence in pension fund performance

This table presents the marginal effects after an ordered logit model. The dependent variable is the quintile ranking based on returns in year $t+1$ with 1 being lowest quintile ranking and 5 being the quintile with highest returns. The $L Y$ ranking independent variable is the quintile ranking in the previous year $t$. We also include the following variables: LogSize - log of average pension fund holdings in a given year, Costs - total fund costs, \%Act - percentage of all holdings invested in active mandates and \%Ext - percentage invested in external mandates. The marginal effects are estimated at the median values. In the ordered logit model we also add year dummy variables and cluster the standard errors by funds. Panel A presents the marginal effects for U.S. funds market timing returns and Panel B for U.S. funds security selection returns. The marginal effects are presented with their standard errors in brackets. We denote significance levels with ${ }^{*}{ }^{* *}$ and ${ }^{* * *}$, which correspond to $0.10,0.05$ and 0.01 , respectively.

\begin{tabular}{|c|c|c|c|c|c|c|c|c|}
\hline Ranking & Model 1 & Model 2 & & Model 3 & & Model 4 & & \\
\hline & LY ranking & LY ranking & LogSize & LY ranking & Costs & LY ranking & $\%$ Act & \%Ext \\
\hline \multicolumn{9}{|c|}{ Panel A: Market timing returns } \\
\hline \multirow[t]{2}{*}{1} & $-0.033^{* * * *}$ & $-0.033^{* * * *}$ & 0.003 & $-0.033^{* * * *}$ & $-0.067^{*}$ & $-0.032^{* * * *}$ & 0.017 & $-0.047^{*}$ \\
\hline & [0.009] & [0.009] & {$[0.006]$} & [0.009] & {$[0.036]$} & [0.009] & [0.034] & [0.029] \\
\hline \multirow[t]{2}{*}{2} & -0.009 & -0.009 & 0.001 & -0.009 & -0.018 & -0.009 & 0.005 & -0.014 \\
\hline & [0.006] & [0.006] & {$[0.002]$} & [0.006] & {$[0.016]$} & [0.006] & [0.011] & [0.013] \\
\hline \multirow[t]{2}{*}{3} & 0.007 & 0.006 & -0.001 & 0.006 & 0.013 & 0.006 & -0.003 & 0.008 \\
\hline & {$[0.006]$} & {$[0.006]$} & {$[0.001]$} & {$[0.006]$} & {$[0.013]$} & {$[0.006]$} & {$[0.006]$} & [0.009] \\
\hline \multirow{2}{*}{4} & $0.016^{* * *}$ & $0.016^{* * *}$ & -0.002 & $0.016^{* * * *}$ & $0.032^{*}$ & $0.016^{* * *}$ & -0.008 & $0.023^{*}$ \\
\hline & [0.003] & {$[0.003]$} & [0.003] & [0.003] & [0.017] & [0.003] & {$[0.016]$} & [0.014] \\
\hline \multirow[t]{2}{*}{5} & $0.020^{* * * *}$ & $0.020^{* * * *}$ & -0.002 & $0.020^{* * * *}$ & $0.041^{*}$ & $0.020^{* * * *}$ & -0.011 & 0.030 \\
\hline & {$[0.006]$} & {$[0.006]$} & {$[0.003]$} & {$[0.006]$} & {$[0.025]$} & {$[0.006]$} & {$[0.021]$} & [0.022] \\
\hline \multicolumn{9}{|c|}{ Panel B: Security selection returns } \\
\hline \multirow[t]{2}{*}{1} & $-0.017^{* * * *}$ & $-0.016^{* *}$ & $-0.014^{*}$ & $-0.017^{* * *}$ & 0.055 & $-0.017^{* *}$ & -0.004 & 0.049 \\
\hline & {$[0.005]$} & {$[0.008]$} & [0.007] & {$[0.006]$} & {$[0.035]$} & {$[0.008]$} & {$[0.031]$} & {$[0.036]$} \\
\hline \multirow[t]{2}{*}{2} & $-0.007^{* * * *}$ & -0.007 & -0.006 & $-0.007^{* * * *}$ & 0.023 & -0.006 & -0.002 & 0.019 \\
\hline & {$[0.003]$} & [0.005] & {$[0.004]$} & {$[0.003]$} & {$[0.014]$} & [0.005] & {$[0.012]$} & [0.017] \\
\hline \multirow[t]{2}{*}{3} & 0.001 & 0.002 & 0.001 & 0.002 & -0.005 & 0.002 & 0.001 & -0.006 \\
\hline & [0.002] & [0.006] & [0.006] & [0.002] & [0.009] & {$[0.006]$} & [0.004] & {$[0.020]$} \\
\hline \multirow[t]{2}{*}{4} & $0.009^{* * * *}$ & $0.008^{* * *}$ & $0.007^{* *}$ & $0.009^{* * * *}$ & -0.029 & $0.009^{* * * *}$ & 0.002 & -0.026 \\
\hline & [0.003] & [0.003] & [0.003] & [0.003] & {$[0.018]$} & [0.003] & {$[0.016]$} & {$[0.016]$} \\
\hline \multirow[t]{2}{*}{5} & $0.013^{* * * *}$ & $0.013^{*}$ & $0.011^{*}$ & $0.013^{* * * *}$ & $-0.043^{*}$ & $0.012^{*}$ & 0.003 & -0.036 \\
\hline & {$[0.004]$} & [0.007] & {$[0.006]$} & {$[0.004]$} & {$[0.026]$} & [0.007] & [0.023] & [0.026] \\
\hline
\end{tabular}

In Appendix Table A.4 we present the actual transition matrixes. The percentage of funds repeating as best performers is in all cases higher than the percentage of best performers of last year ending in one of the four lower quintiles this year. The same holds for the worst performing funds. We also look at the returns in year $t+1$ of funds ranked in the lowest and highest quintile in year $t$. Funds ranked in the top quintile have higher average returns in the following year than the funds ranked in the bottom quintile.

These persistence tests are performed directly on the benchmark-adjusted market timing and security selection returns. As we only have access to annual data, we cannot use the riskadjusted performance in these estimations. Hence, we do not test whether pension funds can persistently deliver abnormal returns, or estimate the effect of liquidity constraints on persis- 
tence. Nevertheless, these results show that certain pension funds are persistently better in outperforming their benchmarks using market timing and security selection.

\subsection{Conclusion}

After risk-adjusting and net of all costs, pension funds obtain a positive return of 89 basis points per year from their asset management decisions, i.e. compared to maintaining the strategic asset allocation policy from the previous year and investing in the benchmark. Pension funds are thus on average able to provide positive returns to their participants. To identify the sources of the positive total return, we decompose it into three active asset management components: asset allocation, market timing and security selection. For each of the three return components, pension funds are able to beat their benchmarks before and after risk-adjusting. Changes in asset allocation policy result in positive abnormal returns of 25 basis points per year. These abnormal returns are due to pension funds changing their asset allocation policy across broader asset classes over time, not to changes within equity or fixed income.

Market timing delivers a positive alpha of 26 basis points per year. This abnormal return is larger among smaller funds. Market timing alpha is completely due to passive market movements, i.e. the ability of pension funds to exploit 'time series' momentum by investing in multiple asset classes. Pension funds do not have active rebalancing skills. In addition, more than half of the alpha comes from market timing within different equity styles (such as domestic versus international stocks, and large versus small cap stocks). Overall, these results suggest that funds that try to stay as close as possible to their strategic asset allocation policy may miss market timing opportunities. If fund managers can obtain positive returns from the passive market movements due to time series momentum (see Moskowitz et al., 2012), as our results indicate, letting the actual weights deviate from the strategic weights and not rebalancing back immediately can in fact improve performance, in line with Sharpe (2010) idea of an 'adaptive asset allocation policy.'

Security selection delivers an insignificant return of 25 basis points per year after riskadjusting, which is driven by the momentum factor. Once we control for this factor, security selection delivers an insignificant negative alpha of -10 basis points per year.

Larger pension funds do not manage to transfer their lower investment costs into higher net returns. Rather, we document diseconomies of scale in pension fund performance. The diseconomies of scale are primarily apparent for funds investing in less liquid assets, as proxied by fund total return loadings on the traded systematic liquidity factor. As a result, the performance of large pension funds seems to be subject to size-induced liquidity limitations. These liquidity limitations related to size are significant in all three asset management components. Larger funds face liquidity constraints even when investing in public equity. Our results suggest that funds with high equity allocations tend to deviate from their benchmark by selecting relatively illiquid stocks, which only results in better performance if the funds are relatively small. Smaller pension funds obtain higher total returns and especially higher market timing returns. The better market timing returns of smaller funds can be explained by two effects. 
First, smaller funds can be regulated in a more flexible way with wider bandwidths that enable them to deviate further from their strategic asset allocation weights and exploit the across asset class momentum. Second, even if smaller pension funds have to rebalance to restore their strategic weights, such rebalancing has lower market impact.

Lastly, we find persistence in pension funds' ability to deliver higher market timing and security selection returns. Funds belonging to the best performing quintile this year are more likely to remain among the best performers in the following year.

Overall, pension funds seem to have most expertise in designing strategic asset allocation and market timing policies, rather than in actively selecting securities or in finding external managers with superior security selection skills. Pension funds benefit significantly from time series momentum across multiple asset classes. Our results thus suggest that pension funds, and especially the larger funds, would have done better if they invested in passive mandates without frequent rebalancing across asset classes. This conclusion is confirmed when we compare the total performance of funds depending on the percentage of their assets that is actively managed. The most actively managed group of pension funds has significantly greater liquidity-related diseconomies of scale, as its funds that are in the largest quartile group underperform similarly sized funds with much less active management by about 62 basis points a year. Our paper thus documents three separate reasons for the attractiveness of passive management, especially for the largest pension funds. First, pension funds on average had insignificant risk-adjusted security selection performance. Second, passive management is much cheaper than active management. Third, performance in passive mandates is less subject to liquidity-related diseconomies of scale. 


\subsection{Chapter 3 Appendix}

\section{Table A.1: Replication of Dyck and Pomorski (2011)}

This table can be compared with Table 3 of Dyck and Pomorski (February 2011). The dependent variable is the overall fund net benchmark-adjusted return in year $t$ (security selection return component on a fund level). The main independent variable is the log of year $t-1$ fund size. Regressions are estimated over the pooled sample of U.S. and Canadian funds (All) or on a single-country level and, where indicated, we use also year fixed effects. Corporate is a dummy variable, which is equal to 1 if the pension fund is classified as corporate and 0 otherwise. Panel A presents the results using the entire sample period 1990-2010 period, whereas in Panel B we use a shorter sample period (1990-2008), which is comparable with Dyck and Pomorski (2011).

\begin{tabular}{lccccc}
\hline & U.S. & U.S. & U.S. & Canada & All \\
\hline Panel A: Sample period 1990-2010 & & & & & \\
\hline Log of end of year $t-1$ plan size & 0.054 & 0.051 & 0.075 & & \\
& $(1.11)$ & $(1.10)$ & $(1.58)$ & & \\
Corporate plan dummy & & & 0.386 & & \\
& & & $(2.81)$ & & \\
Observations & 2,501 & 2,501 & 2,501 & & \\
R-squared & 0.001 & 0.136 & 0.139 & & \\
Year fixed effects & No & Yes & Yes & & \\
Plan fixed effects & No & No & No & & \\
\hline Panel B: Sample period 1990-2008 & & \multicolumn{5}{c}{0.086} \\
Log of end of year $t-1$ plan size & 0.108 & 0.090 & 0.107 & 0.068 & 0.086 \\
& $(2.28)$ & $(1.97)$ & $(2.31)$ & $(1.50)$ & $(2.65)$ \\
Corporate plan dummy & & & 0.268 & 0.179 & 0.221 \\
& & & $(1.98)$ & $(1.38)$ & $(2.22)$ \\
Observations & 2,175 & 2,175 & 2,175 & 1,393 & 3,568 \\
R-squared & 0.002 & 0.144 & 0.145 & 0.236 & 0.118 \\
Year fixed effects & No & Yes & Yes & Yes & Yes \\
Plan fixed effects & No & No & No & No & No \\
\hline
\end{tabular}




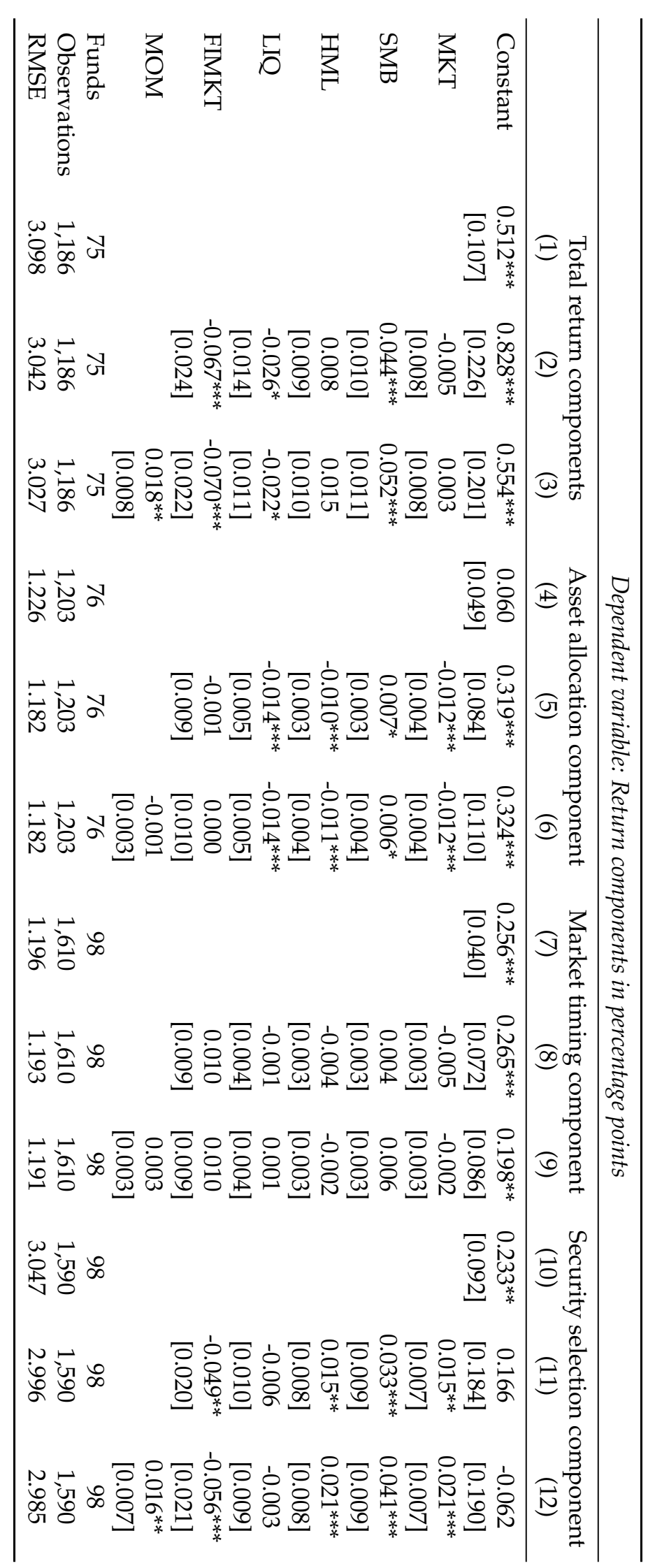

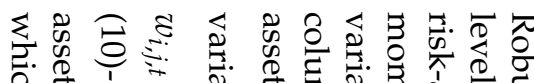

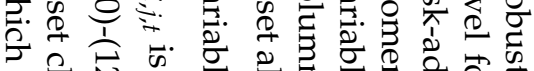

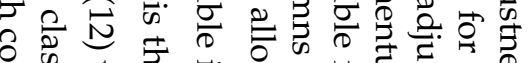

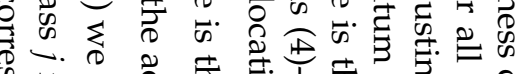

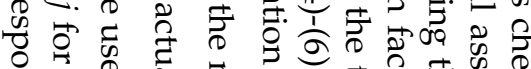

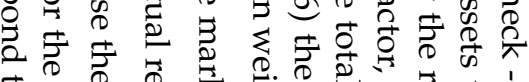

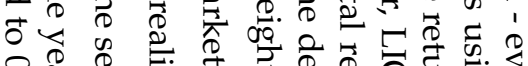

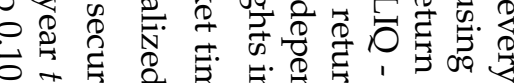

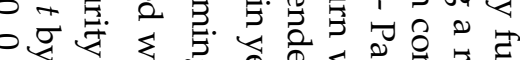

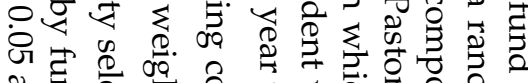

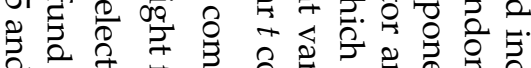

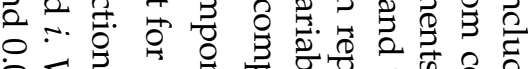

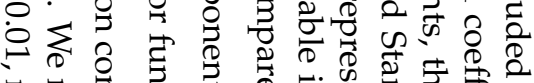

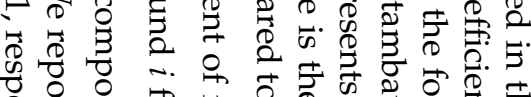
क०

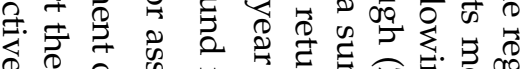
要

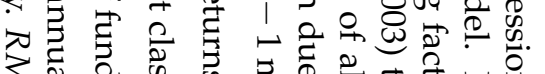
उ

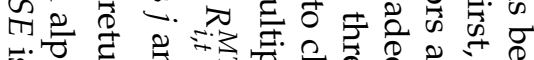
फ. क人 क क

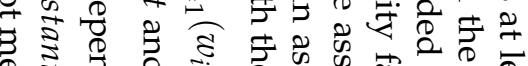

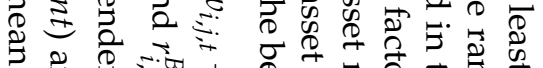

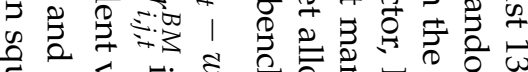

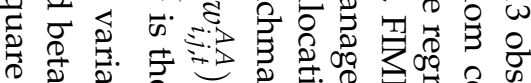

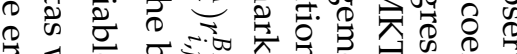

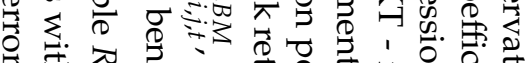

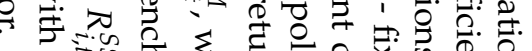

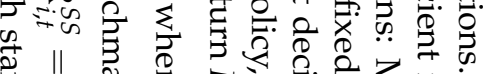

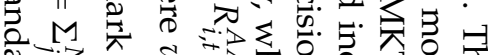
는

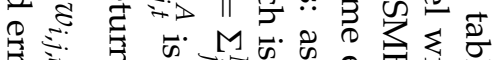

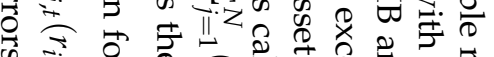
5 .

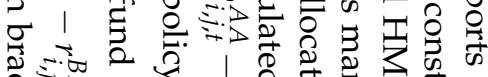

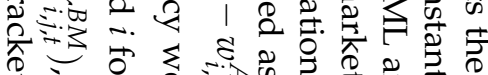
क

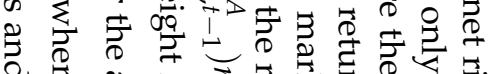
त क og. F: 在

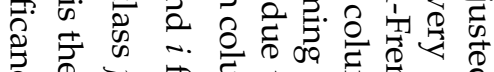

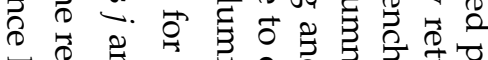
。

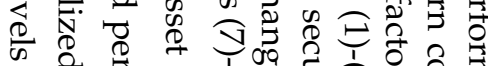

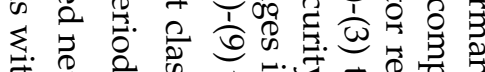

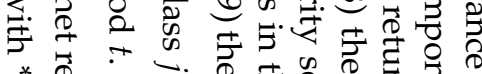
**

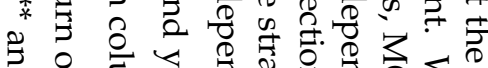

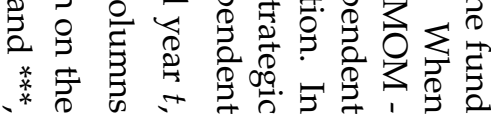


Table A.3: Pension fund characteristics and security selection returns in equity

In columns (1)-(3) we do not risk-adjust the security selection (net benchmark-adjusted returns) returns in and directly estimate the relations between them and pension fund characteristics using FamaMacBeth regressions and correcting for autocorrelation and heteroskedasticity using Newey-West with three lags. Estimations in columns (1)-(3) include all funds (observations), whereas in columns (4)-(7) we risk-adjust the equity returns and include only funds with at least seven observations. In columns (4)-(7) in the first step we regress the equity security selection returns on a five factor model that includes the MKT, SMB, HML, LIQ and MOM. In the second step we augment the alphas retrieved from the first step with the error terms of the first step and run Fama-MacBeth regressions and correct for autocorrelation and heteroskedasticity (using Newey-West with three lags). The following characteristics are included in the Fama-MacBeth regressions: \%Equity - percentage allocation to equity from total assets, LogSize - log of the total equity holdings, Costs - investment costs, \%Act - percentage in active mandates and $\%$ Ext - percentage in external mandates from the equity holdings. We also include Size $*$ Liq, which is an interaction term of the log mandate size with the first step fund-specific loading on the liquidity factor. The Observations row presents the number of observations included in the analysis. We report the coefficients with standard errors in brackets and denote significance levels with *** and ***, which correspond to $0.10,0.05$ and 0.01 , respectively.

\begin{tabular}{|c|c|c|c|c|c|c|c|}
\hline & \multicolumn{3}{|c|}{ Security selection returns in equity } & \multicolumn{4}{|c|}{ Risk-adjusted security selection returns in equity } \\
\hline & (1) & (2) & (3) & (4) & (5) & $(6)$ & $(7)$ \\
\hline Constant & $\begin{array}{l}-0.697^{*} \\
{[0.356]}\end{array}$ & $\begin{array}{c}-0.168 \\
{[0.609]}\end{array}$ & $\begin{array}{c}-0.278 \\
{[0.758]}\end{array}$ & $\begin{array}{c}-1.236^{* * *} \\
{[0.432]}\end{array}$ & $\begin{array}{c}0.341 \\
{[1.066]}\end{array}$ & $\begin{array}{c}-0.682 \\
{[0.550]}\end{array}$ & $\begin{array}{c}1.767 \\
{[2.148]}\end{array}$ \\
\hline$\%$ Equity & $\begin{array}{l}1.692^{* *} \\
{[0.661]}\end{array}$ & $\begin{array}{l}1.313^{*} \\
{[0.754]}\end{array}$ & $\begin{array}{l}2.109^{* *} \\
{[0.851]}\end{array}$ & $\begin{array}{c}2.529 * * * \\
{[0.789]}\end{array}$ & $\begin{array}{c}-0.576 \\
{[0.997]}\end{array}$ & $\begin{array}{c}2.574^{* * *} \\
{[0.774]}\end{array}$ & $\begin{array}{l}-1.725 \\
{[2.068]}\end{array}$ \\
\hline LogSize & & & $\begin{array}{c}-0.105 \\
{[0.120]}\end{array}$ & & $\begin{array}{c}-0.005 \\
{[0.081]}\end{array}$ & & $\begin{array}{c}-0.148 \\
{[0.179]}\end{array}$ \\
\hline Costs & & $\begin{array}{c}-0.797 \\
{[1.121]}\end{array}$ & & & & $\begin{array}{c}-1.780 \\
{[1.395]}\end{array}$ & \\
\hline$\%$ Act & & & $\begin{array}{c}1.447 \\
{[1.422]}\end{array}$ & & & & $\begin{array}{c}1.795 \\
{[1.784]}\end{array}$ \\
\hline$\%$ Ext & & & $\begin{array}{c}-1.018 \\
{[0.768]}\end{array}$ & & & & $\begin{array}{c}-1.058 \\
{[0.844]}\end{array}$ \\
\hline Size*Liq & & & & & $\begin{array}{c}-1.432^{* * *} \\
{[0.254]}\end{array}$ & & $\begin{array}{c}-1.493^{* * *} \\
{[0.274]}\end{array}$ \\
\hline Observations & 3,268 & 3,268 & 3,268 & 2,412 & 2,412 & 2,412 & 2,412 \\
\hline
\end{tabular}


Table A.4: Transition matrixes: persistence in pension fund performance

In Panel A funds are placed into quintiles based on their market timing returns. In Panel B funds are placed into quintiles based on their security selection (net benchmark-adjusted) returns. High row or column represents the quintile with the highest market timing return. Percentages represent the probability that a fund which was ranked in one of the 5 quintiles in year $t$ ends up in one of the quintiles in year $t+1$ or exits the database. Exit column presents the percentage of funds exiting the CEM database in year $t+1$. Return in $t+1$ columns present the market timing or security selection returns in year $t+1$ of the top and bottom quintiles, which are formed in year $t$. Test Diff column is a $\mathrm{t}$-statistic of the difference in returns between the low and high quintile.

\begin{tabular}{|c|c|c|c|c|c|c|c|c|c|c|}
\hline \multicolumn{11}{|c|}{ Panel A: U.S. Funds Market Timing Returns } \\
\hline & & \multicolumn{5}{|c|}{ Year $t+1$ ranking } & \multirow[b]{2}{*}{ Exit } & \multicolumn{2}{|c|}{ Return in $t+1$} & \multirow{2}{*}{$\begin{array}{l}\text { Test } \\
\text { Diff }\end{array}$} \\
\hline & & Low & 2 & 3 & 4 & High & & Low & High & \\
\hline \multirow{5}{*}{$\begin{array}{l}\text { Year } \mathrm{t} \\
\text { ranking }\end{array}$} & Low & $22.71 \%$ & $17.26 \%$ & $11.95 \%$ & $13.13 \%$ & $12.54 \%$ & $22.42 \%$ & 0.086 & 0.211 & 1.36 \\
\hline & 2 & $16.44 \%$ & $18.09 \%$ & $16.89 \%$ & $12.11 \%$ & $10.46 \%$ & $26.01 \%$ & & & \\
\hline & 3 & $12.44 \%$ & $16.19 \%$ & $19.94 \%$ & $15.59 \%$ & $11.84 \%$ & $23.99 \%$ & & & \\
\hline & 4 & $11.66 \%$ & $15.55 \%$ & $15.99 \%$ & $18.24 \%$ & $13.75 \%$ & $24.81 \%$ & & & \\
\hline & High & $17.75 \%$ & $10.17 \%$ & $11.23 \%$ & $15.63 \%$ & $20.64 \%$ & $24.58 \%$ & & & \\
\hline \multicolumn{11}{|c|}{ Panel B: U.S. Funds Security Selection Returns } \\
\hline & & \multicolumn{5}{|c|}{ Year $t+1$ ranking } & & \multicolumn{2}{|c|}{ Return in $t+1$} & Test \\
\hline & & Low & 2 & 3 & 4 & High & Exit & Low & High & Diff \\
\hline \multirow{5}{*}{$\begin{array}{l}\text { Year } \mathrm{t} \\
\text { ranking }\end{array}$} & Low & $20.06 \%$ & $12.87 \%$ & $13.77 \%$ & $14.82 \%$ & $13.77 \%$ & $24.70 \%$ & 0.130 & 0.450 & 1.27 \\
\hline & 2 & $12.71 \%$ & $16.79 \%$ & $16.94 \%$ & $16.49 \%$ & $11.04 \%$ & $26.02 \%$ & & & \\
\hline & 3 & $13.24 \%$ & $16.89 \%$ & $16.89 \%$ & $15.53 \%$ & $13.09 \%$ & $24.35 \%$ & & & \\
\hline & 4 & $12.25 \%$ & $16.04 \%$ & $18.31 \%$ & $17.10 \%$ & $14.52 \%$ & $21.79 \%$ & & & \\
\hline & High & $15.82 \%$ & $11.83 \%$ & $12.29 \%$ & $14.29 \%$ & $20.58 \%$ & $25.19 \%$ & & & \\
\hline
\end{tabular}




\section{Chapter 4}

\section{Delegated Investment Management in Alternative Assets}

\subsection{Introduction}

Institutional investors have increased the amount of investments in alternative asset classes, attracted by the promise of superior absolute returns and low correlation with traditional assets such as equities and bonds. Despite the marked increase in the popularity and size of portfolio allocations to these alternative asset classes, relatively few empirical papers have considered how institutional investors choose in which alternative asset class to invest and how the level of intermediation and the level of specialization affect their performance. In this paper, I examine the allocations of institutional investors to real assets, private equity and hedge funds, quantifying the performance and costs of the intermediation and specialization decisions.

I can distinguish three levels of intermediaries serving as interface between investors and assets. Institutional investors can manage the alternative investments internally (in-house), delegate the asset management to external managers or delegate even the selection of external managers to fund-of-funds. Investors usually hire financial intermediaries because they lack a high level of expertise necessary to achieve superior returns in private markets (Allen, 2001). Financial intermediaries, such as external managers and fund-of-funds, focus on gathering information only in one asset class, which may enable them to obtain superior returns by capitalizing on the acquired informational advantage (Admati and Pfleiderer, 1994). Additionally, financial intermediaries pool capital from multiple institutions and can spread the evaluation, monitoring and transaction costs as well as the liquidity needs across these institutions.

However, relying on financial intermediaries may expose institutional investors to agency conflicts. According to Sharpe (1981) and Binsbergen, Brandt, and Koijen (2008), decentralized delegated investment management can cause several misalignments of objectives between the institutional investors and the financial intermediaries, such as loss of diversification, unobservable managerial appetite for risk, and different investment horizons. When investing through financial intermediaries, institutional investors extensively use placement agents and consultants (Cain, Davidoff, and McKeon, 2013; Goyal and Wahal, 2008), whose compensation may depend on kickbacks (Stoughton, Wu, and Zechner, 2011). In this case, the external 
managers and fund-of-funds can capitalize on the relations to the detriment of investors. Overall, when delegating the asset management to financial intermediaries, institutional investors trade-off higher anticipated returns from these intermediaries against the increased difficulty in coordinating their risk-taking and the greater uncertainty about their true incentives and skills.

Alternatively, if institutional investors expect that the coordination problems will prevail, they can bypass the financial intermediaries by establishing internal investment divisions to directly select alternative assets. Establishing a competitive internal asset management division requires investor to pay high fixed costs for employee compensation, information gathering and structuring of investments. The private markets for alternative assets offer an appropriate setting to compare the performance across the three levels of intermediation (internal management, external management and fund-of-funds), since the identification of good managers or projects is impeded by limited disclosure, rapidly growing number of funds and proliferation of investment strategies in all three alternative asset classes (real assets, private equity and hedge funds).

Next, I consider the specialization decision, which captures whether institutions invest only in one alternative asset class or, invest simultaneously in two or three alternative asset classes. Prior research has examined the role of specialization at the asset manager level by comparing the risk-taking and performance of balanced (multi-asset) managers with specialized equity managers (Blake, Rossi, Timmermann, Tonks, and Wermers, 2013). I analyze the specialization decision on an institutional investor (sponsor) level. From a mean-variance perspective, adding asset classes to the overall portfolio brings diversification benefits. However, each alternative asset class is different and requires its own expertise. For instance, if an institution has investment skills in real assets, that does not necessarily enable this investor to implement better hedge fund trading strategies internally, or to select better hedge fund managers.

My main contribution is to consider how levels of intermediation and specialization relate to costs and performance of institutional investors in real assets, private equity and hedge funds. The investment approach and specialization decisions are interrelated and can jointly influence the allocation and performance of institutional investors in alternative assets.

This paper employs the CEM data ${ }^{1}$ which provides information on alternative investments of institutional investors, mainly pension funds, for the 1990-2011 period. The institutional investors are based in four regions: U.S., Canada, Europe and Australia / New Zealand. I categorize the alternative investments in three broad groups. Based on the amount of assets, the largest group is real assets, which includes investments in real estate, infrastructure, natural resources and commodities. Private equity is the second group and includes investments in

\footnotetext{
${ }^{1}$ CEM Benchmarking Inc. (CEM) collects data from institutional investors through yearly questionnaires. CEM data provides a detailed perspective on the strategic asset allocation and performance of institutional investors during the 1990-2011 period, and the data has been used previously by French (2008) to study the cost of active investing, and by Andonov, Bauer, and Cremers (2013) to examine the pension fund asset allocation and liability discount rates.
} 
venture capital, LBO, mezzanine, and distressed financing. The third group includes investments in hedge funds and tactical asset allocation (TAA) mandates. ${ }^{2}$

I document that institutional investors across all regions have increased their allocation to alternative assets from 8 percent in 1990 to more than 15 percent in 2011. However, for larger institutional investors, the increase in the allocation to alternative assets is relatively more pronounced. Large investors allocate a greater percentage of their assets to alternative investments, and are also more likely to invest simultaneously in multiple alternative asset classes. For example, doubling the fund size increases the probability that an institution invests simultaneously in real assets, private equity and hedge funds \& TAA by 9.5 percent.

In addition to size, institutional investors that diversify their public equity investment internationally, invest also a higher percentage of their total assets in multiple alternative asset classes at the same time. So both methods of diversifications, across asset classes and across geographical regions, complement each other. Institutional investors that use more active rather than passive management in public equity, are investing relatively more in alternative asset classes, where passive investing is virtually impossible. My results suggest that institutional investors do not substitute active management in public equity with alternative investments, but rather engage simultaneously in active investing in public and private markets.

With respect to the levels of intermediation, I observe that larger institutional investors establish internal management divisions significantly more frequently than smaller investors. A one unit increase in the log of investor size reduces the allocation to external managers and fund-of-funds by 7.1 and 5.7 percent, respectively, while increasing the allocation to internal managers. This suggests that size is a major determinant of the levels of intermediation standing between investors and assets, consistent with economies of scale associated with managing large alternative asset portfolios internally. Examining heterogeneity in investment approach across regions, I document that Canadian, European and Australian / New Zealand institutional investors tend to invest more internally, whereas U.S. investors are more inclined towards delegating asset management of alternative investments to external managers and fund-of-funds, even after controlling for size.

In alternative assets, the average allocation to internal mandates has declined from 22 percent in 1990 to 9 percent in 2011, at the expense of increased relative importance of external managers and fund-of-funds. I consider what explains this move towards delegated portfolio management. When investing through financial intermediaries institutional investors trade off higher expected returns from their expertise against potential agency conflicts. One possibility is that institutional investors rely more on delegated investment management because they have become more successful in coordinating and monitoring financial intermediaries. If this is the case, external managers and fund-of-funds will deliver higher gross returns in alternative assets than internal mandates, which may transfer in a better net performance, depending

\footnotetext{
${ }^{2}$ I combine TAA mandates with hedge funds, because both investments include long only and long/short strategies and may allow leveraged positions. I use the term asset class to refer to hedge fund and TAA mandates, even though they can be also described as vehicles and trading strategies.
} 
on the investment costs. Alternatively, the increased prevalence of delegated asset management over time may simply be due to institutional investors paying higher fees to reduce anxiety about risk taking or to shift responsibility for potentially poor performance to external managers and fund-of-funds (Gennaioli, Shleifer, and Vishny, 2013; Lakonishok, Shleifer, and Vishny, 1992). Based on this hypothesis, even though the investments made by external managers and fund-of-funds deliver lower net returns than the internally managed investments, institutions will still retain the financial intermediaries, because they are anxious to make risky investments on their own.

In terms of net benchmark-adjusted returns, institutional investors that invest through internal managers tend to perform better than their counterparts, which rely on financial intermediaries. More layers of financial intermediation result in lower performance in all three alternative asset classes: real assets, private equity and hedge funds \& TAA. Fund-of-funds significantly underperform as compared to external and internal managers, while external managers underperform internal managers. For example, in private equity, internally managed investments have 5.72 percentage points higher net benchmark-adjusted returns than investments managed by external managers, and 7.54 percentage points higher annual returns than investments managed by fund-of-funds.

My results suggest that the outperformance of internal managers compared to financial intermediaries stems from two sources. First, for sufficiently large institutional investors, establishing internal management divisions costs significantly less than investing through external managers and fund-of-funds. Second, internal managers can successfully compete with financial intermediaries in the private markets and manage to obtain similar or higher gross returns in all three alternative asset classes: real assets, private equity and hedge funds \& TAA. Similarly, using data on the direct private equity investments of seven large institutional investors, Fang, Ivashina, and Lerner (2013) document that direct investors outperform intermediaries, especially when investing locally or in later stage deals.

I observe that the effect of specialization on performance is non-uniform and depends on mandate size. Smaller institutional investors that specialize in one alternative asset class perform significantly better than smaller investors that invest simultaneously in multiple alternative asset classes. Small specialized institutional investors obtain 1.51 percentage points higher net benchmark-adjusted returns than small funds that invest at the same time in real assets, private equity and hedge funds. The opposite is true for larger institutions. Large specializing investors may face liquidity related diseconomies of scale and are better off when investing simultaneously in multiple alternative assets. Overall, the increased investments in multiple alternative asset classes by larger institutional investors are, in part, a response to the scale diseconomies. On the other hand, specialization enables smaller investors to outweigh the scale disadvantages in alternative assets. My conclusion about the relation between performance and specialization is based primarily on institutional allocation to real assets, as more than 80 percent of the specialization observations are in real assets, whereas few institutional investors specialize in private equity and hedge funds \& TAA. 
Prior literature has mainly analyzed performance on an asset class level, but the investor experience might differ. ${ }^{3}$ The returns of investors in alternative assets depend not only on the investment costs and returns of assets they hold, but also on the timing and magnitude of their flows into and out of these assets, possibly creating a gap between asset and investor returns. For example, Dichev and Yu (2011) estimate that investor dollar-weighted returns in hedge funds are significantly lower than the buy-and-hold hedge fund returns and even lower that the return on the S\&P500 Index. In this paper, I analyze the actual investor experience in all alternative assets. I find that especially smaller institutional investors would have been better off by not investing in alternative assets. Using the self-reported benchmark returns and asset allocation weights in public equity, I document that smaller investors would have obtained at least two percentage points higher annual returns, if they invested passively in public equity rather than alternative assets. Smaller institutional investors consistently underperform their self-reported public equity benchmarks in real assets, private equity and hedge funds over the 1990-2011 period.

The results on the effect of investment approach and size on performance in alternative assets are consistent with the model of financial intermediation by Stoughton et al. (2011). The fund-of-funds underperformance on a gross and net basis relative to internal and external managers, confirms the Stoughton et al. (2011) prediction that, in markets with kickback payments to placement agents, underperforming assets are more likely to be sold indirectly, through multiple layers of financial intermediaries. ${ }^{4}$ Economies of scale in alternative assets exist because only large investors can afford to pay high fixed search costs to identify profitable projects or skilled external managers. Thus, larger institutions invest more directly and bypass multiple levels of intermediaries. Even when investing through financial intermediaries larger investors can negotiate access to better projects at lower fees.

My findings on the economies of scale in institutional investor performance in all three alternative assets are in line with the evidence on private equity funds and hedge funds. Kaplan and Schoar (2005) document a concave relation between fund size and performance of private equity funds, whereas Agarwal, Nanda, and Ray (2013) find that larger institutions invest more directly instead of using funds of hedge funds, and outperform the smaller institutions.

The paper adds also to the recent literature on private equity mandates, which has documented systematic differences in private equity returns and investment strategies across several different types of institutional investors (Lerner, Schoar, and Wongsunwai, 2007). Hochberg and Rauh (2013) extend the analysis of heterogeneity in the performance of institutional private equity investments, documenting that especially public pension funds exhibit substan-

\footnotetext{
${ }^{3}$ Hedge fund performance studies find either small and sporadical alpha in part of their holdings (Agarwal, Jiang, Tang, and Yang, 2013; Fung, Hsieh, Naik, and Ramadorai, 2008) or no investment skills once controlling for liquidity restrictions and style allocations (Aragon, 2007; Griffin and $\mathrm{Xu}, 2009$ ). For private equity, Kaplan and Schoar (2005) and Phalippou and Gottschalg (2009) document that the average performance of buyout funds is below that of the S\&P500 after fees are taken into account. In real estate, Hochberg and Mühlhofer (2011) document that the vast majority of both public REIT and private real estate portfolio managers possess little or even negative market timing and investment selection skills, but there is persistence in manager abilities.

${ }^{4}$ The findings in this paper also complement the empirical evidence on the agency conflicts and inferior investment performance resulting from intermediation among equity mutual funds (see, for example, Bergstresser, Chalmers, and Tufano, 2009; Chen, Hong, Jiang, and Kubik, 2013).
} 
tial home-state bias and underperform with their local investments. My contribution is to shed light on two asset management decisions in alternative assets, the level of intermediation and specialization, as potential contributors to the differences in institutional investors performance.

Even though delegated asset managers on average underperform the internal investments net of fees, this is an equilibrium for some institutional investors that delegate portfolio management to intermediaries based on trust (Gennaioli et al., 2013). Despite the underperformance, these institutional investors will prefer to hire financial intermediaries as compared to investing on their own, because the delegation reduces their anxiety about taking risk. Investors will retain the external managers, as an institutional investor who trusts a particular manager perceives returns on risky investments delivered by this manager as less uncertain than those delivered by a less trusted manager (see Gennaioli et al., 2013).

However, institutional investors, relying on financial intermediaries in order to shift responsibility and reduce anxiety, violate their fiduciary duty and do not act in the best interest of their beneficiaries. My findings have some general implications for the asset management industry. Larger investors should evaluate the possibility of investing internally because fewer levels of intermediation enable institutional investors to access better investment opportunities in alternative asset classes. Smaller institutions should consider substituting fund-of-funds with other investment approaches, and specializing in one alternative asset class, instead of simultaneously investing in multiple alternative assets. If smaller investors do not have sufficient skills and resources, they should invest passively in public equity instead of going into alternative assets.

The chapter proceeds as follows. Section 5.3 introduces the institutional investor database. In Section 4.3, I investigate the determinants of investor allocation to alternative assets and the financial intermediation choice. I present results on the investment costs in Section 5.5. In Section 5.6, I analyze the effect of intermediation level, size and specialization on performance in alternative assets. Section 4.6 compares the performance of alternative assets with passive investments in equity. Section 5.7 concludes.

\subsection{Data}

For this study, I use data from CEM Benchmarking Inc. on institutional investor characteristics and their alternative assets investments over the period 1990-2011. The majority of the investors are defined benefit pension funds, but there are also defined contribution funds, sovereign wealth funds, insurance companies and natural disaster insurance funds. These investors come from four broad regions (countries): United States (U.S.), Canada, Europe and Australia/New Zealand. The dataset includes the type of investor (public or corporate), their size in terms of asset under management, their allocations to different alternative asset classes, levels of intermediation, costs, returns and benchmarks.

The CEM database provides a broad and detailed perspective on the choices and outcomes of institutional investor allocations to alternative assets. Using data at the investor level, rather 
than on an asset class level, provides some unique insights into the allocation decisions, costs and returns of alternative investments. First, the CEM data allows me to analyze the characteristics that determine whether an institution invests in alternative asset classes or not, as this dataset also includes information on institutional investors that have no exposure to alternative assets. Second, the CEM data incorporates information on investors preference for financial intermediation through external managers or fund-of-funds, allowing me to distinguish the effects of three different investment approaches on costs and performance. Third, CEM returns of investors reflect the costs of real-life constraints involved in alternative asset investments, such as commitment periods and delays on the withdrawal of capital that external parties impose. Fourth, CEM returns reflect the costs of managing a portfolio of underlying alternative investments in real assets, private equity and hedge funds, as the returns are reported net of an additional layer of fees.

I classify the alternative investments in three broad groups. The first group, real assets, incorporates investments in real estate, REITs, infrastructure, natural resources and commodities. ${ }^{5}$ Private equity is the second group and includes investments in venture capital, LBO and energy partnerships, as well as equity or fixed income investments in turnarounds, start-ups, mezzanine, and distressed financing. The third group includes investments in hedge funds and tactical asset allocation (TAA) mandates. I combine TAA mandates with hedge funds, because they include long only and long/short strategies, and may allow leveraged positions.

Table 4.1 reports the descriptive statistics for the entire sample of 978 institutional investors. U.S. investors represent the majority of the observations, but the database provides also good coverage of Canadian institutional investors. For European, Australian and New Zealand investors, I have fewer observations. Institutional investors have on average 9.7 billion US $\$$ assets under management.

Figure 4.1 Panel A shows that, on average, 74 percent of the investors in the database invest in real assets, which is higher than the number of funds investing in private equity (54 percent) and hedge funds \& TAA (25 percent). The percentage of institutions investing in hedge funds \& TAA has increased substantially during the last decade: in 2000 only 10 percent of the institutional investors invested in hedge funds \& TAA, while in 2011 more than 55 percent of the institutions invested in hedge funds \& TAA.

Figure 4.1 Panel B presents the total allocation to alternative assets, which declined from 8.6 percent in 1990 to 4.9 percent in 1999. Afterwards, the allocation to alternative assets increased substantially in all regions, reaching 15.3 percent of the assets under management in 2011. Real assets have always been the most important alternative asset class and represent 4.42 percent

\footnotetext{
${ }^{5}$ Real estate includes direct real estate holdings, segregated real estate holdings and real estate limited partnerships, whereas REITs capture investments in real estate investment trusts. Infrastructure asset class covers investments in local distribution networks for electricity, water and gas, and certain transportation assets, such as toll roads, airports, bridges and tunnels. Investments in commodities and natural resources refer to actual physical exposures in commodities (i.e., crude oil, sugar, copper etc) or timber, and to commodity funds or products that may invest in an index like the Goldman Sachs Commodities Index (GSCI). The composition of real assets changes over time, but on average direct real estate and REITs represent 91 percent, infrastructure accounts for 4 percent, and commodities and natural resources cover 5 percent.
} 
Figure 4.1: Institutional investments in alternative assets

Panel A: Percentage of funds investing in alternative assets

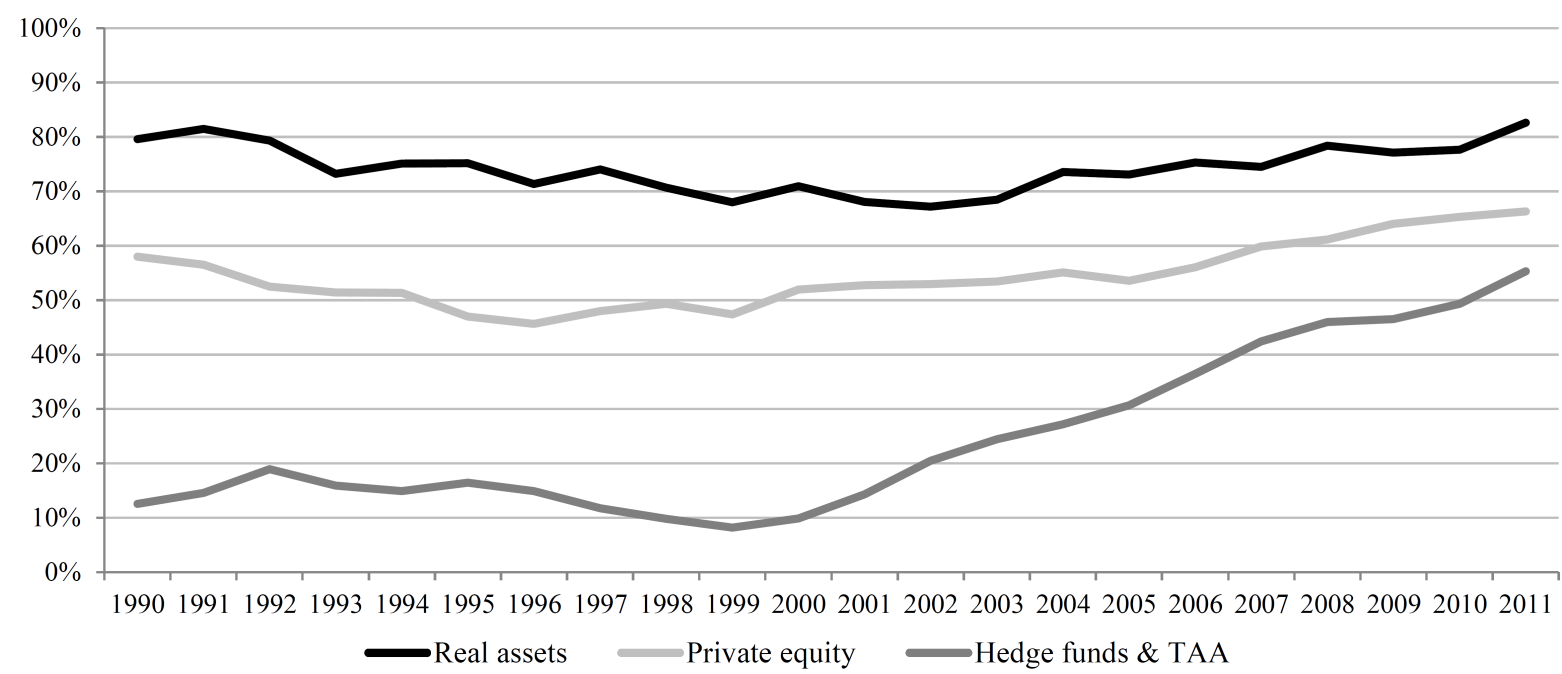

Panel B: Average allocation to alternative assets in percent from total assets under management

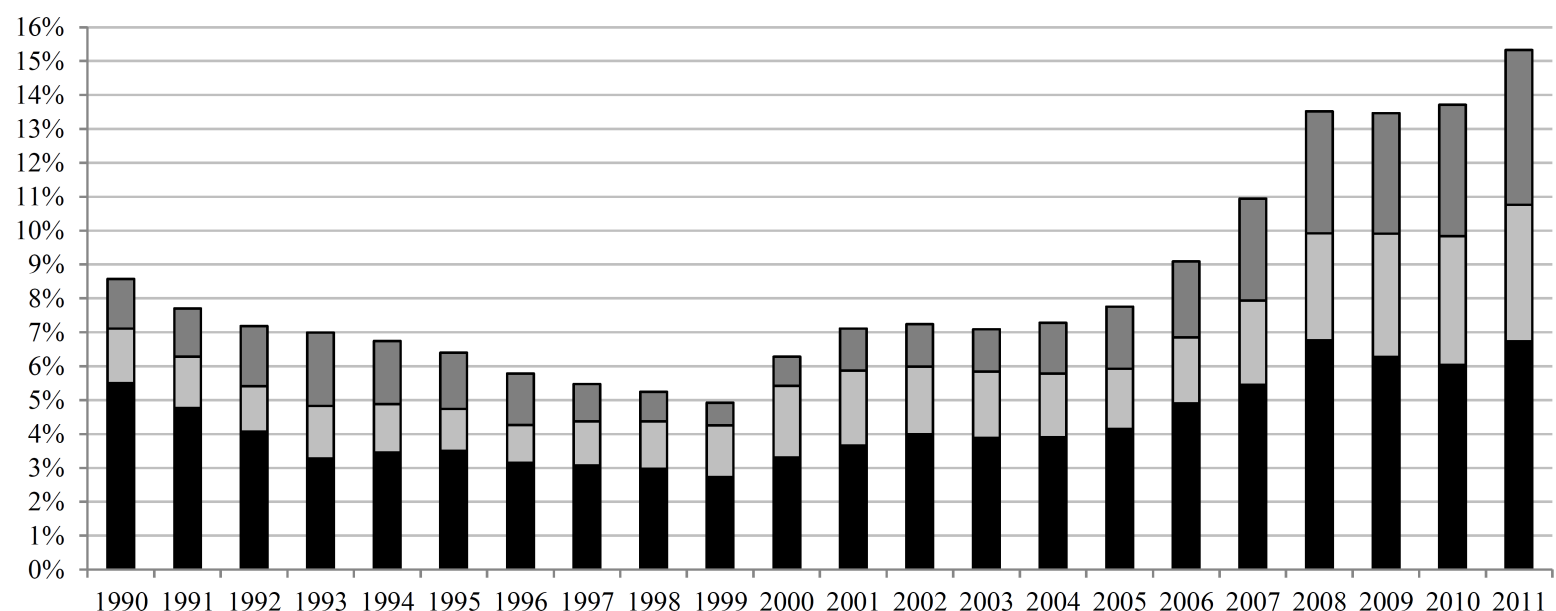

1990199119921993199419951996199719981999200020012002200320042005200620072008200920102011

- Real assets $\square$ Private equity $\quad$ Hedge funds \& TAA

Panel C: Percentage of funds investing simultaneously (NSI) in multiple alternative asset classes

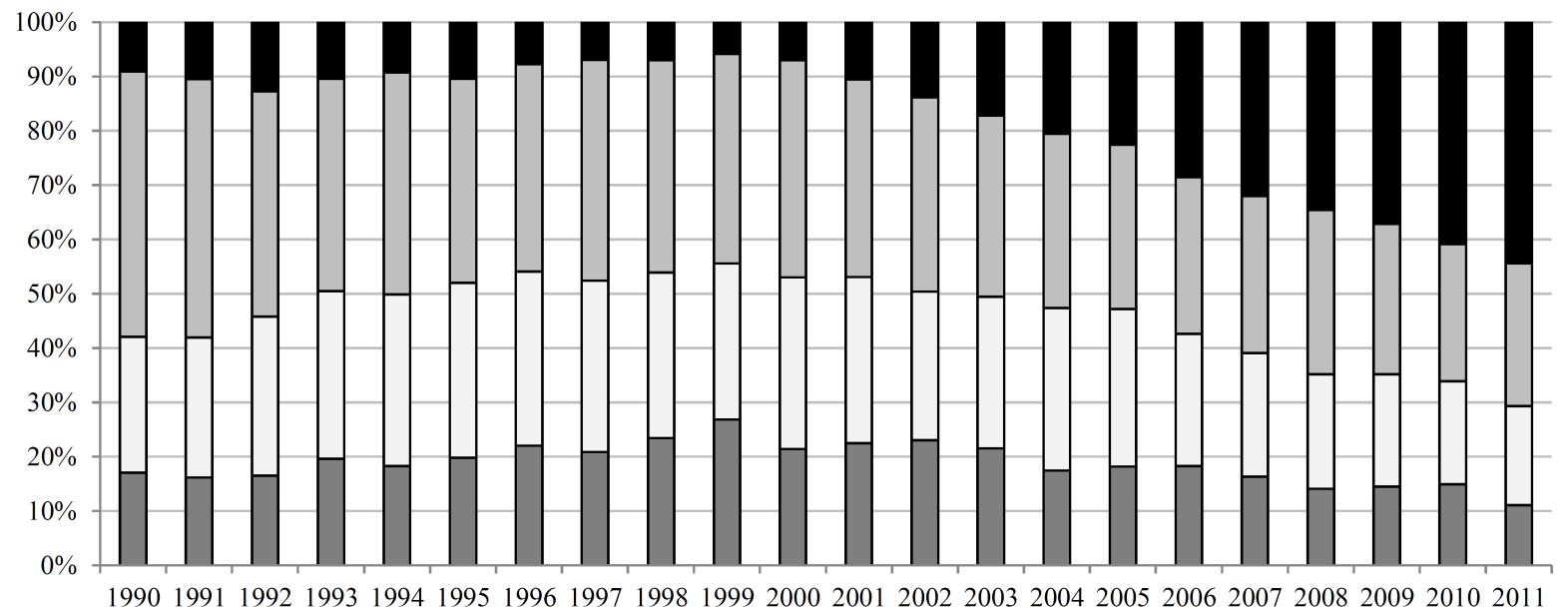

口NSI $=0$ (No alternatives) $\square \mathrm{NSI}=1 \mathrm{aNSI}=2 \mathrm{mNSI}=3$ 
Table 4.1: Summary statistics: Institutional investors

This table shows the number of funds and observations in the CEM dataset. I present the descriptive statistics for all funds together (Total) as well as separately for every region. Size (AUM) presents the mean investor size, measured as asset under management in million US\$. In Percentage allocation columns, I present the equally weighted average allocation to real assets, private equity and hedge funds \& TAA from total assets, taking into account also institutional investors that do not invest in alternative assets. Simultaneous investment columns present the number of observations for all possible values of NSI. The number of simultaneous investments (NSI) in alternative asset classes is equal to 0 , if an institution does not invest in any alternative assets class. NSI $=1, N S I=2$ or $N S I=3$ means that an institution invests at the same time in one, two or all three alternative asset classes (real assets, private equity and hedge funds \& TAA).

\begin{tabular}{|c|c|c|c|c|c|c|c|c|c|c|}
\hline & \multicolumn{3}{|c|}{ Institutional investors } & \multicolumn{3}{|c|}{ Percentage allocation } & \multicolumn{4}{|c|}{ Simultaneous investments } \\
\hline & Funds & Obs & Size (AUM) & $\begin{array}{c}\text { Real } \\
\text { assets }\end{array}$ & $\begin{array}{l}\text { Private } \\
\text { equity }\end{array}$ & $\begin{array}{l}\text { Hedge funds } \\
\text { \& TAA }\end{array}$ & $\mathrm{NSI}=0$ & $\mathrm{NSI}=1$ & $\mathrm{NSI}=2$ & $\mathrm{NSI}=3$ \\
\hline Total & 978 & 6,129 & 9,730 & $4.42 \%$ & $2.17 \%$ & $2.10 \%$ & 1,145 & 1,649 & 2,108 & 1,227 \\
\hline U.S. & 573 & 3,545 & 10,700 & $4.26 \%$ & $2.92 \%$ & $2.78 \%$ & 507 & 810 & 1,405 & 823 \\
\hline Canada & 250 & 2,055 & 4,137 & $3.29 \%$ & $0.89 \%$ & $1.01 \%$ & 598 & 745 & 519 & 193 \\
\hline Europe & 136 & 449 & 27,632 & $9.45 \%$ & $1.91 \%$ & $1.61 \%$ & 31 & 81 & 159 & 178 \\
\hline Aus/Nzd & 19 & 80 & 9,955 & $12.70 \%$ & $3.87 \%$ & $2.79 \%$ & 9 & 13 & 25 & 33 \\
\hline
\end{tabular}

of the total assets, on average. Private equity accounts for 2.17 percent, while hedge funds \& TAA account for 2.10 percent of the total investor assets.

In almost 20 percent of the observations, institutions do not invest in alternative assets (NSI=0). Figure 4.1 Panel C shows that the percentage of institutional investors without alternative investments is highest in 1999, but declines afterwards to 11 percent in 2011. In the last decade, the percentage of institutions that invest simultaneously in all three alternative asset classes (NSI=3) increased substantially. On the contrary, the percentage of investors that specialize into investing in one alternative asset class (NSI=1) declined from 32 percent in 2000 to 18 percent in 2011. Table 4.2 reports that vast majority of the specialization observations are in real assets. Less than 20 percent of the investor specializing observations are in private equity and hedge funds \& TAA.

Institutions invest through three levels of intermediation in alternative assets: internal management, external management and fund-of-funds. Internal investing means that the buy-sell decisions for the individual assets are made within the institution (including wholly-owned subsidiaries). When delegating the asset management to financial intermediaries, institutional investors can directly select the external managers or invest through fund-of-funds. In case of the latter, the fund-of-fund manager selects the external managers (funds), who then acquire the assets.

Figure 4.2 shows the trend in percentage of alternative assets invested through each financial intermediation level. Over time, institutional investors have increased their allocation to fund-of-funds from 0 to 20 percent, primarily at the expense of internal mandates, not external managers. Investing through external managers is the dominant investment approach during the entire period, accounting for roughly 75 percent of the institutional investments in alternative assets. 


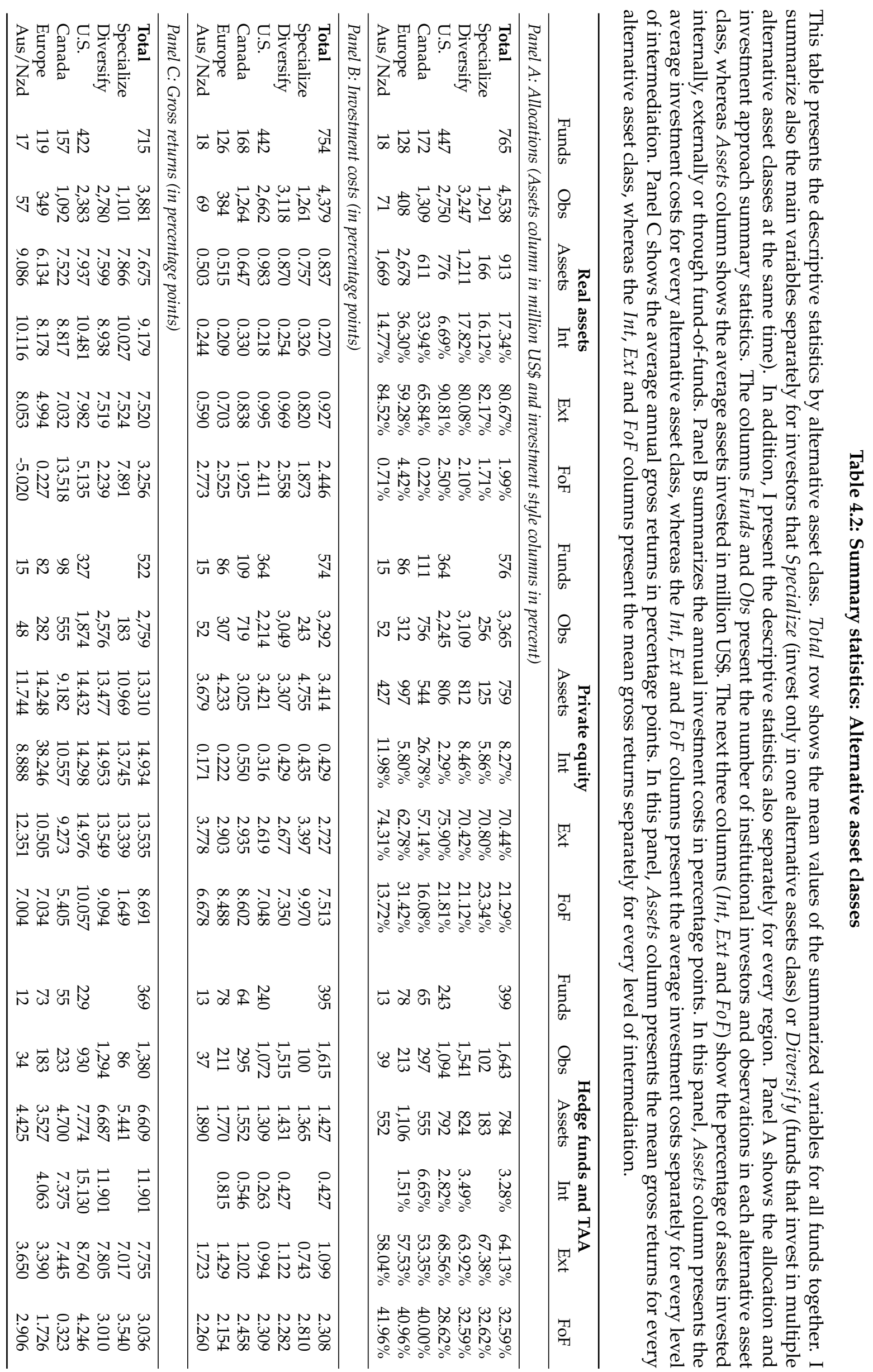


Figure 4.2: Percentage allocated to internal managers, external managers and fund-of-funds

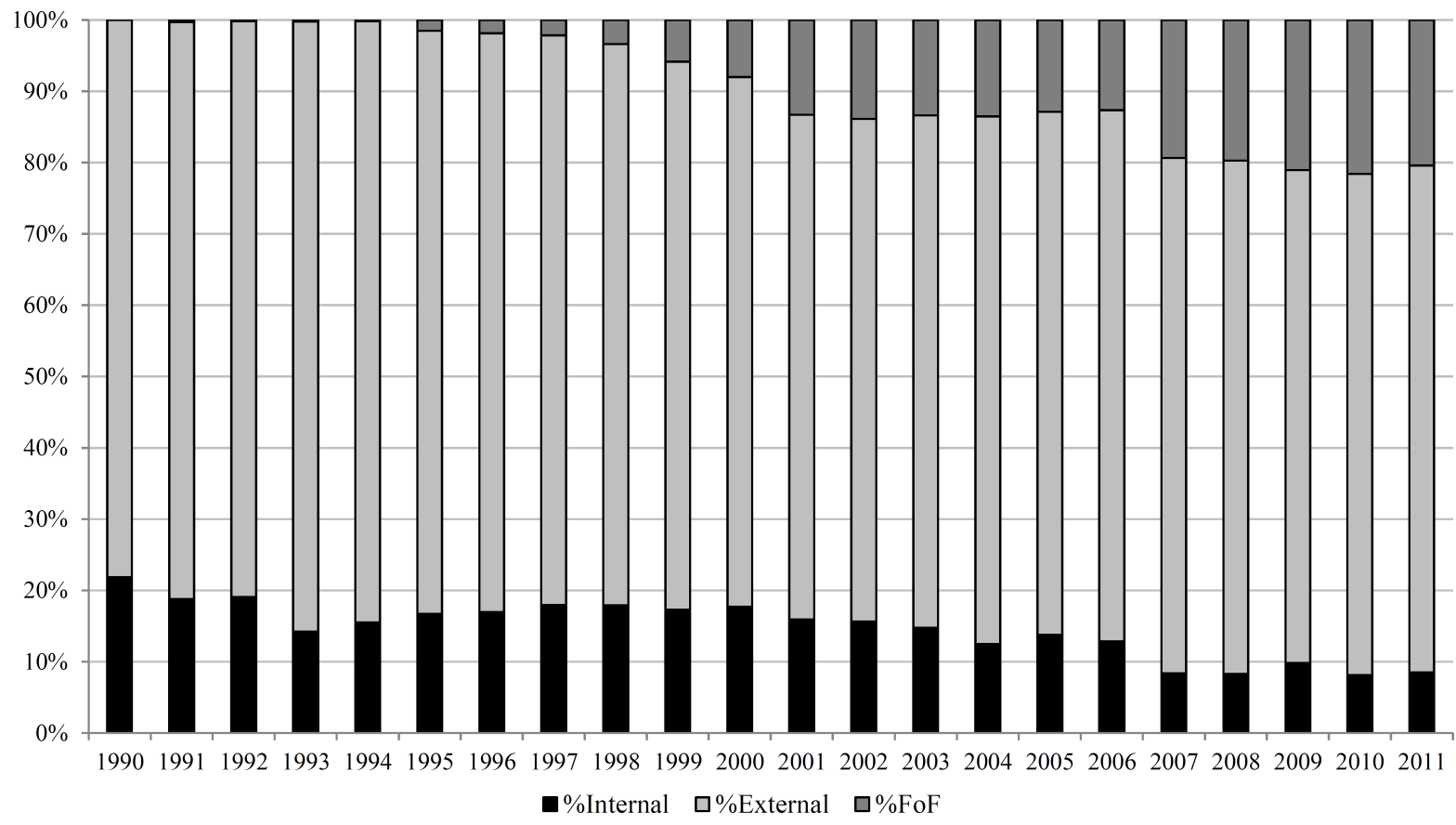

Table 4.2 Panel A presents the investment approach by alternative asset class. In all three alternative asset classes, internal management is less implemented than delegated management to external parties. Internal asset management is mostly used by institutions when investing in real assets and represents 17.34 percent of the real assets. Internal private equity divisions manage only 8.27 percents of the assets invested by institutional investors in private equity, whereas internal hedge funds \& TAA mandates are even less frequent, managing around 3.28 percent of the investments. Investing through fund-of-fund accounts for 32.59 percent of the assets allocated to hedge funds \& TAA, 21.29 percent of the assets invested in private equity and only 1.99 percent of the investments in real assets. There are significant regional differences in the level of intermediation. U.S. institutions invest less through internal mandates in all three alternative asset classes and rely more on external managers.

Table 4.2 Panel B presents the investment costs across different levels of intermediation and alternative asset classes. Internal investment costs include compensation and benefits of employees managing internal portfolios, as well as expenses for support staff, consulting, research, legal, trading services and allocated overhead costs. ${ }^{6}$ External investment costs capture the management fees paid to investment consultants and external asset managers. The performance fees, carried interest and rebates ${ }^{7}$ are directly subtracted from the returns and are not incorporated in the cost figures. External investments costs also include costs (compensation, benefits, travel and education costs) for internal staff whose sole responsibility is to select and monitor external managers in alternative assets. Similarly, for fund-of-funds, cost figures

\footnotetext{
${ }^{6}$ The overhead costs include expenses for rent, utilities, IT, investment accounting, financial control, HR, etc.

${ }^{7}$ Carried interest is a fee that is a portion of returns exceeding a hurdle rate. Rebates are the limited partner share of certain fee income realized by the general partner in connection with the fund, such as fees for break-up, monitoring and funding.
} 
capture the base management fee paid to both the fund-of-funds manager and the underlying managers, but they do not include performance fees and carried interest on either level.

Private equity is the most expensive alternative asset class with average annual costs of 3.41 percentage points, followed by hedge funds \& TAA (1.43 percentage points) and real assets (0.84 percentage points). Investing in real assets costs less than investing in the other alternative assets classes, partially because of the higher allocation to internal management divisions, which cost significantly less than delegating asset management to financial intermediaries.

Institutional investment costs in alternative assets documented in the CEM data are comparable with those documented in prior literature. Based on Table 4.2, the average management fees paid by institutional investors for external investing in hedge funds or through funds-ofhedge-funds are around 1.10 and 2.31 percent, respectively. Similarly, French (2008) documents that the average annual hedge fund management fee is 1.16 percent over the 1996-2007 period, and for funds-of-hedge-funds the estimate is around 2.36 percent. For private equity, Phalippou (2009) and Metrick and Yasuda (2010) estimate that the average buyout fund charges only management fee of more than 2 percent of capital commitments, while the total fee is around 7 percent. According to CEM data, external investing in private equity costs around 2.73 percent annually.

Panel C of Table 4.2 shows the gross returns of institutional investors in alternative assets. Institutions on average obtain the highest gross returns in private equity, whereas real assets and hedge funds \& TAA deliver substantially lower returns. Institutional investors obtain an annual gross return of 13.31 percentage points in private equity. The average gross return in real assets is 7.68 percentage points annually, whereas the return in hedge funds \& TAA is roughly 6.61 percentage points. The gross returns of U.S. institutions are higher than the returns of other institutions in all three alternative asset classes.

On a gross return basis, internal managers perform better than the external managers in all three alternative assets, while fund-of-funds deliver the lowest returns. In the performance analysis, I subtract the investment costs and the benchmark returns from the gross returns, and then focus on the net benchmark-adjusted returns.

\subsection{Institutional investments in alternative assets}

I first explore how the allocation to alternative assets is related to investor size, diversification and active management use. Subsection 4.3.2 focuses on the number of alternative asset classes in which institutions invest simultaneously and analyze the association between the number of simultaneous investments and institutional investor characteristics. Subsection 4.3.3 analyzes how investor size and specialization influence the allocation to the three intermediation levels.

\subsubsection{Percentage allocated to alternative assets}

I estimate the relation between percentage allocated to alternative assets (\%Alternatives) and investor characteristics using Tobit regressions that control for left censoring in the allocation 
variable:

$$
\begin{array}{r}
\% \text { Alternatives }_{i, t}^{*}=\beta_{0}+\beta_{1} Z_{i, t}+\beta_{2} \text { Region }_{i}+\beta_{3} Y D_{t}+v_{i, t} \\
\% \text { Alternatives }_{i, t}= \begin{cases}\% \text { Alternatives }_{i, t}^{*} & \text { if } \% \text { Alternatives }_{i, t}^{*}>0 \\
0 & \text { if } \% \text { Alternatives }_{i, t}^{*} \leq 0\end{cases}
\end{array}
$$

where $Z_{i, t}$ represents the main variables of interest: Fund size, the logarithm of total institutional investor assets; \%IntEquity, the percentage allocated to international (non-domestic) equity assets from total public equity holdings; MSCI World, the annual returns on the MSCI World equity index expressed in local currency; the percentage of public equity and fixed income investments managed actively and externally (\%ActEquity, \%ActFI, \%ExtEquity and $\% E x t F I)$. I control for investor type using the Public dummy variable, which is equal to 1 if an institutional investor is a public fund and 0 for corporate funds. ${ }^{8}$ I also control for region fixed effects $\left(\right.$ Region $\left._{i}\right)$, include year dummies $(Y D)$ and I cluster the robust standard errors by investor, allowing for intragroup correlation.

In Table 4.3, I find that percentage allocated to alternative assets is positively and significantly associated with institutional investor size. Larger funds invest relatively more in alternative assets: a one unit increase in the Fund Size, i.e. doubling the fund size, results in 1.9 percentage points increase in the allocation to alternative assets. Importantly, larger institutions invest relatively more in all three alternative asset classes: real assets, private equity and hedge funds \& TAA.

There are two ways for institutional investors to diversify their portfolios: by investing in more asset classes and by investing across more geographical regions. Table 4.3 sheds light on whether investments in alternative assets are driven by demands for diversification. Interestingly, funds, that have more internationally diversified public equity holdings, invest also relatively more in alternative assets. For example, based on column (2), if an institution invests $50 \%$ of the public equity assets in non-domestic markets, than this institution will also allocate 7.25 percent more to alternative assets $(0.5 * 0.145)$. Institutional investors with international public equity holdings invest especially more in private equity and hedge funds \& TAA. My results suggest that both methods of diversification complement each other: institutions that invest more internationally, at the same time, allocate higher percentage of their assets to alternatives. Contrasting, institutional investors that hold only domestic equity will invest less in alternative assets.

The use of active management in public equity also explains the percentage allocated to alternative assets. Institutional investors can decide whether to engage in active management in all asset classes or to combine active management in alternative assets with passive management in traditional assets such as public equity and bonds. I document that institutional investors that use more passive rather than active management in public equity, invest relatively less in alternative assets. For instance, an investor that manages all public equity investments in an active way will invest 5.5 percent more in alternative assets as compared to an investor

\footnotetext{
${ }^{8}$ The majority of the public investors are public defined benefit pension funds, but there are also defined contribution funds and few sovereign wealth funds in the database.
} 
that manages all equity investments in a passive way. Institutions that manage their public equity holdings passively invest less especially in hedge funds \& TAA, which is the alternative asset class exposed mainly to listed securities.

\section{Table 4.3: Tobit regressions: Percentage allocated to alternative assets}

The dependent variable is the percentage allocated to alternative assets from total investor assets, $\%$ Alternatives. I estimate a Tobit regression, since the allocation variable is censored at 0 . The dependent variable is defined based on the actual asset allocation in columns (1) and (2), and based on the strategic asset allocation in columns (3) and (4). In columns (5), (6) and (7) I decompose the dependent variable to percentage allocated to real asset, private equity and hedge funds \& TAA. As independent variables, I include: Fund size, the logarithm of total institutional investor assets; \%IntEquity, the percentage allocated to international (non-domestic) equity assets from total public equity holdings; MSCI World, the annual returns on the MSCI World equity index expressed in local currency; \%ActEquity, $\% A c t F I, \% E x t E q u i t y$ and \%ExtFI, which capture the institutional investment approach in public equity and fixed income (the percentage of public equity investments managed actively, the percentage of fixed income investments managed actively, the percentage of public equity investments managed by external managers and the percentage of fixed income assets managed by external managers). I control for investor type using the (Public) dummy variable, which is equal to 1 if the institutional investor is a public fund and 0 for corporate funds. Canada, Europe and Aus / Nzd are regional dummy variables (the base result refers to U.S. investors). I include year dummies and cluster the robust standard errors by institutional investor. I report standard errors in brackets. ${ }^{*}, * *$, and ${ }^{* * *}$ indicate significance levels of $0.10,0.05$, and 0.01 , respectively.

\begin{tabular}{|c|c|c|c|c|c|c|c|}
\hline & $\begin{array}{c}(1) \\
\% \text { Alternatives } \\
\text { (actual) }\end{array}$ & $\begin{array}{c}(2) \\
\text { \%Alternatives } \\
\text { (actual) }\end{array}$ & $\begin{array}{c}(3) \\
\text { \%Alternatives } \\
\text { (strategic) }\end{array}$ & $\begin{array}{c}(4) \\
\text { \%Alternatives } \\
\text { (strategic) }\end{array}$ & $\begin{array}{c}(5) \\
\text { \%Real } \\
\text { assets }\end{array}$ & $\begin{array}{c}(6) \\
\text { \%Private } \\
\text { equity }\end{array}$ & $\begin{array}{l}\text { (7) } \\
\text { \%Hedge funds } \\
\text { and TAA }\end{array}$ \\
\hline \multirow{2}{*}{ Constant } & $-0.109^{* * *}$ & $-0.109^{* * *}$ & $-0.097^{* * *}$ & $-0.110^{* * *}$ & $-0.064^{* * *}$ & $-0.118^{* * *}$ & $-0.205^{* * *}$ \\
\hline & [0.026] & [0.032] & [0.027] & {$[0.035]$} & [0.021] & [0.020] & [0.051] \\
\hline \multirow{2}{*}{ Fund size } & $0.019 * * *$ & $0.019^{* * *}$ & $0.018^{* * *}$ & $0.019^{* * *}$ & $0.010^{* * *}$ & $0.014^{* * *}$ & $0.013^{* * *}$ \\
\hline & [0.003] & [0.003] & {$[0.003]$} & [0.003] & {$[0.002]$} & [0.002] & [0.003] \\
\hline \multirow[t]{2}{*}{ \%IntEquity } & $0.145^{* * *}$ & $0.145^{* * *}$ & $0.122^{* * *}$ & $0.120^{* * *}$ & 0.021 & $0.067^{* * *}$ & $0.172^{* * *}$ \\
\hline & [0.032] & [0.032] & [0.029] & [0.029] & [0.014] & [0.014] & [0.040] \\
\hline \multirow[t]{2}{*}{ MSCI World } & $0.054^{* * *}$ & $0.054^{* * *}$ & $0.046^{*}$ & $0.046^{*}$ & 0.017 & $0.025^{* *}$ & -0.028 \\
\hline & {$[0.020]$} & {$[0.020]$} & {$[0.024]$} & [0.024] & [0.012] & [0.011] & [0.037] \\
\hline \multirow[t]{2}{*}{ Public } & $-0.013^{*}$ & $-0.013^{*}$ & -0.002 & -0.002 & 0.003 & $-0.014^{* * *}$ & $-0.033^{* * *}$ \\
\hline & {$[0.007]$} & [0.007] & [0.008] & [0.008] & [0.004] & [0.004] & [0.012] \\
\hline \multirow[t]{2}{*}{$\%$ ActEquity } & $0.055^{* * *}$ & $0.055^{* * *}$ & $0.039^{* *}$ & $0.040^{* *}$ & $0.016^{* *}$ & $0.016^{*}$ & $0.082^{* * *}$ \\
\hline & [0.015] & [0.015] & [0.016] & [0.016] & [0.008] & [0.009] & {$[0.024]$} \\
\hline \multirow[t]{2}{*}{$\%$ ActFI } & 0.014 & 0.014 & $0.020^{*}$ & $0.021^{*}$ & $0.010^{*}$ & $0.015^{* *}$ & -0.012 \\
\hline & {$[0.012]$} & [0.012] & [0.012] & [0.012] & [0.006] & [0.006] & [0.020] \\
\hline \multirow{2}{*}{ \%ExtEquity } & & 0.005 & & 0.016 & 0.003 & -0.003 & 0.002 \\
\hline & & [0.019] & & {$[0.021]$} & [0.010] & [0.013] & [0.025] \\
\hline \multirow[t]{2}{*}{$\%$ ExtFI } & & -0.004 & & -0.008 & -0.003 & -0.006 & -0.003 \\
\hline & & [0.015] & & [0.016] & [0.008] & [0.010] & [0.021] \\
\hline \multirow[t]{2}{*}{ Canada } & $-0.068^{* * *}$ & $-0.069^{* * *}$ & $-0.073^{* * *}$ & $-0.072^{* * *}$ & -0.008 & $-0.037^{* * *}$ & $-0.101^{* * *}$ \\
\hline & [0.011] & {$[0.011]$} & {$[0.011]$} & {$[0.011]$} & {$[0.005]$} & {$[0.006]$} & {$[0.018]$} \\
\hline \multirow[t]{2}{*}{ Europe } & $-0.044^{* * *}$ & $-0.044^{* * *}$ & -0.024 & -0.023 & $0.038^{* * *}$ & $-0.050^{* * *}$ & $-0.088^{* * *}$ \\
\hline & {$[0.015]$} & {$[0.016]$} & [0.015] & [0.016] & {$[0.010]$} & [0.007] & [0.017] \\
\hline \multirow[t]{2}{*}{ Aus/Nzd } & 0.053 & 0.053 & 0.047 & 0.047 & $0.081^{* * *}$ & -0.005 & $-0.046^{*}$ \\
\hline & {$[0.039]$} & {$[0.039]$} & {$[0.037]$} & [0.037] & [0.019] & {$[0.029]$} & {$[0.026]$} \\
\hline Year dummies & Yes & Yes & Yes & Yes & Yes & Yes & Yes \\
\hline Funds & 972 & 972 & 972 & 972 & 972 & 972 & 972 \\
\hline Observations & 6,091 & 6,091 & 6,091 & 6,091 & 6,091 & 6,091 & 6,091 \\
\hline
\end{tabular}

Even after controlling for size, international equity investments and preferences for active management, I still find significant regional differences in percentage allocated to alternative assets. Canadian and European institutional investors allocate lower percentage of their assets to alternative investments as compared to U.S. investors. Non-U.S. investors have substantially 
lower exposure to hedge funds \& TAA and private equity, while European and Australian / New Zealand funds invest slightly more in real assets than U.S. funds.

\subsubsection{The number of simultaneous investments in alternative assets}

The next question I consider is whether institutions decide to specialize in one alternative asset class or to diversify across multiple alternative asset classes. I estimate the determinants of the number of simultaneous investments (NSI) in alternative assets using an ordered logit model. The dependent variable NSI takes a value of one, if an institution invests only in one alternative asset class. The dependent variable can have a maximum value of three, if an institution invests at the same time in real assets, private equity and hedge funds \& TAA.

$$
\begin{array}{r}
N S I_{i, t}^{*}=\gamma_{1} Z_{i, t}+\gamma_{2} \text { Region }_{i}+\gamma_{3} Y D_{t}+\varepsilon_{i, t} \\
N S I_{i, t}= \begin{cases}1 & \text { if } N S I_{i, t}^{*} \leq \mu_{1} \\
2 & \text { if } \mu_{1}<N S I_{i, t}^{*} \leq \mu_{2} \\
3 & \text { if } \mu_{2}<N S I_{i, t}^{*}\end{cases}
\end{array}
$$

where $Z_{i, t}$ represents the main variables of interest: Fund size, the logarithm of total investor assets; \%Alternatives, the percentage allocated to alternatives from total assets; \%IntEquity, the percentage allocated to international (non-domestic) equity assets from total public equity holdings; MSCI World, the annual returns on the MSCI World equity index expressed in local currency; the percentage of public equity and fixed income investments managed actively and externally (\%ActEquity, \%ActFI, \%ExtEquity and \%ExtFI). I control for investor type using the Public dummy variable, which is equal to 1 if an institutional investor is a public fund and 0 for corporate funds. I also control for region fixed effects $\left(\right.$ Region $\left._{i}\right)$, include year dummies $(Y D)$ and I cluster the robust standard errors by investor, allowing for intragroup correlation.

Table 4.4 presents the marginal effects estimated at median values for every potential outcome of the dependent variable NSI. I test whether institutional investors substitute active management in public equity with investing in multiple alternative assets, where passive management is not possible. However, I document that institutional investors using more active rather than passive management in public equity also invest in multiple alternative asset classes at the same time. An institution that manages all public equity investments in an active way has 17.8 percent higher probability to invest at the same time in all three alternative asset classes as compared to an institution that manages all public equity investments in a passive way. This result suggests that institutional investors do not substitute active management in public equity with investments in alternative assets, but rather that if institutional investors use active management, they do that in multiple public and private markets at the same time.

Diversification is another important determinant of the number of simultaneous investments in alternative assets. Institutional investors, that diversify their public equity assets by investing internationally, are also more likely to diversify across asset classes by holding multiple alternative asset classes at the same time. 
Table 4.4: Ordered logit regressions: Number of simultaneous investments (NSI)

I estimate an ordered logit model and the dependent variable equals the number of alternative asset classes in which an institution invests at the same time. The NSI dependent variable takes a maximum value of three when an institution invests at the same time in real assets, private equity and hedge funds \& TAA. The sample is restricted to investors with at least one alternative asset class in their portfolio. As independent variables, I include: Fund size, the logarithm of total fund assets; \%Alternatives, the percentage allocated to alternatives from total assets; \%IntEquity, the percentage allocated to international (non-domestic) equity assets from total public equity holdings; MSCI World, the annual returns on the MSCI World equity index expressed in local currency; \%ActEquity, \%ActFI, \%ExtEquity and $\% E x t F I$, which capture the institutional investment approach in public equity and fixed income (the percentage of public equity investments managed actively, the percentage of fixed income investments managed actively, the percentage of public equity investments managed by external managers and the percentage of fixed income assets managed by external managers). I control for investor type using the (Public) dummy variable, which is equal to 1 if the institutional investor is a public fund and 0 for corporate funds. Canada, Europe and Aus/Nzd are regional dummy variables (the base result refers to U.S. investors). I include year dummies and cluster the robust standard errors by institutional investor. I report the the marginal effects estimated at median values for all probability outcomes (NSI=1, NSI=2 and NSI=3). I report standard errors in brackets. ${ }^{*}, * *$, and ${ }^{* * *}$ indicate significance levels of $0.10,0.05$, and 0.01 , respectively.

\begin{tabular}{lccc}
\hline & $\mathrm{NSI}=1$ & $\mathrm{NSI}=2$ & $\mathrm{NSI}=3$ \\
\hline Fund size & $-0.083^{* * *}$ & -0.012 & $0.095^{* * *}$ \\
& {$[0.012]$} & {$[0.020]$} & {$[0.015]$} \\
\%Alternatives & $-1.834^{* * *}$ & -0.269 & $2.103^{* * *}$ \\
& {$[0.278]$} & {$[0.437]$} & {$[0.239]$} \\
\%IntEquity & $-0.161^{*}$ & -0.024 & $0.184^{* *}$ \\
& {$[0.086]$} & {$[0.038]$} & {$[0.089]$} \\
MSCI World & 0.076 & 0.011 & -0.087 \\
& {$[0.095]$} & {$[0.018]$} & {$[0.101]$} \\
Public & $0.080^{* * *}$ & -0.010 & $-0.070^{* * *}$ \\
& {$[0.031]$} & {$[0.018]$} & {$[0.024]$} \\
\%ActEquity & $-0.155^{* * *}$ & -0.023 & $0.178^{* * *}$ \\
& {$[0.046]$} & {$[0.039]$} & {$[0.060]$} \\
\%ActFI & -0.012 & -0.002 & 0.013 \\
& {$[0.039]$} & {$[0.007]$} & {$[0.045]$} \\
\%ExtEquity & 0.054 & 0.008 & -0.062 \\
& {$[0.062]$} & {$[0.014]$} & {$[0.069]$} \\
\%ExtFI & 0.016 & 0.002 & -0.019 \\
& {$[0.049]$} & {$[0.009]$} & {$[0.056]$} \\
Canada & $0.100^{* *}$ & -0.018 & $-0.083^{* * *}$ \\
& {$[0.041]$} & {$[0.024]$} & {$[0.028]$} \\
Europe & 0.092 & -0.015 & $-0.078^{* *}$ \\
& {$[0.057]$} & {$[0.026]$} & {$[0.039]$} \\
Aus/Nzd & 0.098 & -0.017 & -0.081 \\
& {$[0.098]$} & {$[0.043]$} & {$[0.060]$} \\
Year dummies & Yes & & \\
Funds & 832 & & \\
Observations & 4,968 & & \\
\hline & & & \\
\hline
\end{tabular}


Investor size and percentage allocated to alternative assets have the expected positive effect on the number of simultaneous investments. Larger institutional investors are more likely to invest in multiple alternative asset classes at the same time. A one unit increase in the log of Fund size increases the probability that a fund invests simultaneously in real assets, private equity and hedge funds \& TAA by 9.5 percent. Similarly, if an investor allocates higher percentage of the total assets to alternative investments, than this fund is also more likely to invest in multiple alternative asset classes at the same time.

Furthermore, I observe significant regional effects: Canadian and European institutions are less likely to simultaneously invest in all three groups of alternative assets. The probability that a Canadian institutional investor specializes in one alternative asset class $(N S I=1)$ is 10 percent higher than the probability for a U.S. institutional investor, controlling for size, international diversification and active management in public equity.

\subsubsection{Financial intermediation levels}

In this section, I analyze the determinants of institutional decision to manage the alternative investments internally, to select external asset managers or to invest through fund-of-funds. For every intermediation level, I estimate a Tobit model where the dependent variable is the percentage of assets managed internally, externally and by fund-of-funds. The Tobit regressions in Table 4.5 control for left-censoring of the investment approach variables at 0 and rightcensoring at 1 . For example, the dependent variable \% Internal equals 0 if investor $i$ does not manage alternative investments internally in year $t$, and 1 if all the alternative investments are managed internally.

$$
\begin{array}{r}
\% \text { InvApproach }_{i, t}^{*}=\delta_{0}+\delta_{1} Z_{i, t}+\delta_{2} \text { Region }_{i}+\delta_{3} Y D_{t}+v_{i, t} \\
\% \text { InvApproach }{ }_{i, t}= \begin{cases}1 & \text { if } \text { InvApproach }_{i, t}^{*} \geq 1 \\
\% \text { InvApproach } & \text { if } 0<\% \text { InvApproach }_{i, t}^{*}<1 \\
0 & \text { if } \% \operatorname{InvApproach}_{i, t}^{*} \leq 0\end{cases}
\end{array}
$$

where $Z_{i, t}$ represents the independent variables. To estimate the effect of specialization in alternative assets on the percentage allocated to the different intermediation levels, I include three variables: Specialzie, a dummy variable that is equal to 1 if an institution invests only in one alternative asset class and 0 , if it invests in more than one alternative asset class; NSI, a count variable that measures the number of alternative asset classes in which an institution invests; and Concentartion, the Herfindahl-Hirschman Index measure of alternative investments concentration. I control for region fixed effects $\left(\right.$ Region $\left._{i}\right)$, include year dummies $(Y D)$ and cluster the robust standard errors by investor, allowing for intragroup correlation.

Columns (1), (4) and (7) in Table 4.5 present the base results. In line with expectations, larger institutions invest more internally and less through external managers and fund-of-funds. According to column (1), a one unit increase in the logarithm of assets (i.e., doubling the fund size) increases the allocation to internal managers by 29 percent. Smaller institutional investors delegate the asset management responsibilities to external managers and fund-of-funds. A one 


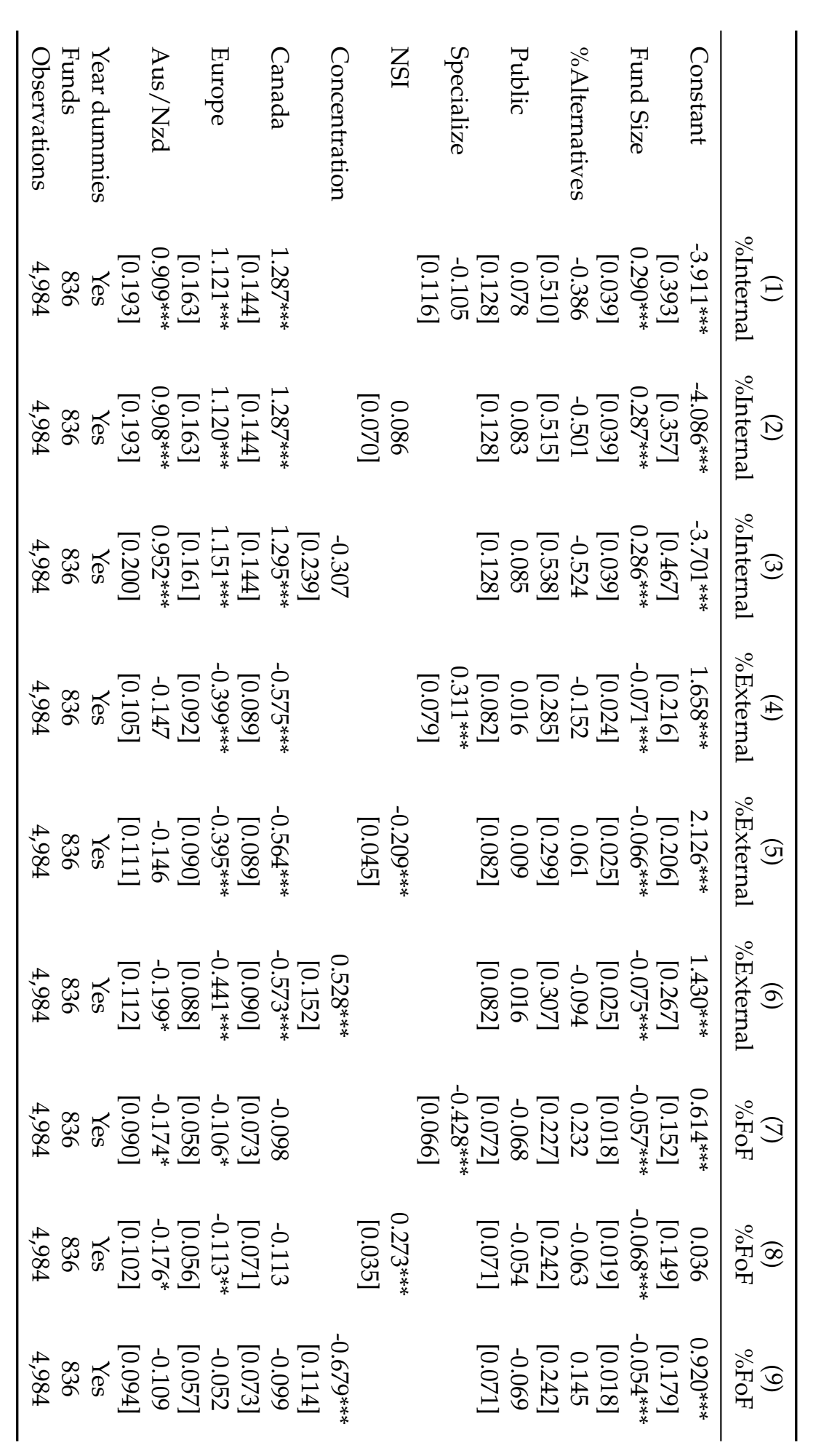

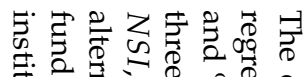

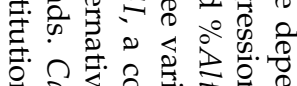

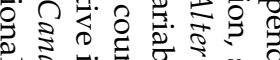

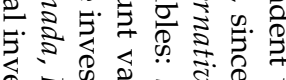

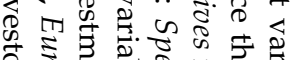

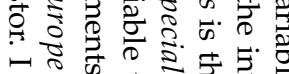

年

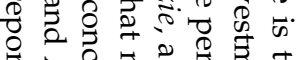

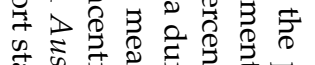

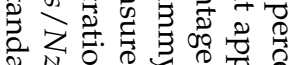

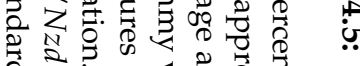

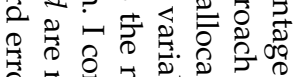

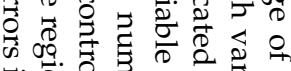

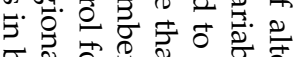

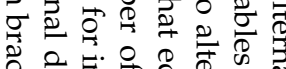

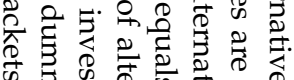

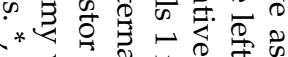

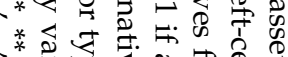

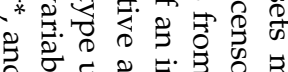

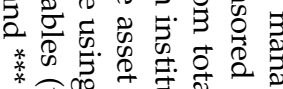

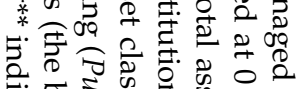

뉴.

क के क्ते क.

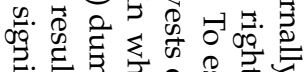

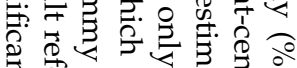

Әे

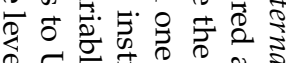

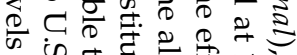

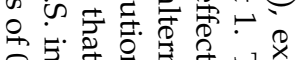

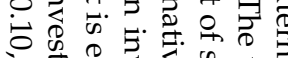

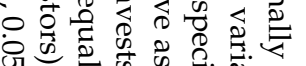

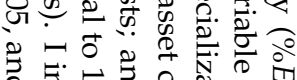

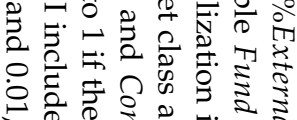

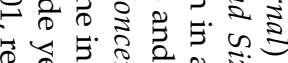

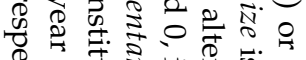

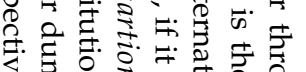

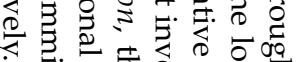

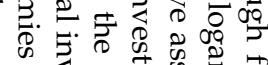

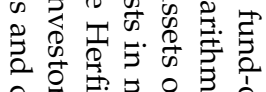

告.

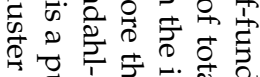

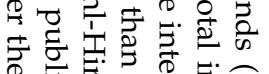

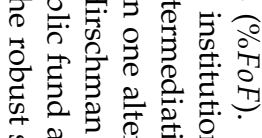

क :

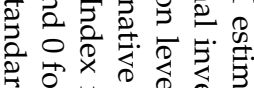

$\begin{array}{llll}0 & 0 \\ 0 & 0 & 0 & 0 \\ 0 & 0 & 0 & 0 \\ 0 & 0 & 0 \\ 0 & 0 & 0 \\ 0\end{array}$

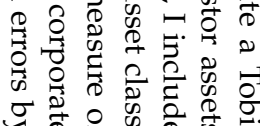


unit increase in the log size decreases the percentage of alternative investments delegated to external managers by 7.1 percent and the percentage of assets allocated to fund-of-funds decreases by 5.7 percent. Interestingly, the relative importance of alternative assets, measured as the percentage invested in alternatives from total assets, is not a significant determinant of the chosen investment approach.

In addition to investor size, another important determinant of the level of intermediation in allocations to alternatives is the decision to specialize or diversify across multiple alternative asset classes. Institutional investors that specialize in one alternative asset class invest less through fund-of-funds. Based on column (7), if an investor decides to specialize in one alternative assets class (usually real assets), the percentage of assets managed by fund-of-funds declines by 42.8 percent. The specializing investor usually hires external managers directly, instead of delegating the hiring responsibility to fund-of-funds.

In columns (2), (5) and (8) of Table 4.5, I replace the specialize dummy variable with the number of simultaneous (NSI) investments in alternative assets. Institutions investing at the same time in multiple alternative asset classes delegate the management of their investments to fund-of-funds, instead of selecting directly external managers. As another robustness check, I measure the concentration of fund alternative asset investments across the three groups. I use the Herfindahl-Hirschman concentration index instead of the specialize dummy variable in models (3), (6) and (9). Institutional investors that hold more diversified alternative portfolios rely more on fund-of-funds, whereas those investors with highly concentrated alternative investments select directly external managers instead of delegating this responsibility to fundof-funds.

Finally, I find differences in the level of intermediation across institutional investors based on their region. Canadian, European and Australian / New Zealand institutions invest more through internal managers and rely less on external managers and fund-of-funds as compared to U.S. institutional investors.

Overall, larger funds manage internally their alternative investments and avoid delegating the investment management to financial intermediaries. Controlling for fund size, the decision to specialize in one alternative assets class results in lower allocation to fund-of-funds.

\subsection{Investment costs}

As a next step, I investigate the effect of mandate size, intermediation level and specialization on investment costs in alternative assets. In Table 4.6, I estimate the cross-sectional differences in institutional investor costs using panel regressions:

$$
{\operatorname{Inv} \operatorname{Costs}_{i, t}}=\theta_{0}+\theta_{1} Z_{i, t}+\theta_{2} \text { Region }_{i}+\theta_{3} Y D_{t}+\epsilon_{i, t}
$$

where $Z_{i, t}$ represents the independent variables. To estimate the effect of intermediation level on investment costs, I include \%External, the percentage allocation to external managers, and $\% F o F$, the percentage allocation to fund-of-funds. I examine the effect of size and specialization on costs by controlling for $\log$ Assets, the logarithm of institutional investor holdings in every 
alternative asset class, and Specialzie, a dummy variable that equals 1 if an institution invests only in one alternative asset class and 0 , if it invests in more than one alternative asset class. $Y D$ are the year dummies, Region ${ }_{i}$ captures regional fixed effects, and $\epsilon_{i, t}$ is the idiosyncratic error. I independently double cluster the robust standard errors in all regressions by investor and by year.

Investing through financial intermediaries, such as external managers and fund-of-funds significantly increases the investment costs in all three alternative asset classes. The effect is particularly pronounced in private equity investments, where an institution that invests internally has 1.14 percentage points lower investment costs than an institution that delegates the asset management to external managers. Similarly, institutional investor managing the private equity investments through fund-of-funds has more than 4.00 percentage points higher investment costs than internal investor. In real assets and hedge funds, external managers have around 0.50 percentage points higher investment costs than internal managers, while fund-offunds have roughly 1.60 percentage points higher investment costs.

When investing in alternative asset classes, institutional investors generally realize strong scale advantages in their investment costs. In real assets, a one unit increase in the log of assets (i.e., doubling the holdings size) reduces the investment costs by approximately 0.11 percentage points, even after controlling for the level of intermediation. The economies of scale are stronger for private equity investments, where a one unit increase in the log of assets results in around 0.70 percentage points lower costs, whereas for hedge funds \& TAA investments asset size does not provide scale advantages, once controlling for investment approach.

Previously I documented that in more than 80 percent of the specialization observations are in real assets and that specializing investors prefer external managers to fund-of-funds. In Table 4.6, I find that, the decision to specialize leads to lower investment costs in real assets, when controlling for size and intermediation level. Institutional investors that specialize in real assets negotiate around 20 basis points lower investment fees. In private equity and hedge funds \& TAA, there are no differences in the investment costs of specializing and diversifying investors.

I find strong regional effects only in the real asset investment costs. Based on column (3), in real assets, U.S. institutional investors pay 0.26 percentage points higher investment fees than Canadian, 0.39 percentage points than European and 0.36 percentage points than Australian / New Zealand institutional investors. Institutional investors from different regions pay similar investment fees in private equity and hedge funds.

Overall, cost savings are an important advantage of internal investing in alternative assets. This confirms the observation by Fang et al. (2013) that the compensation is significantly different from the " 2 -and-20" fee structure in internal (direct) private equity deals of institutional investors. In case of private equity co-investments, which are also classified as internal investing, large institutions have a negotiation power and resent paying additional charges for these deals originated by general partners. Similarly, Andonov, Bauer, and Cremers (2012) document economies of scale in investment costs on an overall investor level. I find that the economies of scale are especially economically significant in alternative assets. 


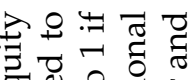

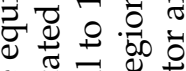

过

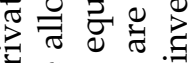

2.

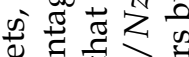

के

बृ.

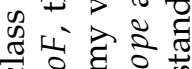

냉 हो

is 0 क

60.05

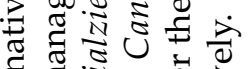

चृ

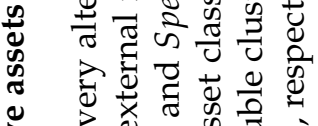

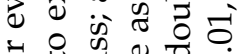

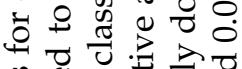

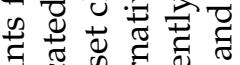

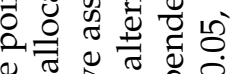

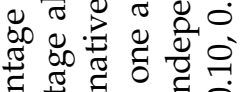

屯ี Ð

过 $\mp$ व

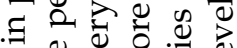

क्ष

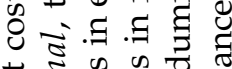

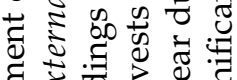

䓛

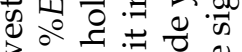

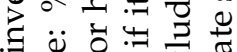

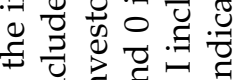

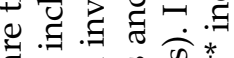

ส

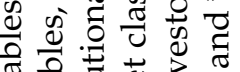

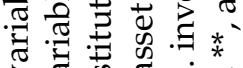

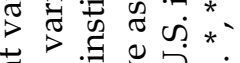

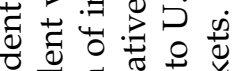

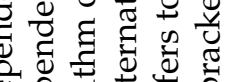

के 웡 考

త.

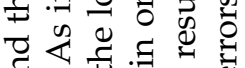

穴必云弯

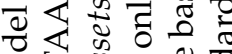

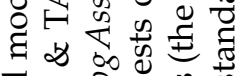

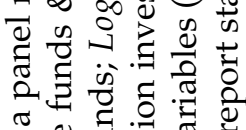

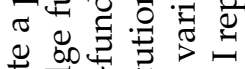

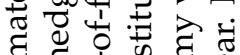

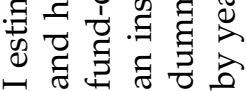

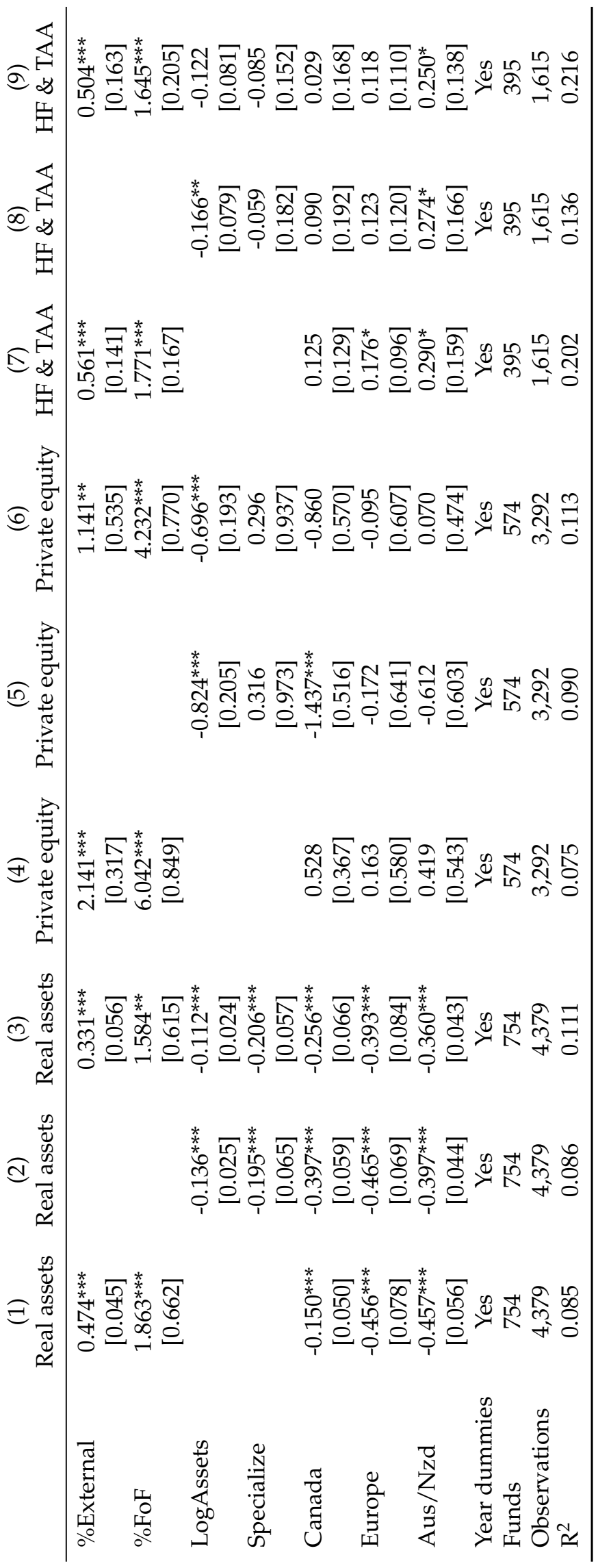




\subsection{Performance in alternative assets}

In the performance analysis, I focus on the effect of intermediation level and investor size on returns in real assets, private equity and hedge funds. I also estimate whether investor size and specialization are interrelated and can jointly influence the performance of institutional investors in alternative assets.

\subsubsection{Financial intermediation level and performance}

In this section, I analyze how the level of intermediation influences the performance in alternative assets. One possibility is that alternative investments require more knowledge and monitoring skills, and the vast majority of institutional investors are not able to establish efficient internal asset management divisions. If the external managers and fund-of-funds have an informational advantage compared to internal management departments of institutional investors, one would expect that the investments through financial intermediaries deliver higher gross returns than internally managed alternative assets. Hence, the savings in costs achieved through internal investing will not translate into better performance. Another possibility is that financial intermediaries do not have an informational advantage and investing through them is akin not only to higher costs, but also to agency conflicts, which may lead to lower net returns than following an internal investment approach.

Table 4.7 presents the net benchmark-adjusted returns of institutional investors in alternative assets. To estimate the net benchmark-adjusted returns I deduct the investment costs and the self-declared benchmark returns from the gross returns. In the CEM database, institutional investors declare their benchmarks, which are usually market indexes (for example, the NCREIF Index and the FTSE/NAREIT Index for U.S. real estate investments or the HFRI Index for hedge fund investments), against which performance is measured. Benchmark returns can also be a weighted combination of multiple indices. The realized returns and benchmark returns are generally provided in the local currency, but if an investor hedges the currency risk, than the hedged returns and benchmarks are provided. Appendix Table B.1 presents the most frequent self-reported benchmarks in every alternative asset class.

The advantage of using self-declared benchmarks is that these benchmarks more precisely reflect the geographical allocation and risk exposure of the alternative asset investments. For example, if an institutional investor is exposed only to office buildings in the U.S., benchmarking its returns against the NCREIF Office Index is more appropriate than using the broader NCREIF Property Index or IPD Global Index. Similarly, if an institution invests internationally and engages in any currency management, the benchmark returns are a weighted average of indices in multiple countries and account for the implemented hedging policy.

Institutional investors on average obtain negative net benchmark-adjusted returns in all three alternative asset classes. The underperformance is largest in hedge funds \& TAA, where investors obtain an annual net benchmark-adjusted return of -1.12 percentage points. In real 


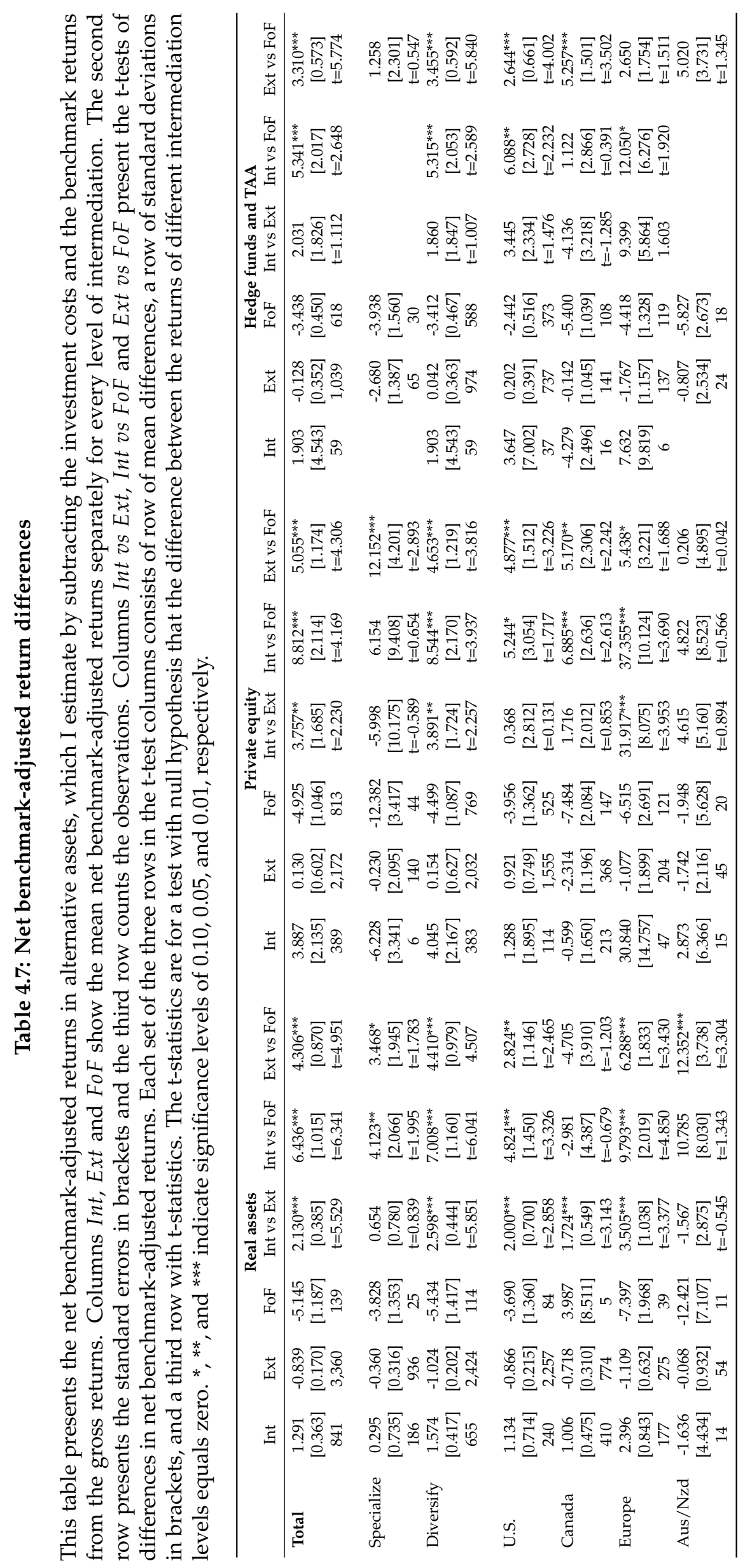


assets funds underperform the benchmarks by 0.57 percentage points annually, whereas the underperformance in private equity is roughly 0.12 percentage points.

Table 4.7 presents t-tests of differences in net benchmark-adjusted returns between the three intermediation levels separately for every alternative asset class. I analyze the differences in net benchmark-adjusted returns across all institutional investors, as well as by splitting the sample by region and by the decision to specialize in one alternative asset class. Each set of three rows consists of a row of means, a row of standard errors, and a third row with observation counts and $\mathrm{t}$-statistics. The $\mathrm{t}$-statistic is for the test with the null hypothesis that the difference between the net benchmark-adjusted returns across different investment approaches equals zero.

The real assets panel of Table 4.7 shows that in terms of net benchmark-adjusted returns, internal investments outperform external managers and fund-of-funds by 2.13 and 6.44 percentage points and the difference is statistically significant with t-statistics of 5.53 and 6.34, respectively. Investments through fund-of-funds are exposed to one more level of financial intermediation than investments through external managers and underperform compared to external managers by 4.31 percentage points ( $t$-stat of 4.95). The return differences are stronger for private equity investments, where internal managers outperform external managers by 3.76 and fund-of-funds by 8.81 percentage points. For hedge funds \& TAA investments, I observe the same pattern. Thus, based on the average net benchmark-adjusted returns, more levels of intermediation result in lower returns: internal managers perform better than the external managers, while fund-of-funds deliver the lowest returns in all three alternative asset class.

This pattern appears particularly strong among institutions that invest simultaneously in multiple alternative assets. If an institutional investor diversifies across alternative assets instead of specializing in one asset class, than the level of intermediation has a stronger effect on performance. For diversifying investors, the difference between internal and external net benchmark-adjusted returns in real assets is 2.60 , between internal and fund-of-funds returns is 7.01, and between external and fund-of-funds returns is 4.41 percentage points.

When examining the differences in returns by region, I observe similar effects of the intermediation level on performance across all regions. Internal management delivers higher net benchmark-adjusted returns than external managers and fund-of-funds consistently in all regions and alternative asset classes, but the differences are not always significant, as the number of observations in some cases is low. The number of return observations is lowest for hedge funds \& TAA investments, where the dataset has only 59 internal net benchmark-adjusted returns.

Appendix Table B.2 shows that internally managed investments obtain higher returns not only due to lower costs, but also from higher gross returns. In real assets, internal mandates deliver 1.52 and 4.56 percentage points higher gross benchmark-adjusted returns than external managers and fund-of-funds. On a gross basis, internal mandates also have better performance in private equity and hedge funds \& TAA, though the difference is not always significant.

Using univariate tests, I document that internal investments by institutional investors outperform investments delegated to external managers and fund-of-funds. Tables 4.8 and 4.9 
present regression versions of the t-test results in Table 4.7. In the panel regressions, the dependent variable is the investor net benchmark-adjusted return $\left(N T R_{i, t}-B M_{i, t}\right)$ in real assets, private equity and hedge funds \& TAA.

$$
N T R_{i, t}-B M_{i, t}=\lambda_{0}+\lambda_{1} Z_{i, t}+\lambda_{2} \text { Region }_{i}+\lambda_{3} Y D_{t}+\xi_{i, t}
$$

The independent variables of primary interest are the percentage of assets invested through external managers and fund-of-funds. I cluster the standard errors independently on an investor and year level to control for potentially correlated performance shocks within investors and across (vintage) years. I also examine the effect of specialization on performance by including an indicator for whether the institutional investor has allocation only to one alternative asset class. I further augment the models with the log of institutional assets under management in real assets, private equity or hedge funds \& TAA to control for potential economies of scale in performance. In all models, I include region and time fixed effects.

In Table 4.8, I observe similar patterns across all three alternative asset classes. Based on column (3), in real assets, investments managed by external managers and fund-of-funds underperform internally managed investments by 1.58 and 2.19 percentage points annually. In private equity, I observe economically stronger effects of the intermediation level on performance: institutional investments in private equity through external managers and fund-of-funds have 5.55 and 7.30 percentage points lower net benchmark-adjusted returns than internally managed investments.

For hedge fund \& TAA investments, the number of internal management observations is low (59 non-zero observations). Hence, in columns (8) and (11), I estimate the effect of $\%$ Internal and \%External on performance relative to \%FoF. I find that hedge funds \& TAA investments managed by external managers deliver around 3.20 percentage points higher net benchmark-adjusted returns than investment managed by fund-of-funds. Internal hedge fund \& TAA asset management divisions also seem to perform better than fund-of-funds, but the difference is not statistically significant due to the low number of internal observations.

Institutional investors realize significant economies of scale in alternative assets, even after controlling for differences in intermediation level. I document that institutional investors with more assets under management have better performance in real assets and private equity. For hedge funds \& TAA, the positive economies of scale are not significant once I control for the effect of investment approach on performance. Based on column (6), a one unit increase in the log of private equity assets (i.e. doubling the holdings size) results in 1.18 percentage points higher returns.

Table 4.9 repeats the analysis in Table 4.8, substituting the pooled panel regressions with Fama and MacBeth (1973) regressions. Panel regression results might be influenced by years with higher number of observations and Fama and MacBeth (1973) overcome this potential bias by putting equal weight on every year. In Table 4.9, I present the Fama and MacBeth (1973) regression results for institutional investments in real assets and private equity. For hedge fund \& TAA, I cannot estimate these regressions as the number of cross-sectional observations 


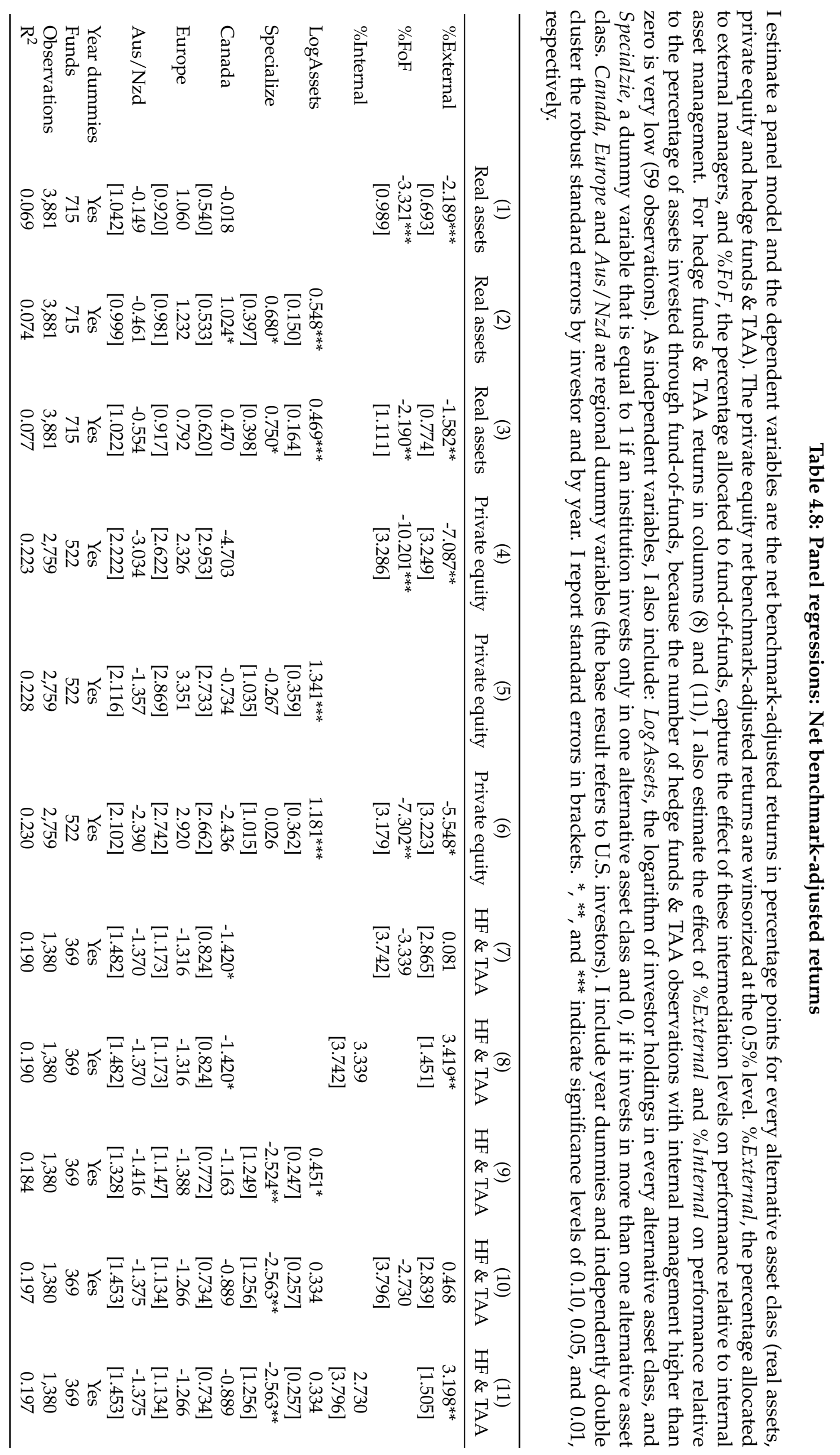


is very low at the beginning of the sample period and continuously increasing afterwards (see Figure 4.1 Panel A).

\section{Table 4.9: Fama-MacBeth regressions: Net benchmark-adjusted returns}

I estimate a Fama and MacBeth (1973) model and correct for autocorrelation and heteroscedasticity using Newey-West with three lags. The dependent variables are the net benchmark-adjusted returns in percentage points for real assets and private equity. The private equity net benchmark-adjusted returns are winsorized at the $0.5 \%$ level. For hedge funds \& TAA returns, I am not able to estimate the Fama-MacBeth regressions because the number of institutions investing in hedge funds \& TAA increases continuously over time (see Figure 4.1 Panel A). \%External, the percentage allocated to external managers, and \%FoF, the percentage allocated to fund-of-funds, capture the effect of these intermediation levels on performance relative to internal asset management. As independent variables, I also include: LogAssets, the logarithm of investor holdings in every alternative asset class, and Specialzie, a dummy variable that equals 1 if an institution invests only in one alternative asset class and 0 , if it invests in more than one alternative asset class. Canada, Europe and Aus/Nzd are regional dummy variables (the base result refers to U.S. investors). I report standard errors in brackets. ${ }^{*}{ }^{* *}$, and ${ }^{* * *}$ indicate significance levels of $0.10,0.05$, and 0.01 , respectively.

\begin{tabular}{lcccccc}
\hline & $(1)$ & $(2)$ & $(3)$ & $(4)$ & $(5)$ & $(6)$ \\
& Real assets & Real assets & Real assets & Private equity & Private equity & Private equity \\
\hline Constant & $1.320^{* * *}$ & $-3.839^{* * *}$ & -1.745 & $8.803^{* * *}$ & $-5.501^{* *}$ & 0.241 \\
& {$[0.607]$} & {$[0.307]$} & {$[1.209]$} & {$[3.199]$} & {$[2.513]$} & {$[3.976]$} \\
\%External & $-2.264^{* * *}$ & & $-1.745^{* *}$ & $-8.494^{* * *}$ & & $-5.025^{* *}$ \\
& {$[0.683]$} & & {$[0.857]$} & {$[2.030]$} & & {$[2.172]$} \\
\%FoF & $-3.327^{* * *}$ & & $-2.839^{* * *}$ & $-10.745^{* * *}$ & & $-6.458^{* *}$ \\
& {$[0.807]$} & & {$[0.812]$} & {$[3.031]$} & & {$[3.203]$} \\
LogAssets & & $0.579^{* * *}$ & $0.496^{* * *}$ & & $1.097^{* * *}$ & $0.993^{* * *}$ \\
& & {$[0.137]$} & {$[0.171]$} & & {$[0.344]$} & {$[0.353]$} \\
Specialize & & $0.788^{* * *}$ & $0.891^{* * *}$ & & 0.312 & 0.797 \\
Canada & 0.326 & {$[0.262]$} & {$[0.277]$} & & {$[1.919]$} & {$[1.641]$} \\
& {$[0.599]$} & {$[0.652]$} & {$[0.892$} & -3.444 & 0.560 & -1.093 \\
Europe & $1.629^{* * *}$ & $1.325^{*}$ & 0.875 & {$[2.334]$} & {$[1.744]$} & {$[2.188]$} \\
& {$[0.812]$} & {$[0.679]$} & {$[0.689]$} & {$[4.392$} & 4.339 & 3.742 \\
Aus/Nzd & 0.151 & 0.094 & 0.173 & -1.486 & {$[4.409]$} & {$[4.114]$} \\
& {$[0.517]$} & {$[0.560]$} & {$[0.650]$} & {$[1.441]$} & -0.686 & -0.966 \\
Funds & 715 & 715 & 715 & 522 & $52.021]$ & {$[1.298]$} \\
Observations & 3,881 & 3,881 & 3,881 & 2,759 & 2,759 & 522 \\
\hline
\end{tabular}

In Table 4.9, I continue to observe that investments in alternative asset made through financial intermediaries have lower performance and the effect is statistically stronger in some specifications. Institutional investments managed by fund-of-funds underperform internally managed investments by 2.84 percentage points in real assets and by 6.46 percentage points in private equity. Investments through external managers have also significantly lower net benchmark-adjusted returns than investments done by internal asset management divisions in real assets and private equity. The relation between the mandate size and performance remains positive and significant. Larger institutional investors are able to access better investment projects in alternative assets at lower investment costs.

I extend the analysis on the effect of investment approach on performance by controlling for different definitions of the specializing variable and by estimating the effect of investor asset management policy in other assets. In Table 4.10, in addition to the Specialize dummy variable, 
I control for the number of simultaneous investments in alternative assets and for the concentration of alternative investments. To control for the asset management policy of institutional investors in public equity and fixed income, I include the \%IntEquity, \%ActEquity and \%ActFI in the panel regressions. One possibility is that institutional investors which engage in active management in public equity and fixed income have more active investing experience, which will enable them to select better investments or managers in alternative asset classes. Alternatively, these investors do not have a sufficient capacity to monitor active investments in public and private markets at the same time, which will lead to suboptimal allocation decisions in alternative assets. I do not find a consistent effect of the percentage allocation to active managers in equity and fixed income on the performance of institutional investors in real assets, private equity and hedge funds \& TAA. The degree of international diversification of investor holdings in public equity also does not have a consistent effect on the net benchmark-adjusted returns across the three alternative assets.

Importantly, the delegated investment approach variables, capturing the percentage allocation to external managers and fund-of-funds, remain negative and significant in all models in Table 4.10. For example, in private equity, external managers and fund-of-funds underperform internally managed investments by 5.72 and 7.54 percentage points annually. The economies of scale in alternative assets also remain significant in real assets and private equity. Doubling the holdings size in real assets results in 0.49 percentage points higher net benchmark-adjusted returns.

Based on the results in Table 4.10, the effect of specialization on performance varies across alternative asset classes. Institutional investors that specialize in real assets perform better than investors who simultaneously invest in multiple alternative asset classes. A specializing institutional investors obtains around 0.87 percentage points higher annual returns in real assets as compared to investor who combines real asset holdings with other alternative assets. In private equity and hedge funds \& TAA, specialization has neutral to weakly negative effect on performance. In the next section, I test whether the effect of specialization on performance differs across smaller and larger institutional investors.

\subsubsection{Specialization and performance}

When analyzing the effect of specialization on performance, I focus primarily on institutional allocation to real assets. The vast majority of the specializations are happening in real assets (1,291 out of 1,649 specializing observations are in real assets), whereas few institutional investors specialize in private equity and hedge funds \& TAA. In Table 4.11, I split the institutional investors into tertiles (small, medium and large) based on the amount invested in real assets. I estimate whether specialization has different effects on performance among small and large institutional investors. The markets for alternative assets are generally less transparent than public (equity and bond) markets, and institutional investors face higher fixed costs related to understanding, monitoring and learning about the investments. Hence, for smaller 


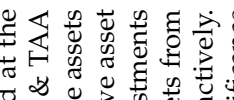

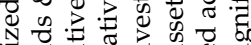

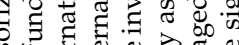

品步

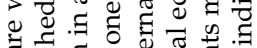

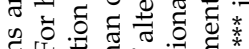

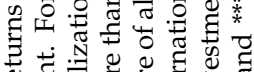

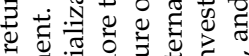

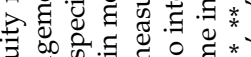

可

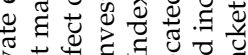

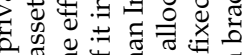

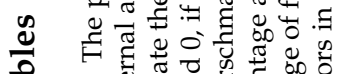

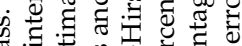

o क

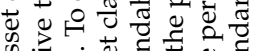

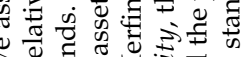

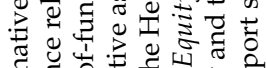

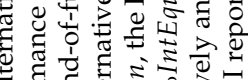

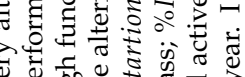

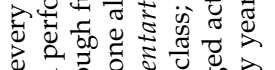

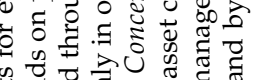

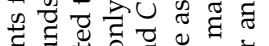

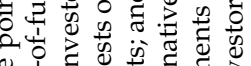

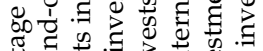

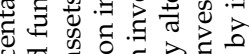

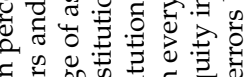

द्व

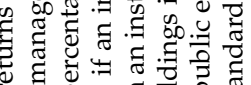

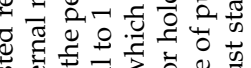

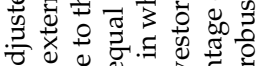

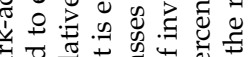

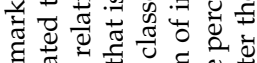

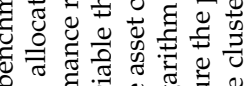



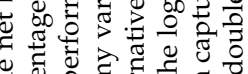

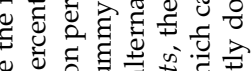

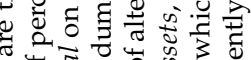

品

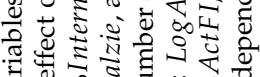

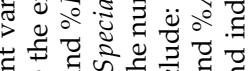

‡ च के

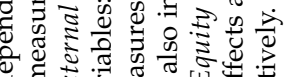

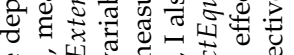

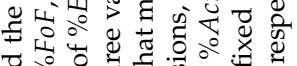

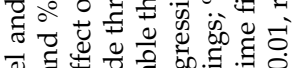

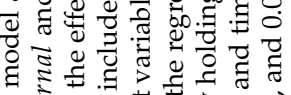

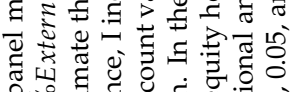

\%

正

g

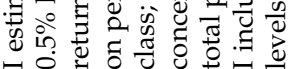

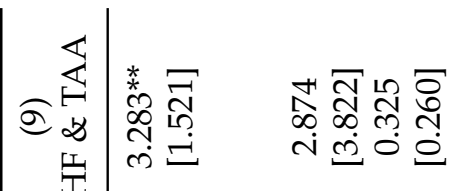

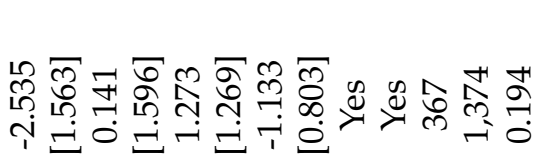

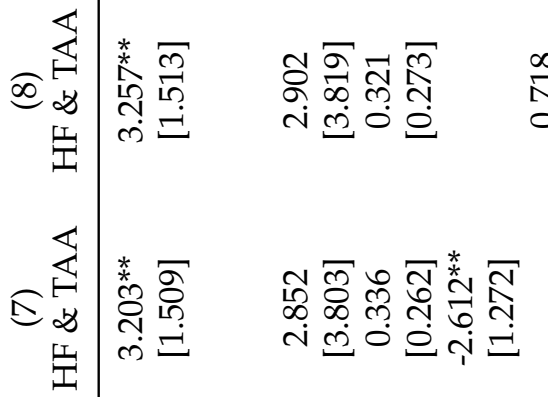

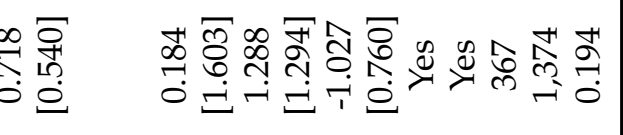

总

6

定

苟

色

ลิํํ유유

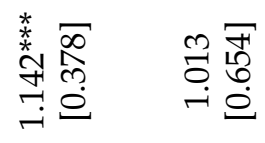

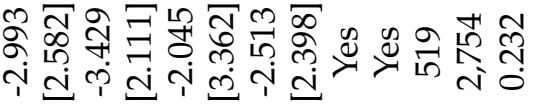

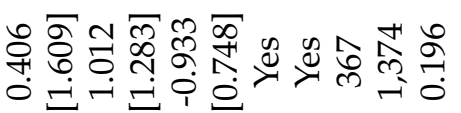

\&

.

ङ

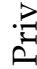

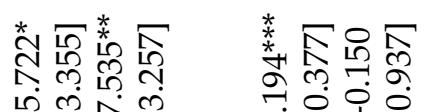

फिल

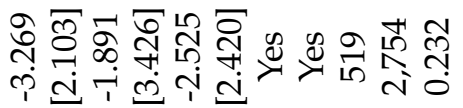

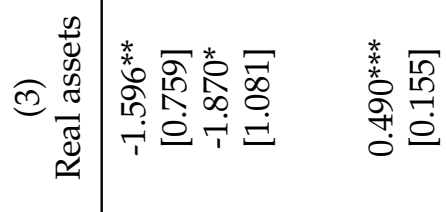

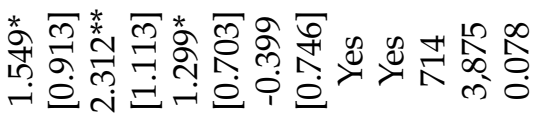

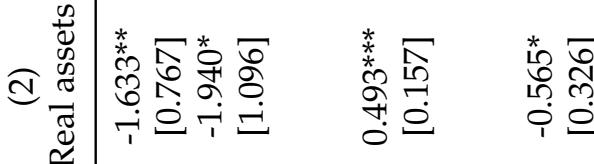

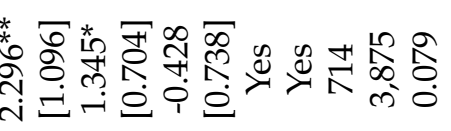

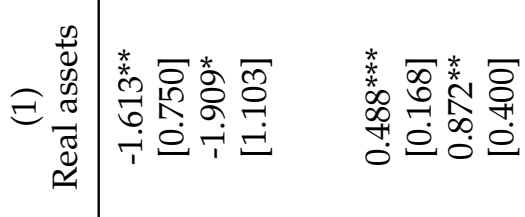

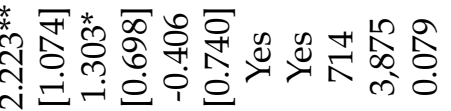

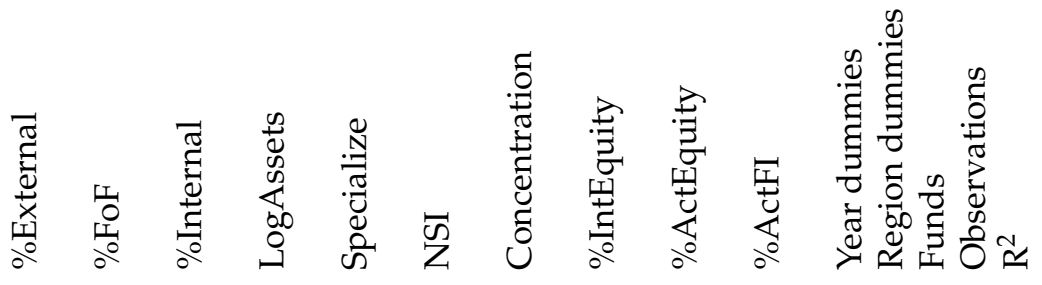


investors it may be beneficial to specialize in one alternative assets class, rather than diversifying across multiple alternative assets. However, for larger institutional investors, specialization can lead to lower performance due to liquidity related diseconomies of scale, because all alternative asset classes can be classified as illiquid investments.

In the panel regressions, I include interaction terms between the size tertiles and the specialize dummy variable to test whether the specializing decision has a non-uniform effect on performance in alternative assets. In addition to size and specialization, I also control for intermediation level, asset management policy in equity and fixed income, regional and time fixed effects.

Based on column (1), small investors have 1.37 percentage points lower net benchmarkadjusted returns. However, smaller institutional investors that specialize in real assets manage to overcome the scale disadvantages in performance. The interaction term Small $*$ Specialize shows that specializing small investors outperform diversified small investors by 1.79 percentage points. In the second part of Table 4.11, I examine whether small specializing investors underperform compared to large investors, by testing whether Small + Small $*$ Specialize $=0$. In all columns, the two coefficients together are not significantly different from zero, which shows that small investors can significantly offset the economies of scale in alternative assets by focusing only on one alternative asset class.

The tertile dummy variables confirm the previously documented economies of scale in the returns of institutional investors in alternative assets. Large institutional investors obtain significantly higher net benchmark-adjusted returns than small and medium investors. However, large specializing institutional investors do not enjoy economies of scale in alternative assets. The interaction term Large $*$ Specialize is negative and significant, while the joint test of Large + Large $*$ Specialize $=0$ is not different from zero. When large institutional investors specialize in one alternative asset class, they underperform other investors with similar amount of investments, but exposed to multiple alternative asset classes, by around 1.40 percentage points annually.

Overall, the majority of the specializing investments are done in real assets and their effect on performance is non-uniform. Taken together, my results suggest that in the small tertile, specialization results in higher returns, while in the large tertile specializing investors underperform. In private equity and hedge funds \& TAA, I observe similar non-uniform trend as in real assets, but the effect of specialization on performance is not significant, possibly due to the low number of specializing observation.

In sum, institutional investments in alternative asset managed by external managers and fund-of-funds have worse performance than their internally managed investments, by roughly 2-6 percentage points of net benchmark-adjusted returns per year, and these differences cannot be explained solely by the lower investment costs. I observe that investments through financial intermediaries perform significantly worse in all three alternative asset classes. In addition to the level of intermediation, holdings size provides significant positive economies of scale in alternative assets. Larger institutional investors manage to select and retain better internal 


\section{Table 4.11: Panel regressions: Specialization and performance across size tertiles}

I split the institutional investors into tertiles (small, medium and large) based on the amount invested in real assets. I estimate a panel model and the dependent variable is the net benchmark-adjusted returns in real assets. In the regressions, I include Small and Large dummy variables to control for the effect of mandate size on returns. Specialzie is a dummy variable that equals 1 if an institution invests only in one alternative asset class and 0 , if it invests in more than one alternative asset class. Small $*$ Specialize and Large $*$ Specialzie are two interaction terms, capturing the difference in specialization effect on performance between small and large investors. \% External, the percentage allocated to external managers, and \%FoF, the percentage allocated to fund-of-funds, measure the effect of these investment approaches on performance relative to internal asset management. In column (6), I also include: \%IntEquity, the percentage allocated to international equity assets from total public equity holdings; $\%$ ActEquity and \%ActFI, the percentage of public equity investments managed actively and the percentage of fixed income investments managed actively. Canada, Europe and Aus/Nzd are regional dummy variables (the base result refers to U.S. investors). I report standard errors in brackets. ${ }^{*}, * *$ and ${ }^{* * *}$ indicate significance levels of $0.10,0.05$, and 0.01 , respectively. In the second part of the table, I test whether specialization in one alternative asset class can mitigate the scale economies in alternative assets. P-values of the tests are presented in the parentheses.

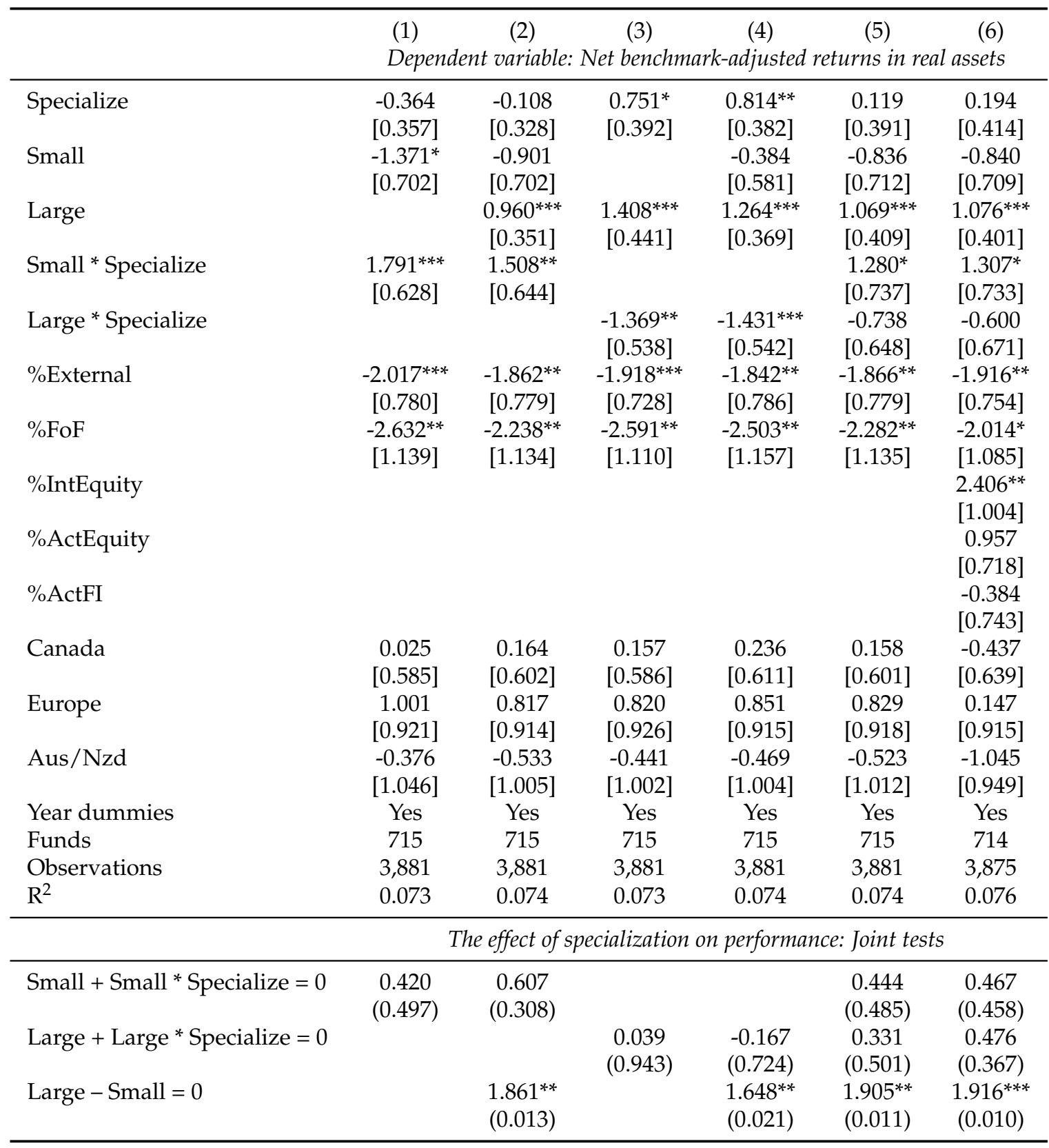


and external managers, which results in better performance. However, among real asset investments, where the vast majority of the institutional specializations are happening, there is a significant non-uniform effect of specialization on performance. While specialization is an advantage for smaller investor in alternative assets, for larger investors it is a limitation and results in lower net benchmark-adjusted returns.

I acknowledge that precise measures of risk for the alternative investments are not available and therefore that differences in returns may in theory be attributed to differences in risk profiles of investments managed internally, externally or by fund-of-funds. However, there is little reason to believe that riskier projects will be managed internally and not by financial intermediaries focused on one asset class and potentially higher expertise.

\subsection{The contribution of alternative assets to investor performance}

I now examine the contribution of alternative investments for the overall performance of institutional investors. Even though external managers and fund-of-funds underperform internal managers, it could be that they deliver higher net returns than public equity. In this case, the decision of institutional investors to rely on delegated investment management in alternative assets benefits their overall performance despite the underperformance on an asset class level. I compare the net returns of institutional investors in alternative assets with the potential returns they could have achieved, if they invested all their alternative holdings passively in public equity. In the CEM database, investors report their self-designated benchmarks and asset allocation weights for all public equity asset classes. Hence, the potential passive performance in equity is estimated separately for each institutional investor, as a weighted average of benchmark returns across all equity asset classes. This scenario takes into account the actual investor allocation in public equity and assumes that investors can spread their holdings in alternative assets across passive mandates in these equity asset classes.

In Table 4.12, I conduct the analysis separately for large, medium and small institutional investors, because mandate size is an important determinant of performance in alternative assets. I split the institutional investors into tertiles (small, medium and large) separately for every alternative asset class, based on the amount of assets invested in that alternative asset class. Investors in the small tertile invest around 24-63 million US\$ in alternative assets, while large investors manage more than 2 billion US\$ in every alternative asset class.

Using the self-reported benchmark returns and asset allocation in public equity, I observe that private equity is the only alternative asset class that delivered higher returns than passive investing in public equity. Institutional investors significantly underperform their passive equity benchmarks by investing in real assets and hedge funds \& TAA. Nevertheless, one can argue that this estimation is based on historical data and the comparison between asset classes is not capturing the expected returns.

However, across all three alternative asset classes there is strong underperformance pattern among small institutional investors. Even in private equity, which delivered higher average net returns, small investors significantly underperform their passive equity benchmarks by 
Table 4.12: Scenario: Passive investments in public equity instead of alternative assets

I split the institutional investors into tertiles (small, medium and large) separately for every alternative asset class, based on the amount of assets invested in that alternative asset class. All investors column presents the estimates for the three size tertiles together. Assets row presents the average assets invested in million US\$. The scenario analysis compares the net returns in alternative assets $\left(\mathrm{NR}_{\mathrm{Alter}}\right)$ with the potential passive returns in public equity $\left(\mathrm{BMR}_{\text {Equity }}\right)$. The potential passive performance in public equity is estimated separately for each institutional investor as a weighted average of benchmark returns across all public equity asset classes. In the estimation, I use the self-reported benchmarks and allocation weights for every public equity asset class in the CEM data, which differ significantly across investors. Panels A, B and C present the differences in returns between alternative assets and public equity for real assets, private equity and hedge funds \& TAA, respectively.

\begin{tabular}{lcccc}
\hline & Small & Medium & Large & All investors \\
\hline Panel A: Real assets & & & & \\
\hline Assets in million \$US & 31 & 176 & 2,417 & \\
NR $_{\text {Alter }}-$ BMR $_{\text {Equity }}$ & $-3.044^{* * *}$ & $-2.316^{* * *}$ & $-2.028^{* * *}$ & $-2.464^{* * *}$ \\
\hline Panel B: Private equity & & & & \\
\hline Assets in million $\$ \mathrm{US}$ & 24 & 164 & 2,201 & \\
NR $_{\text {Alter }}-$ BMR $_{\text {Equity }}$ & $-2.786^{* * *}$ & $3.733^{* *}$ & $3.797^{* * *}$ & $1.558^{* *}$ \\
\hline Panel C: Hedge funds and TAA & & & \\
\hline Assets in million $\$ \mathrm{US}$ & 63 & 273 & 2,031 & \\
NR $_{\text {Alter }}-$ BMR $_{\text {Equity }}$ & $-2.321^{* * *}$ & $-1.897^{* * *}$ & -0.938 & $-1.726^{* * *}$ \\
\hline
\end{tabular}

2.79 percentage points annually. Small institutional investors underperform their self-reported equity benchmarks in real assets and hedge funds \& TAA by similar amount. I observe that small investors would have obtained at least 2 percentage points higher annual returns, if they invested passively in public equity rather than alternative assets.

The scenario analysis suggests that, when investing in alternative assets, investor size is an important determinant of performance. Smaller investors should reconsider their allocation to alternative asset classes, since these results suggests that they cannot get access to the same investment projects as larger investors. The amount of asset under management limits the ability of small institutional investors to select and retain good managers or investment projects.

\subsection{Conclusion}

I examine the allocations and performance of institutional investors in alternative assets. In private equity, real assets and hedge funds, institutional investors usually do not act as the ultimate portfolio manager, but rather delegate the asset management decisions to financial intermediaries. When investing through financial intermediaries, institutional investors tradeoff higher expected returns from these intermediaries against the increased exposure to agency conflicts arising from greater coordination problems and uncertainty about their skills and incentives. Institutional investors can also bypass the financial intermediaries, by investing internally and select directly alternative investments. 
Over time, the average allocation to internal mandates has declined at the expense of external managers and fund-of-funds, even though institutional investors that establish internal asset management divisions in alternative assets tend to perform better than their counterparts, which rely on financial intermediaries. The underperformance of financial intermediaries in real assets, private equity and hedge funds is consistent with the Stoughton et al. (2011) theoretical model of financial intermediation. I document that multiple levels of delegated asset management result in lower performance in all three alternative asset classes. This result confirms the implication of the Stoughton et al. (2011) financial intermediation model that underperforming assets are more likely to be sold indirectly, through external managers and fund-of-funds, in private markets which allow kickback payments to consultants and placement agents.

Fund size is an important determinant of intermediation level and performance. Larger institutional investors are more likely to invest internally in alternative assets, which reduces their investment costs and improves significantly their performance. In addition to establishing efficient internal mandates, the large amount of asset under management provides negotiation power to these large institutional investors, which enables them to select and retain better external managers at lower investment costs. Smaller institutional investors can offset the scale disadvantage by specializing in one alternative asset class. Small specializing investors rely less on fund-of-funds and perform significantly better than small institutional investors that invest simultaneously in real assets, private equity and hedge funds. However, the majority of the small investors do not specialize, and I document that they would have obtained at least 2 percentage points higher annual net returns, if they invested passively in public equity rather than alternative assets.

Overall, the levels of intermediation serving as interface between investors and assets lead to systematic differences across institutional returns in alternative assets. Even though delegated asset managers underperform the internal investments net of fees, this is an equilibrium for institutional investors that delegate portfolio management to intermediaries based on trust. According to the Gennaioli et al. (2013) asset management model, investors will retain underperforming external managers, as an institutional investor who trusts a particular manager perceives returns on risky investments delivered by this manager as less uncertain than those delivered by a less trusted manager. These institutional investors will also continue investing through funds-of-funds, because this intermediation level enables institutions investing based on trust to reduce the responsibility and anxiety about external managers selection. 


\subsection{Chapter 4 Appendix}

\section{Table B.1: Examples of self-reported benchmarks in the CEM data}

This table presents the most frequent return benchmarks for every alternative asset class. For real assets, I present the benchmarks separately for direct real estate, REITs, infrastructure, natural resources and commodities. In private equity, investors report benchmarks separately for venture capital, leveraged buyout and diversified private equity, which includes VC, LBO, turnarounds, start-ups, mezzanine, and distressed financing.

\begin{tabular}{|c|c|}
\hline \multicolumn{2}{|r|}{ Benchmark description } \\
\hline Real assets & \\
\hline - Direct real estate & $\begin{array}{l}\text { NCREIF (national, regional and property types); Wilshire RE Securities } \\
\text { IPD Global; RCPI; ICREIM/IPD; GPR 250; EPRA Global; Carnegie Real estate } \\
\text { Custom (XX\% NCREIF + XX\% REIT); CPI + X\%; Government bonds + X\% }\end{array}$ \\
\hline - REITs & $\begin{array}{l}\text { FTSE EPRA/NAREIT; Wilshire REIT; MSCI US REIT; S\&P/TSX REIT } \\
\text { GPR250 Europe; FTSE EPRA/NAREIT Developed RE }\end{array}$ \\
\hline - Infrastructure & $\begin{array}{l}\text { CPI + X\%; Eurozone inflation + X\%; Australian CPI + X\%; Euribor + X\% } \\
\text { S\&P Global Infrastructure Index; Dow Jones Infrastructure Index; BNP Clean Energy } \\
\text { Target IRR or Absolute return of X\%; 5year Barclays Bellwether swap + X\% } \\
\text { 50\% DEX Real Bonds + 50\% MSCI World; ASX300+X\%; GSCI and S\&P Materials } \\
\text { Cambridge Associates Private Equity Index; NCREIF; ICREIM/IPD; Energy LPs }\end{array}$ \\
\hline - Natural resources & $\begin{array}{l}\text { NCREIF Timberland; NZSU Timber; S\&P Global Timber and Forestry Index } \\
\text { Energy Index; TSX Oil\&Gas; S\&P GSCI; 50\% S\&P GSCI + 50\% NCREIF Timber } \\
\text { Barclays US Aggregate; Barclays US TIPS; Handelsbanken Index-linked + X\% } \\
\text { NCREIF ODCE; } 10 \text { year Euro government bonds + X\%; Russell } 2000+X \% \\
\text { LIBOR + X\%; Local CPI + X\% + country risk premium; } X \% \text { Hurdle; T-Bills + X\% }\end{array}$ \\
\hline - Commodities & $\begin{array}{l}\text { S\&P GSCI Index; Dow Jones UBS Index; Schroder / Wellington Commodities } \\
\text { XAU Gold and Silver Mining Index; S\&P GSCI light energy } \\
\text { Forward Oil Contract; GSCI Petroleum; GSCI excluding Gas / Oil } \\
\text { RPI + X\%; } 3 \text { months Euribor + X\%; CPI Qtr lag + X\% } \\
\text { Custom (XX\% Equity index + XX\% Commodity Index) }\end{array}$ \\
\hline \multicolumn{2}{|l|}{ Private equity } \\
\hline - Venture capital & $\begin{array}{l}\text { Cambridge VC; Thomson Venture Economic Index } \\
\text { Equity index (Wilshire5000, MSCI Europe Small Cap) } 1 \text { Quarter Lag + X\% }\end{array}$ \\
\hline - Leveraged buyout & $\begin{array}{l}\text { Equity indexes (S\%P500 / Wilshire5000 / S\&P/ASX / MSCI Europe + X\%) } \\
\text { Absolute return X\%; Cambridge PE; Equity index } 1 \text { Quarter Lag + X\% }\end{array}$ \\
\hline - Diversified & $\begin{array}{l}\text { Equity indexes (Russel2000 / Wilshire5000 / S\&P/TSX / MSCI World + X\%) } \\
\text { S\&P500 / Wilshire } 5000 \text { moving } 3 \text { year average } \\
\text { Cambridge PE; Thomson Venture Economic Index } \\
\text { Absolute return X\%; LIBOR + X\% }\end{array}$ \\
\hline \multicolumn{2}{|l|}{ Hedge funds \& TAA } \\
\hline - Hedge funds & $\begin{array}{l}\text { HFRI/HFRX Indexes (all indexes and sub strategies); Credit Suisse Indexes } \\
\text { CPI + X\%; Libor + X\%; T-Bill + X\%; Bank of Canada Overnight Rate + X\% } \\
\text { Equity indexes (S\&P500, TSE300, FTSE); Custom (S\&P500 + X\%) } \\
\text { Absolute return X\%; } 50 \% \text { Absolute return X\% + 50\% S\&P500 }\end{array}$ \\
\hline - TAA & $\begin{array}{l}\text { Custom }(X X \% \text { equity index }+X X \% \text { fixed income benchmark) } \\
\text { MSCI World (hedged or unhedged) } \\
\text { CPI }+X \% \text {; Libor }+X \% \text {; Euribor }+X \% \text {; T-Bill }+X \% \\
\text { Hedge fund indices (HFRI, HFRX and Credit Suisse Indexes) } \\
\text { Absolute return } X \%\end{array}$ \\
\hline
\end{tabular}




\section{Table B.2: Gross benchmark-adjusted return differences}

This table presents the gross benchmark-adjusted returns in alternative assets, which I estimate by subtracting the benchmark returns from the gross returns. Columns Int, Ext and FoF show the mean gross benchmark-adjusted returns separately for every intermediation level. The second row presents the standard errors in brackets and the third row counts the observations. Columns Int vs Ext, Int vs FoF and Ext vs FoF present the t-tests of differences in gross benchmark-adjusted returns. Each set of the three rows in the t-test columns consists of row of mean differences, a row of standard deviations in brackets, and a third row with t-statistics. The t-statistics are for the test with null hypothesis that the difference between the returns of different levels of intermediation equals zero. ${ }^{*}, * *$, and ${ }^{* * *}$ indicate significance levels of $0.10,0.05$, and 0.01 , respectively.

\begin{tabular}{|c|c|c|c|c|c|c|}
\hline & \multicolumn{6}{|c|}{ Gross benchmark-adjusted returns } \\
\hline & Int & Ext & FoF & Int vs Ext & Int vs FoF & Ext vs FoF \\
\hline Real assets & $\begin{array}{c}1.571 \\
{[0.363]} \\
841\end{array}$ & $\begin{array}{c}0.060 \\
{[0.168]} \\
3,360\end{array}$ & $\begin{array}{c}-2.994 \\
{[1.178]} \\
139\end{array}$ & $\begin{array}{c}1.511^{* * *} \\
{[0.381]} \\
t=3.967\end{array}$ & $\begin{array}{l}4.565^{* * *} \\
{[1.012]} \\
\mathrm{t}=4.511\end{array}$ & $\begin{array}{c}3.054^{* * *} \\
{[0.858]} \\
t=3.560\end{array}$ \\
\hline Private equity & $\begin{array}{c}4.312 \\
{[2.133]} \\
389\end{array}$ & $\begin{array}{c}2.502 \\
{[0.597]} \\
2,172\end{array}$ & $\begin{array}{c}1.671 \\
{[0.913]} \\
813\end{array}$ & $\begin{array}{c}1.810 \\
{[1.674]} \\
t=1.081\end{array}$ & $\begin{array}{c}2.641 \\
{[1.980]} \\
t=1.334\end{array}$ & $\begin{array}{c}0.831 \\
{[1.124]} \\
t=0.739\end{array}$ \\
\hline Hedge funds \& TAA & $\begin{array}{c}2.294 \\
{[4.529]} \\
59\end{array}$ & $\begin{array}{c}0.954 \\
{[0.370]} \\
1,039\end{array}$ & $\begin{array}{c}-1.110 \\
{[0.449]} \\
618\end{array}$ & $\begin{array}{c}1.340 \\
{[1.887]} \\
t=0.710\end{array}$ & $\begin{array}{l}3.403^{*} \\
{[2.011]} \\
t=1.692\end{array}$ & $\begin{array}{c}2.063^{* * * *} \\
{[0.592]} \\
t=3.486\end{array}$ \\
\hline
\end{tabular}




\section{Table B.3: Panel regressions: Private equity net benchmark-adjusted return (related to Table 4.8)}

I estimate a panel model and the dependent variable is the private equity net benchmark-adjusted return in percentage points. As compared to Table 4.8, the private equity net benchmark-adjusted returns are not winsorized. \%External, the percentage allocated to external managers, and $\% F o F$, the percentage allocated to fund-of-funds, capture the effect of these intermediation levels on performance relative to internal asset management. As independent variables, I also include: LogAssets, the logarithm of investor holdings in every alternative asset class, and Specialzie, a dummy variable that is equal to 1 if the institution invests only in one alternative asset class and 0 , if it invests in more than one alternative asset class. Canada, Europe and Aus/Nzd are regional dummy variables (the base result refers to U.S. investors). I include year dummies and independently double cluster the robust standard errors by investor and by year. I report standard errors in brackets. ${ }^{*}, * *$, and ${ }^{* * *}$ indicate significance levels of $0.10,0.05$, and 0.01 , respectively.

\begin{tabular}{lccc}
\hline & $(1)$ & $(2)$ & $(3)$ \\
& Private equity & Private equity & Private equity \\
\hline \%External & $-9.209^{*}$ & & -7.660 \\
& {$[4.828]$} & & {$[4.829]$} \\
\%FoF & $-12.737^{* * *}$ & & $-9.819^{* *}$ \\
& {$[4.838]$} & & {$[4.717]$} \\
LogAssets & & $1.401^{* * *}$ & $1.190^{* * *}$ \\
& & {$[0.399]$} & {$[0.382]$} \\
Specialize & & -0.355 & 0.054 \\
& & {$[1.130]$} & {$[1.055]$} \\
Canada & -5.551 & -0.935 & -3.267 \\
& {$[3.528]$} & {$[2.895]$} & {$[3.323]$} \\
Europe & 3.247 & 4.442 & 3.846 \\
& {$[3.652]$} & {$[4.100]$} & {$[3.776]$} \\
Aus/Nzd & -3.252 & -1.215 & -2.601 \\
& {$[2.262]$} & {$[2.159]$} & {$[2.133]$} \\
Year dummies & Yes & Yes & Yes \\
Funds & 522 & 522 & 522 \\
Observations & 2,759 & 2,759 & 2,759 \\
$\mathrm{R}^{2}$ & 0.187 & 0.188 & 0.192 \\
\hline
\end{tabular}





\section{Chapter 5}

\section{Value Added From Investment}

\section{Managers in Private Markets? Evidence from Pension Fund Investments in Real Estate $^{*}$}

\subsection{Introduction}

Over the last decade, institutional investors have significantly increased their exposure to alternative assets. For instance, pension funds increased their exposure to real estate, private equity, hedge funds, infrastructure and commodities from 9 percent in 1990 to 16 percent in 2010 (Andonov, Bauer, and Cremers, 2012), while university endowment funds increased the allocation to alternative assets from 7 percent in 1989 to 19 percent in 2005 (Brown, Garlappi, and Tiu, 2010). The markets for these private assets are generally less transparent than public markets, and institutional investors face significant fixed costs related to understanding, monitoring and learning about the investments.

To achieve superior returns in private markets, gathering information about specific assets and capitalizing on the acquired informational advantage requires a high level of specialization. This induces the majority of institutional investors to pick multiple external asset managers who are specialized in a single asset class and to delegate portfolio decisions to these specialists. However, according to Binsbergen, Brandt, and Koijen (2008) delegated investment management can cause several misalignments of objectives between the institutional investors and their external managers, such as loss of diversification, unobservable managerial appetite for risk, and different investment horizons. Institutional investors can significantly offset these agency conflicts by employing good specialized asset managers to work in their internal investment divisions, but they face high search costs. In this paper, we investigate whether pension funds have rationally moved toward delegated portfolio management in private markets, given the greater coordination problem and higher fees that delegation brings. Alternatively, it

${ }^{*}$ This chapter is co-authored with Piet Eichholtz (Maastricht University) and Nils Kok (Maastricht University). 
is possible that the increased prevalence of delegated asset management is simply due to pension funds shifting responsibility for potentially poor performance to external managers and fund-of-funds (Lakonishok, Shleifer, and Vishny, 1992).

Within the delegated asset management, investors can directly select external managers or invest through fund-of-funds. We empirically test the implications of Stoughton, $\mathrm{Wu}$, and Zechner (2011) financial intermediation model, which predicts that the variety of intermediation channels by which an asset is sold is related to its performance. We compare the performance of investments managed by fund-of-fund with investments through internal and external managers, testing whether underperforming assets can only be sold indirectly, through multiple intermediaries, like fund-of-funds. Overall, we extend the delegated portfolio management literature by providing implications for the approach of institutional investors towards investing in private assets.

This paper examines the allocation and performance of pension funds in real estate investments, which is the most significant alternative asset class for institutional investors. ${ }^{2}$ The paper adds to the recent literature on the performance of private equity mandates, another asset class characterized by illiquidity and a seemingly inefficient market, but accounting for a lower share of pension fund wealth. For example, Lerner, Schoar, and Wongsunwai (2007) analyze whether there are systematic differences in private equity returns and investment strategies across several different classes of institutional investors (limited partners), e.g. banks, corporate and public pension funds, endowments, advisors, and insurance companies. Hochberg and Rauh (2013) extend the analysis of heterogeneity in the performance of private equity investments by institutional investors, documenting that especially public pension funds exhibit substantial home-state bias and underperform with their local investments. ${ }^{3}$

We contribute to the literature on financial intermediation and investment performance in illiquid alternative assets by providing new insights into the investment behavior, fee structure and performance of pension funds in their allocations to real estate. Real estate offers unique possibilities to explore the role of intermediated investment management. First, real estate is the alternative asset class with most heterogeneity in the implemented investment approach. On the one hand, internal management, i.e. direct selection of properties of REITs (without intermediaries), accounts for a significant part of pension fund assets. On the other hand, in addition to delegating investments to external managers, pension funds increasingly use fund-of-funds, which yields an additional layer of intermediation. Internal management is also possible in private equity, but this approach is significantly less common, ${ }^{4}$ whereas for investments in hedge funds, internal management is almost impossible and the choice of

\footnotetext{
${ }^{2}$ For example, all properties in the most widely used U.S. private real estate index, the NCREIF Property Index (representing more than $\$ 315$ billion in 2012), have been acquired, at least in part, on behalf of tax-exempt institutional investors - the great majority of which are pension funds. Outside of the U.S., pension funds constitute more than 60 percent of the investors in the IPD U.K. property database (Bond and Mitchell, 2010), the main U.K. private real estate index.

${ }^{3}$ See also Kaplan and Schoar (2005) and Phalippou and Gottschalg (2009) for analysis of private equity fund performance.

${ }^{4}$ According to the CEM database, on average, only 11 percent of the private equity investments are managed internally, while in real estate internal investment approach accounts for 19 percent of the assets (http://www . cembenchmarking.com/Default . aspx).
} 
investment approach is limited to external managers or fund-of-funds. Second, only in real estate investors have the option to substitute an illiquid product (direct real estate) with a liquid product (REITs) that generally has comparable long term performance. ${ }^{5}$

We use the CEM dataset, the broadest global database on pension fund investments. This unique database contains data for almost 900 defined benefit pension funds across the world over the 1990-2009 period. The assets under management of these funds exceeded $\$ 4.7$ trillion in 2009. ${ }^{6}$ The CEM database provides extensive coverage of both direct real estate investments and REIT holdings. For instance, the aggregate pension fund holdings of private commercial real estate in the database add up to more than $\$ 240$ billion in 2009, which represents 30 percent of the aggregate market value of the IPD Global Property Index (and equals the total market value of the U.S. NCREIF Property Index). REIT holdings of pension funds covered by CEM in 2009 equal some $\$ 74$ billion, which corresponds to more than 11 percent of the FTSE EPRA/NAREIT Global Index in 2009.

Our results show that about 75 percent of the pension funds in the CEM database invest in real estate, allocating on average 5.36 percent of pension fund assets (average allocations to private equity and hedge funds are 4.00 and 3.23 percent, respectively). Once pension funds decide to invest in real estate, they have to make two choices. First, pension funds have to decide on the real estate investment approach. Funds typically employ three investment approaches: internal management, external management and investing through fund-of-funds. We document that just 19 percent of real estate investments are managed internally by pension funds. Larger pension funds are more likely to invest internally, whereas smaller funds are more likely to rely on intermediaries, investing externally or through fund-of-funds. However, even among the largest quintile of pension funds, with on average $\$ 33$ billion in assets under management, only 42 percent of the funds manage direct real estate or REIT portfolios internally. Importantly, pension funds with greater allocation to other alternative asset classes, like private equity and hedge funds, are more likely to invest in real estate through financial intermediaries, suggesting that internal management can be viewed as a more specializing approach.

Second, funds select the investment subcategory: direct real estate investments or investments in REITs. Although listed REITs provide liquid and scalable property exposure, which should make these vehicles attractive to smaller investors, we document that larger funds are in fact more likely to invest in REITs. Allocations to REITs are mostly implemented as complementary investments to the direct real estate holdings of larger pension funds.

The choice of investment subcategory and approach has significant effects on the costs and performance of pension fund investments in real estate. On average, pension funds pay fees of 76 basis points for investments in real estate, which are higher for direct real estate (83 basis points) and lower for REITs (41 basis points). Even though our cost figures do not include

\footnotetext{
${ }^{5}$ Pagliari, Scherer, and Monopoli (2005) document that the return characteristics of direct real estate and listed real estate investment trusts (REITs) are not different after controlling for leverage, property mix and appraisal smoothing.

${ }^{6} \mathrm{CEM}$ collects data from pension funds investing in multiple asset classes and the data have been used previously by French (2008) to study the cost of active investing, and by Andonov et al. (2012) to examine the asset allocation, market timing and security selection skills of pension funds.
} 
the performance fees (which are subtracted directly from returns in the CEM database), real estate investment fees are substantially lower than fees for investments in private equity and hedge funds. Phalippou (2009) and Metrick and Yasuda (2010) estimate that the average private equity buyout fund charges fees of more than 7 percent per year (the annual management fee alone is 2 percent of capital commitments). For hedge funds, French (2008) documents that the average annual fee is 4.26 percent of assets (the management fee alone is 1.16 percent) over the 1996-2007 period, and for funds-of-hedge-funds, the average fees are even higher.

We find strong economies of scale in the costs of real estate investments: doubling the size of a real estate mandate reduces the annual costs by 32 basis points. Importantly, we document that larger pension funds are not only able to organize internal mandates more efficiently, but also negotiate lower fees with external investment managers. Financial intermediation, like external management and fund-of-funds, considerably increases the overall investment costs. A fund that invests internally has 21 basis points lower investment costs than a fund that invests through external managers. Investing through fund-of-funds increases the costs by 122 basis points.

On a net benchmark-adjusted basis, we find that pension funds generally meet the thresholds of their benchmarks. There is substantial heterogeneity in the investment returns of pension fund allocations to real estate. We document that larger funds obtain higher net benchmarkadjusted returns: doubling the size of real estate holdings increases returns by 32 to 43 basis points. We observe these economies of scale both among REIT investments and direct real estate investments. In addition, larger funds have a better performance in their internal as well as external mandates. These results suggest that larger pension funds not only invest more efficiently internally, but can also select and retain better external managers.

The investment approach has an even stronger effect on performance. When controlling for size and costs, pension funds investing through internal asset management divisions obtain 102 basis points higher net benchmark-adjusted returns than funds that delegate the asset management to external managers. Moreover, investing through fund-of-funds results in a 202 basis points lower return. Overall, financial intermediation through externally delegated asset management in real estate investments results in significant underperformance.

Our results on the effect of investment approach on performance in alternative assets are in line with the theoretical model of financial intermediation by Stoughton et al. (2011), where only high net-worth institutions invest directly and achieve superior returns, while underperforming assets are only sold indirectly, through external managers and fund-of-funds. The findings in this paper also complement the empirical evidence on the agency conflicts and inferior investment performance resulting from intermediation among equity mutual funds (see, for example, Bergstresser, Chalmers, and Tufano, 2009; Chen, Hong, Jiang, and Kubik, 2013).

The economies of scale in pension fund performance in real estate are contrasting the diseconomies of scale that have been documented for equity mutual funds (Chen, Hong, Huang, and Kubik, 2004), but are in line with the evidence on private equity funds and hedge funds. Kaplan and Schoar (2005) document a concave relation between fund size and performance of private equity funds, whereas Agarwal, Nanda, and Ray (2013) find that larger institutions 
invest more directly instead of using funds of hedge funds, and outperform the smaller institutions.

Our findings have some general implications for the investment management industry. In line with Lakonishok et al. (1992) and Goyal and Wahal (2008) we conclude that pension funds should avoid extended intermediation chains, like fund-of-funds, and could benefit from considering the full range of investment approaches. Especially larger investors should evaluate the possibility of investing internally. The findings also show that portfolio size provides negotiating power with respect to cost and access to better investment opportunities. Smaller pension funds should therefore reconsider their approach to real estate investments, substituting direct holdings with REITs and specializing in one alternative asset class, instead of simultaneously investing in multiple alternative assets.

\subsection{How institutional investors invest in real estate}

Thus far, academic research has focused predominantly on the risk-return characteristics of real estate in a mixed-asset portfolio. Compared to typical portfolio models, predicting about 10-20 percent allocations to real estate, ${ }^{7}$ institutional investors generally have more modest allocations to private and public real estate investments. In this section, we explain the institutional marketplace and the investment process for institutional investors considering an allocation of assets to real estate. Figure 5.1 provides a stylized chart of the decision process and financial intermediation layers that investors face when investing in real estate.

The first decision is whether an institutional investor includes real estate in the strategic asset allocation. Institutional investors seeking exposure to real estate can invest in debt-type assets and equity-type assets. Debt-type assets include private commercial real estate debt (whole loans or mortgages) and commercial mortgage-backed securities. The debt real estate assets are usually part of a broader fixed income portfolio and are not the focus of this paper. Our analysis covers real estate equity investments, which are generally organized as separate mandates in the pension fund portfolio. There are two subcategories of real estate equity assets: (1) direct (private) commercial real estate and (2) listed (public) real estate equity, in many countries structured as real estate investment trusts (REITs), or an equivalent legal structure.

After deciding to invest in real estate directly, through REITs, or using a combination, a pension fund selects an investment approach. Investing in direct (private) real estate can be executed internally or can be outsourced to third-party fund managers. If a fund decides to invest in direct real estate internally, it typically establishes a separate or "at-arms-length" division. ${ }^{8}$ When outsourcing the investment decision, institutional investors can directly select the

\footnotetext{
${ }^{7}$ See for example: Friedman (1971) and Kallberg, Liu, and Greig (1996).

${ }^{8}$ Internal investing means that the buy-sell decisions for the individual properties are made within the organization (including wholly-owned subsidiaries).
} 


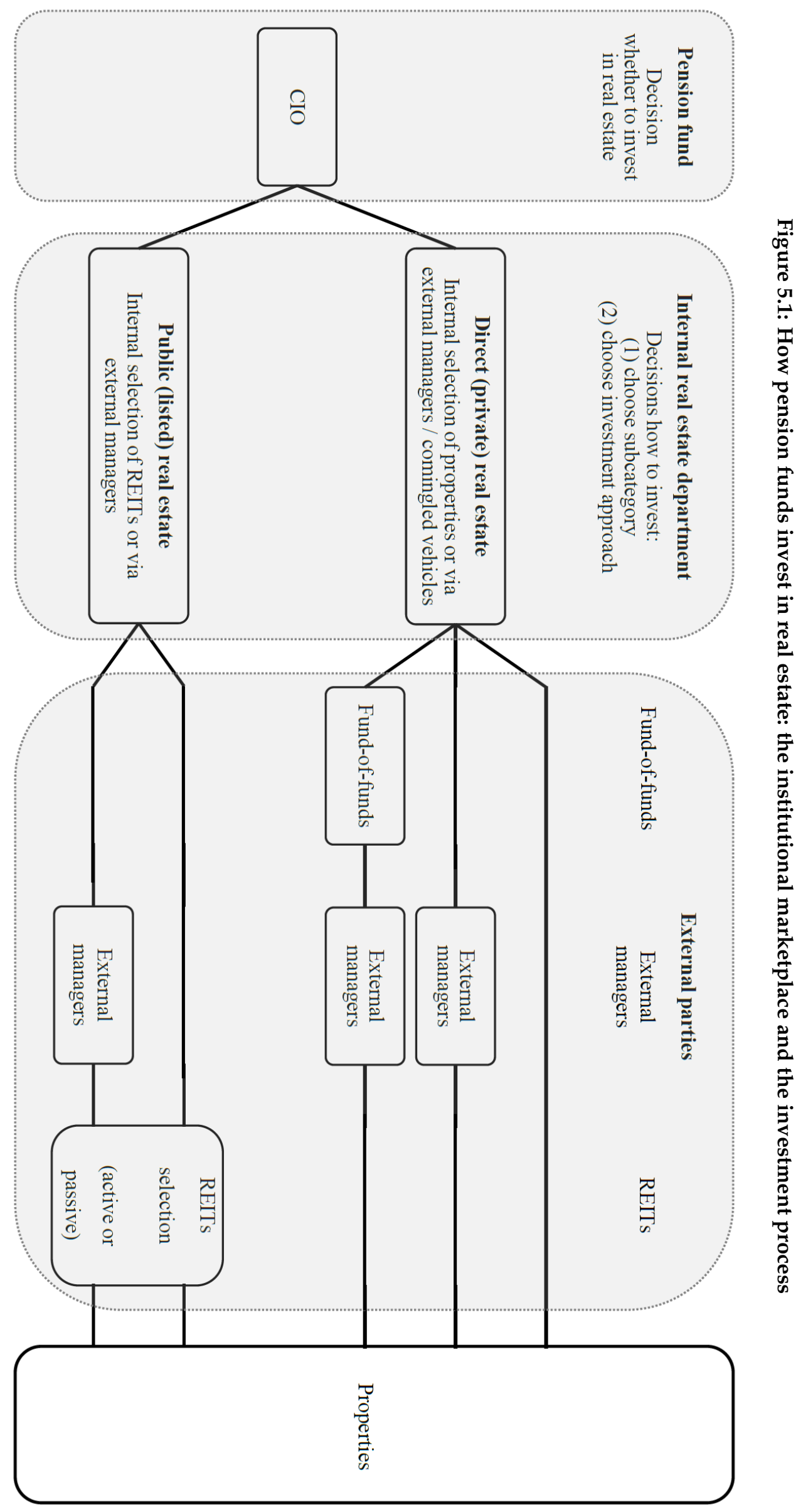


external managers (funds) or invest via fund-of-funds. ${ }^{9}$ In case of the latter, the fund-of-fund manager selects the external managers (funds), who then acquire the assets.

Investing in public real estate securities requires selection of REITs, which can be outsourced to external investment managers, or can be executed internally by the pension fund. REIT investments can also be classified as passive if they replicate a broad capital market benchmark (e.g., the FTSE NAREIT Index) or are dedicated to matching a specific set of liabilities (i.e., if REIT investments are part of a strategic asset allocation designed to match fund-specific liabilities).

Overall, an institutional investor directly acquires or disposes of properties only if that institutions internally invests in direct real estate. External investing in direct real estate and REITs creates additional intermediation layers between the pension fund and the assets. Figure 5.1 illustrates these additional layers. The involvement of third-party intermediaries potentially creates principal-agent conflicts and increases the investment costs, as each intermediation layer leads to additional fees. However, not all approaches delegating investments create similar agency problems. REITs, for example, are listed on the stock market, which not only increases transparency and liquidity, but also lowers investment costs. In addition, the institutional design of REITs may reduce agency conflicts, for example by mandatory dividend distributions (Bauer, Eichholtz, and Kok, 2010). External investing in direct real estate demands strong monitoring capacities from the investor, especially in the absence of a stock market to mitigate potential agency conflicts. In addition, the costs for external investments in private real estate are typically higher, because they incorporate management fees as well as performance fees. Investing through fund-of-funds adds another layer of both management and performance fees. Hence, when delegating investments in private real estate assets, pension funds need more skills as compared to investments in public equities and fixed income, in order to select and monitor the external parties. See Lakonishok et al. (1992), Goyal and Wahal (2008) and Stoughton et al. (2011) for an elaborate discussion of agency problems in the investment management industry.

\subsection{Data}

We use of the defined benefit pension fund data collected by CEM Benchmarking Inc. Pension funds included in the CEM database had more than $\$ 4.66$ trillion of assets under management in 2009 and covered around 35 percent of global defined benefit pension fund assets (which is also more than 20 percent of total global pension fund assets). ${ }^{10}$ Over the 1990-2009 period, the U.S. pension funds included in the dataset controlled more than 40 percent of the total assets under management by the U.S. defined benefit pension fund sector. Canadian pension

\footnotetext{
${ }^{9}$ External investing also incorporates real estate limited partnerships. The limited partnerships are investments in real estate funds which focus on active management of properties, ranging from moderate reposition or releasing of properties to development or extensive redevelopment. These funds typically have a fixed life span during which properties are acquired, actively managed and then sold. This category includes value added and opportunistic partnerships.

${ }^{10}$ The comparison is based on the Towers Watson Global Pension Assets Study 2010 (http: //www . towerswatson . com/en-IE/Insights/IC-Types/Survey-Research-Results/2010/02/Global-Pension-Asset-Study-2010).
} 
funds included in the CEM database held approximately 80-90 percent of the total assets under management by Canadian pension funds. The CEM database also covers a smaller percentage of, mostly larger, European, Australian and New Zealand pension funds. Table 5.1 presents the number of pension funds in the CEM database, the number of funds investing in real estate and the average size of these funds. To our knowledge, this is the broadest global database on pension fund asset allocation and performance available for academic research.

The CEM database contains detailed information on each fund's annual asset allocation decisions, self-declared benchmarks for each asset class, and precise cost structure and performance data for all separate asset classes and their benchmarks. While CEM collects data from pension funds investing in multiple asset classes, we solely focus on the real estate allocations in this paper. In the data, real estate includes assets invested in direct real estate holdings, segregated real estate holdings, real estate limited partnerships and real estate investment trusts (REITs). ${ }^{11}$

The CEM database provides a broad and complete perspective on the choices and outcomes of pension fund real estate allocations. Using data at the pension fund level rather than realestate-only datasets (like those offered by NCREIF, IPD, or NAREIT) provides some unique insights into the allocation decisions, costs and returns of real estate investments. First, pension fund returns reflect the costs of real-life constraints involved in real estate investments, such as commitment periods and delays on the withdrawal of capital that external parties impose. Second, pension fund returns reflect the costs of managing a portfolio of underlying real estate investments in private, public or both real estate subcategories, as the returns are reported net of an additional layer of fees. Third, the CEM data incorporates returns in both public and private real estate investments, taking into account the time trend in weights assigned to both subcategories. Focusing on either NCREIF or NAREIT data does not reflect the overall real estate portfolio of an institutional investor, and does not provide insight into the allocation choices that institutional investors face within their real estate allocation.

As reporting to CEM is voluntary, the data is potentially vulnerable to self-reporting bias. Andonov et al. (2012) address the self-reporting issue by constructing a Cox proportional hazard model. The authors test whether the decision of a particular fund to exit the database is related to its returns (from all asset classes), costs or size. The results show that the database does not suffer from self-reporting bias with respect to costs and returns, though larger funds are more likely to survive in the CEM database. ${ }^{12}$

Table 5.1 shows that, on average, 75.6 percent of the pension funds in the CEM database invest in real estate. In Europe and Australia/New Zealand this percentage is higher, which may be due to the database covering fewer, mostly large funds. In Canada, the percentage of

\footnotetext{
${ }^{11}$ REIT investments are reported separately in the CEM database - CEM explicitly asks pension funds to split REIT investments from the small cap equity mandate. Some pension funds may not be able to filter out REITs from passive index investments, and our results may thus slightly understate actual allocations to REITs.

${ }^{12}$ Bauer, Cremers, and Frehen (2010) also address the self-reporting bias by matching the CEM data with the Compustat SFAS data. They test whether the decision to stop reporting is related to the overall fund performance, but the results indicate that there is no evidence of a self-reporting bias related to performance in the exiting and entering years.
} 


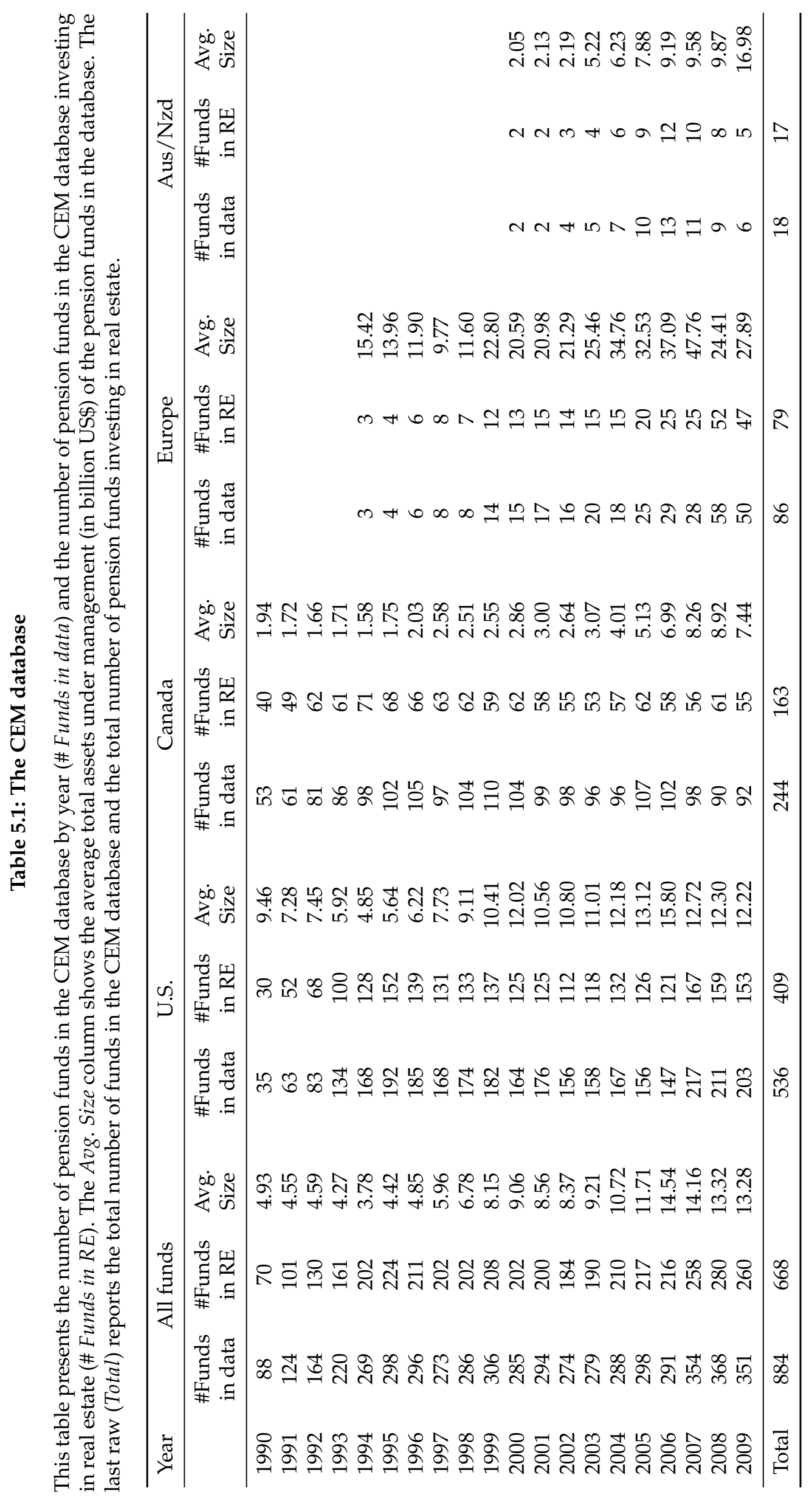


Figure 5.2: Real estate as a percentage of total pension fund assets

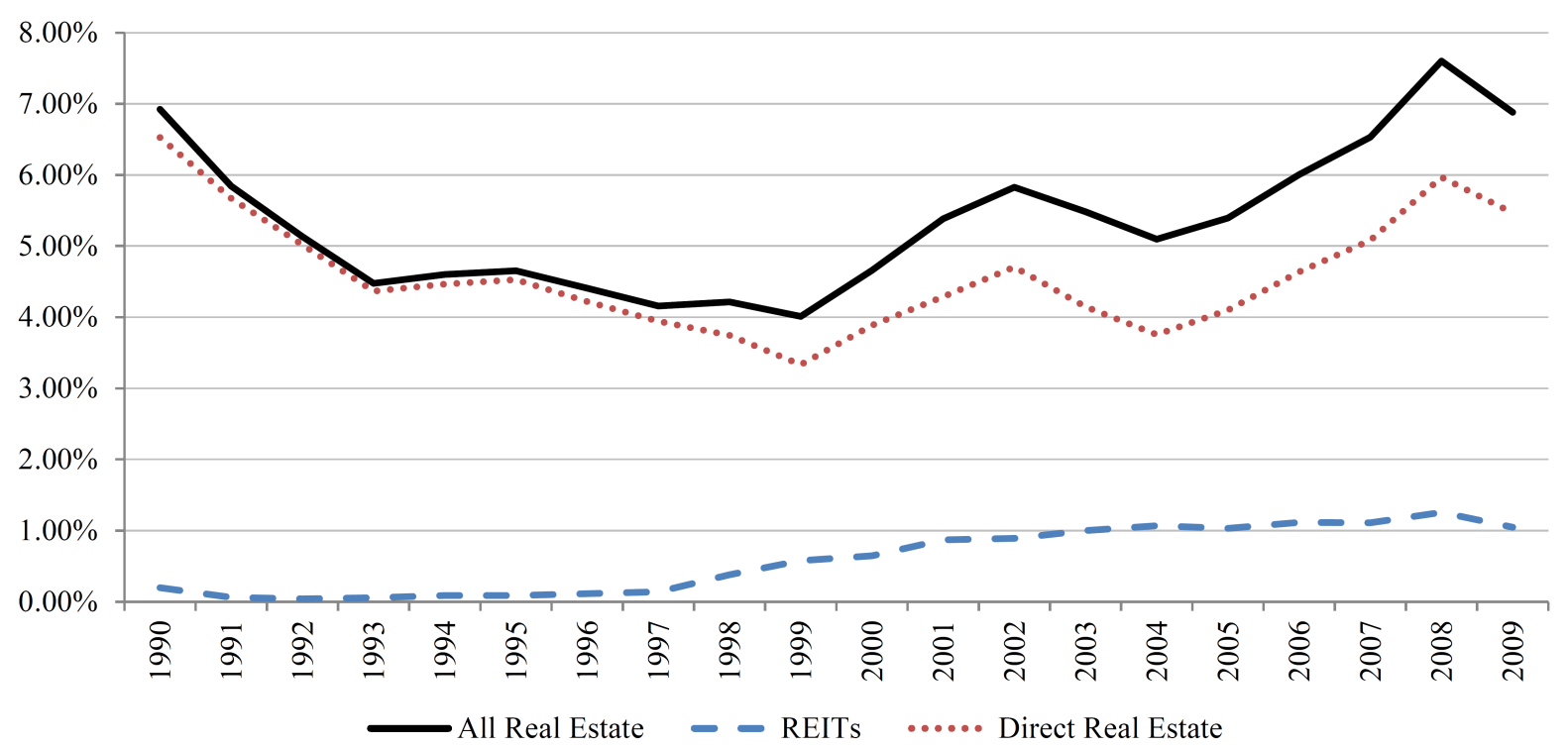

funds investing in real estate decreases over time, from 75.5 percent in 1990 to 59.8 percent in 2009.

During the 1990-2009 period, pension fund real estate holdings increased substantially and their total value amounted to more than $\$ 320$ billion in 2009. In line with Pagliari et al. (2005) we find that pension funds favor private real estate investments over REITs. In 2009, pension fund holdings in direct real estate were more than $\$ 240$ billion and the holdings in REITs were around $\$ 74$ billion. $^{13}$

When we include all pension funds in the database, real estate represents on average 3.9 percent of pension fund assets. This compares to 1.9 percent allocation to private equity and 0.7 percent allocation to hedge funds. When we focus just on pension funds investing in real estate, these funds allocate, on average, 5.4 percent of their assets to real estate. Figure 5.2 shows that real estate assets as a percentage of total pension fund total assets were higher at the beginning of the sample period and picked up again after 2000. Real estate investments represented 6.9 percent of the total assets by 2009 .

Panel A of Table 5.2 shows that there is substantial variation in the allocation to real estate assets across regions. Fund size and geography are important determinants of this heterogeneity. European and Australian/New Zealand funds are substantially larger and their real estate holdings, in dollar terms, are substantially larger than the holdings of U.S. and Canadian funds. In Panel $C$ of Table 5.2, we observe the size of the real estate investments by subcategory. The size of REIT mandates is comparable to the size of direct real estate mandates, but the number of pension funds that invest in direct real estate is substantially higher than the number of

\footnotetext{
${ }^{13}$ A minor part of pension fund real estate holdings is classified as "other real assets", which captures investments that could not be classified as direct real estate or REITs. For instance, a building owned by the pension fund and used as office space by the fund, but also partially leased to other tenants for a rent, will be classified as such. Other real assets also capture investments in raw land.
} 
Table 5.2: Descriptive statistics: real estate holdings

This table provides descriptive statistics of pension fund investments in real estate. We present the time series averages of cross-sectional statistics for the 1990-2009 time period, showing the following statistics: median, mean and standard deviation (StDev). Columns \# Funds and \# Obs present the number of funds investing in real estate or in one of the subcategories and the number of observations. Panels A, $\mathrm{B}$ and $\mathrm{C}$ display the summary statistics of real estate holdings in million US\$. In Panel A, the real estate assets descriptive statistics are presented separately for U.S., Canadian, European and Australian/New Zealand funds. In Panel B, we split the real estate investments into two subcategories: real estate investment trusts (REITs) and direct real estate. Panel C presents the real estate holdings summary statistics by investment approach. For internal and external statistics we use the entire period 1990-2009. Fundof-funds exist in the data since 1995 and we present the time series averages of cross-sectional statistics for the 1995-2009 period.

\begin{tabular}{lccccc}
\hline \multicolumn{7}{c}{ Median } & Mean & StDev & \# Funds & \# Obs \\
\hline Panel A: Real estate holdings (in million & US\$) \\
\hline All funds & 116 & 650 & 1,578 & 668 & 3,928 \\
U.S. & 147 & 647 & 1,417 & 409 & 2,408 \\
Canada & 47 & 399 & 1,072 & 163 & 1,178 \\
Europe & 1,049 & 2,311 & 3,589 & 79 & 281 \\
Aus /Nzd & 451 & 668 & 626 & 17 & 61 \\
\hline Panel B: Real estate holdings by & subcategory (in million US\$) \\
\hline REITs & 104 & 407 & 1,290 & 220 & 966 \\
Direct real estate & 107 & 549 & 1,235 & 635 & 3,616 \\
\hline Panel C: Real estate holdings by investment approach (in million US\$) \\
\hline Internal & 230 & 899 & 1,690 & 160 & 914 \\
External & 92 & 517 & 1,242 & 611 & 3,324 \\
Fund-of-funds & 83 & 96 & 50 & 32 & 94 \\
\hline \multicolumn{7}{c}{}
\end{tabular}

funds that invest in REITs. Figure 5.3 Panel A shows that REITs gained popularity after 1997 and make up about 20 percent of the overall real estate holdings, on average.

Pension funds implement three main investment approaches within their real estate allocation: internal management, external management and investing via fund-of-funds. In Figure 5.3 Panel B we observe that pension funds have some 80 percent of their assets managed externally, with little variation over time. Interestingly, the allocation to internal mandates has decreased from 22.4 percent in 1990 to 15.6 percent in 2009, due to an increased allocation to fund-of-funds. The percentage allocation to fund-of-funds has increased from zero in 1990 to 5.3 percent in 2009, mainly at the expense of internal, not external mandates. Even though the vast majority of funds use external management, Panel D of Table 5.2 shows that the dollar value of internal mandates is substantially larger than the value of external mandates.

Table 5.3 shows more descriptives on pension fund investment approaches to real estate investment. In Panel A, we document that the percentage of internal management is lowest among U.S. funds (7.6 percent). Canadian funds, even though they are significantly smaller than U.S. funds, allocate 35.6 percent of their real estate investments through internal mandates. European and Australian/New Zealand funds have higher allocations through internal 
Figure 5.3: Allocations to real estate subcategories and investment approaches

Panel A: Average pension fund investments in real estate subcategories

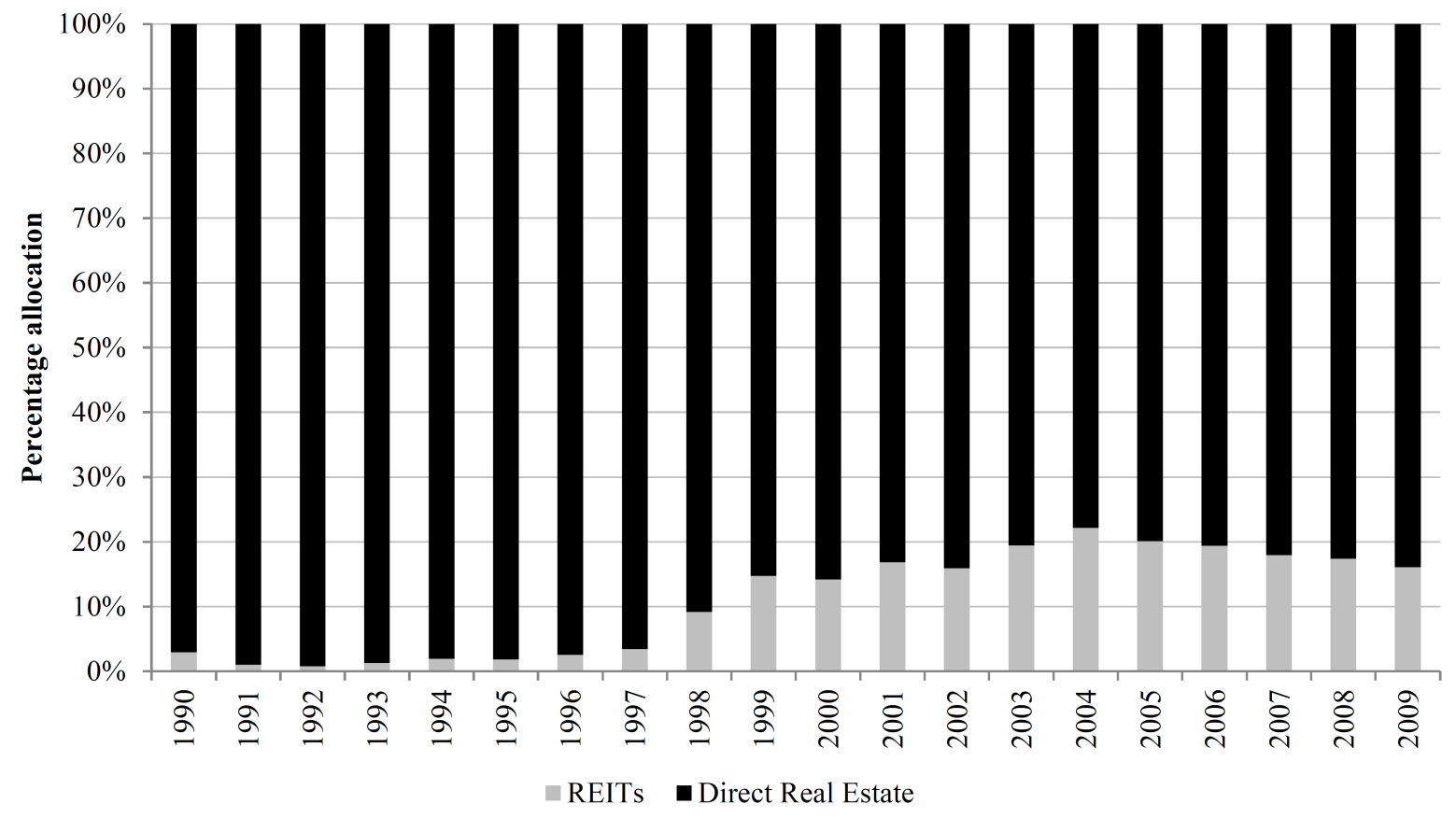

Panel B: Average percentage of assets allocated to an investment approach

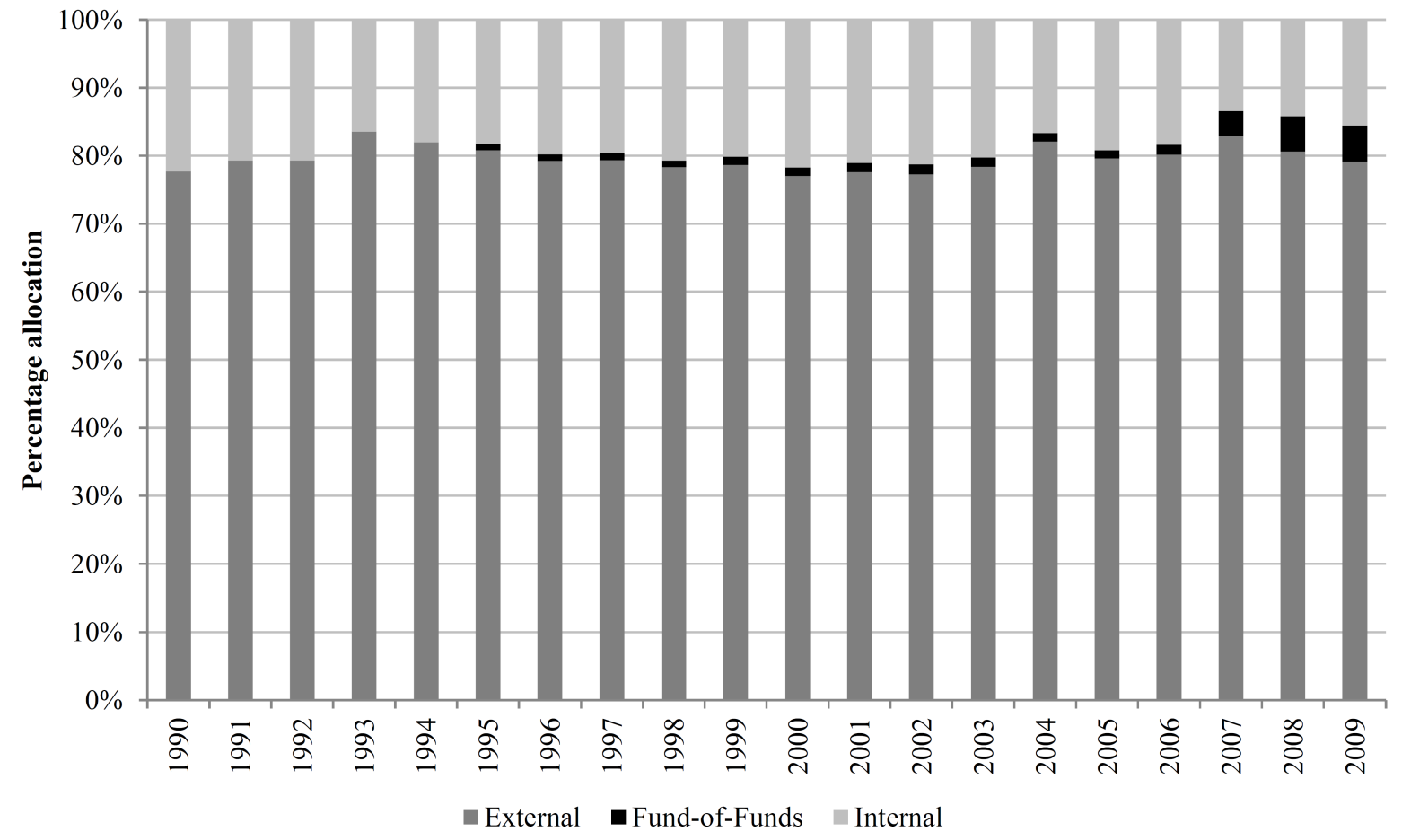


Table 5.3: Descriptive statistics: investment approach

This table shows pension fund investment approaches in real estate. For every variable we present the time series averages of cross-sectional means. Columns $\% E x t$ and $\%$ Int present the percentage of assets managed externally and internally in the period 1990-2009. \%FoF shows the percentage of assets invested in fund-of-funds during the 20 years period. Panel A shows the investment approach separately for U.S., Canadian, European and Australian/New Zealand funds. Panel B presents the percentage allocations to different real estate investment approaches for REITs and direct real estate. For REITs our data allows for two distinct decompositions. In addition to $\% E x t$ and $\%$ Int, we also decompose REIT investments into percentage of assets managed actively ( $\% A c t)$ and passively ( $\% P a s)$. For direct real estate assets we observe one decomposition in four different investment approaches. In addition to $\% E x t, \% \operatorname{Int}, \%$ FoF we also add the percentage of assets invested in limited partnerships $(\% L P)$. (In Panel A \%LP is combined with \%Ext.)

\begin{tabular}{|c|c|c|c|c|c|c|}
\hline \multicolumn{7}{|c|}{ Panel A: Real estate investment approach (in percent) } \\
\hline & \multicolumn{2}{|c|}{$\%$ Ext } & \multicolumn{2}{|c|}{$\%$ Int } & \multicolumn{2}{|c|}{$\%$ FoF } \\
\hline All funds & \multicolumn{2}{|c|}{79.63} & \multicolumn{2}{|c|}{18.94} & \multicolumn{2}{|c|}{1.43} \\
\hline U.S. & \multicolumn{2}{|c|}{90.40} & \multicolumn{2}{|c|}{7.62} & \multicolumn{2}{|c|}{1.97} \\
\hline Canada & \multicolumn{2}{|c|}{64.25} & \multicolumn{2}{|c|}{35.62} & \multicolumn{2}{|c|}{0.13} \\
\hline Europe & \multicolumn{2}{|c|}{47.11} & \multicolumn{2}{|c|}{51.48} & \multicolumn{2}{|c|}{1.41} \\
\hline Aus $/ \mathrm{Nzd}$ & \multicolumn{2}{|c|}{84.41} & \multicolumn{2}{|c|}{14.85} & \multicolumn{2}{|c|}{0.74} \\
\hline \multicolumn{7}{|c|}{ Panel B: Real estate investment approach by subcategory (in percent) } \\
\hline & $\%$ Ext & $\%$ Int & $\%$ FoF & $\%$ LP & $\%$ Act & $\%$ Pas \\
\hline REITs & 54.66 & 45.34 & - & - & 94.05 & 5.95 \\
\hline Direct real estate & 78.41 & 16.81 & 1.74 & 3.04 & - & - \\
\hline
\end{tabular}

mandates as well. Investments in fund-of-funds are mainly implemented by U.S. and European pension funds.

Panel B of Table 5.3 shows that pension funds are more likely to invest internally in REITs rather than in direct real estate: the average allocation to internal mandates is 45.3 percent among REITs as compared to 16.8 percent among direct real estate investments.

Passive management in real estate is not really possible, except investments that held through REITs. Investments are classified as passive in the CEM data if they replicate a broad capital market benchmark (like the FTSE NAREIT Index) or match a specific set of liabilities, i.e., if they are part of a strategic asset allocation based on the pension fund liabilities. On the basis of that definition, the vast majority of the REIT investments are managed actively (94 percent) and there are very few pension funds that passively invest in REITs.

\subsection{Pension fund characteristics and real estate investments}

In this section, we study the two main investment decisions presented in Figure 5.1 for the institutional investors with an existing real estate allocation. First, we investigate which pension fund characteristics influence the choice of real estate subcategories. Second, we examine which investment approach pension funds implement in their allocation to real estate. We 
estimate the following logit model:

$$
\operatorname{Pr}\left(y_{i, t}=1 \mid X\right)=F\left(\beta_{1} \text { FundSize }_{i, t}+\beta_{2} \text { Alter }_{i, t}+\beta_{3} P T_{i}+\beta_{4} \text { Region }_{i}+\beta_{5} Y D_{t}+v_{i, t}\right)
$$

where $F$ is a logit function taking on values strictly between zero and one, and $y_{i, t}$ is a binary dependent variable. For example, the dependent binary variable $y_{i, t}$ is 1 if pension fund $i$ invests internally in real estate in year $t$ and 0 otherwise. We model the probabilities as a function of pension fund characteristics (X), focusing on total fund size (FundSize) and the allocation to other alternative asset classes (Alter) of fund $i$ in year $t$. FundSize is the natural logarithm of the dollar value of the pension fund assets under management. The Alter variable captures the asset allocation to private equity, hedge funds, infrastructure, tactical asset allocation mandates, commodities and natural resources. We control for plan type (PT), i.e., whether the pension plan is public, corporate or other. We also control for regional effects, include year dummies $(Y D)$ and we cluster the standard errors by pension funds, allowing for intragroup correlation.

Table 5.4 shows the results of model (1). In Panel A, we analyze which characteristics determine whether a pension fund invests only in direct real estate, only in REITs, or simultaneously in both direct real estate and REITs. The dependent binary variable is 1 if a fund has direct real estate holdings only and 0 otherwise. We find that smaller pension funds are more likely to invest in direct real estate only but not in REITs, although REITs provide easy and low-scale property exposure, which should make them especially attractive to smaller investors. A one unit increase in the logarithm of assets under management (i.e., doubling the fund size) decreases the probability that a pension fund invests in direct real estate only by 4.0 to 5.8 percent. Moreover, pension funds with higher allocations to other alternative assets have a higher probability to invest in real estate only directly. For example, the probability to invest in direct real estate only for pension funds that have no allocation to other alternative assets is 79.8 percent. This probability increases to 83.3 percent for funds that have at least 10 percent of assets allocated to other alternative asset classes. Based on the regional dummies, European pension funds are less likely to invest in direct real estate than their U.S. counterparts, whereas Canadian funds are more likely to invest in direct real estate only.

The probability to invest in direct real estate, given that a pension fund decides to invest in real estate, is close to 100 percent and the percentage of funds investing only in REITs but not in direct real estate is very low. This implies that REITs are typically incorporated in a portfolio of larger pension funds as complementary to existing exposure to direct real estate investments. Indeed, a one unit increase in the logarithm of assets under management increases the probability that a pension fund invests simultaneously in both REITs and direct real estate by 4.1 to 5.3 percent. $^{14}$

Summarizing, smaller funds are less likely to invest in REITs, but not in direct real estate. This finding is surprising, since we document later in this paper that investing in private real estate is more expensive. Moreover, direct real estate investments are less liquid and require

\footnotetext{
${ }^{14}$ Our results are in line with Ciochetti, Craft, and Shilling (2002), who document that the largest pension plans invest more in REITs.
} 
ฮี

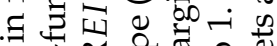

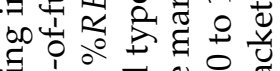

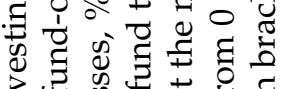

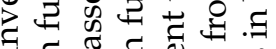

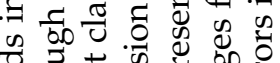

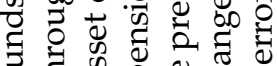

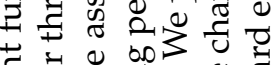
$\vec{c}$ o ช

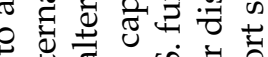

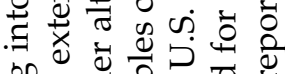
o. 匹

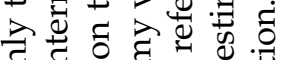
: 可芯 का व

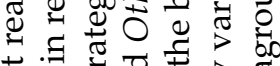
.

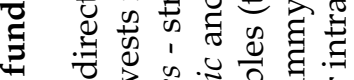

5

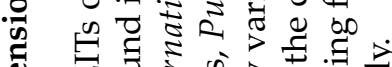

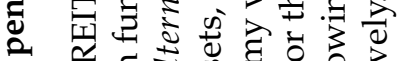

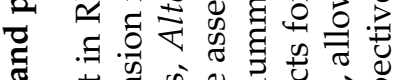

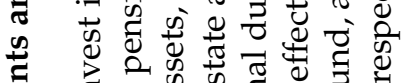

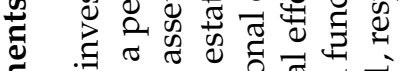

5

क

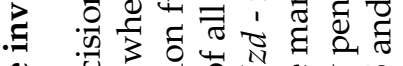

䒕 क्षे

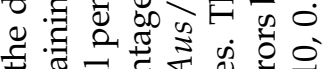

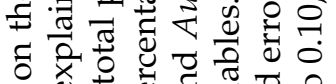

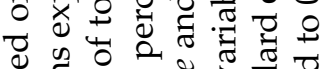
政

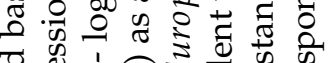

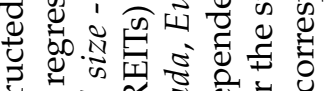

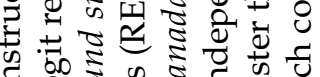

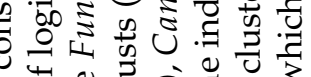
क

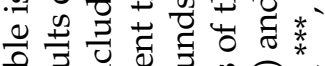

. एक 30 क 苛

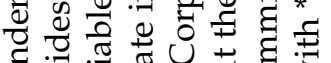
잉

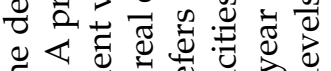

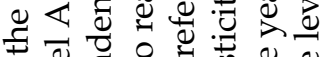

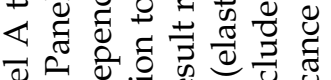
记

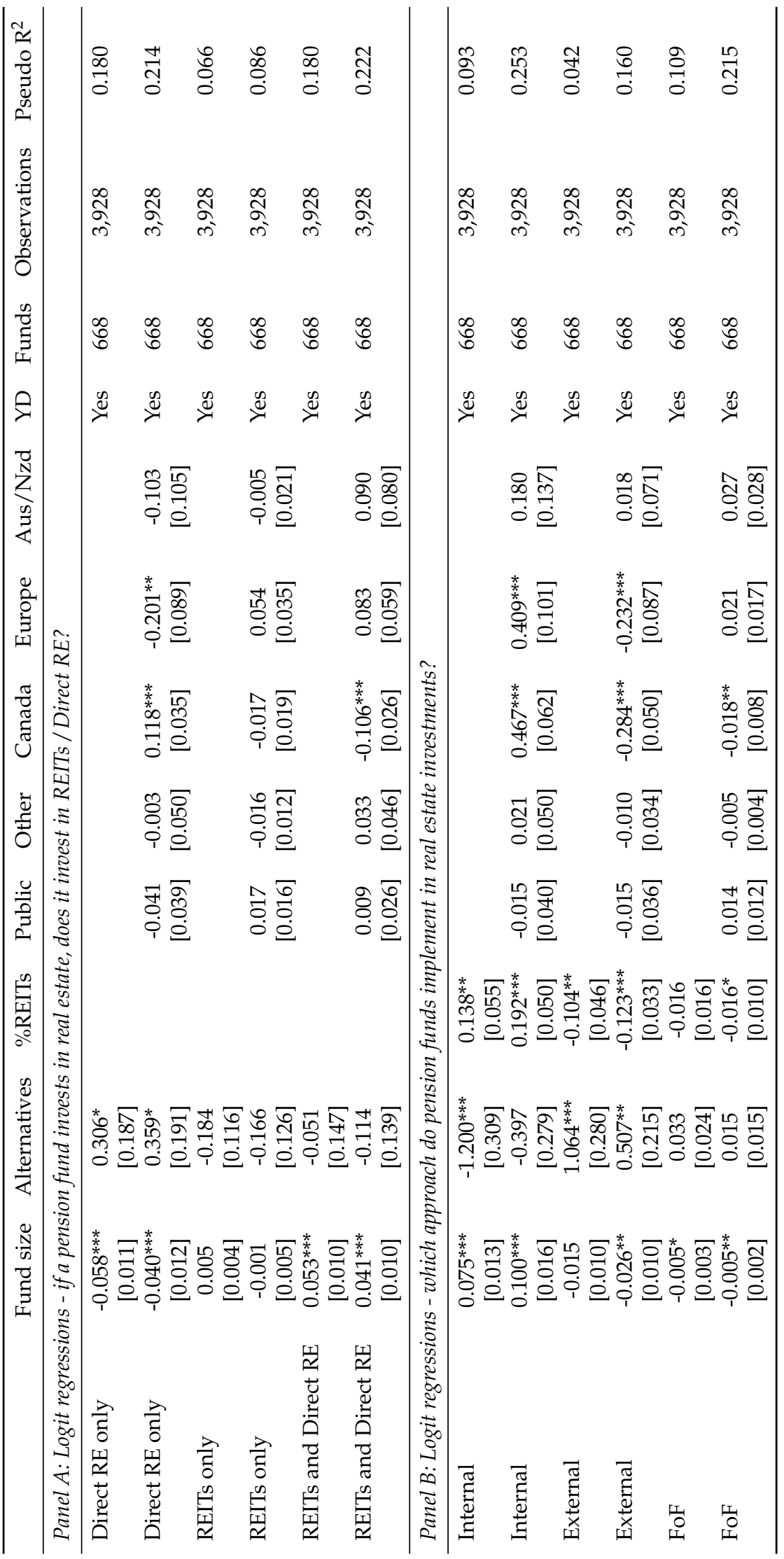

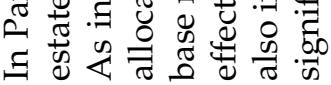


Figure 5.4: Pension fund investment approach in real estate by size quintiles

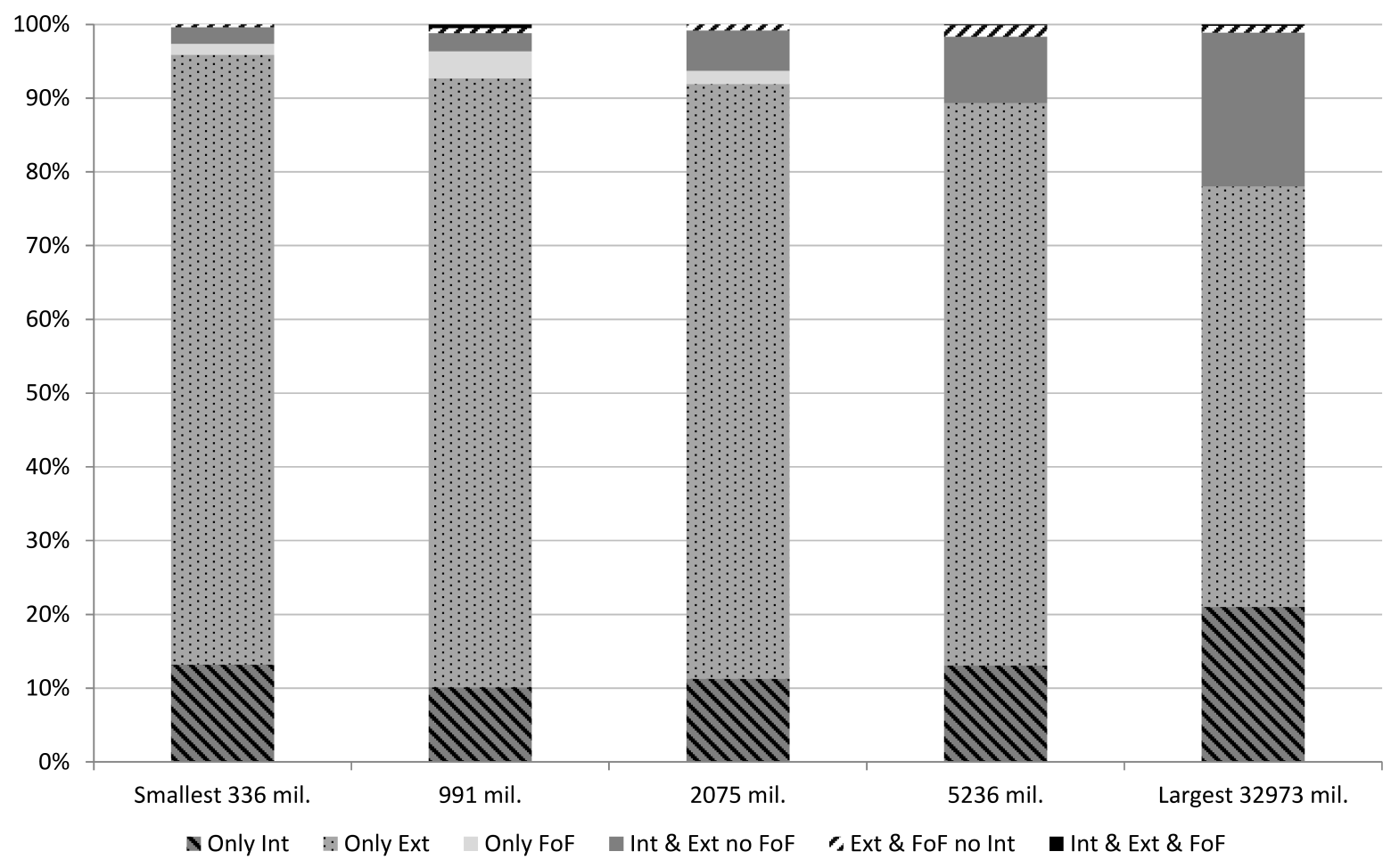

more monitoring skills, because of the increased potential for agency conflicts following from asymmetric information problems. In addition, institutional investors with larger allocations to other alternative assets are more likely to invest in direct real estate, which means that they simultaneously allocate capital to multiple alternative asset classes.

Table 5.4 Panel B presents the analysis of the characteristics which determine whether a pension fund invests internally, externally or through fund-of-funds. The dependent binary variable is 0 if a fund does not invest in real estate internally and 1 otherwise. In the other specifications, the dependent variable reflects external management and fund-of-funds investments, respectively.

In line with expectations, larger pension funds are more likely to invest internally. A one unit increase in the logarithm of assets (i.e., doubling the fund size) increases the probability that a pension fund invests internally by 10 percent. Smaller funds are more likely to delegate investment management by investing externally and through fund-of-funds. A one unit increase in the log size decreases the probability that a pension fund invests externally by 2.6 percent. Furthermore, the allocation to other alternative assets is significantly and positively related to the probability to externally invest in real estate. The marginal effect of allocations to alternatives estimated at means indicates that a 10 percent increase in the allocation to alternatives increases the probability of external investing in real estate by 5.1 percent. Importantly, even after controlling for size, investments in other alternative asset classes and allocation to REITs, Canadian and European pension funds are significantly more likely to invest internally than U.S. pension funds. 
Since pension funds can simultaneously invest via one or more investment approaches, Figure 5.4 analyzes further the relation between pension fund size and investment approach. We split the funds into quintiles based on their size and calculate the percentage of funds selecting a particular combination of investment approaches. The majority of funds across all size quintiles invest only externally in real estate. Among the smaller quintiles, this holds for more than 80 percent of the funds. Additionally, only pension funds in the smaller quintiles invest exclusively through fund-of-funds. As we move from the smallest to the largest quintile, the percentage of pension funds investing internally (only internally or simultaneously internally and externally) is increasing. However, even among the largest quintile, some 57 percent of the funds do not manage properties or REITs internally.

Our results indicate that larger funds are more likely to invest internally, but a minority of the smallest funds also take that approach. In the smallest quintile, about 13.2 percent of funds decide to invest internally. Internal management requires devoting sufficient resources to establish an internal real estate department or an "at-arms-length" operating division. Establishing such an internal department for direct selection of properties or REITs is costly and can be regarded as a more long-term commitment. In line with this statement, we observe that funds with a larger allocation to other alternative asset classes are more likely to invest externally. This positive relation suggests that especially external real estate mandates are part of a broader portfolio of alternatives. When a pension fund decides to invest in real estate internally, it is likely to devote significant organizational resources and to specialize in real estate for a longer period, rather than to invest in a broader portfolio of alternatives.

\subsection{The costs of pension fund real estate investments}

In this section, we analyze the level of overall real estate investment costs, the differences in costs between REITs and direct real estate, and the role of investment approach and size as determinants of cost differences. The CEM database contains detailed information on the investment costs of pension funds. Internal investment costs include compensation and benefits of employees managing internal portfolios and support staff, related research expenses and allocated overhead costs. In the CEM database, external investment costs capture the management fees paid to investment consultants and external money managers. The performance fees, carried interest and rebates ${ }^{15}$ are directly subtracted from the returns and are not incorporated in the cost figures. External investments costs also include costs for internal staff whose sole responsibility is overseeing the external investments in real estate assets. Similarly, for fund-offunds, cost figures capture the base management fee paid to both the fund-of-funds manager and the underlying managers, but they do not include performance fees and carried interest on either layer.

\footnotetext{
${ }^{15}$ Carried interest is a fee that is a portion of returns exceeding a hurdle rate. Rebates are the limited partners' share of certain fee income realized by the general partner in connection with the fund, such as fees for break-up, monitoring and funding.
} 
Figure 5.5: Real estate investment costs by region and subcategory

Panel A: Overall real estate investment costs by region (in basis points)

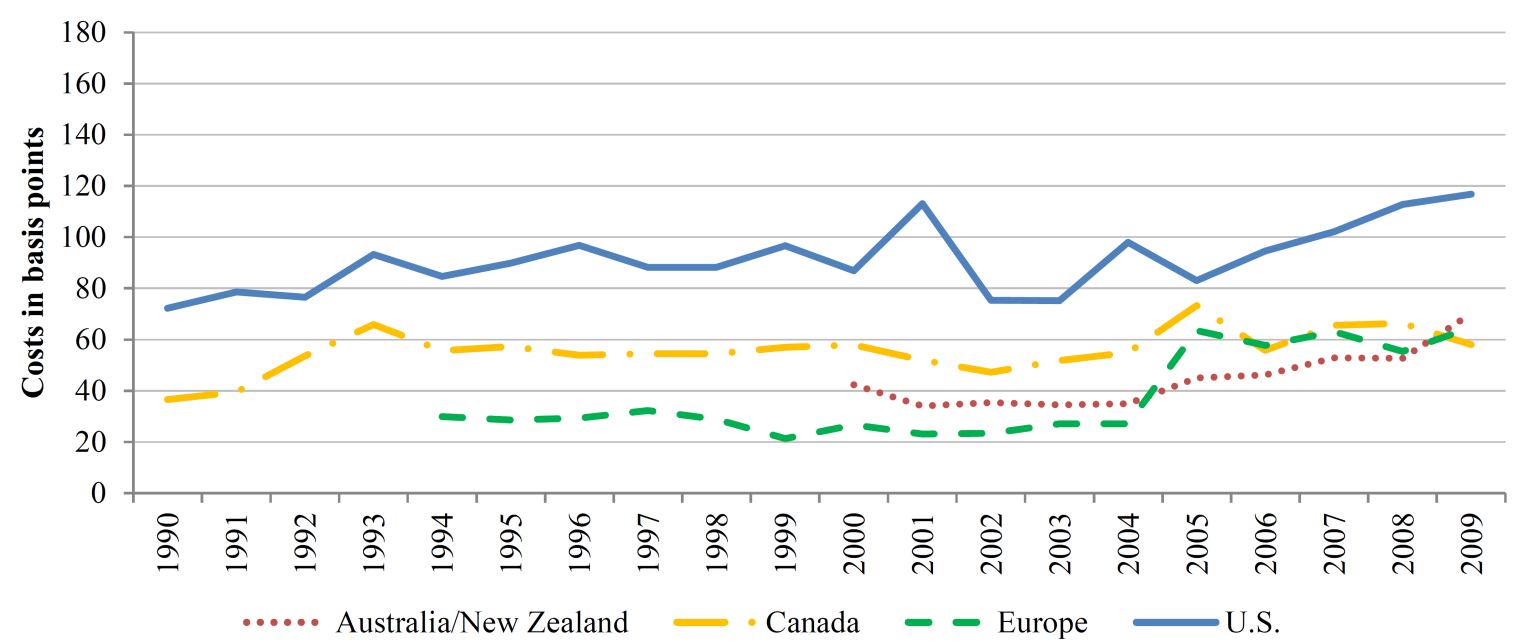

Panel B: REIT investment costs by region (in basis points)

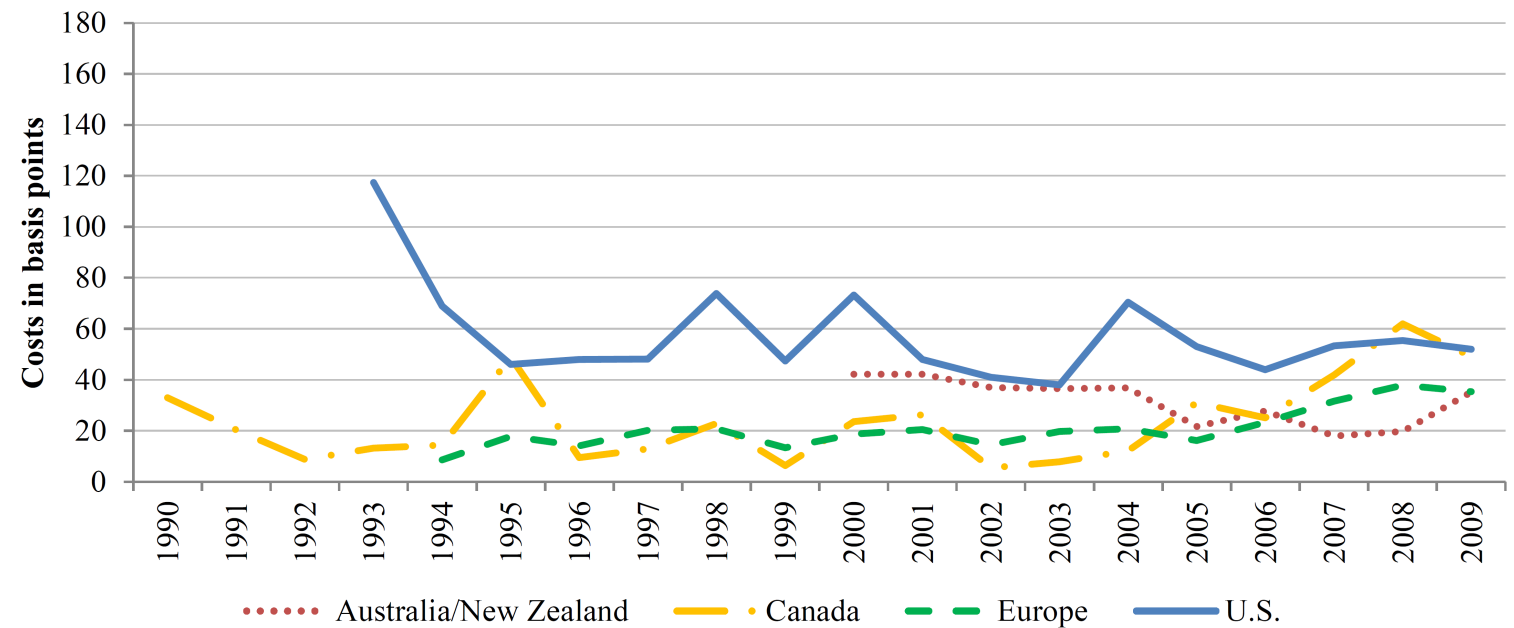

Panel C: Direct real estate investment costs by region (in basis points)

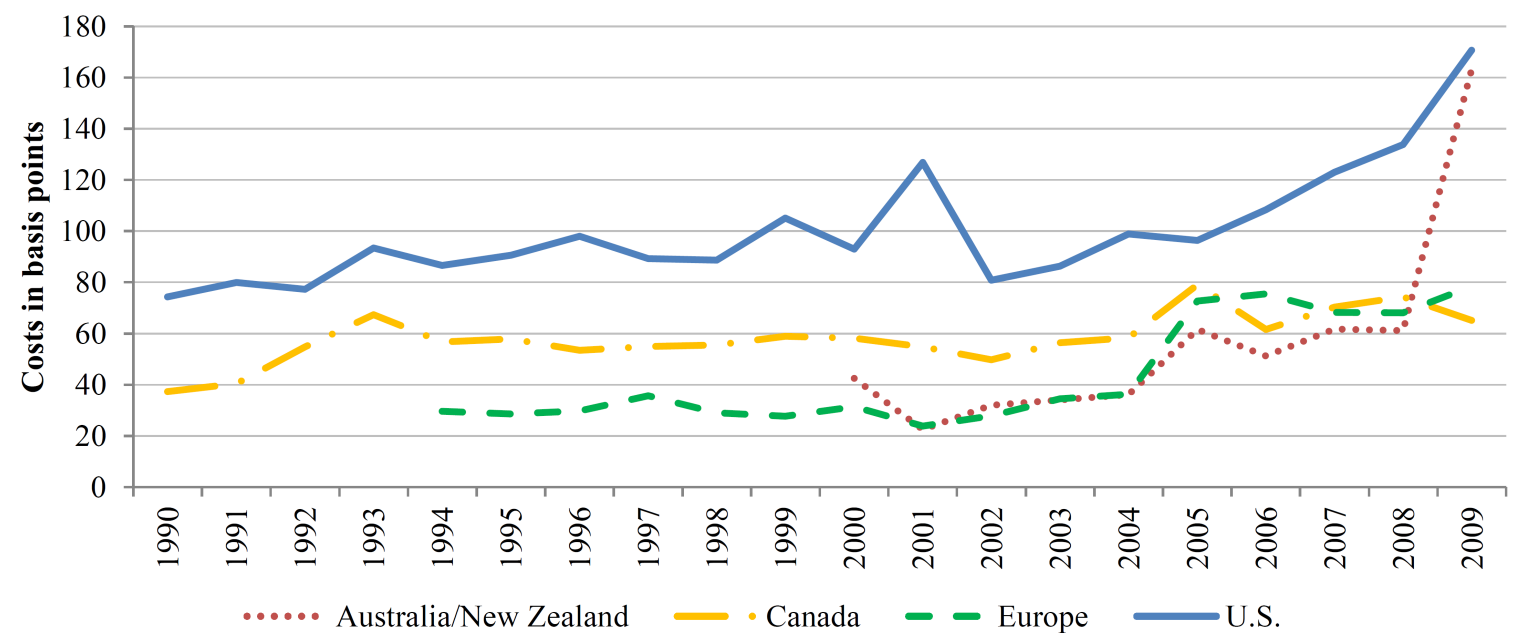


Table 5.5 provides the summary statistics of real estate investment costs per region. Pension funds pay fees of about 76 basis points for real estate investments. We find that U.S. pension funds have higher real estate investment costs than funds from other regions: the average costs of U.S. pension funds amount to 91 basis points, which is about twice the percentage that their foreign peers are paying. Canadian funds pay 56 basis points, European funds pay 38 basis points and Australian/New Zealand funds pay 45 basis points for their real estate investments. Figure 5.5 shows that these cost differences are consistent during the 1990-2009 period. Moreover, U.S. pension funds have higher costs for investing in both REITs (Panel B) and direct real estate (Panel C). The three panels of Figure 5.5 suggest that there are no particular time patterns in REIT investment costs, but direct real estate investment costs have increased since 2002. The increasing costs in direct real estate are mostly due to the increasing allocations to fund-of-funds, which is the most expensive approach to invest in real estate.

\section{Table 5.5: Descriptive statistics: real estate investment costs}

This table provides the descriptive statistics on investment costs of pension funds investing in real estate (in basis points). The values presented are time series averages of cross-sectional statistics for the 19902009 time period (for fund-of-funds 1995-2009). The statistics presented are median, mean and standard deviation (StDev). In Panel A, the cost statistics are presented for all funds, as well as separately for U.S., Canadian, European and Australian/New Zealand funds. In Panel B, we split the real estate investment costs into REITs and direct real estate. We split REIT investment costs into two investment approaches: internal and external. For direct real estate we distinguish four approaches: internal, external, limited partnerships and fund-of-funds. Costs for all internal mandates are a weighted average of internal investment costs across all subcategories. Costs for all external mandates are calculated as a weighted average of costs for external mandates in REITs, external mandates in direct real estate, limited partnerships in direct real estate and external mandates in other real assets. Investments in direct real estate via fund-of-funds are the only category from Panel B not incorporated in Panel C, because we analyze the fund-of-funds as a separate investment approach.

\begin{tabular}{|c|c|c|c|c|c|}
\hline & Median & Mean & StDev & \# Funds & \# Obs \\
\hline \multicolumn{6}{|c|}{ Panel A: Costs in basis points by region } \\
\hline All funds & 67.24 & 76.19 & 84.61 & 662 & 3,815 \\
\hline U.S. & 83.48 & 91.12 & 90.61 & 407 & 2,353 \\
\hline Canada & 44.97 & 55.54 & 51.55 & 161 & 1,144 \\
\hline Europe & 30.31 & 37.62 & 33.74 & 77 & 259 \\
\hline Aus/Nzd & 42.90 & 44.82 & 18.79 & 17 & 59 \\
\hline \multicolumn{6}{|c|}{ Panel B: Costs in basis points by subcategory and investment approach } \\
\hline REITs: & 32.75 & 41.45 & 57.18 & 213 & 917 \\
\hline - Internal & 8.35 & 12.06 & 14.04 & 50 & 286 \\
\hline - External & 52.61 & 62.75 & 68.37 & 181 & 698 \\
\hline Direct real estate: & 72.47 & 82.89 & 100.30 & 635 & 3,595 \\
\hline - Internal & 22.81 & 31.40 & 31.63 & 129 & 675 \\
\hline - External & 78.52 & 88.09 & 85.73 & 567 & 2,941 \\
\hline - Limited partnership & 122.58 & 143.15 & 131.74 & 53 & 154 \\
\hline - Fund-of-funds & 170.70 & 182.56 & 43.94 & 32 & 94 \\
\hline \multicolumn{6}{|c|}{ Panel C: Costs in basis points by investment approach } \\
\hline Internal & 18.51 & 26.24 & 27.88 & 148 & 834 \\
\hline External & 76.35 & 86.08 & 88.63 & 607 & 3,245 \\
\hline
\end{tabular}


Cost summary statistics for subcategories are presented in Panel B of Table 5.5. The average costs for investing in direct real estate are 83 basis points and are about double the costs for investing in REITs (41 basis points). Internal investing in REITs and internal direct selection of properties are associated with substantially lower costs than the external investment approaches. Furthermore, within direct real estate investments, limited partnerships and fund-of-funds yield substantially higher costs than other ways of gaining real estate exposure: 143 and 183 basis points, respectively. Panel $C$ of Table 5.5 shows that costs for all external mandates are 86 basis points, on average, as compared to just 26 basis points for all internal mandates, on average. ${ }^{16}$

Overall, the descriptives indicate that the selected subcategories and investment approach strongly influence the overall level of real estate investment costs. But of course, these nonparametric comparisons are not conclusive: for example, U.S. pension funds have a low allocation to internal mandates (just 7.6 percent) as compared to funds from other regions, which may explain their higher costs. For more precise inferences, and to disentangle the effects of real estate portfolio size, allocation to subcategories and investment approach, we estimate the following model, using pooled panel regressions with year and regional, or fund fixed effects:

$$
C_{i, t}=\gamma_{0}+\gamma_{1} \text { Mandate }_{i, t}+\gamma_{2} \text { InvApproach }_{i, t}+\gamma_{3} Y D_{t}+\gamma_{4} F E_{i}+u_{i, t} \quad t=1,2, \ldots, 20
$$

where $C_{i, t}$ refers to the investment costs, $F E_{i}$ captures regional or fund fixed effects, $Y D_{t}$ refers to year dummies and $u_{i, t}$ are idiosyncratic errors. Mandate is the log of the dollar value of the real estate investment portfolio, and Inv Approach refers to the percentage allocation to external managers, fund of funds, etcetera.

Table 5.6 presents the results of the analysis. Regressions for the pooled sample of all funds indicate that pension funds allocating more assets to real estate realize strong scale advantages in their investment costs. For the full sample, a one unit increase in the log of the real estate mandate (i.e., doubling the mandate size) reduces the costs by 32 basis points, even when controlling for investment approach, year and fund fixed effects. Our results also indicate that allocations to external investment managers and fund-of-funds significantly increase the overall investment costs. A pension fund that delegates the asset management to external managers has 21 basis points higher investment costs than a fund that invests internally in real estate. Investing through fund-of-funds would increase the costs by 122 basis points as compared to internal management.

When we split the sample into regions, we still document strong economies of scale among U.S. and Canadian funds. For Europe and Australia/New Zealand, the log of real estate assets under management is insignificant, which may be due to the smaller sample size and the fact that funds are generally very large. (The size of the minimum allocation to real estate in Europe and Australia/New Zealand is equal to the median real estate investment mandate of U.S. and

\footnotetext{
${ }^{16}$ Costs for all external mandates are calculated as a weighted average of costs for external mandates in REITs, external mandates in direct real estate, limited partnerships in direct real estate and external mandates in other real assets. Costs for all internal mandates are also a weighted average of internal investment costs across all subcategories. Investments in direct real estate via fund-of-funds are the only category from Panel B not incorporated in Panel C, because we analyze the fund-of-funds as a separate investment approach.
} 
Canadian funds.) The observed scale advantages are strongest among U.S. funds, where a one unit increase in the log of real estate holdings reduces the investment cost by 42 basis points. Greater allocation to external mandates and fund-of-funds remain positively related to costs in the regional regression results.

In Panel B of Table 5.6 we investigate the importance of size and investment approach in explaining the costs of investments in REITs and direct real estate. In the regressions with region and year fixed effects, the size coefficient is significantly negatively related to investment costs for both subcategories. ${ }^{17}$ Controlling for investment approach also explains part of the heterogeneity in investment costs. The percentage of assets managed externally is positively related to the costs associated with REIT investments. Similarly, the percentage of assets invested in external mandates, fund-of-funds and limited partnerships result in substantially higher costs for direct real estate investments.

Table 5.6 Panel C shows that larger pension funds have lower costs in all three investment approaches: internal, external and fund-of-funds investments. The magnitude of the economies of scale is much stronger for external mandates, where a one unit increase in the $\log$ of assets managed externally reduces the costs by 35 basis points. For internal costs, a one unit increase in the log of internally managed assets reduces the internal costs by 7 basis points. ${ }^{18}$ These findings suggest that larger funds not only organize internal mandates more efficiently, but also negotiate lower fees for their external investments in real estate. This points at bargaining power with external asset managers.

Even after controlling for size and investment approach, we find that U.S. pension funds have costs that are 28 to 41 basis points higher compared to pension funds from other regions. Results in Panel C indicate that the higher costs of U.S. pension funds can be attributed chiefly to their external mandates, whereas their costs for internal investing are similar to those of pension funds from other regions. In addition, the results in Panel B suggest that U.S. funds overpay mainly for their mandates in direct real estate. The higher costs of U.S. funds for external investments in direct real estate could be due to a worse relative negotiating position of U.S. pension funds, as the vast majority of funds do not seem to consider the option to invest internally and rather use exclusively external managers. One would expect that greater attention to internal management increases the competitive pressure on the external real estate investment managers.

Summarizing, we document that pension funds allocating more assets to real estate realize strong scale advantages in their internal and external investment costs. Investment approach is also a major determinant of real estate investment costs, since greater external management

\footnotetext{
${ }^{17}$ Adding fund fixed effects removes considerable variation as the amount of fund investments in real estate subcategories does not vary strongly over time, especially relative to the large cross-sectional variation in size. Thus, the coefficient for log Mandate becomes insignificant for REITs and less significant for direct real estate investment costs.

${ }^{18}$ Larger fund pay lower fees also for investing in fund-of-funds, but the Mandate variable is not significant once we control for fund fixed effects, because the number of funds investing in fund-of-funds is low and the fund fixed effects capture most of the relation.
} 
Table 5.6: Regression results: real estate investment costs

Panel A of this table reports the results of pooled panel regressions of the real estate investment costs for all funds and per region. Panel B reports the results of pooled panel regressions of the investment costs for different real estate subcategories. In Panel C, we use the costs by investment approach as dependent variable. As independent variables, we include the log of real estate assets in millions of dollars (Mandate), and the percentage allocations to externally managed ( $\% E x t)$ mandates and fund-offunds $(\% F o F)$. When analyzing the REITs costs, we include the following independent variables: log of REIT investments (Mandate) and the percentage allocations to externally ( $\% E x t)$ and actively $(\% A c t)$ managed REIT assets. When analyzing Direct RE costs, we include: log of direct real estate investments (Mandate) and the percentage allocations to externally managed (\%Ext) mandates, limited partnerships $(\% L P)$ and fund-of-funds (\%FoF). In Panel C, Mandate refers to the log of assets managed internally, externally or through fund-of-funds, respectively. We use two types of pooled panel regressions: (1) with year and regional dummies; and (2) with year and fund fixed effects $(F E)$. All regressions use robust standard errors clustered by fund. We report standard errors in brackets and significance levels with *,** and ${ }^{* * *}$, which correspond to $0.10,0.05$ and 0.01 , respectively. The $R^{2}$ column presents the adjusted R-square.

\begin{tabular}{|c|c|c|c|c|c|c|c|c|c|c|c|}
\hline & Cons. & Mandate & $\%$ Ext & $\%$ Act & $\% \mathrm{FoF}$ & $\%$ LP & Canada & Europe & Aus/Nzd & $\mathrm{FE}$ & $\mathrm{R}^{2}$ \\
\hline \multicolumn{12}{|c|}{ Panel A: Costs regressions for all funds and by region } \\
\hline All funds & $\begin{array}{c}89.67^{* * * *} \\
{[12.23]}\end{array}$ & $\begin{array}{c}-9.80^{* * * *} \\
{[0.91]}\end{array}$ & $\begin{array}{c}33.12^{* * * *} \\
{[4.96]}\end{array}$ & & $\begin{array}{c}100.49^{* * *} \\
{[13.94]}\end{array}$ & & $\begin{array}{c}-36.29^{* * *} \\
{[4.12]}\end{array}$ & $\begin{array}{c}-27.61^{* * *} \\
{[6.88]}\end{array}$ & $\begin{array}{c}-40.64^{* * *} \\
{[13.23]}\end{array}$ & No & 0.10 \\
\hline All funds & $\begin{array}{c}185.96^{* * *} \\
{[65.96]}\end{array}$ & $\begin{array}{c}-32.25^{* *} \\
{[14.24]}\end{array}$ & $\begin{array}{c}21.36^{* *} \\
{[9.31]}\end{array}$ & & $\begin{array}{c}122.03^{* * *} \\
{[41.95]}\end{array}$ & & & & & Yes & 0.25 \\
\hline U.S. & $\begin{array}{c}222.76^{* *} \\
{[97.62]}\end{array}$ & $\begin{array}{c}-41.51^{* *} \\
{[20.91]}\end{array}$ & $\begin{array}{c}30.87 \\
{[21.15]}\end{array}$ & & $\begin{array}{c}151.48^{* * *} \\
{[52.75]}\end{array}$ & & & & & Yes & 0.20 \\
\hline Canada & $\begin{array}{c}71.57^{* * * *} \\
{[16.73]}\end{array}$ & $\begin{array}{c}-10.71^{* * *} \\
{[3.93]}\end{array}$ & $\begin{array}{l}23.43^{* *} \\
{[11.09]}\end{array}$ & & $\begin{array}{l}-28.31 \\
{[26.81]}\end{array}$ & & & & & Yes & 0.43 \\
\hline Europe & $\begin{array}{c}154.03 \\
{[133.85]}\end{array}$ & $\begin{array}{l}-20.04 \\
{[22.10]}\end{array}$ & $\begin{array}{c}15.85^{* *} \\
{[6.76]}\end{array}$ & & $\begin{array}{l}72.79^{* *} \\
{[35.82]}\end{array}$ & & & & & Yes & 0.76 \\
\hline Aus/Nzd & $\begin{array}{l}-10.65 \\
{[27.83]}\end{array}$ & $\begin{array}{c}1.79 \\
{[4.59]}\end{array}$ & $\begin{array}{c}23.75 \\
{[16.53]}\end{array}$ & & $\begin{array}{c}131.28^{* * *} \\
{[35.60]}\end{array}$ & & & & & Yes & 0.83 \\
\hline \multicolumn{12}{|c|}{ Panel B: Costs regressions by real estate subcategory } \\
\hline REITs & $\begin{array}{c}6.41 \\
{[78.27]}\end{array}$ & $\begin{array}{c}-9.89^{* * *} \\
{[1.67]}\end{array}$ & $\begin{array}{c}30.82^{* * * *} \\
{[6.96]}\end{array}$ & $\begin{array}{c}35.29^{* * *} \\
{[10.67]}\end{array}$ & & & $\begin{array}{l}-10.81 \\
{[9.17]}\end{array}$ & $\begin{array}{c}-15.50^{* *} \\
{[7.00]}\end{array}$ & $\begin{array}{c}-22.41 \\
{[14.09]}\end{array}$ & No & 0.12 \\
\hline REITs & $\begin{array}{c}185.22 \\
{[151.45]}\end{array}$ & $\begin{array}{l}-32.99 \\
{[27.44]}\end{array}$ & $\begin{array}{l}33.27^{* *} \\
{[16.07]}\end{array}$ & $\begin{array}{c}10.88 \\
{[17.58]}\end{array}$ & & & & & & Yes & 0.47 \\
\hline Direct & $\begin{array}{c}110.94^{* * *} \\
{[19.77]}\end{array}$ & $\begin{array}{c}-12.72^{* * *} \\
{[1.28]}\end{array}$ & $\begin{array}{c}26.50^{* * * *} \\
{[7.10]}\end{array}$ & & $\begin{array}{c}85.71^{* * * *} \\
{[17.98]}\end{array}$ & $\begin{array}{c}139.67^{* * *} \\
{[14.67]}\end{array}$ & $\begin{array}{c}-43.29^{* * *} \\
{[5.81]}\end{array}$ & $\begin{array}{c}-33.54^{* * *} \\
{[9.71]}\end{array}$ & $\begin{array}{l}-33.46^{*} \\
{[18.40]}\end{array}$ & No & 0.09 \\
\hline Direct & $\begin{array}{c}164.89^{* * *} \\
{[62.37]}\end{array}$ & $\begin{array}{l}-25.82^{*} \\
{[13.33]}\end{array}$ & $\begin{array}{c}17.76^{* *} \\
{[8.82]}\end{array}$ & & $\begin{array}{c}135.81^{* * *} \\
{[44.68]}\end{array}$ & $\begin{array}{l}111.42^{*} \\
{[62.76]}\end{array}$ & & & & Yes & 0.61 \\
\hline \multicolumn{12}{|c|}{ Panel C: Costs regressions by investment approach } \\
\hline Internal & $\begin{array}{c}33.19^{* * * *} \\
{[7.46]}\end{array}$ & $\begin{array}{c}-3.57^{* * *} \\
{[0.51]}\end{array}$ & & & & & $\begin{array}{l}6.19^{* * * *} \\
{[2.25]}\end{array}$ & $\begin{array}{c}0.07 \\
{[3.04]}\end{array}$ & $\begin{array}{c}1.90 \\
{[8.27]}\end{array}$ & No & 0.08 \\
\hline Internal & $\begin{array}{c}58.34^{* * * *} \\
{[16.43]}\end{array}$ & $\begin{array}{c}-6.84^{* *} \\
{[3.06]}\end{array}$ & & & & & & & & Yes & 0.65 \\
\hline External & $\begin{array}{c}126.79^{* * *} \\
{[15.51]}\end{array}$ & $\begin{array}{c}-11.06^{* * *} \\
{[1.10]}\end{array}$ & & & & & $\begin{array}{c}-41.44^{* * *} \\
{[4.88]}\end{array}$ & $\begin{array}{c}-25.44^{* * *} \\
{[8.49]}\end{array}$ & $\begin{array}{c}-40.90^{* * *} \\
{[14.89]}\end{array}$ & No & 0.05 \\
\hline External & $\begin{array}{c}218.12^{* * *} \\
{[63.15]}\end{array}$ & $\begin{array}{l}-34.92^{* *} \\
{[15.68]}\end{array}$ & & & & & & & & Yes & 0.21 \\
\hline FoF & $\begin{array}{c}240.61^{* * *} \\
{[75.34]}\end{array}$ & $\begin{array}{c}-16.41^{*} \\
{[9.76]}\end{array}$ & & & & & $\begin{array}{c}-74.86 \\
{[53.22]}\end{array}$ & $\begin{array}{c}22.72 \\
{[26.66]}\end{array}$ & $\begin{array}{l}80.21^{* *} \\
{[39.21]}\end{array}$ & No & 0.09 \\
\hline FoF & $\begin{array}{c}346.84^{*} \\
{[177.03]}\end{array}$ & $\begin{array}{c}-54.04 \\
{[58.39]}\end{array}$ & & & & & & & & Yes & 0.64 \\
\hline
\end{tabular}


and allocation to fund-of-funds considerably increase the overall costs. Moreover, U.S. pension funds have considerably higher costs for investing in real estate, even after controlling for mandate size and investment approach.

\subsection{Pension fund performance in real estate investments}

In the previous sections, we documented that pension funds opt for investing in direct real estate over REITs, and prefer delegated investment management over internal management, despite the higher costs associated with these approaches. It may be possible that the investment preferences are driven by performance differences in investment approaches. In this section, we examine whether pension fund real estate returns justify their preference for more expensive investment approaches. We first address the performance of allocations to REITs and direct real estate, after deducting returns on self-reported benchmarks and the investment costs. We then relate the net benchmark-adjusted returns to fund characteristics, such as the size of the real estate mandate and the implemented investment approach. We also investigate the persistence in pension fund real estate investment performance.

\subsubsection{Benchmark-adjusted returns}

Table 5.7 reports the returns of pension fund real estate investments by subcategory and investment approach. Panel A shows that the average gross return of pension funds in real estate is about 7 percent during the 1990-2009 period. REITs delivered a higher gross return (10.92 percent) than direct real estate investments (6.70 percent). The gross returns on internally managed assets (7.77 percent) are higher than the returns on external mandates (6.82 percent).

To put these returns into perspective, we compare them with the returns on self-reported benchmarks. In the CEM database, pension funds declare their benchmarks, which are usually market indexes (for example, the NCREIF Index or the FTSE/NAREIT Index for U.S. real estate investments), against which performance is measured. Benchmark returns can also be a combination of multiple indices, weighted by the asset allocation. The realized returns and the benchmark returns are provided in the local currency. ${ }^{19}$ The advantage of using self-declared benchmarks is that these benchmarks more precisely reflect the allocation and risk exposure of the real estate allocations. For example, if a fund is exposed to office buildings in the U.S., benchmarking its returns against the NCREIF Office Index is more appropriate than using the broader NCREIF Property Index. Similarly, if a pension fund invests internationally and engages in any currency management, the benchmark returns are a weighted average of indices in multiple countries and account for the implemented hedging policy. The disadvantage of using self-declared benchmarks is that pension funds can strategically select benchmarks which are easier to outperform, which implies that one should be careful when drawing conclusions if outperformance relative to these benchmarks would be documented.

\footnotetext{
${ }^{19}$ If currency risk hedging is done at the asset class level, pension funds provide hedged returns and benchmarks.
} 


\section{Table 5.7: Pension fund returns in real estate investments}

This table presents the pension fund returns in real estate investments. Panel A shows the time series averages of cross-sectional mean gross returns for the 1990-2009 time period (for fund-of-funds 1995-2009). Standard deviations of the gross returns are in brackets. In Panel B, we deduct self-declared benchmark returns from pension fund returns, resulting in gross benchmark-adjusted returns. In Panel C, we also deduct the investment costs, resulting in net benchmark-adjusted returns. In Panels B and C, we run a random coefficient model with a constant only, for every fund that has at least three observations. The All RE Assets column presents the constants for the performance in all real estate assets together for all funds and per region. The consecutive two columns present the constants for performance in subcategories: REITs and direct real estate. The last three columns report the performance of different investment approaches: internal, external and fund-of-funds $(F o F)$. In Panels B and C, we report the constant and standard error in brackets, and denote significance levels with *,** and ${ }^{* * *}$, which correspond to 0.10, 0.05 and 0.01, respectively. In Panel D, we report the number of funds and observations (in parentheses) included in these regressions.

\begin{tabular}{|c|c|c|c|c|c|c|}
\hline & \multirow{2}{*}{ All RE Assets } & \multicolumn{2}{|c|}{ Subcategory } & \multicolumn{3}{|c|}{ Approach } \\
\hline & & REITs & Direct RE & Internal & External & FoF \\
\hline \multicolumn{7}{|c|}{ Panel A: Gross returns (percent) } \\
\hline All funds & $\begin{array}{c}7.00 \\
{[9.41]}\end{array}$ & $\begin{array}{c}10.92 \\
{[10.21]}\end{array}$ & $\begin{array}{c}6.70 \\
{[8.40]}\end{array}$ & $\begin{array}{c}7.77 \\
{[11.20]}\end{array}$ & $\begin{array}{c}6.82 \\
{[9.17]}\end{array}$ & $\begin{array}{c}6.72 \\
{[7.85]}\end{array}$ \\
\hline \multicolumn{7}{|c|}{ Panel B: Gross benchmark-adjusted returns (percent) } \\
\hline All funds & $\begin{array}{l}-0.10 \\
{[0.26]}\end{array}$ & $\begin{array}{l}1.13^{* *} \\
{[0.52]}\end{array}$ & $\begin{array}{c}-0.18 \\
{[0.30]}\end{array}$ & $\begin{array}{l}1.08^{* *} \\
{[0.49]}\end{array}$ & $\begin{array}{l}-0.20 \\
{[0.31]}\end{array}$ & $\begin{array}{l}-1.71 \\
{[3.21]}\end{array}$ \\
\hline U.S. & $\begin{array}{l}-0.38 \\
{[0.34]}\end{array}$ & $\begin{array}{c}1.06 \\
{[0.67]}\end{array}$ & $\begin{array}{l}-0.47 \\
{[0.40]}\end{array}$ & $\begin{array}{c}0.47 \\
{[0.90]}\end{array}$ & $\begin{array}{l}-0.38 \\
{[0.38]}\end{array}$ & $\begin{array}{c}-2.08^{* *} \\
{[0.91]}\end{array}$ \\
\hline Canada & $\begin{array}{c}0.40 \\
{[0.50]}\end{array}$ & $\begin{array}{c}1.92 \\
{[1.48]}\end{array}$ & $\begin{array}{c}0.31 \\
{[0.50]}\end{array}$ & $\begin{array}{l}1.20^{*} \\
{[0.72]}\end{array}$ & $\begin{array}{c}0.28 \\
{[0.61]}\end{array}$ & \\
\hline Europe & $\begin{array}{c}0.42 \\
{[0.75]}\end{array}$ & $\begin{array}{c}1.56 \\
{[1.23]}\end{array}$ & $\begin{array}{c}0.40 \\
{[1.10]}\end{array}$ & $\begin{array}{l}1.75^{* *} \\
{[0.89]}\end{array}$ & $\begin{array}{l}-0.25 \\
{[1.43]}\end{array}$ & \\
\hline Aus/Nzd & $\begin{array}{c}0.02 \\
{[1.45]}\end{array}$ & $\begin{array}{l}-0.06 \\
{[0.35]}\end{array}$ & $\begin{array}{c}-0.04 \\
{[1.58]}\end{array}$ & & $\begin{array}{c}0.14 \\
{[1.64]}\end{array}$ & \\
\hline \multicolumn{7}{|c|}{ Panel C: Net benchmark-adjusted returns (percent) } \\
\hline All funds & $\begin{array}{c}-0.86^{* * *} \\
{[0.27]}\end{array}$ & $\begin{array}{c}0.70 \\
{[0.52]}\end{array}$ & $\begin{array}{c}-0.98^{* * *} \\
{[0.30]}\end{array}$ & $\begin{array}{l}0.81^{*} \\
{[0.49]}\end{array}$ & $\begin{array}{c}-1.05^{* * *} \\
{[0.32]}\end{array}$ & $\begin{array}{l}-3.90 \\
{[3.39]}\end{array}$ \\
\hline U.S. & $\begin{array}{c}-1.27^{* * *} \\
{[0.35]}\end{array}$ & $\begin{array}{c}0.56 \\
{[0.66]}\end{array}$ & $\begin{array}{c}-1.43^{* * *} \\
{[0.41]}\end{array}$ & $\begin{array}{c}0.21 \\
{[0.90]}\end{array}$ & $\begin{array}{c}-1.29^{* * *} \\
{[0.39]}\end{array}$ & $\begin{array}{c}-3.76^{* * * *} \\
{[0.92]}\end{array}$ \\
\hline Canada & $\begin{array}{l}-0.17 \\
{[0.51]}\end{array}$ & $\begin{array}{c}1.59 \\
{[1.52]}\end{array}$ & $\begin{array}{l}-0.28 \\
{[0.51]}\end{array}$ & $\begin{array}{c}0.89 \\
{[0.72]}\end{array}$ & $\begin{array}{c}-0.45 \\
{[0.62]}\end{array}$ & \\
\hline Europe & $\begin{array}{c}0.00 \\
{[0.78]}\end{array}$ & $\begin{array}{c}1.33 \\
{[1.23]}\end{array}$ & $\begin{array}{l}-0.10 \\
{[1.12]}\end{array}$ & $\begin{array}{l}1.55^{*} \\
{[0.90]}\end{array}$ & $\begin{array}{l}-0.98 \\
{[1.45]}\end{array}$ & \\
\hline Aus/Nzd & $\begin{array}{c}-0.41 \\
{[1.47]}\end{array}$ & $\begin{array}{c}-0.31 \\
{[0.33]}\end{array}$ & $\begin{array}{c}-0.59 \\
{[1.61]}\end{array}$ & & $\begin{array}{c}-0.30 \\
{[1.66]}\end{array}$ & \\
\hline \multicolumn{7}{|c|}{ Panel D: Number of funds and observations included in the regressions } \\
\hline All funds & $\begin{array}{c}392 \\
(3,136)\end{array}$ & $\begin{array}{c}107 \\
(703)\end{array}$ & $\begin{array}{c}373 \\
(3,004)\end{array}$ & $\begin{array}{c}83 \\
(686)\end{array}$ & $\begin{array}{c}346 \\
(2,624)\end{array}$ & $\begin{array}{c}8 \\
(55)\end{array}$ \\
\hline U.S. & $\begin{array}{c}248 \\
(1,967)\end{array}$ & $\begin{array}{c}76 \\
(491)\end{array}$ & $\begin{array}{c}232 \\
(1,872)\end{array}$ & $\begin{array}{c}25 \\
(198)\end{array}$ & $\begin{array}{c}234 \\
(1,833)\end{array}$ & $\begin{array}{c}5 \\
(46)\end{array}$ \\
\hline Canada & $\begin{array}{c}109 \\
(955)\end{array}$ & $\begin{array}{c}10 \\
(75)\end{array}$ & $\begin{array}{c}106 \\
(918)\end{array}$ & $\begin{array}{c}43 \\
(386)\end{array}$ & $\begin{array}{c}83 \\
(626)\end{array}$ & \\
\hline Europe & $\begin{array}{c}26 \\
(173)\end{array}$ & $\begin{array}{c}16 \\
(114)\end{array}$ & $\begin{array}{c}26 \\
(171)\end{array}$ & $\begin{array}{l}14 \\
(99)\end{array}$ & $\begin{array}{c}21 \\
(127)\end{array}$ & \\
\hline Aus/Nzd & $\begin{array}{c}9 \\
(41)\end{array}$ & $\begin{array}{c}5 \\
(23)\end{array}$ & $\begin{array}{c}9 \\
(43)\end{array}$ & & $\begin{array}{c}8 \\
(38)\end{array}$ & \\
\hline
\end{tabular}


The results in Table 5.7 Panel B show that pension funds mostly match, but do not outperform, their self-declared benchmarks on a gross return basis. In this panel, we run a random coefficient regression, with a constant only, for returns on all real estate assets, returns by subcategory and returns by investment approach. An important advantage of the random coefficient model is that it allows for heteroscedasticity-adjusted and fund-specific alphas, while being more robust to outliers than the standard Fama and MacBeth (1973) approach. Following Swamy (1970), the random coefficient model is similar to a generalized least squares approach that puts less weight on the return series of funds that are more volatile. In the regressions, we include every pension fund that has at least three return observations. ${ }^{20}$

The overall gross benchmark-adjusted returns of all pension funds are not significantly different from zero. ${ }^{21}$ However, we observe outperformance in two cases. First, pension funds obtain positive abnormal annual returns of 108 basis points from internally managed real estate investments. Across all regions, the benchmark-adjusted returns on internal investments are positive, and they are statistically significant for Canadian and European pension funds. Second, we observe positive and significant outperformance of 113 basis points per year for REIT investments. Of course, we cannot conclude that pension funds obtain alpha on a risk-adjusted basis, because our annual data does not allow to control for multiple benchmarks, which may explain a significant portion of REIT returns. ${ }^{22}$

U.S. pension funds that delegate investment management through investing in fund-offunds underperform their self-declared benchmarks by 208 basis points per year, even before deducting investment costs. Part of this significant underperformance may be due to higher performance fees of fund-of-fund managers, because the CEM database captures just the management fees paid to both the fund-of-funds manager and the underlying managers. (Our cost data do not include the performance fees and carried interest paid on either layer, as these costs are deducted directly from the gross returns.)

In Panel C of Table 5.7 we deduct the investment costs and focus on the net benchmarkadjusted performance of pension fund investments in real estate. Overall, we document an annual underperformance of 86 basis points. This seems to be driven mostly by the underperformance of U.S. pension funds, which significantly underperform their self-declared benchmarks, by 127 basis points per year. The returns on pension fund real estate investments in other regions are not significantly different from zero. Interestingly, U.S. pension funds do not underperform in their internal real estate mandates, but rather in their selection of external asset managers (-129 basis points) and fund-of-funds (-376 basis points). This large and sig-

\footnotetext{
${ }^{20}$ Our results do not change if we use all funds in the sample, regardless of the number of observations, or if we use pension funds with at least five observations only.

${ }^{21}$ In a related paper, using data on publicly traded REIT portfolios as well as portfolios of private entities, Hochberg and Mühlhofer (2011) find that both public and private real estate portfolio managers do not exhibit market timing or security selection skills.

${ }^{22}$ Hartzell, Mühlhofer, and Titman (2010) investigate REIT mutual fund performance using three sets of REITbased benchmarks, plus an index of returns derived from non-REIT real estate firms, including homebuilders and real estate operating companies. The REIT-based factors consist of a set of characteristic factors, a set of propertytype factors and a set of statistical factors. Using annual return data, we cannot control for this extensive list of factors.
} 
Figure 5.6: Performance of U.S. pension funds in direct real estate

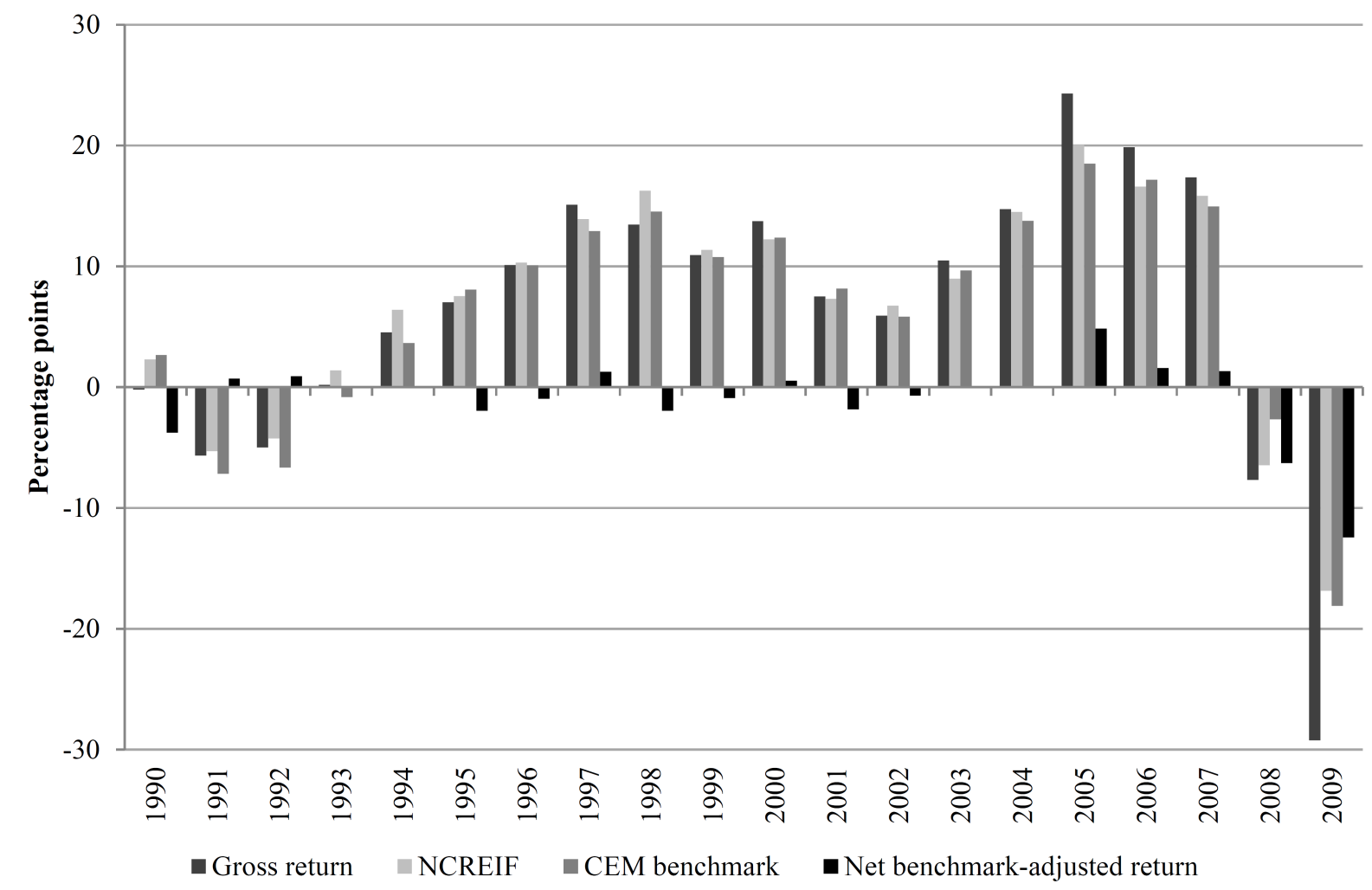

nificant underperformance cannot be explained solely by investment costs, because these are much lower than the size of the estimated alphas.

We investigate in more detail why U.S. pension funds underperform their benchmarks during the sample period. Figure 5.6 displays the gross returns of U.S. pension funds in direct real estate, the returns on the CEM self-declared benchmarks, the returns on the NCREIF Property Index, and the net benchmark-adjusted returns. Until 2004, the performance of U.S. funds in direct real estate was close to their benchmarks. Between 2005 and 2007, U.S. pension funds achieved positive net benchmark-adjusted returns. However, in the last two years of the sample period (2008-2009) U.S. pension funds experienced substantial underperformance in direct real estate. As Figure 5.6 shows, the net benchmark-adjusted return in 2008 was -6.28 percent, on average. In 2009, the average return of U.S. pension funds in direct real estate was -29.24 percent and they underperformed their self-declared benchmarks by 12.43 percent. The graph provides some evidence that the average underperformance of U.S. funds is to a large extent due to the dismal performance during the recent economic downturn. We cannot further explain the performance of U.S. pension funds using the CEM database, but the poor performance may be due to increased usage of leverage in direct real estate holdings and the choice of more risky allocations during the 2005-2009 period. We observe similar patterns among pension funds from the other three regions, but not as extreme as among U.S. pension funds. 


\subsubsection{Performance and characteristics}

In this section, we relate the net benchmark-adjusted returns to a selection of pension fund characteristics, employing Fama and MacBeth (1973) regressions. In the first stage, we regress the fund-specific net benchmark-adjusted returns on a set of pension fund characteristics for each sample year:

$$
R_{i, t}=\alpha_{t}+\delta_{1, t} \text { Mandate }_{i, t}+\delta_{2, t} \operatorname{Costs}_{i, t}+\delta_{3, t} \text { Inv Approach }_{i, t}+\varepsilon_{i, t} \quad \text { for each } t .
$$

where $R_{i, t}$ refers to the net benchmark-adjusted returns of fund $i$ in year $t$. Mandate is the log of the dollar value of the real estate asset portfolio, Costs refers to the real estate investment costs in percentage points, and InvApproach refers to the percentage allocation to external managers, fund of funds, etcetera. The error term $\varepsilon_{i, t}$ is normally distributed with zero-mean. In the second stage we estimate the coefficients as the average of the cross-sectional regression estimates:

$$
\hat{\alpha}=\frac{1}{T} \sum_{t=1}^{T} \hat{\alpha}_{t} \quad \hat{\delta}_{1}=\frac{1}{T} \sum_{t=1}^{T} \hat{\delta}_{1, t} \quad \hat{\delta}_{2}=\frac{1}{T} \sum_{t=1}^{T} \hat{\delta}_{2, t} \quad \hat{\delta}_{3}=\frac{1}{T} \sum_{t=1}^{T} \hat{\delta}_{3, t}
$$

We correct for autocorrelation and heteroscedasticity using Newey-West standard errors.

Results in Panel A of Table 5.8 show that real estate mandate size is positively related to performance. A one unit increase in the log of real estate holdings (Mandate) increases the net benchmark-adjusted returns by 32 to 43 basis points. The documented economies of scale remain even after controlling for costs and investment approach. Furthermore, we observe that higher costs reduce performance. An increase in costs by 100 basis points results in 103 basis points lower returns. The results also indicate that external management and fund-of-funds diminish performance. A pension fund that delegates the asset management responsibilities to external managers experiences a decrease in net benchmark-adjusted returns of 102 to 189 basis points as compared to a pension fund that invests internally in real estate. Adding more intermediaries in the asset management process, by investing through fund-of-funds, reduces returns by at least 202 basis points.

In Panel B of Table 5.8 we examine the relation between performance in real estate subcategories and pension fund characteristics. In this panel, mandate size, costs and investment approach variables refer to REITs and direct real estate investments, respectively. For REITs, we use a shorter time period (1998-2009), as the number of observations during the first years is low (see Figure 5.3 Panel A) and Fama and MacBeth (1973) regressions assign equal weight to every year in the second stage. Our results for REITs indicate that the size of REIT holdings is positively related to performance, controlling for investment approach and costs. There is no significant relation between investment costs or approach and net benchmark-adjusted returns in REITs.

We find significantly positive economies of scale for direct real estate investments as well. A one unit increase in the log of direct real estate assets improves the performance by 31 to 37 basis points. Higher investment costs in direct real estate are disproportionally negatively related 
Table 5.8: Regression results: performance and characteristics

We estimate Fama and MacBeth (1973) regressions on the net benchmark-adjusted returns and correct for autocorrelation and heteroscedasticity using Newey-West with three lags. The net benchmarkadjusted returns are constructed after deducting the costs and self-declared benchmark returns from pension fund real estate returns. In Panel A, the dependent variable is the net benchmark-adjusted return on all real estate assets of all pension funds. In Panel B, the dependent variable is the net benchmark-adjusted return on REITs or direct real estate. In Panel C, the dependent variable is the net benchmark-adjusted return on all assets managed internally, externally or via fund-of-funds. We include the following characteristics: Mandate - log of total holdings in real estate (Panel A), log of holdings in one subcategory (Panel B) or log of holdings in one investment approach (Panel C), Costs - total costs for investing in real estate, subcategory of real estate or investment approach, \%Ext - percentage of investments in external mandates, $\% A c t$ - percentage in active mandates, $\% F o F$ - percentage in fund-of-funds, and \%LP - percentage in limited partnerships. We report standard errors in brackets and significance levels with ${ }^{*}, * *$ and ${ }^{* * *}$, which correspond to $0.10,0.05$ and 0.01 , respectively.

\begin{tabular}{|c|c|c|c|c|c|c|c|c|c|}
\hline & Cons. & Mandate & Costs & $\%$ Ext & $\%$ Act & $\% \mathrm{FoF}$ & $\%$ LP & \# Funds & \# Obs. \\
\hline \multicolumn{10}{|c|}{ Panel A: Performance and characteristics for all real estate assets } \\
\hline All assets & $\begin{array}{c}-2.51^{* * *} \\
{[0.37]}\end{array}$ & $\begin{array}{c}0.43^{* * *} \\
{[0.12]}\end{array}$ & & & & & & 634 & 3,463 \\
\hline All assets & $\begin{array}{c}1.06 \\
{[0.75]}\end{array}$ & & & $\begin{array}{c}-1.89^{* * * *} \\
{[0.58]}\end{array}$ & & $\begin{array}{c}-3.33^{* * *} \\
{[0.98]}\end{array}$ & & 634 & 3,463 \\
\hline All assets & $\begin{array}{l}-0.85 \\
{[0.79]}\end{array}$ & $\begin{array}{c}0.37^{* * *} \\
{[0.13]}\end{array}$ & & $\begin{array}{c}-1.56^{* *} \\
{[0.64]}\end{array}$ & & $\begin{array}{c}-3.05^{* * * *} \\
{[0.87]}\end{array}$ & & 634 & 3,463 \\
\hline All assets & $\begin{array}{c}-0.28 \\
{[0.97]} \\
\end{array}$ & $\begin{array}{l}0.32^{* *} \\
{[0.15]}\end{array}$ & $\begin{array}{c}-1.03^{* * *} \\
{[0.36]} \\
\end{array}$ & $\begin{array}{c}-1.02^{* *} \\
{[0.48]} \\
\end{array}$ & & $\begin{array}{c}-2.02^{* * * *} \\
{[0.69]} \\
\end{array}$ & & 634 & 3,463 \\
\hline \multicolumn{10}{|c|}{ Panel B: Performance and characteristics by real estate subcategory } \\
\hline REITs & $\begin{array}{c}-5.77^{* * *} \\
{[2.24]}\end{array}$ & $\begin{array}{c}0.61^{* * *} \\
{[0.24]}\end{array}$ & & $\begin{array}{c}2.54 \\
{[1.74]}\end{array}$ & $\begin{array}{c}1.46 \\
{[1.27]}\end{array}$ & & & 199 & 802 \\
\hline REITs & $\begin{array}{l}-6.38^{*} \\
{[3.21]}\end{array}$ & $\begin{array}{l}0.70^{* *} \\
{[0.32]}\end{array}$ & $\begin{array}{c}0.13 \\
{[1.22]}\end{array}$ & $\begin{array}{c}2.42 \\
{[1.47]}\end{array}$ & $\begin{array}{c}1.61 \\
{[1.57]}\end{array}$ & & & 199 & 802 \\
\hline Direct RE & $\begin{array}{c}-0.85 \\
{[0.83]}\end{array}$ & $\begin{array}{c}0.37^{* * *} \\
{[0.10]}\end{array}$ & & $\begin{array}{c}-1.66^{* * * *} \\
{[0.68]}\end{array}$ & & $\begin{array}{c}-3.59^{* * *} \\
{[1.05]}\end{array}$ & $\begin{array}{c}0.25 \\
{[1.87]}\end{array}$ & 608 & 3,324 \\
\hline Direct RE & $\begin{array}{c}-0.02 \\
{[1.05]}\end{array}$ & $\begin{array}{c}0.31^{* * * *} \\
{[0.12]}\end{array}$ & $\begin{array}{c}-1.11^{* * *} \\
{[0.34]}\end{array}$ & $\begin{array}{c}-1.22^{* *} \\
{[0.56]}\end{array}$ & & $\begin{array}{c}-2.63^{* * * *} \\
{[0.78]}\end{array}$ & $\begin{array}{c}1.00 \\
{[1.50]}\end{array}$ & 608 & 3,324 \\
\hline \multicolumn{10}{|c|}{ Panel C: Performance and characteristics by investment approach } \\
\hline Internal & $\begin{array}{l}-1.18 \\
{[1.37]}\end{array}$ & $\begin{array}{l}0.43^{*} \\
{[0.26]}\end{array}$ & & & & & & 141 & 761 \\
\hline Internal & $\begin{array}{l}-0.71 \\
{[2.09]}\end{array}$ & $\begin{array}{c}0.43 \\
{[0.28]}\end{array}$ & $\begin{array}{l}-2.56 \\
{[2.96]}\end{array}$ & & & & & 141 & 761 \\
\hline External & $\begin{array}{c}-2.29^{* * *} \\
{[0.41]}\end{array}$ & $\begin{array}{c}0.35^{* * *} \\
{[0.13]}\end{array}$ & & & & & & 580 & 2,937 \\
\hline External & $\begin{array}{l}-1.07 \\
{[0.70]}\end{array}$ & $\begin{array}{l}0.30^{* *} \\
{[0.14]}\end{array}$ & $\begin{array}{c}-1.13^{* * *} \\
{[0.41]}\end{array}$ & & & & & 580 & 2,937 \\
\hline FoF & $\begin{array}{c}1.48 \\
{[4.94]}\end{array}$ & $\begin{array}{l}-1.96 \\
{[2.02]}\end{array}$ & & & & & & 29 & 53 \\
\hline FoF & $\begin{array}{c}4.92 \\
{[15.84]}\end{array}$ & $\begin{array}{c}-2.16 \\
{[2.50]}\end{array}$ & $\begin{array}{l}-1.05 \\
{[4.58]}\end{array}$ & & & & & 29 & 53 \\
\hline
\end{tabular}


to net benchmark-adjusted returns. Higher allocations to external managers and fund-of-funds also result in lower returns from direct real estate. Investing in direct real estate via external managers instead of internal selection of properties results in a 122 to 166 basis point annual decrease in the net benchmark-adjusted returns. Investing through fund-of-funds reduces the net benchmark-adjusted returns by 263 to 359 basis points.

In Table 5.8 Panel $C$ we analyze the relation between performance and characteristics per investment approach. ${ }^{23}$ The results show that larger pension funds have better returns within both internal and external real estate mandates. For externally managed portfolios, a one unit increase in the log of assets improves the annual net benchmark-adjusted returns by 30 to 35 basis points. The scale effect is even stronger for internal management, where a one unit increase in the log of assets increases the returns by 43 basis points. Investment costs are negatively related to external management returns. A 100 basis point increase in the costs reduces returns by 113 basis points per year.

The previous section showed that the last two years of the sample period had a strong influence on investment performance. As a robustness check, we examine whether the exclusion of the 2008-2009 period influences the relation between real estate investment performance and pension fund characteristics. The findings in Appendix Table C.1 confirm that size is positively related to performance, while external management and investing in fund-of-funds have a disproportionally negative effect on returns. Moreover, the economies of scale effect becomes even stronger.

Summarizing, we document that pension funds investing internally in real estate outperform those funds opting for delegated investment management. Moreover, investing in real estate through fund-of-funds results in substantial underperformance (more than 200 basis points per year) as compared to other investment approaches, which may be due to multiple layers of fees, lack of skill, and possibly greater agency conflicts. Larger funds seem to have better skills, which enable them to select better properties when investing internally, and to select better investment managers when investing externally. When investing externally, larger funds are likely to get preferential treatment, have greater monitoring capacity and may have access to better investment opportunities at lower cost. The positive relation between fund size and performance is in line with evidence on private equity funds, for which a concave relation between fund size and performance has been documented (Kaplan and Schoar, 2005). In contrast, increased fund flows generally lead to underperformance for mutual funds (Chen et al., 2004).

\subsubsection{Persistence}

We document that pension funds generally meet, but do not exceed the performance of their benchmarks, and that performance is positively related to the size of real estate holdings, and to the implementation of internal management. We examine whether there is persistence in the performance of pension fund real estate investments, splitting pension funds into five quintiles

\footnotetext{
${ }^{23}$ For fund-of-funds we focus on a shorter time period (2007-2009) because the number of observations in the earlier years is very low (see Figure 5.3 Panel B).
} 
based on their net benchmark-adjusted returns. Table 5.9 presents the transition matrixes, i.e., the probabilities that a fund ranked in one of the five quintiles in year $t$ ends up in any of the quintiles in year $(t+1)$. We also investigate the difference in returns in year $(t+1)$ between funds ranked in the lowest and highest quintile in year $t$. Under the null hypothesis of no persistence, the value of the difference in returns in year $(t+1)$ should be centered on zero, which would mean that past performance is no prediction of future performance. Carpenter and Lynch (1999) show that the $t$-test for the difference between top and bottom portfolios ranked by past performance is best specified under the null hypothesis of no persistence, as it is the most powerful against the alternatives considered. ${ }^{24}$

In Panel A of Table 5.9, we document strong persistence in the performance of pension fund real estate investments. Funds are more likely to end up in a high-ranked quintile next year if they perform well in this year, and funds are more likely to rank low next year if they performed relatively poorly this year. Funds have, on average, a 30 percent chance to remain in the same quintile, and if they do not, they are most likely to move to an adjacent quintile.

The results in Panel B show that there is no persistence in REIT performance. Pension funds ranked in the highest quintile are in fact most likely to end up in the bottom quintile next year. The difference in REIT returns between the top and bottom ranked funds in the following year is small and insignificant. The overall persistence in real estate performance is entirely due to the persistence in direct real estate performance, as shown in Panel C. The last columns of the table provide the year $(t+1)$ average net benchmark-adjusted return for the pension funds that are in the lowest and highest ranked quintiles in year $t$, and the $t$-statistic for the performance difference between the two groups. The net benchmark-adjusted return for the bottom quintile is -3.26 percent, while the return is 1.56 percent for the top quintile. The difference is statistically significant, with a $t$-statistic of 6.23 .

The persistence in performance can potentially be explained by the fact that direct real estate returns are susceptible to appraisal smoothing of property valuations. ${ }^{25}$ However, Geltner and Goetzmann (2000) argue that the NCREIF Property Index, which captures direct real estate investments, is more like an annual index, partially updated each quarter. Hence, the use of annual returns in this paper should help minimize the problems associated with "stale" appraisals of direct real estate returns. Nevertheless, we also address the persistence in pension fund performance in direct real estate by using a two-year horizon, when the appraisal smoothing effect should have lapsed. Table 5.9 Panel D shows that 29.82 percent of the funds in the best performing quintile in year $t$ will end up in the same quintile two years later. Funds are also more likely to end up in the worst performing quintile in year $(t+2)$, if they were ranked in that quintile in year $t$. The difference in returns in years $(t+2)$ between the best and worst performing pension funds ranked in year $t$ is 1.98 percentage points ( $t$-statistic of 2.46).

\footnotetext{
${ }^{24}$ Similar methodology has been used by Tonks (2005) to examine the persistence in pension fund returns and Carhart (1997) to examine the performance persistence among mutual funds.

${ }^{25}$ For instance, the NCREIF database has various statistical problems, including smoothing and lagging due to the partial adjustment in the index caused by the stale valuations, and artificial seasonality in the index returns due to the clustering of the reappraisals in the fourth calendar quarter.
} 
Table 5.9: Persistence in the performance of pension fund real estate investments

Pension funds are placed into quintiles based on their total net benchmark-adjusted returns (Panel A), direct real estate returns (Panels B and C) and REIT returns (Panel D). High row or column represents the quintile with the highest return. In the transition matrices, percentages represent the probability that a fund which was ranked in one of the five quintiles in year $t$ ends up in any of the quintiles in year $(t+1)$. Return in $(t+1)$ columns present the total, direct real estate and REIT net benchmarkadjusted returns in year $(t+1)$ of the top and bottom quintiles, which are formed in year $t$. The Test Diff column is a $t$-statistic of the difference in net benchmark-adjusted returns between the low and high quintile. In Panel C, we investigate the persistence in the performance of pension fund direct real estate investments over a two-year horizon to control for possible short-term smoothing of the returns. In Panel D, the analysis of persistence in performance of pension fund REIT investments is based on the 1998-2009 period, whereas in the other panels we employ the entire sample period.

\begin{tabular}{cccccccccc}
\hline \multicolumn{1}{c}{ Panel A: All real estate } & \multicolumn{10}{c}{ Year $(t+1)$ ranking } & \multicolumn{3}{c}{ Return in $(t+1)$} & Test \\
& & Low & 2 & 3 & 4 & High & Low & High & Diff \\
\hline \multirow{4}{*}{ Year $t$ ranking } & Low & $\mathbf{3 4 . 1 0} \%$ & $22.04 \%$ & $16.01 \%$ & $12.89 \%$ & $14.97 \%$ & -2.95 & 1.31 & $5.89^{* * *}$ \\
& 2 & $22.11 \%$ & $\mathbf{2 7 . 0 1 \%}$ & $23.09 \%$ & $14.48 \%$ & $13.31 \%$ & & & \\
& 3 & $15.54 \%$ & $20.12 \%$ & $\mathbf{2 9 . 0 8 \%}$ & $21.31 \%$ & $13.94 \%$ & & & \\
& 4 & $12.14 \%$ & $15.61 \%$ & $16.38 \%$ & $\mathbf{3 1 . 9 8 \%}$ & $23.89 \%$ & & & \\
& High & $16.57 \%$ & $12.48 \%$ & $11.70 \%$ & $20.66 \%$ & $\mathbf{3 8 . 6 0 \%}$ & & & \\
\hline
\end{tabular}

Panel B: REITs (1998-2009 period)

\begin{tabular}{|c|c|c|c|c|c|c|c|c|c|}
\hline & \multicolumn{6}{|c|}{ Year $(t+1)$ ranking } & \multicolumn{2}{|c|}{ Return in $(t+1)$} & \multirow{2}{*}{$\begin{array}{l}\text { Test } \\
\text { Diff }\end{array}$} \\
\hline & & Low & 2 & 3 & 4 & High & Low & High & \\
\hline \multirow{5}{*}{ Year $t$ ranking } & Low & $30.36 \%$ & $13.39 \%$ & $15.18 \%$ & $21.43 \%$ & $19.64 \%$ & -0.56 & -0.35 & 0.13 \\
\hline & 2 & $16.04 \%$ & $31.13 \%$ & $29.25 \%$ & $14.15 \%$ & $9.43 \%$ & & & \\
\hline & 3 & $13.16 \%$ & $28.07 \%$ & $18.42 \%$ & $24.56 \%$ & $15.79 \%$ & & & \\
\hline & 4 & $15.97 \%$ & $10.92 \%$ & $25.21 \%$ & $30.25 \%$ & $17.65 \%$ & & & \\
\hline & High & $31.19 \%$ & $12.84 \%$ & $16.51 \%$ & $14.68 \%$ & $24.77 \%$ & & & \\
\hline
\end{tabular}

Panel C: Direct real estate (one-year persistence)

\begin{tabular}{cccccccccc}
\hline & & \multicolumn{4}{c}{ Year $(t+1)$ ranking } & \multicolumn{3}{c}{ Return in $(t+1)$} & Test \\
& & Low & 2 & 3 & 4 & High & Low & High & Diff \\
\hline \multirow{4}{*}{ Year $t$ ranking } & Low & $\mathbf{3 4 . 3 0} \%$ & $22.11 \%$ & $16.94 \%$ & $13.84 \%$ & $12.81 \%$ & -3.26 & 1.56 & $6.23^{* * *}$ \\
& 2 & $19.80 \%$ & $\mathbf{2 7 . 9 6 \%}$ & $23.06 \%$ & $15.10 \%$ & $14.08 \%$ & & & \\
& 3 & $15.43 \%$ & $20.04 \%$ & $\mathbf{2 6 . 6 5 \%}$ & $22.44 \%$ & $15.43 \%$ & & & \\
& 4 & $13.43 \%$ & $15.70 \%$ & $17.98 \%$ & $\mathbf{2 9 . 7 5 \%}$ & $23.14 \%$ & & & \\
& High & $15.34 \%$ & $12.55 \%$ & $12.75 \%$ & $20.32 \%$ & $\mathbf{3 9 . 0 4 \%}$ & & & \\
\hline
\end{tabular}

Panel D: Direct real estate (two-years persistence)

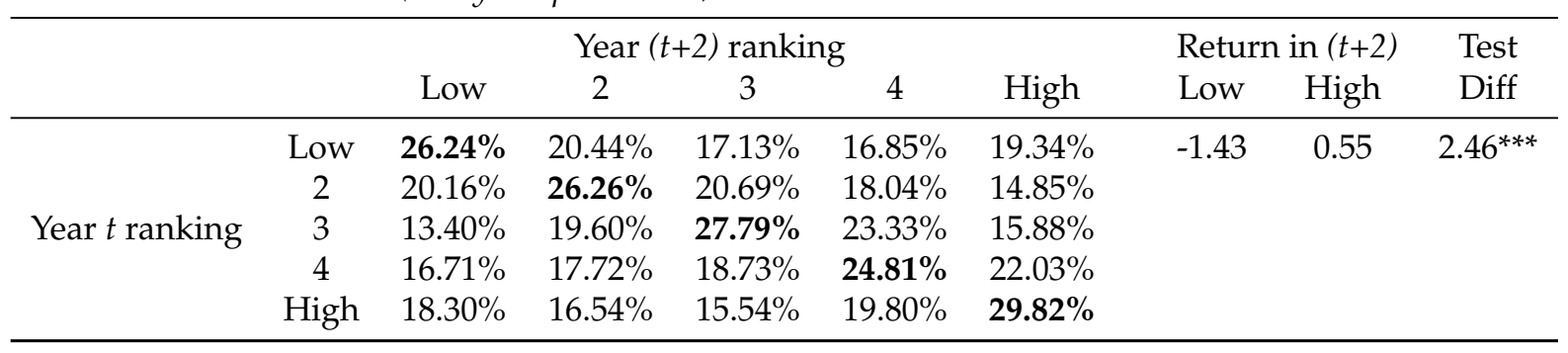


In Appendix Table C.2 we examine whether the persistence results are robust to controlling to the effect of size and investment approach on performance. We run an ordered logit model, where the dependent variable is the quintile ranking based on the performance in year $t+1$ and the main independent variable is the quintile ranking in year $t$, while controlling for real estate mandate size and investment approach. The results indicate that pension fund performance ranking in year $t$ has a significant positive effect on the performance ranking in year $t+1$. For example, looking at all real estate assets (Panel A), an increase in the quintile ranking from 3 to 4 increases the probability of ranking among the best performers in year $t+1$ by $4.5 \%$. Again, we document persistence only for pension fund performance in direct real estate.

These results suggest that certain pension funds are persistently more likely to outperform (or underperform) their direct real estate benchmarks, while that is not the case for REIT investors. This finding may be explained by the fact that direct real estate markets are illiquid and not very transparent, which may give insiders an edge. On the other hand, the stock listing of REITs makes the REIT market more transparent and efficient, and outperformance more difficult. Additionally, higher transaction costs and market illiquidity limit the possibility to exploit persistence in direct real estate returns. ${ }^{26}$

Similar to our findings on persistence in direct real estate performance, persistence has been documented among private equity funds and hedge funds as well. Kaplan and Schoar (2005) find substantial persistence in leverage buyout (LBO) and venture capital (VC) fund performance. General partners (GPs) whose private equity funds outperform the industry in one fund are likely to outperform the industry in the next and vice versa. Fung, Hsieh, Naik, and Ramadorai (2008) document that better performing hedge funds, generating positive alpha, are less likely to be liquidated, and have a higher propensity to persistently deliver alpha.

\subsection{Conclusion}

Comparable to investments in private equity and hedge funds, pension funds face a palette of choices to deploy capital in the illiquid property market, the most significant alternative asset class. The allocations to real estate can be managed internally, externally and through fund-offunds, and can be invested both in REITs and directly in fixed assets. This offers the opportunity to investigate the impact of delegated investment management on costs and performance of investments in private markets. Binsbergen et al. (2008) argue that investing through multiple external asset managers is costly, as it causes agency conflicts between the institutional investor and external managers. We evaluate whether sufficiently large investors can reduce these agency conflicts in diversification, risk-taking and investment horizon objectives, by establishing an internal asset management division, instead of delegating the asset management decisions. According to Stoughton et al. (2011) financial intermediation model, if it is costly

\footnotetext{
${ }^{26}$ Prior research on performance persistence in real estate has arrived at similar conclusions. Among mutual funds that invest only in the REIT sector, Kallberg, Liu, and Trzcinka (2000) document little evidence of persistence. On the other hand, among fund managers investing in the direct real estate market, Bond and Mitchell (2010) document performance persistence over a short-term horizon, but there is little evidence of persistence in fund returns over a medium and long-term horizon.
} 
to identify higher quality fund managers, the choice between direct and intermediated asset management will depend upon investor size, since search costs are more easily offset by better performance on a larger investment.

Exploiting the access to a unique sample of pension funds, we document that the costs and performance of pension fund real estate investments are mainly determined by two main variables: mandate size and the choice to invest internally or externally. We find strong scale advantages in pension fund real estate investments: large pension funds not only have lower investment costs, but also achieve higher net benchmark-adjusted returns. This is partly due to the fact that larger funds are more likely to opt for internal management, rather than selecting financial intermediaries. Internal management is associated with substantially lower costs and better gross performance as compared to external managers. Moreover, even when large pension funds select an external investment approach, they seem to have better skills than the smaller pension funds in our sample. When investing through financial intermediaries in real estate, larger funds can presumably assert more negotiating power, which then leads to access to more favorable investment opportunities at lower costs.

Surprisingly, larger funds are also more likely to invest in REITs, whereas smaller funds allocate more capital to fund-of-funds in direct real estate. Investing through fund-of-funds results in substantial underperformance as compared to other investment approaches. This is at least partly due to multiple layers of fees, but fund-of-fund managers also seem to lack unique skills in selecting investment managers, since both their gross and net benchmark-adjusted returns are significantly negative. Especially smaller pension funds do not seem to recognize that REITs represent an investment approach in real estate that is comparable to selecting external managers investing in direct real estate (and much better than fund-of-funds managers), but with substantially lower investment costs.

Overall, the behavior of small and large pension funds suggests that there may be differences between the two groups, with relatively less sophisticated agents among smaller funds, and more sophisticated agents, with an ability to detect profitable real estate investments, among larger funds. Lerner et al. (2007) document that agency conflicts and information gaps associated with assessing private equity fund portfolios lead to dramatic disparities in the performance of venture capital investments across different classes of institutional investors. We document that such information gaps and agency problems can also lead to performance differences within one class of institutional investors - pension funds. These results are consistent with the predictions from the Stoughton et al. (2011) model of financial intermediation, where underperforming assets (funds) can only be sold via financial intermediaries to unsophisticated investors. Our results on the effect of delegated investment management on performance are also in line with Agarwal et al. (2013) finding that the performance of institutions investing in funds of hedge funds is worse than the performance of those institutions investing directly in hedge funds.

Fund-of-funds in direct real estate perform worse than REIT mutual funds and funds investing in hedge funds. The literature on the performance of REIT mutual funds shows that 
this industry generates an average alpha that is either zero or significantly positive. ${ }^{27}$ Funds investing in hedge funds deliver small alphas, albeit sporadically (Fung et al., 2008), but there is no significant underperformance among hedge funds-of-funds either. Compared to these benchmarks, fund-of-funds in direct real estate perform poorly, so it seems surprising that small pension funds increasingly use their services. However, this behavior is consistent with the Lakonishok et al. (1992) model of pension fund portfolio management: despite higher costs and lower returns, pension funds will maintain a preference for external management and fund-of-funds, as a way to shift responsibility for potentially poor performance to the external manager, and even to shift the responsibility for poor selection of managers to the fundof-funds manager. Goyal and Wahal (2008) show that pension funds continuously engage in hiring and firing external money managers, even though these decisions have, on average, no effect on their performance, while creating substantial transition costs.

This paper has some general implications for institutional investors investing in real estate. Pension funds should consider the full range of possible approaches to real estate investments and avoid extended chains of financial intermediaries. Particularly smaller funds should reevaluate their extensive use of fund-of-funds to gain exposure to direct real estate and consider substituting part of this allocation with REITs. Smaller pension funds can also implement more passive strategies in REIT investments in order to remain cost-competitive with larger funds.

\footnotetext{
${ }^{27}$ For instance, Cici, Corgel, and Gibson (2011) find that REIT mutual funds obtained significant abnormal net returns, while Hartzell et al. (2010) document that REIT mutual funds deliver alpha close to zero and fail to outperform any alternative benchmark net of fees.
} 


\subsection{Chapter 5 Appendix}

\section{Table C.1: Regression results: performance and characteristics 1990-2007}

We estimate Fama and MacBeth (1973) regressions on the net benchmark-adjusted returns and correct for autocorrelation and heteroscedasticity using Newey-West with three lags. The net benchmarkadjusted returns are constructed after deducting the costs and self-declared benchmark returns from pension fund real estate returns. In Panel A, the dependent variable is the net benchmark-adjusted return on all real estate assets of all pension funds. In Panel B, the dependent variable is the net benchmark-adjusted return on REITs or direct real estate. In Panel C, the dependent variable is the net benchmark-adjusted return on all assets managed internally, externally or via fund-of-funds. We include the following characteristics: Mandate - log of total holdings in real estate (Panel A), log of holdings in one subcategory (Panel B) or log of holdings in one investment approach (Panel C), Costs - total costs for investing in real estate, subcategory of real estate or investment approach, \%Ext - percentage of investments in external mandates, $\%$ Act - percentage in active mandates, $\%$ FoF - percentage in fund-of-funds, and \%LP - percentage in limited partnerships. We report standard errors in brackets and significance levels with ${ }^{*},{ }^{* *}$ and ${ }^{* * *}$, which correspond to $0.10,0.05$ and 0.01 , respectively.

\begin{tabular}{|c|c|c|c|c|c|c|c|c|c|}
\hline & Cons. & Mandate & Costs & $\%$ Ext & $\%$ Act & $\% \mathrm{FoF}$ & $\%$ LP & \#Funds & \# Obs. \\
\hline \multicolumn{10}{|c|}{ Panel A: Performance and characteristics for all real estate assets } \\
\hline All assets & $\begin{array}{c}-2.35^{* * *} \\
{[0.42]}\end{array}$ & $\begin{array}{c}0.52^{* * *} \\
{[0.10]}\end{array}$ & & & & & & 570 & 2,985 \\
\hline All assets & $\begin{array}{c}1.45 \\
{[0.89]}\end{array}$ & & & $\begin{array}{c}-1.63^{* * * *} \\
{[0.49]}\end{array}$ & & $\begin{array}{c}-3.38^{* * *} \\
{[1.08]}\end{array}$ & & 570 & 2,985 \\
\hline All assets & $\begin{array}{l}-1.14 \\
{[0.70]}\end{array}$ & $\begin{array}{c}0.48^{* * *} \\
{[0.09]}\end{array}$ & & $\begin{array}{c}-1.17^{* * * *} \\
{[0.42]}\end{array}$ & & $\begin{array}{c}-2.87^{* * *} \\
{[0.89]}\end{array}$ & & 570 & 2,985 \\
\hline All assets & $\begin{array}{c}-0.78 \\
{[0.77]}\end{array}$ & $\begin{array}{l}0.45^{* * * *} \\
{[0.09]}\end{array}$ & $\begin{array}{l}-0.75^{* *} \\
{[0.30]}\end{array}$ & $\begin{array}{c}-0.79^{* * *} \\
{[0.37]}\end{array}$ & & $\begin{array}{c}-2.21^{* * *} \\
{[0.80]}\end{array}$ & & 570 & 2,985 \\
\hline \multicolumn{10}{|c|}{ Panel B: Performance and characteristics by real estate subcategory } \\
\hline REITs & $\begin{array}{c}-6.51^{* *} \\
{[2.76]}\end{array}$ & $\begin{array}{c}0.81^{* * *} \\
{[0.32]}\end{array}$ & & $\begin{array}{c}2.27 \\
{[2.04]}\end{array}$ & $\begin{array}{c}1.74 \\
{[1.50]}\end{array}$ & & & 166 & 601 \\
\hline REITs & $\begin{array}{l}-7.08^{*} \\
{[3.30]}\end{array}$ & $\begin{array}{l}0.87^{* *} \\
{[0.36]}\end{array}$ & $\begin{array}{c}-0.40 \\
{[1.27]}\end{array}$ & $\begin{array}{c}2.26 \\
{[1.53]}\end{array}$ & $\begin{array}{c}2.10 \\
{[1.33]}\end{array}$ & & & 166 & 601 \\
\hline Direct RE & $\begin{array}{c}-0.90 \\
{[0.89]}\end{array}$ & $\begin{array}{c}0.44^{* * *} \\
{[0.08]}\end{array}$ & & $\begin{array}{c}-1.23^{* * *} \\
{[0.43]}\end{array}$ & & $\begin{array}{c}-3.39^{* * *} \\
{[1.06]}\end{array}$ & $\begin{array}{c}1.48 \\
{[1.58]}\end{array}$ & 543 & 2,869 \\
\hline Direct RE & $\begin{array}{c}-0.35 \\
{[1.00]}\end{array}$ & $\begin{array}{c}0.41^{* * *} \\
{[0.08]}\end{array}$ & $\begin{array}{c}-0.89^{* * *} \\
{[0.32]}\end{array}$ & $\begin{array}{c}-0.90^{* *} \\
{[0.37]}\end{array}$ & & $\begin{array}{c}-2.67^{* * *} \\
{[0.85]}\end{array}$ & $\begin{array}{c}1.67 \\
{[1.48]}\end{array}$ & 543 & 2,869 \\
\hline \multicolumn{10}{|c|}{ Panel C: Performance and characteristics by investment approach } \\
\hline Internal & $\begin{array}{c}-1.79 \\
{[1.25]}\end{array}$ & $\begin{array}{l}0.60^{* * *} \\
{[0.22]}\end{array}$ & & & & & & 130 & 665 \\
\hline Internal & $\begin{array}{l}-1.30 \\
{[2.18]}\end{array}$ & $\begin{array}{l}0.58^{* *} \\
{[0.27]}\end{array}$ & $\begin{array}{c}-2.13 \\
{[3.18]}\end{array}$ & & & & & 130 & 665 \\
\hline External & $\begin{array}{c}-2.14^{* * *} \\
{[0.44]}\end{array}$ & $\begin{array}{c}0.46^{* * *} \\
{[0.10]}\end{array}$ & & & & & & 519 & 2,520 \\
\hline External & $\begin{array}{l}-1.32^{*} \\
{[0.73]}\end{array}$ & $\begin{array}{c}0.43^{* * * *} \\
{[0.10]}\end{array}$ & $\begin{array}{c}-0.86^{* *} \\
{[0.37]}\end{array}$ & & & & & 519 & 2,520 \\
\hline
\end{tabular}


Table C.2: Regression results: performance persistence

The net benchmark-adjusted returns are constructed after deducting the costs and self-declared benchmark returns from pension fund real estate returns. Pension funds are placed into quintiles based on their total net benchmark-adjusted returns (Panel A), direct real estate returns (Panels B and C) and REIT returns (Panel D). In Panel C, we investigate the persistence in the performance of pension fund direct real estate investments over a two-year horizon to control for possible short-term smoothing of the returns. In Panel D, the analysis of persistence in performance of pension fund REIT investments is based on the 1998-2009 period, whereas in the other panels we employ the entire sample period. The coefficients in the table present the marginal effects after an ordered logit model. The dependent variable is the quintile ranking based on returns in year $t$. We show the marginal effects for the probability to be ranked in the quintile with lowest and in the quintile with the highest returns. The Rank $(t-1)$ variable is the quintile ranking in the previous year. The Rank $(t-2)$ variable is the quintile ranking two years ago. We also include the following variables: Mandate - log of total holdings in real estate (Panel A), log of REIT holdings (Panel B) or log of direct real estate holdings (Panels C and D), Costs - total costs for investing in real estate, REITs or direct real estate, $\% E x t$ - percentage of investments in external mandates, $\% A c t$ - percentage in active mandates, $\%$ FoF - percentage in fund-of-funds, and \%LP - percentage in limited partnerships. The marginal effects are estimated at the median values. In the ordered logit model we also add year dummy variables and cluster the standard errors by funds. We report standard errors in brackets and significance levels with *** and **, which correspond to 0.10, 0.05 and 0.01 , respectively.

\begin{tabular}{|c|c|c|c|c|c|c|c|c|c|}
\hline & $\operatorname{Rank}_{(t-1)}$ & $\operatorname{Rank}_{(t-2)}$ & Mandate & Costs & $\%$ Ext & $\%$ Act & $\% \mathrm{FoF}$ & $\%$ LP & YD \\
\hline \multicolumn{10}{|c|}{ Panel A: All real estate assets } \\
\hline \multirow[t]{2}{*}{ Low ranking } & $-0.054^{* * *}$ & & $-0.016^{* * *}$ & $0.059^{* * *}$ & $0.033^{*}$ & & 0.002 & & Yes \\
\hline & [0.007] & & [0.004] & [0.019] & {$[0.020]$} & & [0.062] & & \\
\hline \multirow[t]{2}{*}{ High ranking } & $0.045^{* * *}$ & & $0.013^{* * *}$ & $-0.048^{* * *}$ & $-0.027^{*}$ & & -0.002 & & Yes \\
\hline & {$[0.006]$} & & [0.003] & [0.017] & [0.016] & & [0.051] & & \\
\hline \multicolumn{10}{|c|}{ Panel B: Direct real estate (one-year persistence) } \\
\hline \multirow[t]{2}{*}{ Low ranking } & $-0.053^{* * *}$ & & $-0.013^{* * *}$ & $0.045^{* * *}$ & $0.042^{* *}$ & & 0.022 & 0.039 & Yes \\
\hline & [0.006] & & [0.004] & {$[0.017]$} & [0.018] & & [0.046] & [0.045] & \\
\hline \multirow[t]{2}{*}{ High ranking } & $0.048^{* * *}$ & & $0.012^{* * *}$ & $-0.041^{* *}$ & $-0.038^{* * *}$ & & -0.020 & -0.035 & Yes \\
\hline & [0.006] & & [0.003] & [0.017] & [0.015] & & [0.042] & [0.041] & \\
\hline \multicolumn{10}{|c|}{ Panel C: Direct real estate (two-year persistence) } \\
\hline \multirow{2}{*}{\multicolumn{2}{|c|}{ Low ranking }} & $-0.018^{* * *}$ & $-0.016^{* * *}$ & $0.074^{* * *}$ & $0.058^{* *}$ & & $0.087^{*}$ & 0.039 & Yes \\
\hline & & [0.005] & [0.005] & [0.021] & {$[0.025]$} & & [0.050] & [0.062] & \\
\hline \multirow[t]{2}{*}{ High ranking } & & $0.015^{* * *}$ & $0.014^{* * *}$ & $-0.062^{* * *}$ & $-0.049^{* * *}$ & & $-0.073^{*}$ & -0.033 & Yes \\
\hline & & [0.005] & [0.004] & {$[0.020]$} & [0.019] & & [0.041] & [0.052] & \\
\hline \multicolumn{10}{|c|}{ Panel D: REITs (1998-2009) } \\
\hline \multirow[t]{2}{*}{ Low ranking } & -0.010 & & $-0.021^{*}$ & -0.037 & -0.025 & $-0.086^{* *}$ & & & Yes \\
\hline & [0.011] & & [0.012] & {$[0.068]$} & [0.041] & [0.036] & & & \\
\hline \multirow[t]{2}{*}{ High ranking } & 0.009 & & $0.018^{*}$ & 0.031 & 0.022 & $0.074^{*}$ & & & Yes \\
\hline & [0.009] & & [0.010] & [0.054] & [0.037] & [0.039] & & & \\
\hline
\end{tabular}




\section{Chapter 6}

\section{Conclusion}

\subsection{Agency conflicts among defined benefit pension funds}

In investment management, pension funds and other institutions serve as agents that enable the principle, plan members, to save for retirement or reach other financial goals. People rely on DB pension funds to manage their wealth because these funds provide insurance to members against the risk of outliving their assets by allowing for intergenerational and intragenerational risk sharing (Ball and Mankiw, 2007; Davidoff, Brown, and Diamond, 2005). However, DB pension funds also serve as agent for multiple principles: different generations of plan members as well as for the taxpayers, if the pension benefits are explicitly or implicitly guaranteed. In this dissertation, I show that this agency relations in DB retirement systems could create two agency conflicts.

First, different generations of plan members have opposing interests when the pension fund is underfunded. Current stakeholders have an incentive to postpone restructuring the pension benefit promises and to transfer the underfunding risk to future generations. Chapter 2 shows that pension fund asset allocation decisions implemented by the current generation can be influenced by the regulatory incentives to mask funding problems and shift the risk to future generations as well as to taxpayers.

Second, when people delegate the management of their retirement saving to pension funds, plan members trade off higher anticipated returns from these intermediaries against the increased difficulty in coordinating their risk-taking and the greater uncertainty about their true incentives and skills. The management of retirement assets involves multiple levels of intermediaries, such as pension fund executives, asset managers, placement agents, consultants and actuaries. Chapters 4 and 5 show that multiple layers of intermediation result in higher investment costs and lower performance, especially in alternative assets.

Both of these agency conflicts can be reduced substantially by greater transparency in the pension fund reporting of financial situation as well as in the relations between pension funds and asset management intermediaries. 


\subsubsection{Implications for pension fund regulation}

My research on U.S. public pension funds documents that their regulation permits the current generation to shift concealed funding deficits to future generations by using liability discount rates based on the expected rate of return, not the riskiness of promised pension benefits. This regulation can lead to substantial intergenerational redistribution of wealth and I argue that the policy pertaining to U.S. public pension funds needs a reform.

Pension fund accounting standards should promote transparency, which includes making fair disclosure of the funding situation. The current regulation of U.S. public pension funds permits smoothing of the asset value and discounting the liabilities with the expected rate of return. These valuation rules obscure pension plans true funding status and impact pension fund planning, budgeting and restructuring. In 2010, the average self-declared funding ratio of U.S. public pension funds, estimated using these rules, was equal to 75 percent. In order to overcome this significant underfunding, the vast majority of U.S. public pension funds would have to modify the pension deal. However, restructuring of the contribution rates and promised pension benefits cannot be successful and fair across generations, if it is based on self-reported funding ratios which do not reflect the financial situation. Hence, increasing the transparency in U.S. public pension fund reporting is a necessary precondition before discussing the potential reforms.

In my policy implications, I do not want to make any assertion about the optimal funding level of pension plans. Ricardo (1820) postulates that it is irrelevant for the public welfare whether the current spending is financed with debt or taxes. However, the Ricardian equivalence is applicable to the intergenerational consequences of public pension debt only if the current and future generations are informed about the level of pension plan underfunding and state indebtedness. The current regulation of U.S. public pension funds camouflages their funding situation and indirectly the state indebtedness, making it difficult for people to estimate the magnitude of intergenerational transfers. I believe that it is important to provide the plan members and taxpayers with accurate estimates of pension fund financial situation and their projected cash-flows in order to enable them to make sound financial decisions.

\subsubsection{Implications for pension fund investment management}

The investment management of retirement assets involves many intermediaries, such as pension fund boards and executives, asset managers, placement agents and consultants. These intermediaries provide expertise in information gathering and scale advantages in investment costs. However, the multiple layers of intermediation can also create agency conflicts and misalignment of objectives, which will reduce the retirement wealth of plan participants.

DB pension funds are among the largest institutional investors. The large size enables them to obtain scale advantages in information gathering as well as in the investment costs, but also makes DB funds prone to liquidity-related diseconomies of scale. According to Chapter 3 , large pension funds experience diseconomies of scale when they invest actively in multiple asset classes, such as equities and bonds. In these assets, some larger pension funds could 
have performed better, if they had invested in passive mandates without frequent rebalancing decisions. Instead of focusing on traditional active management, DB pension funds can benefit more from designing dynamic asset allocation and market timing policies.

In alternative assets, institutional investors delegate more than 85 percent of the asset management to financial intermediaries, even though multiple layers of intermediation result in higher investment costs and lower performance. These results suggest that part of the delegation decisions of pension funds may be made sub-optimally and driven by considerations other than where the best investment opportunities. For instance, institutional investors may retain underperforming intermediaries because delegation reduces their anxiety about taking risk as compared to internal investing. Pension funds delegating the asset management to intermediaries in order to shift responsibility perceive the returns delivered by these intermediaries as less risky than those delivered by an internal investment division (Gennaioli, Shleifer, and Vishny, 2013; Lakonishok, Shleifer, and Vishny, 1992). If institutional investors delegate the asset management to intermediaries in order to shift responsibility and reduce perceived risk, than they violate their fiduciary duty and do not act in the best interest of their beneficiaries.

Based on Chapters 4 and 5, larger pension funds should evaluate the possibility to reduce the intermediation by investing internally in alternative asset classes. Smaller pension funds should consider substituting fund-of-funds with other less intermediated investment approaches, and specializing in one alternative asset class, instead of simultaneously investing in multiple alternative assets. If smaller investors do not have sufficient capacity to manage alternative investments, they should invest passively in public equity.

\subsection{Future research}

\subsubsection{The effect of regulation and governance on asset allocation policy}

In Chapter 2, I examine the risk-taking and liabilities valuation of pension funds. Using data on U.S., Canadian and European defined benefit pension funds, I study how pension funds modify their asset allocation policy over time in response to maturing member population and declining interest rates, and whether the changes in strategic asset allocation policy depend on the differences in regulation of liability discount rates. U.S. public funds face distinct regulations that link the liability discount rate to their expected return on assets rather than to the riskiness of their promised pension benefits. Accordingly, they behave differently from all other pension funds. In the past two decades, U.S. public pension funds uniquely increased allocations to riskier investments to maintain high discount rates (especially as more members retired), thereby camouflaging the degree of underfunding. This increased risk-taking is associated with an annual underperformance of more than 60 basis points.

However, even among U.S. public pension funds, there is substantial heterogeneity in strategic asset allocation, fund maturity and liability valuation. I plan to extend this research by examining the governance of pension funds. The governance of pension funds is important because the increased risk-taking and underfunding can lead to redistribution across generations and may create significant conflicts of interest between current and future stakeholders. I 
plan to analyze whether the cross-sectional differences in contribution rates, allocation to risky asset and liability discount rates can be explained by the composition of pension fund Board of Truestees and by the characteristics of pension fund executives.

For example, board members who represent the general public are always appointed and do not participate in the pension plan themselves, which suggests that they have different incentives from employee and retiree representatives, who are pension fund participants. Whereas board members representing actual pension participants (either employees or retirees) would likely give a higher priority to the economic welfare of the pension plan participants, board members representing the general public may give a relatively higher priority to the provision of public services more generally rather than funding pension plans in particular.

Overall, I would like to extend my empirical work on pension fund asset allocation and regulation by studying how the board composition and the background of their executives affect pension fund asset allocation, benefit payments and funding level.

\subsubsection{Institutional investor asset management decisions}

Institutional investors continuously engage in asset management through changing the strategic asset allocation weights over time, deviating from those in short-term market timing, and by selecting particular securities within asset classes.

Changes in asset allocation policy result in positive abnormal returns, which are due to pension funds changing their asset allocation policy across broader asset classes over time, not to changes within equity or fixed income. Market timing also delivers a positive alpha that is larger among smaller pension funds. Market timing alpha is due to passive market movements, and pension funds have the ability to exploit 'time series' momentum by investing in multiple asset classes at the same time. However, pension funds do not have active rebalancing skills. These results suggest that funds that try to stay as close as possible to their strategic asset allocation policy may miss market timing opportunities. If fund managers can obtain positive returns from the passive market movements due to time series momentum, letting the actual weights deviate from the strategic weights and not rebalancing back immediately can in fact improve performance. Security selection delivers an insignificant negative return after riskadjusting and controlling for the momentum factor.

Larger pension funds do not manage to transfer their lower investment costs into higher net returns. Rather, I document diseconomies of scale in pension fund performance. The diseconomies of scale are primarily apparent for funds investing in less liquid assets, as proxied by fund total return loadings on the traded systematic liquidity factor. As a result, the performance of large pension funds seems to be subject to size-induced liquidity limitations. These liquidity limitations related to size are significant in all three asset management components. Smaller pension funds obtain higher total returns and especially higher market timing returns.

I would like to extend this research by examining pension fund holdings on a security level, which will provide more precise of the pension fund exposure to illiquid assets. These holdings data will enable me to test whether the long-term liability structure enables pension funds to exploit the illiquidity premium in public as well as private markets. Pension fund holdings data 
can also provide an opportunity to test the Berk and Green (2004) model of decreasing returns of scale. Pension funds invest through both internal and external managers, and combine both active and passive strategies. According to Berk and Green (2004) model, the amount of assets that pension funds could manage successfully by active internal mandates is limited, but large pension funds may potentially avoid the scale disadvantages by invetsing in passive mandates or by selecting multiple external managers.

\subsubsection{Investing in alternative assets}

Over the last decades, institutional investors have increased especially the amount of investments in alternative asset classes, attracted by the promise of superior absolute returns and low correlation with traditional assets such as equities and bonds. In Chapters 4 and 5, I examine the allocations of institutional investors to private equity, real estate and hedge funds, focusing on how levels of intermediation and specialization relate to costs and performance of institutional investors in alternative assets.

When delegating the asset management to financial intermediaries, institutional investors trade-off higher anticipated returns from these intermediaries against the increased difficulty in coordinating their risk-taking and the greater uncertainty about their true incentives and skills. In private equity, real estate and hedge fund investments, I can distinguish three levels of intermediaries serving as interface between investors and assets. Institutional investors can manage the alternative investments internally (in-house), delegate the asset management to external managers or delegate even the selection of external managers to fund-of-funds.

I document that institutional investors that invest through internal managers tend to perform better than their counterparts, which rely on financial intermediaries, in all three alternative asset classes: real assets, private equity and hedge funds. Fund-of-funds significantly underperform as compared to external and internal managers, while external managers underperform internal managers. The outperformance of internal managers compared to financial intermediaries stems from two sources. First, for sufficiently large institutional investors, establishing internal management divisions costs significantly less than investing through external managers and fund-of-funds. Second, internal managers can successfully compete with financial intermediaries in the private markets and manage to obtain similar or higher gross returns in all three alternative asset classes.

I would like to extend this research by merging the CEM institutional investor data with more detailed datasets on an asset class level for private equity, real estate or hedge fund investments. This would enable me to study the exact deals in alternative assets, while controlling for investor characteristics. Using data on an asset class level will enable me to measure precisely the risk and location of different alternative investments. Riskier and more distant alternative investment may require higher levels of expertise, which financial intermediaries may possess. There can be significant differences between the institutional investments managed internally and those delegated to financial intermediaries. Furthermore, it is relevant to study the number of deals that institutions manage in alternative assets. Managing less deals simultaneously 
reduces the monitoring costs and potential agency conflicts, but exposes investors to diversification problems. Overall, I would like to study whether the riskiness, location and number of alternative investments are related to the intermediation level and specialization, while controlling for institutional investor size and strategic asset allocation policy. 


\section{References}

Actuarial Standards Board (adopted in 2007). Selection and use of asset valuation methods for pension valuations.

Actuarial Standards Board (clarified in 2009). Selection and use of asset valuation methods for pension valuations.

Admati, A. R. and P. Pfleiderer (1994). Robust financial contracting and the role of venture capitalists. The Journal of Finance 49(2), 371-402.

Agarwal, V., W. Jiang, Y. Tang, and B. Yang (2013). Uncovering hedge fund skill from the portfolio holdings they hide. The Journal of Finance 68(2), 739-783.

Agarwal, V., V. Nanda, and S. Ray (2013). Institutional investment and intermediation in the hedge fund industry. Working Paper: Georgia State University.

Allen, F. (2001). Presidential address: Do financial institutions matter? The Journal of Finance 56(4), 1165-1175.

Ambachtsheer, K. (2010). GASB's folly. The Ambachtsheer Letter.

Andonov, A., R. Bauer, and M. Cremers (2012). Can large pension funds beat the market? Asset allocation, market timing, security selection and the limits of liquidity. Working Paper: University of Notre Dame.

Andonov, A., R. Bauer, and M. Cremers (2013). Pension fund asset allocation and liability discount rates: Camouflage and reckless risk taking by u.s. public plans? Working Paper: University of Notre Dame.

Andonov, A., P. Eichholtz, and N. Kok (2013). Value added from investment managers in private markets? An examination of pension fund investments in real estate. Working Paper: Maastricht University.

Aragon, G. O. (2007). Share restrictions and asset pricing: Evidence from the hedge fund industry. Journal of Financial Economics 83(1), 33-58.

Ball, L. and N. G. Mankiw (2007). Intergenerational risk sharing in the spirit of arrow, debreu, and rawls, with applications to social security design. Journal of Political Economy 115(4), 523-547.

Bauer, R., M. Cremers, and R. Frehen (2010). Pension fund performance and costs: Small is beautiful. Working Paper: Yale University.

Bauer, R., P. Eichholtz, and N. Kok (2010). Corporate governance and performance: The REIT effect. Real Estate Economics 38(1), 1-29.

Benzoni, L., P. Collin-Dufresne, and R. S. Goldstein (2007). Portfolio choice over the life-cycle when the stock and labor markets are cointegrated. The Journal of Finance 62(5), 2123-2167.

Bergstresser, D., J. M. Chalmers, and P. Tufano (2009). Assessing the costs and benefits of brokers in the mutual fund industry. Review of Financial Studies 22(10), 4129-4156.

Bergstresser, D., M. Desai, and J. Rauh (2006). Earnings manipulation, pension assumptions, and managerial investment decisions. The Quarterly Journal of Economics 121(1), 157-195.

Berk, J. B. and R. C. Green (2004). Mutual fund flows and performance in rational markets. Journal of Political Economy 112(6), 1269-1295. 
Binsbergen, J. H. v., M. W. Brandt, and R. S. Koijen (2008). Optimal decentralized investment management. The Journal of Finance 63(4), 1849-1895.

Blake, C. R., E. J. Elton, and M. J. Gruber (1993). The performance of bond mutual funds. Journal of Business 66(3), 371-403.

Blake, D., B. N. Lehmann, and A. Timmermann (1999). Asset allocation dynamics and pension fund performance. The Journal of Business 72(4), 429-461.

Blake, D., A. G. Rossi, A. Timmermann, I. Tonks, and R. Wermers (2013). Decentralized investment management: Evidence from the pension fund industry. The Journal of Finance 68(3), 1133-1178.

Bollen, N. P. and J. A. Busse (2001). On the timing ability of mutual fund managers. The Journal of Finance 56(3), 1075-1094.

Bond, S. and P. Mitchell (2010). Alpha and persistence in real estate fund performance. The Journal of Real Estate Finance and Economics 41(1), 53-79.

Boudoukh, J. and M. Richardson (1993). Stock returns and inflation: A long-horizon perspective. The American Economic Review 83(5), 1346-1355.

Brown, J. (2008). Guaranteed trouble: The economic effects of the pension benefit guaranty corporation. Journal of Economic Perspectives 22(1), 177-198.

Brown, J. R. and D. W. Wilcox (2009). Discounting state and local pension liabilities. The American Economic Review 99(2), 538-542.

Brown, K. C., L. Garlappi, and C. Tiu (2010). Asset allocation and portfolio performance: Evidence from university endowment funds. Journal of Financial Markets 13(2), 268-294.

Busse, J. A., A. Goyal, and S. Wahal (2010). Performance and persistence in institutional investment management. The Journal of Finance 65(2), 765-790.

Cain, M., S. Davidoff, and S. McKeon (2013). Placement agents and private equity: Information production or influence peddling? Working Paper: Ohio State University.

Campbell, J. Y. and L. M. Viceira (2005). The term structure of the risk-return trade-off. Financial Analysts Journal 61(1), 34-44.

Canadian Institute of Actuaries (September 2011). Accounting discount rate assumption for pension and postemployment benefit plans. Educational Note.

Carhart, M. (1997). On persistence in mutual fund performance. The Journal of Finance 52(1), 57-82.

Carpenter, J. and A. Lynch (1999). Survivorship bias and attrition effects in measures of performance persistence. Journal of Financial Economics 54(3), 337-374.

Chan, L. K., H.-L. Chen, and J. Lakonishok (2002). On mutual fund investment styles. Review of Financial Studies 15(5), 1407-1437.

Chen, J., H. Hong, M. Huang, and J. D. Kubik (2004). Does fund size erode mutual fund performance? the role of liquidity and organization. The American Economic Review 94(5), 1276-1302.

Chen, J., H. Hong, W. Jiang, and J. D. Kubik (2013). Outsourcing mutual fund management: firm boundaries, incentives, and performance. The Journal of Finance 68(2), 523-558.

Chen, Y., W. Ferson, and H. Peters (2010). Measuring the timing ability and performance of bond mutual funds. Journal of Financial Economics 98(1), 72-89.

Cici, G., J. Corgel, and S. Gibson (2011). Can fund managers select outperforming REITs? Examining fund holdings and trades. Real Estate Economics 39(3), 455-486. 
Cici, G. and S. Gibson (2010). The performance of corporate-bond mutual funds: Evidence based on security-level holdings. Journal of Financial and Quantitative Analysis 47(1), 159-178.

Ciochetti, B., T. Craft, and J. Shilling (2002). Institutional investors' preferences for REIT stocks. Real Estate Economics 30(4), 567-593.

Cremers, K. M. and A. Petajisto (2009). How active is your fund manager? A new measure that predicts performance. Review of Financial Studies 22(9), 3329-3365.

Crossley, T. and M. Jametti (2013). Pension benefit insurance and pension plan portfolio choice. The Review of Economics and Statistics 95(1), 337-341.

Davidoff, T., J. R. Brown, and P. A. Diamond (2005). Annuities and individual welfare. American Economic Review, 1573-1590.

Dichev, I. D. and G. Yu (2011). Higher risk, lower returns: What hedge fund investors really earn. Journal of Financial Economics 100(2), 248-263.

Dyck, A. and L. Pomorski (2011). Is bigger better? Size and performance in pension plan management. Working Paper: University of Toronto.

Elton, E. J., M. J. Gruber, and C. R. Blake (1995). Fundamental economic variables, expected returns, and bond fund performance. The Journal of Finance 50(4), 1229-1256.

Fama, E. and J. MacBeth (1973). Risk, return, and equilibrium: Empirical tests. The Journal of Political Economy 81(3), 607-636.

Fang, L., V. Ivashina, and J. Lerner (2013). The disintermediation of financial markets: Direct investing in private equity. Working Paper: National Bureau of Economic Research.

French, K. (2008). Presidential address: The cost of active investing. The Journal of Finance 63(4), 1537-1573.

Friedman, H. (1971). Real estate investment and portfolio theory. Journal of Financial and Quantitative Analysis 6(2), 861-874.

Fung, W., D. A. Hsieh, N. Y. Naik, and T. Ramadorai (2008). Hedge funds: Performance, risk, and capital formation. The Journal of Finance 63(4), 1777-1803.

GASB (2011). Governmental accounting standards board: Pension accounting and financial reporting, plainlanguage supplement to an exposure draft.

GASB (2012). Governmental accounting standards board: New GASB pension statements to bring about major improvements in financial reporting.

Geltner, D. and W. Goetzmann (2000). Two decades of commercial property returns: A repeated-measures regression-based version of the NCREIF index. The Journal of Real Estate Finance and Economics 21(1), 5-21.

Gennaioli, N., A. Shleifer, and R. Vishny (2013). Money doctors. forthcoming in The Journal of Finance.

Goyal, A. and S. Wahal (2008). The selection and termination of investment management firms by plan sponsors. The Journal of Finance 63(4), 1805-1847.

Griffin, J. M. and J. Xu (2009). How smart are the smart guys? A unique view from hedge fund stock holdings. Review of Financial Studies 22(7), 2531-2570.

Gruber, M. J. (1996). Another puzzle: The growth in actively managed mutual funds. The Journal of Finance 51(3), 783-810.

Hartzell, J., T. Mühlhofer, and S. Titman (2010). Alternative benchmarks for evaluating mutual fund performance. Real Estate Economics 38(1), 121-154. 
Hochberg, Y. and T. Mühlhofer (2011). Market timing and investment selection: Evidence from real estate investors. Working Paper: Northwestern University.

Hochberg, Y. and J. Rauh (2013). Local overweighting and underperformance: Evidence from limited partner private equity investments. Review of Financial Studies 26(2), 403-451.

Jensen, M. C. and W. H. Meckling (1976). Theory of the firm: Managerial behavior, agency costs and ownership structure. Journal of Financial Economics 3(4), 305-360.

Jiang, G. J., T. Yao, and T. Yu (2007). Do mutual funds time the market? Evidence from portfolio holdings. Journal of Financial Economics 86(3), 724-758.

Kacperczyk, M., C. Sialm, and L. Zheng (2008). Unobserved actions of mutual funds. Review of Financial Studies 21(6), 2379-2416.

Kallberg, J., C. Liu, and D. Greig (1996). The role of real estate in the portfolio allocation process. Real Estate Economics 24(3), 359-377.

Kallberg, J., C. Liu, and C. Trzcinka (2000). The value added from investment managers: An examination of funds of REITs. Journal of Financial and Quantitative Analysis 35(3), 387-408.

Kaplan, S. and A. Schoar (2005). Private equity performance: Returns, persistence, and capital flows. The Journal of Finance 60(4), 1791-1823.

Kocken, T. (2012). Pension liability measurement and intergenerational fairness. Rotman International Journal of Pension Management 5(1), 16-21.

Kosowski, R., A. Timmermann, R. Wermers, and H. White (2006). Can mutual fund stars really pick stocks? New evidence from a bootstrap analysis. The Journal of Finance 61(6), 2551-2595.

Lakonishok, J., A. Shleifer, and R. Vishny (1992). The structure and performance of the money management industry. Brookings Papers on Economic Activity. Microeconomics, 339-391.

Lerner, J., A. Schoar, and W. Wongsunwai (2007). Smart institutions, foolish choices: The limited partner performance puzzle. The Journal of Finance 62(2), 731-764.

Lopez de Silanes, F., L. Phalippou, and O. Gottschalg (2010). Giants at the gate: On the cross-section of private equity investment returns. Working Paper: University of Oxford.

Love, D. A., P. A. Smith, and D. W. Wilcox (2011). The effect of regulation on optimal corporate pension risk. Journal of Financial Economics 101(1), 18-35.

Lucas, D. and S. P. Zeldes (2006). Valuing and hedging defined benefit pension obligations: The role of stocks revisited. Working Paper: Columbia University.

Lucas, D. J. and S. P. Zeldes (2009). How should public pension plans invest? The American Economic Review 99(2), 527-532.

Malkiel, B. G. (1995). Returns from investing in equity mutual funds 1971 to 1991. The Journal of Finance 50(2), 549-572.

Merton, R. C. (1983). On consumption indexed public pension plans. In Financial Aspects of the United States Pension System, pp. 259-290. University of Chicago Press.

Metrick, A. and A. Yasuda (2010). The economics of private equity funds. Review of Financial Studies 23(6), $2303-2341$.

Moskowitz, T. J., Y. H. Ooi, and L. H. Pedersen (2012). Time series momentum. Journal of Financial Economics 104(2), 228-250.

Myers, S. C. (1977). Determinants of corporate borrowing. Journal of Financial Economics 5(2), 147-175. 
Novy-Marx, R. (2011). Logical implications of gasbs methodology for valuing pension liabilities. Working Paper: NBER.

Novy-Marx, R. and J. Rauh (2011). Public pension promises: How big are they and what are they worth? The Journal of Finance 66(4), 1211-1249.

Novy-Marx, R. and J. D. Rauh (2009). The liabilities and risks of state-sponsored pension plans. The Journal of Economic Perspectives 23(4), 191-210.

Novy-Marx, R. and J. D. Rauh (2012). Fiscal imbalances and borrowing costs: Evidence from state investment losses. American Economic Journal: Economic Policy 4(2), 182-213.

OECD Secretariat (June 2011). Survey of investment regulation of pension funds.

Pagliari, J., K. Scherer, and R. Monopoli (2005). Public versus private real estate equities: A more refined, long-term comparison. Real Estate Economics 33(1), 147-187.

Pastor, L. and R. F. Stambaugh (2003). Liquidity risk and expected stock returns. Journal of Political Economy 111(3), 642-685.

Pennacchi, G. and M. Rastad (2011). Portfolio allocation for public pension funds. Journal of Pension Economics and Finance 10(2), 221-245.

Phalippou, L. (2009). Beware of venturing into private equity. The Journal of Economic Perspectives 23(1), 147-166.

Phalippou, L. and O. Gottschalg (2009). The performance of private equity funds. Review of Financial Studies 22(4), 1747-1776.

Rauh, J. D. (2006). Investment and financing constraints: Evidence from the funding of corporate pension plans. The Journal of Finance 61(1), 33-71.

Rauh, J. D. (2009). Risk shifting versus risk management: Investment policy in corporate pension plans. Review of Financial Studies 22(7), 2687-2733.

Rauh, J. D., I. Stefanescu, and S. P. Zeldes (2013). Cost shifting and the freezing of corporate pension plans. Working Paper: Stanford University.

Ricardo, D. (1820). Essay on the funding system. Various Editions.

Schotman, P. C. and M. Schweitzer (2000). Horizon sensitivity of the inflation hedge of stocks. Journal of Empirical Finance 7(3), 301-315.

Sharpe, W. F. (1981). Decentralized investment management. The Journal of Finance 36(2), 217-234.

Sharpe, W. F. (2010). Adaptive asset allocation policies. Financial Analysts Journal 66(3), 45-59.

Shiller, R. J. (1999). Social security and institutions for intergenerational, intragenerational, and international risksharing. In Carnegie-Rochester Conference Series on Public Policy, Volume 50, pp. 165-204. Elsevier.

Sirri, E. R. and P. Tufano (1998). Costly search and mutual fund flows. The Journal of Finance 53(5), 1589-1622.

Stoughton, N. M., Y. Wu, and J. Zechner (2011). Intermediated investment management. The Journal of Finance 66(3), 947-980.

Sundaresan, S. and F. Zapatero (1997). Valuation, optimal asset allocation and retirement incentives of pension plans. Review of Financial Studies 10(3), 631-660.

Swamy, P. (1970). Efficient inference in a random coefficient regression model. Econometrica 38(2), 311-323.

Timmermann, A. and D. Blake (2005). International asset allocation with time-varying investment opportunities. The Journal of Business 78(1), 71-98.

Tonks, I. (2005). Performance persistence of pension-fund managers. The Journal of Business 78(5), 1917-1942. 



\section{Curriculum Vitae}

Aleksandar Andonov was born on 19 July 1986 in Skopje, Macedonia. He earned his Bachelor of Science in Economics at the University "Ss. Cyril and Methodius", Faculty of Economics in Skopje. After graduation, Aleksandar worked for one year at the Macedonian Ministry of Finance on loan agreements with international financial institutions, such as the World Bank, IMF, and EBRD. In 2009, he completed his Masters of Science in Finance (cum laude) at the Maastricht University School of Business and Economics and received a Top 3\% Award.

In 2009, Aleksandar joined the Finance Department of Maastricht University as a PhD Candidate. At Maastricht University, Aleksandar was responsible for teaching master courses on institutional investors and behavioral finance, and bachelor courses on investments. Aleksandar spent the 2012 spring semester at the International Center for Finance, Yale School of Management. In 2013, he visited the University of Notre Dame, Mendoza College of Business.

In his doctoral work, Aleksandar focused on institutional investors, in particular pension funds and the money management industry, investigating the asset allocation and performance of these investors in public and private markets. He has presented his research on invited faculty finance seminars, such as the Erasmus School of Economics, Cass Business School, University of Connecticut and Aalto University, as well as on various academic conferences, including the American Economic Association (AEA), European Finance Association (EFA) and Financial Intermediation Research Society (FIRS). Aleksandar's research ideas and findings have been covered also in popular financial media, like the Economist and Financial Times.

During his doctoral studies, Aleksandar received financial support for his research by the Rotman International Centre for Pension Management, Inquire Europe and Real Estate Research Institute. 


\section{Rotman ICPM}

This research project received financial support from the Rotman International Centre for Pension Management (Rotman ICPM). The mission of Rotman ICPM is to be an internationally-recognized, high-impact catalyst for fostering effective pension design and management. Its four primary tools to achieve this goal are the funding of objective and transformative research, the organization of interactive, action-oriented discussion forums, the publication of a readable journal relevant to professionals in the pensions and related fields, and the delivery of the globe's leading governance education program for Board members of pension and other long-horizon investment institutions. 